\title{
COMBUSTION CHAMBER DEPOSIT EFFECTS ON HYDROCARBON EMISSIONS FROM A SPARK-IGNITION ENGINE
}

\author{
by \\ Haissam A. Haidar \\ B.S., Mechanical Engineering \\ Boston University (1988) \\ S.M., Mechanical Engineering \\ Massachusetts Institute of Technology (1991) \\ SUBMITTED TO THE DEPARTMENT OF MECHANICAL ENGINEERING \\ IN PARTIAL FULFILLMENT OF THE REQUIREMENTS FOR THE DEGREE OF \\ DOCTOR OF PHILOSOPHY \\ at the \\ MASSACHUSETTS INSTITUTE OF TECHNOLOGY \\ February 1997 \\ (C) Massachusetts Institute of Technology \\ All rights reserved
}

Signature of Author

Department of Mechanical Engineering January 8,1997

Certified by

John B. Heywood

Professor, Department of Mechanical Engineering

Thesis Adviser

Accepted by

Ain A. Sonin

Chairperson, Department Graduate Committee

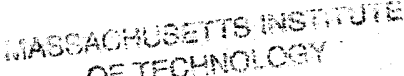

of rechnolos:

Eng.

APR 161997

LIRARAES 


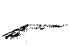

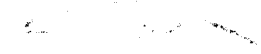




\title{
COMBUSTION CHAMBER DEPOSIT EFFECTS ON HYDROCARBON EMISSIONS FROM A SPARK-IGNITION ENGINE
}

\author{
by \\ Haissam Haidar

\begin{abstract}
Submitted to the Department of Mechanical Engineering on January 20, 1997 in Partial Fulfillment of the

Requirements for the Degree of Doctor of Philosophy
\end{abstract}

\begin{abstract}
Data on the effect of combustion chamber deposits (CCD) on the HC emissions from spark-ignition engines has been scarce and contradictory. With more stringent emissions standards set by the EPA taking effect, quantifying the effect of CCDs on $\mathrm{HC}$ emissions from a modern spark-ignition engine is of significant importance. The objectives of this work can be summarized in three points: quantify the contribution of CCDs to the total engine-out HC emissions; identify the effect of combustion chamber deposits on the HC emissions from a matrix of single-component fuels; develop a model to describe the mechanism(s) by which $\mathrm{CCDs}$ lead to an increase to $\mathrm{HC}$ emissions. The engine is run for periods ranging from 100 to 25 hours, on a deposit build-up cycle. During deposit accumulation, the HC emissions are continuously measured at several operating conditions using an additized, specially-designed fuel that promotes CCD accumulation. In addition, $\mathrm{HC}$ emission measurements are taken using isooctane, benzene, toluene and xylene with the deposited and then clean engine.

The experimental results show that CCDs contribute to about $15 \%$ of the total engine-out $\mathrm{HC}$ emissions from the deposit build-up fuel and from the four single-component fuels. Starting from a clean-engine level, the $\mathrm{HC}$ emissions increase rapidly in the first 10 hours of deposit accumulation and stabilize after about 25 hours. The deposits continue to grow well beyond the point where the HC emissions stabilize. After engine disassembly and CCD removal, the HC emissions drop back to their clean-engine levels, confirming the effect of CCDs on the HC emissions. The data shows no significant difference in the effect of CCDs on the HC emission increase among the four single-component fuels. The deposit pore size distribution is quantified using mercury porosimetry measurements. Using these measurements, it is concluded that the filling of deposit pores with fuel-air mixture at uniform pressure(deposit crevice mechanism) is the dominant mechanism. Accounting for oxidation of some of the fuel stored in the cylinder head and exhaust ports, the model overpredicts the experimental data by about $50 \%$.
\end{abstract}

\author{
Thesis Advisor \\ John Heywood \\ Professor, Mechanical Engineering
}




\section{ACKNOWLEDGEMENTS}

Too many people directly or indirectly contributed to the completion of this work to thank in this small space. I would like to thank the members of my thesis committee, Prof. John Heywood, Prof. Wai Cheng, Prof. Simone Hochgreb and Prof. Adel Sarofim for their guidance and support throughout the work. Working with them was an invaluable learning experience. I especially would like to express my gratitude to my thesis supervisor, Prof. John Heywood for his support and patience when things were not going smoothly in my research.

I want to thank Brian Corkum for his patient help in setting up the experiment and for troubleshooting the problems I had with the set-up. Although he was here during the latter stages of my experiments, Peter Menard was instrumental in fixing the many problems I encountered with my engine. My special thanks go to Karla Stryker for picking me up when I was feeling down and for her patience with my lack of respect for deadlines and for changing appointments at the last minute. My sincere gratitude goes to Nancy Cook for all her help throughout the project. I want to thank my lab mates for their help and patience in sharing the equipment with me, especially Vincent Frottier and Norman Peralta for sharing the engine set-up. My special thanks go to my office mates who were there for me when I needed someone to talk to or when I needed some advice on my research. I would like to thank them for putting up with my constant nuisances and for hogging the computer during my Solitaire marathons. I will miss my friends SungMyeong Han, Younggy shin, Robert Meyer, Norman Peralta, Mike Shelby, Brad VanDer Wege, Mark Dawson and Carlos Herrera.

My family has been my source of support throughout my studies in the US. I want to thank my mom and dad for the endless sacrifices they have made. They were my inspiration throughout this work. My thanks also go to my siblings for their endless support throughout this work.

This work was supported by EPA and by the Engine-Fuels Interaction Consortium, whose members include Chevron Research Corporation, Exxon Research and Engineering Company, Nippon Oil Company Limited and Shell Oil Company.

Haissam A. Haidar

January 1997 


\section{TABLE OF CONTENTS}

ABSTRACT.

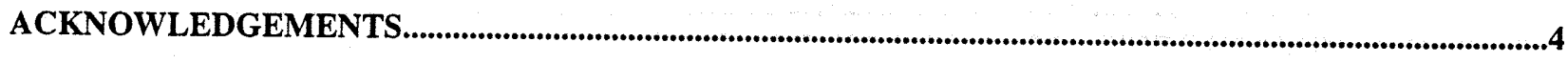

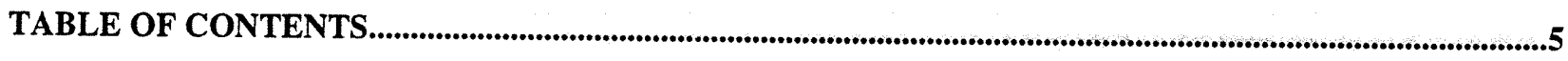

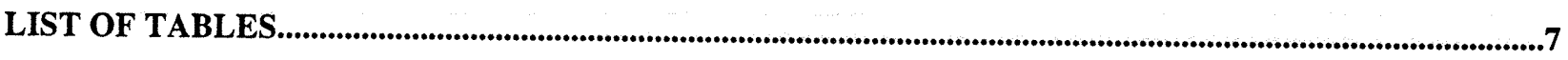

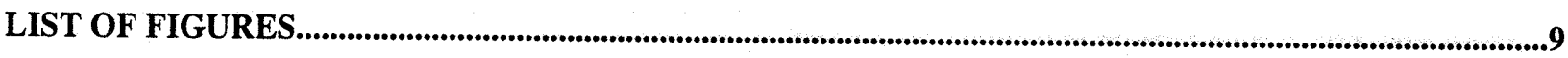

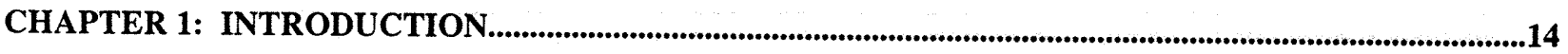

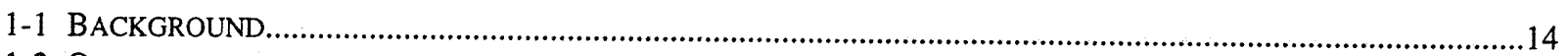

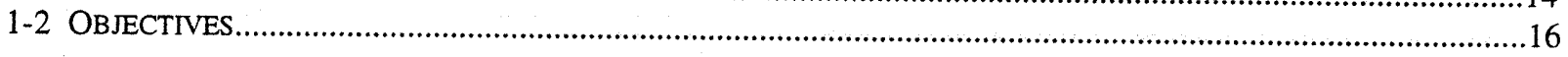

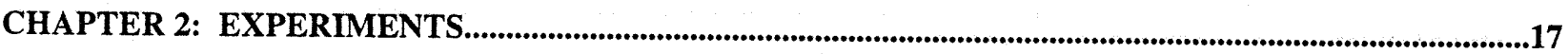

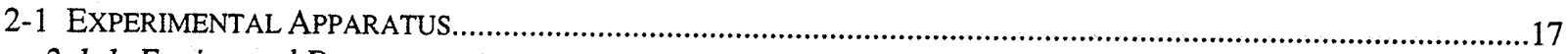

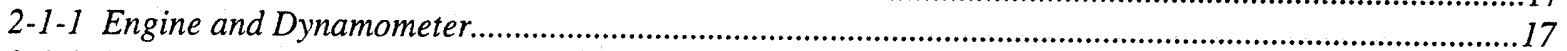

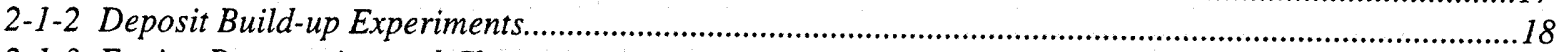

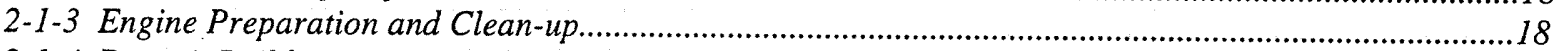

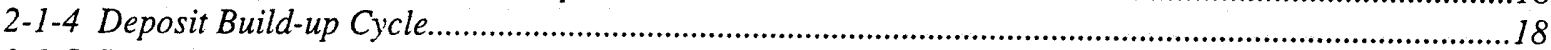

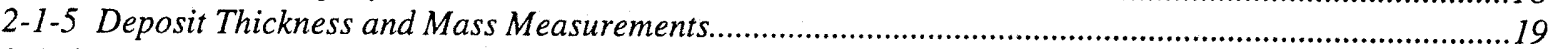

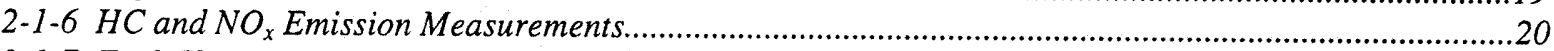

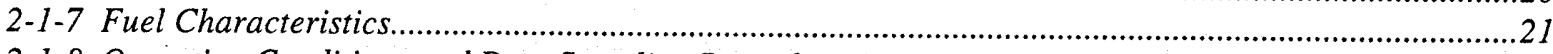

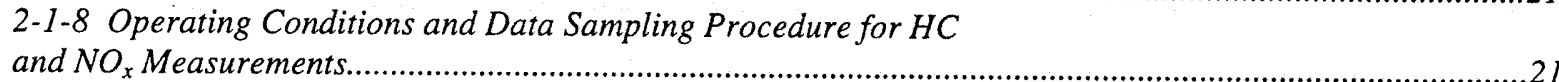

CHAPTER 3: EXPERIMENTAL RESULTS AND DISCUSSION...................................................................29

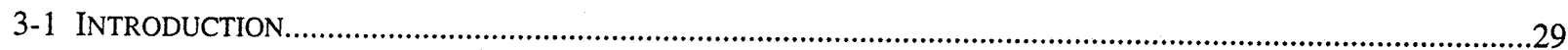

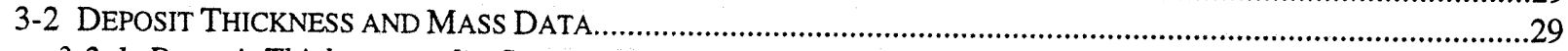

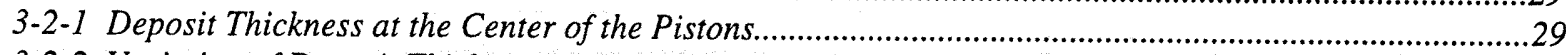

3-2-2 Variation of Deposit Thickness on Piston Surface ............................................................................29

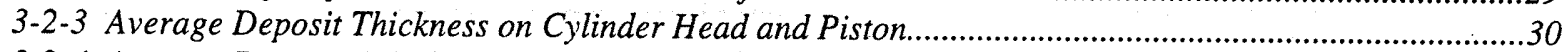

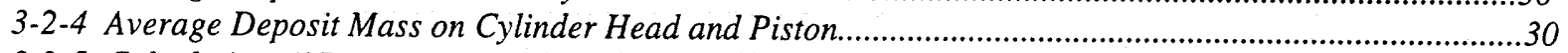

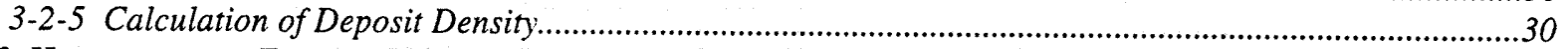

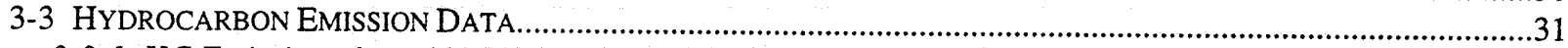

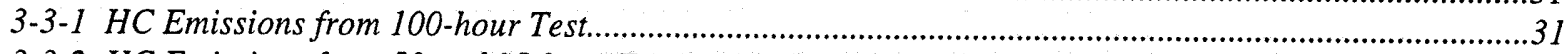

3-3-2 HC Emissions from 50 and 25-hour Tests with Deposit Build-up Fuel.................................................33

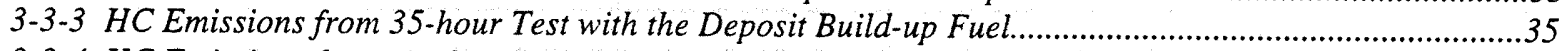

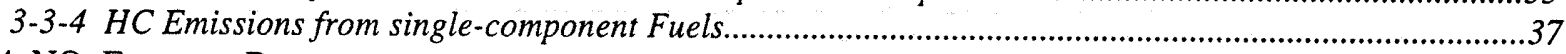

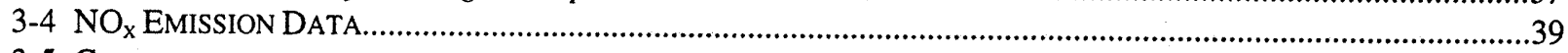

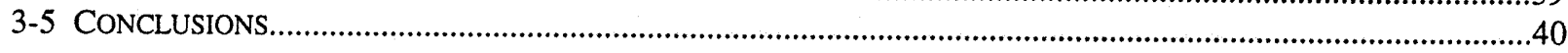

CHAPTER 4: MODELING OF THE EFFECT OF CCD ON HC EMISSIONS.................................................62

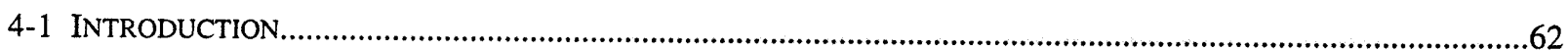

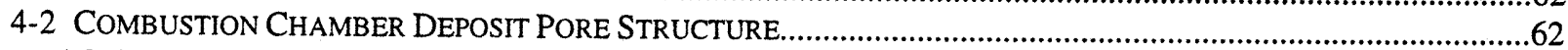

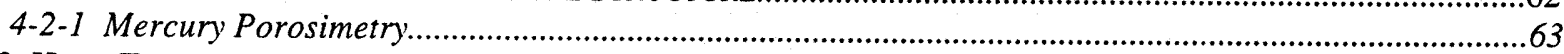

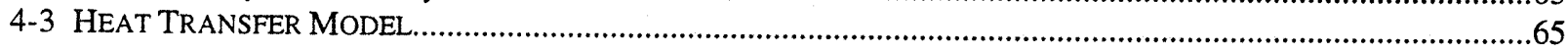




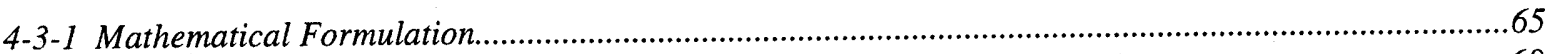

4-3-2 Heat Transfer Model Results..........................................................................................68

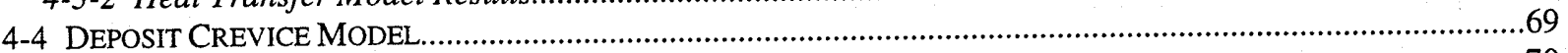

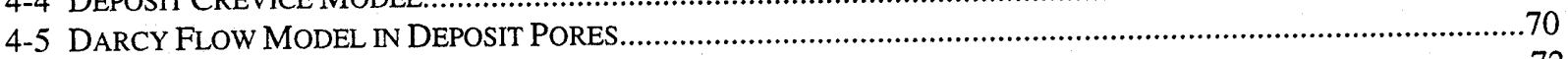

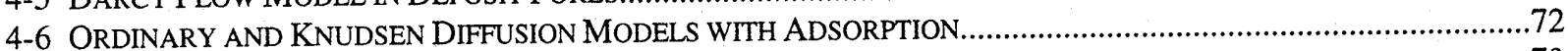

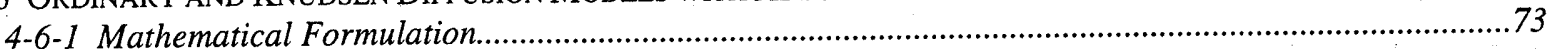

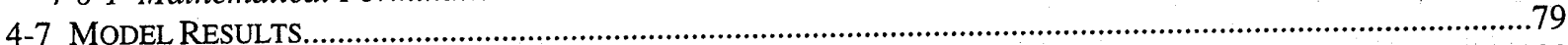

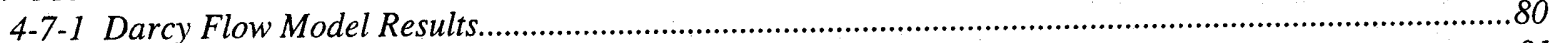

4-7-2 Deposit Crevice and Diffusion Model Results...............................................................................81

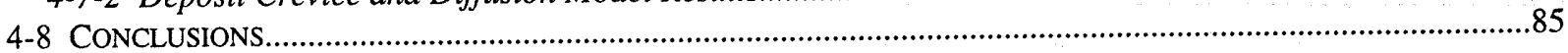

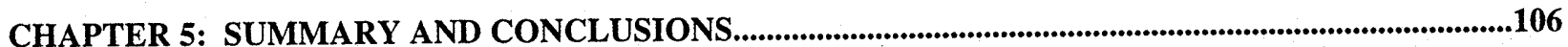

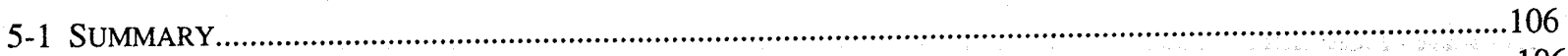

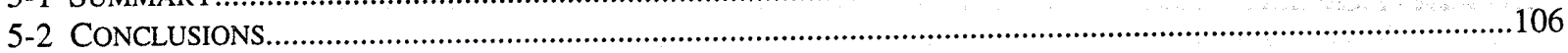

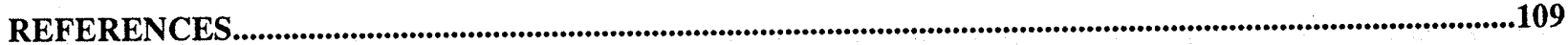

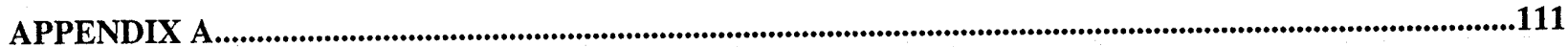

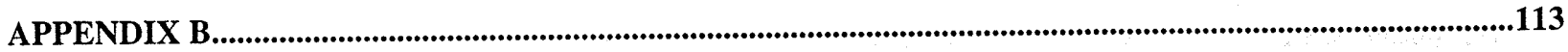

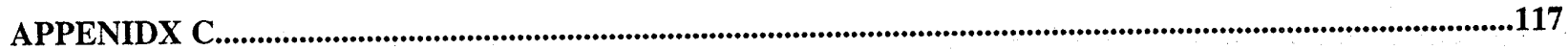

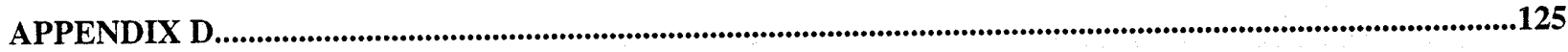




\section{LIST OF TABLES}

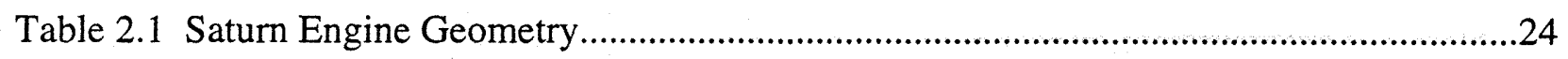

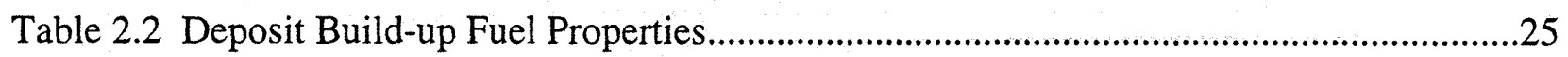

Table 2.3 Operating Conditions for Emissions Measurements. 100-hour Test............................26

Table 2.4 Operating Conditions for Emission Measurements. 50 and 25-hour Tests.................27

Table 2.5 Operating Conditions for Emission Measurements with Deposit

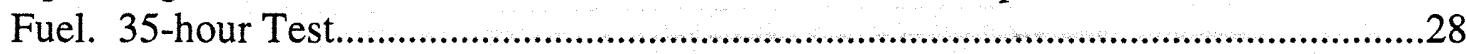

Table 2.6 Operating Conditions for Emission Measurements with Single-

Component Fuels. 35-hour Test......................................................................................28

Table 3.1 Summary of the effect of CCD on HC emission from deposit

build-up fuel. Data from 110-hour run.

Table 3.2 Summary of the effect of CCD on HC emission from indolene.

Data from 110-hour run.

Table 3.3 Summary of the effect of CCD on HC emission from deposit

build-up fuel. Data from 50 -hour run.

Table 3.4 Summary of the effect of CCD on HC emission from deposit build-up fuel. Data from 25-hour run.

Table 3.5 Summary of the effect of CCD on HC emission from deposit build-up fuel.Data from 35-hour run with the EGR off.

Table 4.1 Thermophysical properties of combustion chamber deposits and Aluminum used in the heat transfer model.

Table 4.2 The adsorption equilibrium constant of isooctane, benzene, toluene and Xylene calculated from adsorption isotherms of the four fuels on combustion chamber deposits.

Table 4.3 Breakdown of deposit pore size spectrum into size ranges for four fuel transport mechanisms. Also, porosity of cylinder head and piston top deposits and \% of total pore volume falling in each pore size range. 
Table 4.4 Contribution of each fuel transport mechanism to the $\mathrm{HC}$ emission increase due to CCDs for all four single-component

fuels. Cylinder head deposits at $1500 \mathrm{rpm}, \mathrm{bmep}=318 \mathrm{kPa}$

Table 4.5 Contribution of each fuel transport mechanism to the HC emission increase due to CCDs for all four single-component fuels. Piston top deposits at $1500 \mathrm{rpm}, \mathrm{bmep}=318 \mathrm{kPa}$

Table 4.6 Contribution of each fuel transport mechanism to the HC emission increase due to CCDs for all four single-component fuels. Cylinder head deposits at $2200 \mathrm{rpm}$, bmep $=318 \mathrm{kPa}$

Table 4.7 Contribution of each fuel transport mechanism to the $\mathrm{HC}$ emission increase due to CCDs for all four single-component fuels.

Piston top deposits at $2200 \mathrm{rpm}$, bmep $=318 \mathrm{kPa}$.

Table 4.8 Comparison between the model predictions with and without oxidation and the experimental data for all four singlecomponent fuels at $1500 \mathrm{rpm}$, bmep $=318 \mathrm{kPa}$

Table 4.9 Comparison between the model predictions with and without oxidation and the experimental data for all four singlecomponent fuels at $2200 \mathrm{rpm}$, bmep $=318 \mathrm{kPa}$. 


\section{LIST OF FIGURES}

Fig. 3.1 Average deposit thickness at the center of the pistons from 100-hr, 50-hr, 45 30-hr and 25-hr deposit accumulation tests.

Fig. 3.2 Deposit thickness measurement locations on top of the piston.

Fig. 3.3 Deposit thickness measurements at specified locations on piston top from 46 50-hour deposit accumulation test.

Fig. 3.4 Average deposit thickness over four cylinder heads and piston tops 47 measured at the end of each of the four deposit accumulation tests after engine disassembly.

Fig. 3.5 Average deposit mass over four cylinder heads and piston tops measured at 47 the end of each of the four deposit accumulation tests after engine disassembly.

Fig. 3.6 Calculated deposit density on all four pistons from all four deposit 48 accumulation tests.

Fig. 3.7 Average deposit mass on cylinder head and piston top vs. average deposit 48 thickness on the cylinder head and piston top. Data taken at the end of the four deposit build-up tests.

Fig. 3.8 HC emissions from the deposit build-up fuel vs. engine hours at $1500 \mathrm{rpm}, 49$ bmep $=262 \mathrm{kPa}$. Data from 110-hour deposit build-up test.

Fig. 3.9 HC emissions from the deposit build-up fuel vs. engine hours at $1600 \mathrm{rpm}, 49$ bmep= $411 \mathrm{kPa}$. Data from 110-hour deposit build-up test.

Fig. 3.10 $\mathrm{HC}$ emissions from the deposit build-up fuel vs. engine hours at $1800 \mathrm{rpm}, \quad 50$ bmep $=511 \mathrm{kPa}$. Data from 110-hour deposit build-up test.

Fig. 3.11 HC emissions from the deposit build-up fuel vs. engine hours at $2000 \mathrm{rpm}, \quad 50$ bmep $=625 \mathrm{kPa}$. Data from 110-hour deposit build-up test.

Fig. 3.12 HC emissions from indolene vs. engine hours at $1500 \mathrm{rpm}, \mathrm{bmep}=262 \mathrm{kPa} .51$ Data from 110-hour deposit build-up test.

Fig. 3.13 HC emissions from indolene vs. engine hours at $1600 \mathrm{rpm}, \mathrm{bmep}=411 \mathrm{kPa} .51$ 
Data from 110-hour deposit build-up test.

Fig. 3.14 $\mathrm{HC}$ emissions from indolene vs. engine hours at $1800 \mathrm{rpm}$, bmep= 51152 $\mathrm{kPa}$. Data from 110-hour deposit build-up test.

Fig. 3.15 $\mathrm{HC}$ emissions from indolene vs. engine hours at $2000 \mathrm{rpm}$, bmep= $625 \mathrm{kPa} .52$ Data from 110-hour deposit build-up test.

Fig. 3.16 $\mathrm{HC}$ emissions vs. engine hours with deposit build up fuel at $1500 \mathrm{rpm}, 53$ $\mathrm{bmep}=262 \mathrm{kPa}$. Data from 50 and 25 -hour tests.

Fig. 3.17 HC emissions vs. engine hours with deposit build up fuel at $1500 \mathrm{rpm}, 53$ $\mathrm{bmep}=318 \mathrm{kPa}$. Data from 50 and 25 -hour tests.

Fig. 3.18 HC emissions vs. engine hours with deposit build up fuel at $2200 \mathrm{rpm}, 54$ bmep $=318 \mathrm{kPa}$. Data from 50 and 25 -hour tests.

Fig. 3.19 Effect of cylinder head deposits on $\mathrm{HC}$ emissions at $1500 \mathrm{rpm}$, bmep= 31855 $\mathrm{kPa}$ and $2200 \mathrm{rpm}, \mathrm{bmep}=318 \mathrm{kPa}$. Data from 50-hour deposit accumulation test.

Fig. 3.20 Effect of piston top deposits on $\mathrm{HC}$ emissions at $1500 \mathrm{rpm}$, bmep= $318 \mathrm{kPa} \quad 55$ and $2200 \mathrm{rpm}$, bmep= $318 \mathrm{kPa}$. Data from 50-hour deposit accumulation test.

Fig. 3.21 HC emissions vs. engine hours with deposit build up fuel at $1400 \mathrm{rpm}, 56$ bmep $=106 \mathrm{kPa}$. Data from 35-hour test.

Fig. 3.22 HC emissions vs. engine hours with deposit build up fuel at $1500 \mathrm{rpm}, 56$ bmep $=262 \mathrm{kPa}$. Data from 35-hour test.

Fig. 3.23 HC emissions vs. engine hours with deposit build up fuel at $1500 \mathrm{rpm}, 57$ bmep $=318 \mathrm{kPa}$. Data from 35-hour test.

Fig. 3.24 HC emissions vs. engine hours with deposit build up fuel at $2200 \mathrm{rpm}, 57$ bmep $=318 \mathrm{kPa}$. Data from 35-hour test.

Fig. 3.25 HC emissions with EG R off with the deposited engine and after deposit 58 removal at $1400 \mathrm{rpm}, \mathrm{bmep}=106 \mathrm{kPa}$. Data from 35-hour test.

Fig. 3.26 HC emissions with EG R off with the deposited engine and after deposit 58 removal at $1500 \mathrm{rpm}, \mathrm{bmep}=262 \mathrm{kPa}$. Data from 35-hour test.

Fig. 3.27 HC emissions with EG R off with the deposited engine and after deposit 59 
removal at $1500 \mathrm{rpm}$, bmep $=318 \mathrm{kPa}$. Data from 35-hour test.

Fig. 3.28 HC emissions with EG R off with the deposited engine and after deposit 59 removal at $2200 \mathrm{rpm}$, bmep $=318 \mathrm{kPa}$. Data from 35 -hour test.

Fig. 3.29 Effect of combustion chamber deposit removal on HC emissions from 60 single-component fuels at various operating conditions. Top graph is from 50-hour test with old mechanical EGR valve. Middle and bottom graphs are data from 35-hr test with new electronic EGR system on and off respectively.

Fig. $3.30 \mathrm{NO}_{\mathrm{x}}$ emissions with deposit build-up fuel at $1500 \mathrm{rpm}$, bmep=262 kPa and 61 bmep $=318 \mathrm{kPa}$. Data from 25-hour deposit accumulation test.

Fig. $3.31 \mathrm{NO}_{\mathrm{x}}$ emissions with deposit build-up fuel at $2200 \mathrm{rpm}, \mathrm{bmep}=318 \mathrm{kPa} .61$ Data from 25-hour deposit accumulation test.

Fig. 4.1 Pore size distribution of cylinder head deposits using mercury porosimetry. 91 Cumulative intrusion volume vs. pore diameter.

Fig. 4.2 Pore size distribution of cylinder head deposits using mercury porosimetry. 91 Incremental intrusion volume vs. pore diameter.

Fig. 4.3 Pore size distribution of piston top deposits using mercury porosimetry. 92 Cumulative intrusion volume vs. pore diameter.

Fig. 4.4 Pore size distribution of piston top deposits using mercury porosimetry. 92 Incremental intrusion volume vs. pore diameter.

Fig. 4.5 Temperature distribution in the deposit and aluminum layers in the 93 combustion chamber.

Fig. 4.6 Average in-cylinder gas temperature and its 10-harmonic Fourier series 94 representation vs. crank angle $(\mathrm{CA})$ at $1500 \mathrm{rpm}$, bmep $=318 \mathrm{kPa}$.

Fig. 4.7 Temperature at different cylinder head deposit locations vs. CA at 150095 $\mathrm{rpm}, \mathrm{bmep}=318 \mathrm{kPa}$. Deposit thickness $=120 \mu \mathrm{m}$.

Fig. 4.8 Temperature at different piston top deposit locations vs. CA at $1500 \mathrm{rpm}, 95$ bmep $=318 \mathrm{kPa}$. Deposit thickness $=120 \mu \mathrm{m}$.

Fig. 4.9 In-cylinder isooctane concentration vs. CA and its 40-term Fourier series 96 representation at $1500 \mathrm{rpm}, \mathrm{bmep}=318 \mathrm{kPa}$. 
Fig. 4.10 Measured adsorption isotherm of isooctane, benzene, toluene and xylene on combustion chamber deposits at $313 \mathrm{~K}$. a mass of fuel adsorbed per unit deposit mass vs. relative pressure.

Fig. 4.11 Calculated adsorption isotherm of isooctane, benzene, toluene and xylene on combustion chamber deposits at $450 \mathrm{~K}$. a mass of fuel adsorbed per unit deposit mass vs. pressure.

Fig. 4.12 Pressure at different locations in the cylinder head deposit pores vs. CA at 98 $1500 \mathrm{rpm}, \mathrm{bmep}=318 \mathrm{kPa} . \mathrm{D}_{\mathrm{p}}=1 \mu \mathrm{m}, \tau=10$.

Fig. 4.13 Pressure at different locations in the cylinder head deposit pores vs. CA at 98 $1500 \mathrm{rpm}, \mathrm{bmep}=318 \mathrm{kPa} . \mathrm{D}_{\mathrm{p}}=0.4 \mu \mathrm{m}, \tau=10$.

Fig. 4.14 Pressure at different locations in the cylinder head deposit pores vs. CA at 99 $1500 \mathrm{rpm}, \mathrm{bmep}=318 \mathrm{kPa} . \mathrm{D}_{\mathrm{p}}=0.1 \mu \mathrm{m}, \tau=10$.

Fig. 4.15 Pressure at different locations in the cylinder head deposit pores vs. CA at 99 $1500 \mathrm{rpm}, \mathrm{bmep}=318 \mathrm{kPa} . \mathrm{D}_{\mathrm{p}}=0.01 \mu \mathrm{m}, \tau=10$.

Fig. 4.16 Velocity at different locations in the cylinder head deposit pores vs. CA at 100 $1500 \mathrm{rpm}, \mathrm{bmep}=318 \mathrm{kPa} . \mathrm{D}_{\mathrm{p}}=1 \mu \mathrm{m}, \tau=10$.

Fig. 4.17 Velocity at different locations in the cylinder head deposit pores vs. CA at 100 $1500 \mathrm{rpm}, \mathrm{bmep}=318 \mathrm{kPa} . \mathrm{D}_{\mathrm{p}}=0.1 \mu \mathrm{m}, \tau=10$.

Fig. 4.18 Velocity at different locations in the cylinder head deposit pores vs. CA at 101 $1500 \mathrm{rpm}, \mathrm{bmep}=318 \mathrm{kPa} . \mathrm{D}_{\mathrm{p}}=0.01 \mu \mathrm{m}, \tau=10$.

Fig. 4.19 Deposit crevice model predictions for isooctane (top), benzene (middle) and toluene (bottom) as \% of mass of fuel injected that is stored in cylinder head and piston top deposit pores vs. deposit thickness at $1500 \mathrm{rpm}, \mathrm{bmep}=$ $318 \mathrm{kPa}$ and $2200 \mathrm{rpm}, \mathrm{bmep}=318 \mathrm{kPa}$.

Fig. 4.20 Ordinary diffusion model predictions for isooctane as number of moles per unit deposit area that diffuses into the cylinder head and piston top deposit pores vs. deposit thickness at $1500 \mathrm{rpm}, \mathrm{bmep}=318 \mathrm{kPa}$ and $2200 \mathrm{rpm}$, $\mathrm{bmep}=318 \mathrm{kPa}$.

Fig. 4.21 Knudsen diffusion model predictions for isooctane as number of moles per 103 unit deposit area that diffuses into the cylinder head and piston top deposit pores vs. deposit thickness at $1500 \mathrm{rpm}, \mathrm{bmep}=318 \mathrm{kPa}$ and $2200 \mathrm{rpm}$, bmep $=318 \mathrm{kPa}$. 
Fig. 4.22 Ordinary diffusion model predictions for benzene as number of moles per 104 unit deposit area that diffuses into the cylinder head and piston top deposit pores vs. deposit thickness at $1500 \mathrm{rpm}, \mathrm{bmep}=318 \mathrm{kPa}$ and $2200 \mathrm{rpm}$, bmep $=318 \mathrm{kPa}$.

Fig. 4.23 Knudsen diffusion model predictions for benzene as number of moles per 104 unit deposit area that diffuse into the cylinder head and piston top deposit pores vs. deposit thickness at $1500 \mathrm{rpm}$, bmep $=318 \mathrm{kPa}$ and $2200 \mathrm{rpm}$, bmep $=318 \mathrm{kPa}$.

Fig. 4.24 Ordinary diffusion model predictions for toluene as number of moles per 105 unit deposit area that diffuse into the cylinder head and piston the cylinder head and piston top deposit pores vs. deposit thickness at $1500 \mathrm{rpm}$, bmep= $318 \mathrm{kPa}$ and $2200 \mathrm{rpm}, \mathrm{bmep}=318 \mathrm{kPa}$.

Fig. 4.25 Knudsen diffusion model predictions for toluene as number of moles per 105 unit deposit area that diffuse into the cylinder head and piston top deposit pores vs. deposit thickness at $1500 \mathrm{rpm}, \mathrm{bmep}=318 \mathrm{kPa}$ and $2200 \mathrm{rpm}$, bmep $=318 \mathrm{kPa}$. 


\section{CHAPTER 1: INTRODUCTION}

\section{1-1 Background}

Hydrocarbons in the exhaust of spark-ignition engines, resulting from the incomplete combustion of the fuel, are a major contributor to the urban pollution problem. They are an important precursor to the smog problem in urban areas, especially Los Angeles. The Clean Air Act Amendments of 1990 requires drastic reductions in the hydrocarbon (HC) emission levels from passenger cars and light trucks sold in the US. These amendments reduce the allowable HC levels for passenger cars from $0.26 \mathrm{~g} / \mathrm{km}$ in the $1981-1993$ period, to $0.16 \mathrm{~g} / \mathrm{km}$ from $1994-1996$, and finally to $0.078 \mathrm{~g} / \mathrm{km}$ in 2004 [1]. In addition, California's standard $(0.025 \mathrm{~g} / \mathrm{km})$ for the Ultra Low Emission Vehicle (ULEV) is one tenth of the Federal standard. In order to meet these requirements, numerous investigations have been oriented towards understanding and quantifying the contribution of different sources of $\mathrm{HC}$ emissions from spark-ignition engines [2]. Most of the work in the past 20 years has been focused on identifying the different mechanisms that allow the fuel to escape the main combustion event and contribute to the increase in $\mathrm{HC}$ emissions from spark-ignition engine.

The different mechanisms contributing to the $\mathrm{HC}$ emissions from a warmed-up engine are presented in the paper by Cheng et al. [2] and are summarized in the flow chart in Fig. 1. The numbers in parenthesis indicate percentages of the injected fuel. Starting with the injected fuel (100\%), the main combustion event consumes about $90 \%$ of that, while $10 \%$ escapes combustion through different mechanisms. A hydrocarbon emission source is a mechanism by which fuel molecules escape the main combustion event and get emitted in the exhaust process. The $\mathrm{HC}$ emission source acts as a storage mechanism for these fuel molecules during the combustion process. The HC sources can be broken into fuel only and fuel-air sources. Partly due to the presence of air, a larger fraction of the fuel-air sources ( $2 / 3$ compared to $1 / 3$ for fuel only sources) oxidizes within the cylinder during the expansion and exhaust strokes. Both fuel and fuel-air sources of $\mathrm{HC}$ mix in the exhaust port with higher temperature exhaust gases. About 2/3 of the rest (1.7\% of injected fuel) escapes oxidation in the exhaust port. Approximately $1.3 \%$ of the injected fuel gets retained in the cylinder before exhaust into the next cycle. About $90 \%$ of the surviving HCs ( from the cylinder and exhaust port) gets oxidized in the catalytic converter (when hot enough to be effective).

The fuel-air sources consist of the crevices, the quench layers, and exhaust valve leakage. Of all these three sources, the crevice source is the largest, storing about $5 \%$ of the injected fuel. Crevices are small volumes accessed by the in-cylinder gases, with small entrances that cannot be penetrated by the flame $(<1 \mathrm{~mm}$, the two-wall quench distance of HC flames in engines [3]). Crevices exist in the space between the piston and the cylinder liner, in the threads around the spark plug, and in the gap around the spark plug center electrode. They also exist in the space between the intake and exhaust valves and cylinder head, and finally in the head gasket cutout. The piston top land crevice is 
the largest of all crevices, although the $\mathrm{HC}$ emissions are less sensitive to changes in top land crevice than they are to head crevices[4]. This is because most piston crevice gases are oxidized before leaving the cylinder. Although the total crevice volume is small compared to clearance volume ( about $2 \%$ ), crevices store a significantly higher fraction of the fuel since gas stored in the crevices is cooled by either the cylinder head walls or the cylinder liner walls, giving it a much higher density than the bulk in-cylinder head gases (about 6 times higher).

Another fuel-air source is the quench layers. Due to heat loss to the cool walls, the flame is quenched close to the combustion chamber walls, resulting in a thin layer ( $0.2 \mathrm{~mm})$ of unburned mixture $(\sim 0.5 \%)$, Studies have shown that most of the quench layer HCs diffuse into the hot cylinder gases and oxidize [5,6,7]. Finally, poor gas sealing and deposit flakes caught between the valve and the valve seat causes leakage of fuel-air mixture from the combustion chamber $(-0.1 \%$ of injected), which escapes combustion. The amount of leakage varies considerably over the life of the engine and from engine to engine.

The fuel-only sources are liquid fuel, oil layers, and combustion chamber deposits. The liquid fuel source is most significant during cold start and warm-up, when some of the injected fuel does not vaporize through contact with the still cold port walls and the back of the intake valve, and carries into the combustion chamber. A fraction of it is thought to be carried out with the combustion products and exits as engine-out HC emissions. The mechanism for the oil layer source is that of absorption of the fuel compound molecules in the oil layer on the liner (during the intake, compression, and combustion processes) and desorption into the combustion gases (during the expansion and exhaust processes). The contribution of the oil-layer mechanism to the total $\mathrm{HC}$ emissions is at its maximum during cold start, when the oil layer is thicker and the solubility of fuel in the oil is higher. As the engine warms up, the oil layer becomes thinner and the solubility decreases. The available data on the oil layer contribution to the total engine-out $\mathrm{HC}$ emissions is conflicting, ranging from zero to $30 \%$ of the total engine-out HC emissions $[8,9,10]$.

Few studies have been conducted on the effect of combustion chamber deposits (CCD) on engine HC emissions. The available data is conflicting, some of it suggesting a strong effect of CCD on HC emissions, while other data found no effect. Leikanen et al. [11], compiling data from 18 industrial studies, reported increases between 69 and $100 \%$ in $\mathrm{HC}$ emissions due to deposit build-up, both from fleet and bench engine tests, running on unleaded gasoline. A study by Valtadoros et al.[12] at MIT found an increase of 75\% in $\mathrm{HC}$ emissions due to deposit accumulation, from a Chrysler 2.2-L engine. A study by Bower et al.[13], found that $\mathrm{HC}$ emissions, from a 1983, 4-cylinder engine, were not affected by CCDs. Wagner et al.[14], in a fleet test of 1989-1992 vehicles, concluded that CCDs have no effect on $\mathrm{HC}$ emissions from these vehicles. Harpster et al.[1], using a 2-L 1983 GM engine, found that CCDs contributed to an average increase of $25 \%$ in HC emissions, over 5 operating conditions. 


\section{1-2 Objectives}

As summarized above, data on the effect of CCDs on engine $\mathrm{HC}$ emissions is scarce and conflicting. . Quantification and understanding of this effect is essential in trying to reduce the engine-out $\mathrm{HC}$ emissions and meeting future $\mathrm{HC}$ emission standards. In addition, a significant fraction of the tests were conducted on older carburated or throttlebody-injection (TBI) engines. The effect of deposit accumulation on emissions from modern port-fuel injection engines are needed.

The objectives of this study can be summarized as follows:

1) Design a well controlled test for combustion chamber deposit accumulation on a modern spark-ignited, PFI, engine

2) Quantify the contribution of combustion chamber deposits to the total engine-out HC emissions from a modern engine.

3) Identify the effect of combustion chamber deposits on the $\mathrm{HC}$ emissions from a carefully selected matrix of single-component fuels.

4) Develop a model describing the mechanism(s) by which combustion chamber deposits lead to an increase in $\mathrm{HC}$ emissions. 


\section{CHAPTER 2: EXPERIMENTAL SET-UP}

\section{2-1 Experimental Apparatus}

\section{2-1-1 Engine and Dynamometer}

The engine used in this experiment is a 1991, double overhead cam ,4-cylinder, port fuel injected (PFI) Saturn engine. It is naturally aspirated and has a compression ratio of 9.5:1. Its pent roof combustion chamber has four valves per cylinder, and a centrally-located spark plug. The intake port is straight, generating no swirl or tumble motion. In order to closely duplicate road running conditions, the same equipment as that used in the Saturn car, was used in this set-up. The same intake port, with the Helmholtz resonators is used. The same exhaust system, without the catalytic converter, was also used, although it had to be modified to fit on the engine test bed. The manufacturer's engine control unit (ECU) (calibrated for dynamometer operation) was used for engine control (spark timing, fuel injection, etc.). A detailed description of the engine is provided in [15] and a summary is shown in Table 2.1.

The engine was always maintained at stoichiometric conditions by the engine control unit. To ensure stoichiometric operation, an NTK model MO-1000 air/fuel ratio meter was installed about $20 \mathrm{~cm}$ downstream of the manufacturer's $\mathrm{O}_{2}$ sensor. The engine coolant is internally circulated until it reaches a temperature of between 85 and 88 ${ }^{\circ} \mathrm{C}$, to ensure quick engine warm-up. The engine thermostat then opens and the engine coolant goes through a counter-flow heat exchanger, where it is cooled by tap water. At first, the sump oil was pumped through an external heat exchanger, which kept the oil at about $70^{\circ} \mathrm{C}$. It was then decided to keep the oil in the sump and cool it with an external fan. This system maintained an oil temperature of about $90^{\circ} \mathrm{C}$. The fuel is pumped from a 10-gallon tank, goes through a filter, an accumulator (to reduce pressure fluctuations), and then through a counter-flow heat exchanger (cooled by tap water), maintaining the fuel temperature between 30 and $35^{\circ} \mathrm{C}$, before it enters the engine fuel rail. It then gets pumped back into the 10-gallon tank. In the first 3 deposit accumulation tests, a passive EGR system was used. The system consisted of a diaphragm-type EGR valve, whose opening (i.e. the EGR amount) was regulated by the pressure difference between the intake and exhaust manifolds. For the last deposit build-up test, a new electronic EGR system was installed. The electronic EGR valve opening is controlled by the engine control unit, through a look-up table, based on the intake manifold pressure and the engine speed. This EGR system is supposed to provide precise and repeatable EGR amounts, at each operating conditions.

The engine is equipped with a series of thermocouples and pressure transducers for diagnostic purposes. Temperature measurements (with type $\mathrm{K}$ thermocouples) of the engine coolant (in and out of the engine), engine oil, air entering the engine, fuel, and exhaust are taken and displayed on an LED display. The intake manifold pressure is measured with a pressure transducer mounted on the manifold. The oil pressure and 
engine-out coolant temperature are continuously read from an analog gauge. In addition, barometric pressure and relative humidity readings are recorded at the beginning and end of each day. The engine speed and brake torque are read from an LED display on the dynamometer controller.

The engine is connected, through a shaft, to a Dynamatic Model 405-400 dynamometer. This dynamometer is an eddy-current type dynamometer, which allows for motoring and absorbing (when the engine is firing) of the engine. The dynamometer is connected to a Digalog Model 1022A-STD dynamometer controller, which can either maintain a constant engine speed or a constant brake torque output from the engine. This controller can be fed external engine speed set-points, used when running the engine through the deposit build-up cycle.

\section{2-1-2 Deposit Build-up Experiments}

In order to examine the effect of combustion chamber deposits on engine HC emissions, combustion chamber deposits had to be accumulated over a period of time while the $\mathrm{HC}$ and $\mathrm{NO}_{\mathrm{x}}$ were being monitored. Four deposit accumulation tests of durations of $100,50,25$, and 35 hours have been completed. The details of each test will be separately addressed later on. In what follows, the common features among all four tests will be discussed.

\section{2-1-3 Engine Preparation and Clean-up}

Before the start of each deposit build-up test, the engine is disassembled. Cylinder head (including flat surfaces of intake valves) are cleaned from any deposits. The additive package in the deposit build-up fuel that was used, kept the back of the intake valves almost deposit-free. So, no cleaning of the intake valves was necessary. In addition, all 4 pistons are taken out and any deposits around the periphery of the pistons and in the piston grooves are removed. Deposits on the top edge of the liner are also cleaned. The engine is then reassembled using a new head gasket. It is important to note that the same cylinder head was used in all four tests and that none of the intake or exhaust valves was removed at any point during these test. This ensured that proper valve sealing was maintained throughout the four tests. The engine is then reassembled. A new oil filter is installed and fresh oil is provided to the engine.

After the deposit build-up and emission measurements are completed, the engine is disassembled. The deposit thickness on the cylinder head and piston is measured, and these deposits are then removed. The cleaned engine is reassembled with a new head gasket. The engine is then run until its coolant and oil reach their steady state values. The emission measurements are then taken at the corresponding conditions to verify that the engine emissions return to close to their deposit-free levels.

\section{2-1-4 Deposit Build-up cycle}


Unlike intake valve deposits (BMW test), no single universal deposit build-up procedure is available for combustion chamber deposits. A variation on a CCD build-up cycle, developed by Texaco to study the effect of CCD on octane requirement increase and used at MIT [11], was used. During the deposit build-up test, the engine continuously goes through this cycle consisting of two operating conditions:

C1: $\quad 1400 \mathrm{rpm} @ 10 \%$ load (bmep= $106 \mathrm{kPa})$ for 6 minutes.

C2: $\quad 2200 \mathrm{rpm} @ 30 \%$ load (omep=318 kPa) for 12 minutes.

The brake mean effective pressure (bmep) is a relative engine performance measure that is obtained by dividing the brake torque from the engine per cycle(i.e. after pumping and friction losses) by the cylinder volume displaced per cycle. The engine is run on this cycle for 10 hours daily and is shut off overnight. The engine is run through this cycle using a simple open-loop controller. A PC is used to control a stepper motor, which sets the throttle position at the correct load, for either 6 or 12 minutes. At each throttle position, a screw in the stepper motor lever arm, either opens or closes a switch, providing a voltage corresponding to the external $\mathrm{rpm}$ to the dynamometer controller (1.4 $\mathrm{V}$ for $1400 \mathrm{rpm}$ and $2.2 \mathrm{~V}$ for $2200 \mathrm{rpm}$ ). The dynamometer controller then maintains the engine speed at the desired value. This open-loop controller works well at reproducing the desired load, each time the engine goes through the cycle.

\section{2-1-5 Deposit Thickness and Mass Measurements}

The deposit thickness is measured with the Permascope ${ }^{\circledR}$ D211D, manufactured by Fischer Technology Inc. The instrument is capable of measuring coating thickness of non-magnetic coatings over iron and steel and over non-ferrous metals, such as aluminum. An eddy current probe is used for thickness measurements over the piston top and cylinder head surface (aluminum), while a magnetic probe is used for thickness measurements over the intake valve surfaces (steel). The instrument is calibrated with specimen of known thickness over the flat surfaces of the piston and the intake valves and over the curved surfaces of the cylinder head. The uncertainty in the thickness measurement is $5 \%$. The probes measure thickness by gently pressing them against the surface of the deposits. The instrument then displays the measurement. The instrument also provides statistical properties on a sample of thickness measurements, like the mean, standard deviation, minimum, and maximum values.

The eddy current probe is of cylindrical shape, $10 \mathrm{~mm}$ in diameter. The probe is taped to a stainless steel tube and inserted in the spark plug holes. The thickness at the center of each piston is measured at the beginning of each day of deposit accumulation tests to get the time evolution of deposit thickness. A series of 10 measurements is taken at the center of each piston and the mean value is reported. 
At the end of each deposit build up experiment, the engine was disassembled and deposit thickness profiles were measured over the surface of each piston, cylinder head and intake valve (exhaust valves had very little deposits on them). Because of the inaccessibility by the eddy current probe of some areas on the cylinder head surface (due to its curvature), 30 thickness measurements were randomly taken over the cylinder head area. In addition, 10 measurements are recorded over the surface of each intake valve, using the magnetic probe. Deposit thickness was measured at 30 set locations over each piston top. 30 holes, $7 \mathrm{~mm}$ in diameter, are punched through a thin, circular disc, made of clear plastic, of the same diameter as the piston. The small holes mark the locations of the deposit thickness measurements on the piston surface. The disc was placed over the deposited piston and the thickness measurements are taken. This ensured that the thickness was measured at about the same location on each piston and gave a spatial distribution of the thickness over the piston surface. The locations of the measurement locations are shown in Figure 2.1. After completion of the thickness measurements, deposits on each piston and cylinder head surface (including flat surface of intake valve) are scraped, collected, and weighed. Some of the deposits are lost due to flaking while being scraped. In addition, some aluminum pieces, off the piston and cylinder head surfaces, find their way into the deposits, contributing to the error in the deposit mass measurements. The error analysis will be discussed in greater detail when presenting the results.

\section{2-1-6 $\mathrm{HC}$ and $\mathrm{NO}_{\mathrm{x}}$ Emission Measurements}

Both the hydrocarbon ( $\mathrm{HC}$ ) and $\mathrm{NO}_{\mathrm{x}}$ emissions are measured during deposit accumulation. Separate exhaust samples for $\mathrm{HC}$ and $\mathrm{NO}_{\mathrm{x}}$ emission are continuously taken through two openings in the exhaust pipe, respectively 150 and $160 \mathrm{~cm}$ away from the exhaust port exit. At these locations, the exhaust has cooled down to a point where its composition has been frozen (i.e., reactions stopped occurring). The HC exhaust sample is pumped through a heated line (maintained at $175^{\circ} \mathrm{C}$ to prevent moisture in the exhaust from condensing on the walls) to a Rosemount Analytical Model $402 \mathrm{HC}$ Analyzer. The $\mathrm{HC}$ analyzer is equipped with a flame ionization detector (FID). The HC analyzer is periodically calibrated with a propane- $\mathrm{N}_{2}$ gas mixture of known concentration (4500 ppm $\mathrm{C} 1>$ the largest $\mathrm{HC}$ concentration in the exhaust) to ensure accurate measurement of the $\mathrm{HC}$ concentration in the exhaust. The $\mathrm{NO}_{\mathrm{x}}$ concentration in the exhaust is measured with a Thermo Environmental Instruments Inc. Model $10 \mathrm{NO}_{\mathrm{x}}$ analyzer. Before going through the $\mathrm{NO}_{\mathrm{x}}$ analyzer, the exhaust sample is passed through an ice trap and a Dryerite ${ }^{\circledR}$ filter to remove the water. The $\mathrm{NO}_{\mathrm{x}}$ analyzer is calibrated every day with a calibration gas having a $2700 \mathrm{ppm} \mathrm{NO}$ concentration. In the last three deposit build-up tests, the output signals from the $\mathrm{HC}$ and $\mathrm{NO}_{\mathrm{x}}$ analyzers were fed to a data acquisition system, equipped with an analog/digital (A/D) converter, where the emission measurements were sampled and stored. Details of the sampling procedure will be provided later. 


\section{2-1-7 Fuels Characteristics}

The deposit build-up fuel is the most frequently used fuel in these experiments. It is used for deposit build-up and for $\mathrm{HC}$ emission measurements. It was designed and blended by Chevron and represents an oxygenated commercial gasoline. Its deposit forming tendency places it in the $90^{\text {th }}$ percentile among commercial gasoline. The fuel was blended by mixing $8.5 \%$ by volume of an FCC (Fluid catalytic crack) stream, high in aromatics and olefins to a regular grade pump gasoline. Higher concentrations of aromatics and olefins have been known to increase the deposit-forming tendency of a fuel [16]. In order to separate the effect of intake valve deposits on HC emissions, a polyether-based additive package was added to the fuel, which kept the intake valves and ports virtually deposit-free. A detailed description of the fuel composition and properties is presented in Table 2.2. In addition to the deposit fuel, indolene was used for HC emission measurements in the 100-hr deposit build-up test. Indolene is supposed to represent an average unadditized gasoline. Benzene, isooctane, toluene, and xylene are also used for emission measurements in the 50 and 35 -hour deposit build-up tests. The details of their use will be provided later.

\section{2-1-8 Operating Conditions and Data Sampling Procedure for $\mathrm{HC}$ and $\mathrm{NO}_{\mathrm{x}}$ Measurements}

\section{0-hour Test}

The purpose of this first deposit build-up experiment was to establish whether $\mathrm{CCDs}$ affected the $\mathrm{HC}$ and $\mathrm{NO}_{\mathrm{x}}$ emissions at all. Only limited attention was given to refining the $\mathrm{HC}$ and $\mathrm{NO}_{\mathrm{x}}$ measurement techniques. The $\mathrm{HC}$ and $\mathrm{NO}_{\mathrm{x}}$ data was read directly from the $\mathrm{HC}$ and $\mathrm{NO}_{x}$ analyzers' displays. The values reported represent visual averages of the data. No statistical data was obtained from the $\mathrm{HC}$ and $\mathrm{NO}_{\mathrm{x}}$ emission measurements. The emission measurements were not taken at the deposit build-up cycle operating conditions. They were taken at the operating conditions shown in Table 2.3. In addition to measurement with the deposit fuel, the emission measurements were taken with indolene. After engine disassembly and clean-up, the emission measurements were repeated at the four operating conditions, to verify that the emission values returned to their clean engine levels. All the emission measurements were taken after the engine coolant and oil had reached their steady state values. In this test, the engine's original passive EGR system was used.

\section{0-hour and 25-hour Tests}

The 50-hour test was the second deposit build-up test. Several modifications to the 100$\mathrm{hr}$ test were made resulting in this test. First, the test duration was cut by half because the 100-hr test data showed that the HC emissions increased rapidly and then stabilized after about 25-hrs. Indolene was dropped from the emission measurements because the data from the 100-hr test showed no statistically significant differences between the HC 
emissions of the deposit fuel and indolene. Third, the $\mathrm{HC}$ emission measurements were continuously measured during deposit build-up (at the deposit cycle operating conditions $\mathrm{C} 1$ and $\mathrm{C} 2$ ). The voltage output signals (corresponding to emission measurements) from the $\mathrm{HC}$ and $\mathrm{NO}_{\mathrm{x}}$ analyzers were connected to a data acquisition system, with an analog/digital (A/D) converter. At $\mathrm{C} 1$ and $\mathrm{C} 2$, the data acquisition system sampled the signals from the $\mathrm{HC}$ and $\mathrm{NO}_{\mathrm{x}}$ analyzers every 10 seconds during the deposit build-up. What is presented later are averages over the 6 and 12 minute periods, corresponding to the times the engine operated at operating conditions $\mathrm{C} 1$ and $\mathrm{C} 2$. This sampling over a period of time allowed us to quantify the scatter in the $\mathrm{HC}$ and $\mathrm{NO}_{\mathrm{x}}$ emissions of the engine over the measurement periods. In addition to emission measurements at $\mathrm{C} 1$ and $\mathrm{C} 2$, every 2 hours, the emission measurements were taken at two additional operating conditions (see Table 2.4). At the end of deposit accumulation, the engine was run on three single-component fuels, isooctane, benzene, and a mixture of the three xylenes. The following procedure for emission measurement with the single-component fuels was adapted. The engine was warmed up using the deposit build-up fuel until its coolant and oil reach steady state. Then, the engine was stopped, the fuel system was flushed with isooctane, and the emission data was collected at the above-mentioned operating conditions. The data acquisition system sampled the $\mathrm{HC}$ and $\mathrm{NO}_{\mathrm{x}}$ signals every 1 second for a period of 2 minutes at each operating condition. The data reported in the following chapter represents an average over the 2-minute period. The procedure was repeated for benzene and xylene in the order mentioned. After the engine clean-up and reassembly, the emission measurements were repeated with the deposit fuel and the single-component fuels. The emission tests with the single-component fuels quantified the effect of CCDs on the $\mathrm{HC}$ emissions from those fuels.

The 25-hour test was an exact duplicate of the 50-hr test. It was run to verify the repeatability of the data. Again, because the $\mathrm{HC}$ emissions stabilized after about 25 hours, there was no need to accumulate deposits for 50 hours. The single-component fuel emission measurements were not repeated. The original passive EGR system was used in the 50 and 25 -hr tests.

\section{5-hour Test}

The $\mathrm{NO}_{\mathrm{x}}$ data from the previous three deposit accumulation tests showed large scatter at all operating conditions, suggesting significant variations in the amounts of EGR provided by the EGR system. A new electronic EGR system was installed to better control the EGR amounts provided at each operating condition, and thus reduce the scatter in the $\mathrm{NO}_{\mathrm{x}}$ data. The 35-hr accumulation test was run with the new EGR system in place. The scatter in the $\mathrm{NO}_{x}$ data persisted. In addition, the $\mathrm{HC}$ data showed significant scatter. The trend of rapid increase in the HC data and then stabilization after about 25 hours was not repeated. So at the end of the test, the electronic EGR valve was disconnected, thus running the engine without any EGR. Then, the emission measurements were taken with the EGR off. After the engine clean-up, the emission measurements were repeated with and without EGR. The details of the emission measurements with the deposit fuel are shown in Table 2.5. 
In addition to emission measurements with the deposit build-up fuel, the emission measurements were taken with isooctane, benzene, toluene, and xylene, respectively. This was done to examine the repeatability of the single-component emission data of the 50-hr test. Again, the emission measurements were taken with both the EGR on and off, when the engine is dirty and after the deposit removal. The details of the emission measurements with the single-component fuels is provided in Table 2.6. The data acquisition sampling procedure is the same as the one followed in the 50 -hr test. 


\section{Table 2.1 Saturn Engine Geometry}

No. of Cylinders:

Bore x Stroke (mm)

Displacement $\left(\mathrm{cm}^{3}\right)$

Valvetrain

No. of Valves/Cylinder

Compression Ratio

Combustion Chamber

Fuel System

Max. Power (SAE kW @ RPM)

Max. Torque (SAE N.m. @ RPM)

90\% Max. Torque Range (RPM)

Max. Engine Speed (RPM)
4

$82 \times 90$

1901

DOHC (Chain Drive)

4

$9.5: 1$

Pent Roof

PFI

$92.5 @ 6,000$

$165 @ 4,800$

$1,800-5,800$

6,500 


\section{Table 2.2 Deposit Build-up Fuel Properties}

Test

API Gravity

RVP

Sulfur

Nitrogen

Water

Aromatics

Olefins

Saturates

Oxygenates

Research Octane

Motor Octane

Hydrogen Mass Fraction (by NMR)

Oxygen Mass Fraction $\left(\mathrm{H}_{2} \mathrm{O}+\mathrm{MTBE}\right)$

Carbon Mass Fraction (see note)

Value

58.2

11.2

190

115

233

25.8

9.8

54.6

9.7

91.2

82.5

0.136

\section{Distillation Curve (ASTM D 86)}

Units

deg

psi

mass ppm

mass ppm

mass ppm

vol \%

vol \%

vol \%

vol \%(MTBE)
\%Evaporated

IBP

5

10

20

30

40

50

60

70

80

90

95

End
Temperature

$\left({ }^{\circ} \mathrm{F}\right)$

82.2

104.0

116.6

136.2

154.4

174.9

198.8

230.5

265.2

300.9

345.5

377

423.8

Notes: Specific Gravity $=141.5 /(131.5+$ API Gravity $) ;$ S.G. is at $60^{\circ} \mathrm{F}$ relative to water at $60^{\circ} \mathrm{F}$.

Carbon Mass Fraction=1-H-S-N-O (from oxygenate + water) 
Table 2.3 Operating Conditions for Emission Measurements 100-hour Test

$\begin{array}{lcc}\begin{array}{l}\text { Engine Speed } \\ (\mathrm{rpm})\end{array} & \begin{array}{l}\text { bmep } \\ (\mathrm{kPa})\end{array} & \text { Name } \\ 1500 & 262 & \text { R100A } \\ 1600 & 411 & \text { R100B } \\ 1800 & 511 & \text { R100C } \\ 2000 & 625 & \text { R100D }\end{array}$


Table 2.4 Operating Conditions for Emission Measurements 50 and 25-hour Tests

$\begin{array}{lll}\begin{array}{l}\text { Engine Speed } \\ (\mathrm{rpm})\end{array} & \begin{array}{l}\text { bmep } \\ (\mathrm{kPa})\end{array} & \text { Name } \\ 1400 & 106 \text { (Build-up cycle) } & \mathrm{C} 1 \\ 1500 & 262 & \text { R50A } \\ 1500 & 318 & \text { R50B } \\ 2200 & 318 \text { (Build-up cycle) } & \text { C2 }\end{array}$


Table 2.5 Operating Conditions for Emission Measurements with Deposit Fuel. 35-hour Test

Operating Condition

$\mathrm{rpm}, \mathrm{bmep}(\mathrm{kPa})$

$1400,106(\mathrm{C} 1)$

$1500,262(\mathrm{R} 100 \mathrm{~A})$

1500,318 (R50B)

1600, $411(\mathrm{R} 100 \mathrm{~B})$

$1800,511(\mathrm{R} 100 \mathrm{C})$

$2200,318(C 2)$
Measurement

Frequency

Continuous

Every 2 hours

Every 2 hours

Clean, deposited, and after CCD removal

Clean, deposited, and after CCD removal

Continuous

Table 2.6 Operating Conditions for Emission Measurements with SingleComponent Fuels. 35-hour Test

$\begin{array}{lll}\text { Fuel } & \text { Operating Condition } & \begin{array}{l}\text { Measurement } \\ \text { Frequency }\end{array} \\ \text { Isooctane } & \begin{array}{l}\text { C1, R100A, R50B } \\ \text { R100B, R100C, C2 }\end{array} & \text { Clean, deposited, and after CCD removal } \\ \text { Benzene } & \text { R100A, R50B, C2 } & \text { Clean, deposited, and after CCD removal } \\ \text { Toluene } & \text { R100A, R50B, C2 } & \text { Clean, deposited, and after CCD removal } \\ \text { Xylene } & \text { R100A, R50B, C2 } & \text { Clean, deposited, and after CCD removal }\end{array}$




\section{CHAPTER 3: EXPERIMENTAL RESULTS AND DISCUSSION}

\section{3-1 Introduction}

This chapter presents the experimental results of four deposit build-up experiments of different durations (100,50,25, and 35-hour tests). In this chapter, deposit thickness and mass data will be first presented. Then, the HC and NOx emissions, with the deposit fuel, indolene (100-hr test only) and the single-component fuels from the four deposit build-up tests, will follow. Finally, the effect of CCDs on NOx emissions will be addressed.

\section{3-2 Deposit Thickness and Mass Data}

Deposit thickness data at the center of the pistons was collected during the deposit build-up process. In addition, deposit thickness profiles were measured over the piston and cylinder head surfaces. Finally, deposits from each cylinder and piston top were collected and weighed. In what follows, a summary of this data from the deposit accumulation runs will be presented.

\section{3-2-1 Deposit Tickness at the Center of the Pistons}

Figure 3.1 shows the average deposit thickness (over 4 pistons) at the center as a function of engine run time from the 4 deposit accumulation tests. The data is characterized by a rapid increase in the first 40 hours. After that, the increase tends to slow down and we see evidence of stabilization after about 110 hours. As the deposits build, the deposit surface temperature in contact with the combustion gases increases due to the low thermal conductivity of deposits. As the study by Cheng [17] showed, temperature is the main variable affecting the rate and amount of deposit formation. Using heated plugs inserted in the combustion chamber, he proved that deposit amounts dropped as the plug temperature increased, and that deposits ceased to form on the plug after it had reached a temperature of $310^{\circ} \mathrm{C}$. As later data will show, the thickness is at a minimum at the center of the piston, which is the hottest part of the piston. During engine operation, deposits flake off, burn off, or accumulate. This dynamic process can partly explain the variation in the thickness data among the four runs, estimated at about $20 \mu \mathrm{m}$.

\section{3-2-2 Variation of Deposit Thickness on Piston Surface}

Figure 3.2 shows the 30 fixed locations, where deposit thickness was measured on the piston surface. Figure 3.3 shows the thickness measurements at each of these 30 locations. A few observations can be made. The thickness at locations 1 through 8 and 26 through 30 , which lie at the either end of the piston, are generally higher than at locations in the middle of the piston. The perimeter of the piston is typically its coolest area due to cooling through the piston rings and engine oil. In addition, going diagonally from locations 12 to 19 , the thickness decreases as we move towards the center of the 
piston (hottest area), and then increases again as we move again towards the other end of the piston. Finally, going clockwise around the perimeter of the piston (locations 1, 5, 19, $29,30,26,12,2,1)$, these locations have the highest deposit thickness values on the piston. In summary, the deposit thickness profile on the piston top is an indirect measurement of the temperature profile on the piston surface. Surface temperature is the dominating variable in determining the amount of deposit formation on the combustion chamber surfaces.

\section{3-2-3 Average Deposit Thickness on Cylinder Head and Piston}

At the end of each deposit accumulation test, 30 thickness measurements are taken over each cylinder head and piston top. These 30 measurements are then averaged on each cylinder head and piston. Finally, a mean of those averages from the four cylinder heads and piston tops are then taken. Figure 3.4 shows those resulting mean thickness values from all four deposit accumulation runs. For both the cylinder head and piston top, the thickness increases rapidly the first 35 hours $(4.4 \mu \mathrm{m} / \mathrm{hr}$ for cylinder head and $2 \mu \mathrm{m} / \mathrm{hr}$ for piston). As deposits build up, the outer deposit temperature increases, causing a reduction in the rate of formation of deposits $(0.83 \mu \mathrm{m} / \mathrm{hr}$ for cylinder head and $2 \mu \mathrm{m} / \mathrm{hr}$ for piston). Although the accumulation tests do not run long enough for the thickness to stabilize, eventually, the outer deposit temperature will reach about $310^{\circ} \mathrm{C}$. The deposit level will equilibrate. The difference between the cylinder head and piston top deposit thickness is about $100 \mu \mathrm{m}$. This difference can be correlated to the deposit outer surface temperature on the piston and cylinder head. Cheng's data[17] suggests that the deposit formation decreases by about $3 \mathrm{mg} /{ }^{\circ} \mathrm{C}$. Using the estimated deposit density (which will be discussed later) of $0.83 \mathrm{~g} / \mathrm{cm}^{3}$, this translates into a $0.68 \mu \mathrm{m} /{ }^{\circ} \mathrm{C}$ reduction in the thickness and a $147{ }^{\circ} \mathrm{C}$ difference in the surface temperature between the piston and cylinder head deposits. Our 1-dimensional heat transfer model (see next chapter) predicts a difference of $130{ }^{\circ} \mathrm{C}$ between the piston top and cylinder head deposits, which is in good agreement with the above interpretation.

\section{3-2-4 Average Deposit Mass on Cylinder Head and Piston}

The deposits from each piston and cylinder are scraped with a screw driver. They are separately collected and weighed. Figure 3.5 shows the average deposit mass (over four cylinders) from the four deposit accumulation tests. The main features observed in the thickness data can also be found in the mass data. The early rapid rise in the mass build-up (15.2 $\mathrm{mg} / \mathrm{hr}$ for cylinder head and $9.6 \mathrm{mg} / \mathrm{hr}$ for piston) is followed by slower rise $(8.8 \mathrm{mg} / \mathrm{hr}$ and $5 \mathrm{mg} / \mathrm{hr}$ respectively for cylinder head and piston top). More deposits accumulate on the cylinder head than on the piston top because the piston is hotter than the cylinder head.

\section{3-2-5 Calculation of Deposit Density}


Deposit density can be calculated from the deposit thickness and mass measurements on the cylinder head and piston top, and from their surface areas. It is an important property that will be used later. Figure 3.6 shows the calculated deposit density on all four pistons from the four deposit build-up tests. There is quite a bit of variability in the data. Statistical analysis on the whole data set shows that the density has a mean value of $0.84 \mathrm{~g} / \mathrm{cm}^{3}$ and a standard deviation of $0.19 \mathrm{~g} / \mathrm{cm}^{3}$ (23\% of the mean) This variability can be attributed to many factors. Different cylinders are subjected to different thermal and flow environments, contributing to the differences among the different cylinder heads. Another source of error occurs in the process of scraping and collecting the deposits. During that process, some of the deposits flake off and get lost. In addition, some aluminum chips ( with a density 3 times the deposit density) from the piston get scraped along with the deposits, contributing to higher estimates of the deposit densities. Finally, some oil and engine coolant finds its way into the deposits (especially cylinder head), during engine disassembly.

Figure 3.7 shows a correlation between the deposit mass and its thickness (averages over 4 pistons and cylinder heads) from all four deposit build-up tests. In addition to the experimental data, a linear least-square of each data set is shown, along with the equation of the line. In both cases, the linear square fit is an excellent representation of the data, as indicated by the $\mathrm{R}^{2}$ value (over $95 \%$ in both cases). The slope of the lines is proportional to the deposit density (the proportionality constant is the piston or cylinder head surface area). The data suggests that test-to-test variation in the deposit density is minimal. Calculating the deposit densities for piston and cylinder head deposits, they are found to be 0.83 and $0.69 \mathrm{~g} / \mathrm{cm}^{3}$ respectively.

\section{3-3 Hydrocarbon Emission Data}

In the following sections, the hydrocarbon (HC) emission data from the four deposit accumulation test will be presented in chronological order $(100,50,25$, and finally 35 hour tests). All emission measurements were taken after the engine had fully warmed up (oil and coolant temperature around $90{ }^{\circ} \mathrm{C}$ ). Also, after changing from one operating condition to another, ample time (2-3 minutes) was allowed for the emission to stabilize at the set operating condition before the emission measurements were taken. It is important to note that in the last deposit accumulation test, a new electronic EGR valve replaced the old passive EGR valve, used in the previous three tests. This new electronic EGR valve was supposed to provide better control of the EGR amounts.

\section{3-3-1 HC Emissions from 100-hour Test}

During the 100-hour accumulation test, the HC emissions were regularly measured using the deposit build-up fuel and indolene. Indolene is an industry-wide standard non-additized fuel that represents an average commercial gasoline. The HC emission measurements were read from a digital display on the $\mathrm{HC}$ analyzer. The operating conditions for the $\mathrm{HC}$ emission measurements are the following: 
Figure 3.8 through 3.11 show the variation of the $\mathrm{HC}$ emissions of the deposit build-up fuel, with engine run time (i.e. deposit accumulation) at the four operating conditions. In Figure 3.12 through 3.15, the variation of the $\mathrm{HC}$ emissions of indolene, with engine run time is displayed at the same four operating conditions.

The effect of $\mathrm{CCD}$ on $\mathrm{HC}$ emissions from both fuels is summarized in tables 3.1 and 3.2. The "clean engine" $\mathrm{HC}$ emission level is calculated by averaging the initial 4 data points and those emission points taken after deposit removal, as indicated in the graphs. The "dirty engine" emission level is established by averaging the data points from an engine hour of 30 ( where the $\mathrm{HC}$ emission level stabilizes) until the end of the deposit accumulation test. This averaging better establishes the "clean" dirty engine $\mathrm{HC}$ emission levels by accounting for the scatter in the $\mathrm{HC}$ data. The effect of $\mathrm{CCD}$ on $\mathrm{HC}$ emissions is represented by the difference between the clean and dirty engine emission levels $\Delta[\mathrm{HC}] . \Delta[\mathrm{HC}]$ is the percentage of the injected fuel that is emitted due to $\mathrm{CCD}$. It quantifies the absolute contribution of CCDs to the $\mathrm{HC}$ emissions from the engine. The average standard deviations of the clean and dirty $\mathrm{HC}$ emission levels are also shown in those tables. Finally, $\Delta[\mathrm{HC}] /[\mathrm{HC}]_{\text {dirty }}$ represents the relative contribution of $\mathrm{CCDs}$ to the total $\mathrm{HC}$ emissions from the engine.

Looking at figures 3.8 through 3.15 , a few common characteristics can be incurred. Starting from a "clean-engine" level, the $\mathrm{HC}$ emissions rise rapidly in the first 10 hours, with deposit accumulation. The $\mathrm{HC}$ emissions stabilize after about 25 hours. After engine disassembly and deposit removal, the $\mathrm{HC}$ emissions return to their "clean engine" levels, confirming the effect of CCDs on the $\mathrm{HC}$ emissions. All the HC data ( 2 fuels and all four operating conditions) show these same trends. Although the HC emissions stabilize after about 25 hours, the deposit thickness (on the piston and cylinder head) continues to increase even after about 110 hours, as seen in figure 3.4. The HC emission becomes independent of the deposit thickness after about 25 hours, corresponding to cylinder head and piston thickness of 110 and $50 \mu \mathrm{m}$ respectively. This point will be discussed in greater detail in the following chapter.

Tables 3.1 and 3.2 show a summary of the data shown in figures 3.8 through 3.15. CCDs contribute to an average increase in the $\mathrm{HC}$ emissions (over all operating conditions) of 366 and $430 \mathrm{ppm} \mathrm{C1}$, for the deposit build-up fuel and indolene respectively. This increase is significant and represents 13 to $16 \%$ of the total $\mathrm{HC}$ emissions from the engine. We conclude that $\mathrm{CCDs}$ are a significant source of $\mathrm{HC}$ emissions from this engine, comparable to the other sources (oil layers, crevices, etc....). At each operating condition, there is no significant difference in the clean and dirtyengine $\mathrm{HC}$ emission levels between indolene and the deposit build-up fuel. In addition, CCDs effect on the $\mathrm{HC}$ emissions from each fuel (characterized by $\Delta[\mathrm{HC}]$ ), at all operating conditions is comparable, within the experimental uncertainty. No conclusion can be drawn on the effect of operating conditions on $\Delta[\mathrm{HC}]$. One reason being is that the $\Delta[\mathrm{HC}] \mathrm{s}$ are comparable at all operating conditions. In addition, the $\mathrm{HC}$ emission 
measurements are engine-out measurements. In-cylinder retention and oxidation of fuel, and oxidation of fuel molecules is not accounted for. These depend on the peak cylinder temperature (i.e. load) and residence time of the fuel molecules in the cylinder and exhaust port (which depend on the engine speed).

\section{3-3-2 HC Emissions from 50 and 25-hour Tests with the Deposit Build-up Fuel}

Because the 100-hour test showed that the HC emissions stabilized after about 20-25 hours, the duration of the deposit accumulation test was successively cut in half from 100 to 50 and finally 25 hours. At the end of the 50-hour deposit accumulation test, HC emission measurements were also taken with three singlecomponent fuels, isooctane, benzene, and xylene ( $\mathrm{m}, \mathrm{p}$, and o-xylene) at the four operating conditions listed above. After the engine was disassembled and the deposits removed, the $\mathrm{HC}$ emissions were retaken. This allowed the quantification of the effect of $\mathrm{CCDs}$ on $\mathrm{HC}$ emissions from single-component fuels. It is important to note that only single measurements were taken at the end of deposit accumulation and after deposit clean-up. These measurements were not repeated. A more thorough HC emission measurement with single-component fuels was undertaken with the 35 -hr test, the details of which will be discussed later. One final note is that the original mechanical EGR valve was used in the 50 and 25 -hour tests.

Figures 3.16 through 3.18 show the $\mathrm{HC}$ emissions data as a function of engine hours from both the 50 and 25 -hour runs. Using the same averaging procedure used in Tables 3.1 and 3.2, Tables 3.3 and 3.4 show a summary of the data shown in figures 3.16 through 3.18 .

\section{$1500 \mathrm{rpm}, \mathrm{bmep}=262 \mathrm{kPa}$}

Figure 3.16 shows the $\mathrm{HC}$ emissions vs. engine hours at the above operating condition. Data from both the 25 - and 50 -hr tests shows a rapid increase in the first 17 hours, from a level of about $2450 \mathrm{ppm} \mathrm{C1}$ to about $2720 \mathrm{ppm} \mathrm{C1}$. While the 50hr test data suddenly drops by about $200 \mathrm{ppm}$, the 25 -hr data keeps rising until it reaches a level of about $2850 \mathrm{ppm} \mathrm{Cl}$ after 25 hours. The 50 -hour test data has a lot of scatter in it and is not as well-behaved as the 25-hr data. After removal of CCDs, the HC emission from the 25-hr test returns to its "clean-engine" levels confirming the effect of CCD on the $\mathrm{HC}$ emissions. According to Table 3.4, this drop in $\mathrm{HC}$ emissions is about $375 \mathrm{ppm}$ $\mathrm{C} 1$, a significant one if compared to the standard deviation. The 50 -hr test data (Table 3.3) indicates no significant effect of CCD on HC emissions at this operating condition. One reason for the scatter in the 50-hr data and the discrepancy between the 2 tests, is the variation in the amount of EGR from one time to another. The EGR valve in these tests was of the mechanical type. It was basically an orifice whose opening was modulated by the pressure difference between the intake and exhaust ports. Apparently, It did not adequately control the EGR amounts provided at each operating condition to hold emissions steady. Variations in the EGR amount are critical at this light load because they could affect the combustion quality of the fuel-air mixture and the fraction of fuel 
oxidized, which escapes the main combustion event (by affecting the in-cylinder peak temperature). These two effects would lead to these variations and the lack of repeatability in the $\mathrm{HC}$ emission data that we see in Figure 3.16.

\section{$1500 \mathrm{rpm}, \mathrm{bmep}=318 \mathrm{kPa}$}

The HC emission data at the above operating condition (both 50and 25-hr tests) is shown in Figure 3.17 and a summary of the data is provided in Tables 3.3 and 3.4. Looking at Figure 3.17, the $\mathrm{HC}$ emission rises rapidly in the first 10 hours. In the case of the $25-\mathrm{hr}$ test, the $\mathrm{HC}$ emission continues a monatomic rise throughout the test. Meanwhile, the 50-hr HC data stabilizes after about 15 hours. The reason for the rapid increase and $\mathrm{HC}$ data becoming independent of the deposit thickness will be discussed in detail in the following chapter. After removing the CCDs from the combustion chamber, the HC emissions return to their "clean-engine" levels in both cases. Looking at Tables 3.3 and 3.4, CCDs contribute to significant increases of 312 and $378 \mathrm{ppm} \mathrm{C1}$ (from both tests). These increases correspond to 12 to $14 \%$ of the total engine-out $\mathrm{HC}$ emission level. The $\mathrm{HC}$ data at this operating condition shows less scatter and better repeatability than the previous operating condition. It is apparent that higher loads gave better data. At higher loads, the combustion stability is better and partial-burn or misfiring cycles are much less frequent. Although the engine speed is the same, the load is higher at this operating condition. At this higher load, variations in the EGR amount might not have as significant an effect on the combustion quality and oxidation rates as they would at the higher load.

\section{$2200 \mathrm{rpm}, \mathrm{bmep}=318 \mathrm{kPa}$}

Figure 3.18 shows the $\mathrm{HC}$ emission data at the above operating condition from the 50 and 25-hour tests. Tables 3.3 and 3.4 also have a summary of the data presented in Figure 3.18. The same characteristics in Figure 3.17 are seen in Figure 3.18. The $\mathrm{HC}$ emission data rapidly rises in the first 15 hours from a level of about 2000 ppm C1 until it stabilizes at a level of 2200 ppm C1 after about 30 hours. After the removal of CCDs, the $\mathrm{HC}$ emission returns to the "clean-engine" level of $2000 \mathrm{ppm} \mathrm{C1}$ in both cases confirming the effect of $\mathrm{CCD}$ on the $\mathrm{HC}$ emissions. Looking at the summary in Tables 3.3 and 3.4, the increase in HC emission level ranges from 197 to $237 \mathrm{ppmC1}$. The data shows little scatter and is repeatable from the 50 to the 25 -hour test. In both cases, CCDs contribute to about $10 \%$ of the total engine-out $\mathrm{HC}$ emissions, making it a significant emission source.

\section{Correlation between the HC Emission and the Deposit Thickness}

In the previous sections, we presented the $\mathrm{HC}$ emissions data as a function of engine hours. Although deposit accumulation correlates well with engine running time, comparing $\mathrm{HC}$ emissions directly with deposit thickness gives a better indication of the dependence of the $\mathrm{HC}$ emissions on deposit thickness. Figures 3.19 and 3.20 show the HC emissions at two operating conditions, as a function of deposit 
thickness on the cylinder head and piston top. The average piston top and cylinder head deposit thickness as a function of engine hours, from the four deposit accumulation tests shown in Figure 3.4, is fitted to two least-square exponential functions (one for piston top deposits, the other for cylinder head deposits). The fitting equations are:

$$
\begin{aligned}
& h_{\text {cylinder }}=258.6\left(1-e^{-0.02512 t}\right) \\
& h_{\text {piston }}=167.4\left(1-e^{-0.01544 t}\right)
\end{aligned}
$$

where $h$ represents the deposit thickness and $t$ the engine hours.

As the deposit thickness increases, the $\mathrm{HC}$ emissions increase rapidly until it stabilizes after a certain thickness has been reached. The HC emissions then becomes independent of the deposit thickness. This thickness is $110 \mu \mathrm{m}$ for cylinder head and $50 \mu \mathrm{m}$ for piston top deposits. The reason for this type of dependence of the $\mathrm{HC}$ emission on the deposit thickness will be discussed in detail in the following chapter.

\section{3-3-3 HC Emissions from 35-hour Test with the Deposit Build-up Fuel}

In order to improve the quality of the $\mathrm{NO}_{\mathrm{x}}$ data, it was decided to upgrade to the new electronic EGR system which supposedly would provide a better control of the EGR amounts at each operating condition. This new electronic EGR system was operational for most of the 35-hour test. As will be seen in this section, the $\mathrm{HC}$ emission data showed significant scatter and lack of repeatability when the electronic EGR system was operational. At the end of the deposit accumulation, the EGR valve was disabled. The $\mathrm{HC}$ emissions were repeated with the deposit fuel and a matrix of single component fuels, with the deposited engine and after deposit removal. This improved the data drastically. This data will be presented later. After the EGR valve is disabled, the engine control unit retards the spark timing to prevent engine knock. It is not expected that the spark retard will be significant at the relatively light loads (up to $30 \%$ load) that the engine is operated. Spark retard reduces the cylinder peak temperature, and thus the fraction oxidized of the fuel stored in the deposits, leading to a stronger effect of CCDs on the $\mathrm{HC}$ emissions.

\section{HC Emission from Deposit Fuel with EGR On}

Figures 3.21 through 3.24 show the $\mathrm{HC}$ emission vs. engine hours at four operating conditions with the engine running on the deposit fuel. Looking at Figure $3.21(1400 \mathrm{rpm}, \mathrm{bmep}=106 \mathrm{kPa})$, The $\mathrm{HC}$ data seems to maintain a constant level of about $2350 \mathrm{ppm} \mathrm{C} 1$ the first 20 hours of deposit build up. It can be argued that the $\mathrm{HC}$ emission starts to increase slightly for the next 15 hours. Due to the scatter in the data, which is of the order of $200 \mathrm{ppm} \mathrm{C1}$, no conclusion could be reached on the effect of $\mathrm{CCD}$ on the $\mathrm{HC}$ emission at this operating condition. Cleaning the combustion chamber does not produce any change in the $\mathrm{HC}$ emission level, as this data set indicates. 
Figure 3.22 shows the $\mathrm{HC}$ emission vs. engine hours at $1500 \mathrm{rpm}$ and bmep $=262 \mathrm{kPa}$. The HC data could be characterized by an increase of $250 \mathrm{ppm} \mathrm{Cl}($ from 2200 to $2600 \mathrm{ppm} \mathrm{C1}$ ). After the CCD removal, the $\mathrm{HC}$ emission maintains its steady-state level. Due to the scatter in the data $(\sim 400 \mathrm{ppm} \mathrm{C1})$. It is incurred that the data is inconclusive on the effect of CCD on the HC emissions. It is thought that the scatter in the data is due to a variation in the EGR amount at this operating condition. Another plausible explanation for the scatter in the HC data can be attributed to the way the engine control unit (ECU) controls the EGR valve. The ECU opens the EGR valve after the intake manifold pressure exceeds a threshold value $(40 \mathrm{kPa})$. Adding EGR at lighter loads (lower intake manifold pressure) affects the combustion stability or quality in the cylinder, resulting in non-firing or partially-burning cycles. The intake pressure at the above operating condition $(\sim 42 \mathrm{kPa})$ lies on the threshold for EGR opening. It might be that EGR is provided at certain times and not at others or that the EGR amount is varying, resulting in this variation in the $\mathrm{HC}$ emission.

In Figure 3.23, The HC emission at $1500 \mathrm{rpm}$, bmep= $318 \mathrm{kPa}$ is shown vs. engine hours again. The graph can be characterized by a decreasing trend in the first 5 hours. From about 14 hours, the data shows the same trend seen in the 50 and 25 hour test, namely, a rapid increase for about 10 hours. This increase in emission is about $450 \mathrm{ppm} \mathrm{C1}$, a significant one. Cleaning the CCDs does not change the HC emission from its steady state value. The $\mathrm{HC}$ emission still goes back to the clean-engine level. One plausible explanation for the behavior of the data in the early hours is the filling of the piston crevices with the deposits. We actually see a significant amount of deposit build-up around the circumference of the piston in contact with the liner wall. In addition, a thick layer of deposits builds on top of the cylinder liner. This build-up of deposits fills the piston crevice volume, reducing the amount of fuel stored in these crevice and thus the $\mathrm{HC}$ emissions.

\section{HC Emission from Deposit Fuel with EGR Off}

The HC data with the EGR on did not confirm the results of the previous deposit experiments, it was thought that the new EGR system might be the cause of this inconsistency in the data. So, it was decided to disable the EGR valve and run the engine with no EGR and observe the behavior of the HC data. By doing this, a variable on which the HC emission strongly depends was eliminated. The EGR valve was disabled at the end of the 35-hr accumulation test. It was confirmed that the EGR valve was disabled by comparing the $\mathrm{NO}_{\mathrm{x}}$ emissions with and without the EGR at the same operating condition. There was a jump of up to a factor of 5 in the $\mathrm{NO}_{\mathrm{x}}$ emission after the EGR valve was disconnected. The $\mathrm{HC}$ emission measurements were taken at the above four operating condition at the end of the deposit accumulation test and the CCDs had been removed. In addition, two more operating conditions, used in the first deposit buildup test (the 100-hr test) were added to the test matrix. The HC measurement, with the deposited and clean engine, was repeated at least once on a different day to better quantify the scatter in the data. The results of the measurements at the four operating conditions 
listed above are shown in Figures 3.25 through 3.28. A summary of the data from the six operating conditions is also shown in Table 3.5. Even though the engine was run for about 10 hours after it was cleaned, this does not fully translate into 10 hours of deposit accumulation on the deposit build-up fuel. During that 10-hour period, the engine was run on isooctane which is known for not producing any deposits and may contribute to some removal of the deposits formed by the other fuels.

Looking at the four figures, removing CCDs caused a significant reduction in the $\mathrm{HC}$ emission at all operating conditions. This reduction ranged from 188 $\mathrm{ppm} \mathrm{C1}$ to $570 \mathrm{ppm} \mathrm{C1}$, as shown in Table 3.5. This confirms the conclusion of the previous three deposit accumulation tests that CCDs increase the HC emissions. The contribution of CCDs to the total $\mathrm{HC}$ emission ranges between 7 and $20 \%$ depending on the operating condition (see Table 3.5).

\section{3-3-4 HC Emissions from Single-component Fuels}

In order to quantify the effect of CCDs on the HC emissions from singlecomponent fuels, $\mathrm{HC}$ emission measurements were taken with the engine running on single-component fuels. The emission measurements were taken with the deposited engine and after CCD removal. These single-component $\mathrm{HC}$ emission measurements were taken at the end of the 50-hour and 35-hour tests. The procedure followed in taking these measurements is as follows. The engine is run on the deposit fuel until it is fully warmed up. The engine is turned off and the fuel system is quickly flushed with the single-component fuel to be used for $\mathrm{HC}$ emission measurements. This ensures that no deposit fuel remains in the fuel system. The engine is then run on the single-component fuel for a period of about 10 minutes before emission measurements are taken at different operating conditions. The single-component fuels used at the conclusion of the 50-hr test were isooctane, benzene and xylene while toluene was added to this matrix at the end of the 35 -hr test. It is important to note two distinctions between the two tests. First, the old passive EGR system was operating during emission measurements at the end of the 50-hr test while emission measurements were taken with the new electronic EGR system both on and off during the $35-\mathrm{hr}$ test. Second, at each operating condition, the data from the 50-hr consisted of single-point measurements with the deposited and clean engine while the data from the 35 -hr test was repeated at least once. The data from the 35 -hr test represents an average of the repeated measurements.

\section{Single-component HC Emission from 50-hour Test}

Figure 3.29 shows the $\mathrm{HC}$ emission from isooctane, benzene and xylene at four operating conditions, with the deposited and clean engine respectively. In addition, Tables $\mathrm{A} 1$ through $\mathrm{A} 3$ in appendix $\mathrm{A}$ have the actual data in tabulated form. In those tables, the increase in $\mathrm{HC}$ emission due to $\mathrm{CCD}, \Delta[\mathrm{HC}]$, is converted to a $\%$ of the mass of fuel injected that gets emitted due to CCD. This is thought to form a better basis for comparison between the different fuels. The equation used is the following: 


$$
\frac{\left(m_{\text {emitred }}\right)_{\text {deposit }}}{m_{\text {injected }}}=\frac{\Delta[H C] \times 10^{-6}}{n}\left(\frac{M_{f}}{M_{p}}\right)\left(1+\left(\frac{A}{F}\right)_{s}\right)
$$

Where $\mathrm{n}$ is the number of carbon atoms in the fuel molecule, $\mathrm{M}_{\mathrm{f}}$ the fuel molecular weight, $M_{p}$ the combustion product molecular weight, and $(A / F)_{s}$ the stoichiometric air to fuel ratio. The implied assumptions in the above equation are that the $\mathrm{HC}$ emitted is in the form of molecules (no intermediate species), the fuel-air mixture is stoichiometric, and that the residual gas fraction is negligible.

Looking at Figure 3.29, the $\mathrm{HC}$ emission increases after CCD removal for each fuel. This increase in the $\mathrm{HC}$ emissions can be attributed to the instability of the combustion process at this load. Furthermore, the control of the load at this operating condition was not good ( the brake torque was within 4 N.m. of the set torque of $16 \mathrm{~N} . \mathrm{m}$.), which might have also contributed to this behavior in the $\mathrm{HC}$ emission data. At all three remaining operating conditions, the removal of CCDs caused a significant reduction in the $\mathrm{HC}$ emissions for isooctane and benzene, ranging from 464 $\mathrm{ppm}$ to $844 \mathrm{ppm} \mathrm{C1}$. This reduction translates into a $15.8 \%$ to $30.8 \%$ of the total $\mathrm{HC}$ emission from the engine, proving that $\mathrm{CCDs}$ are a significant source of $\mathrm{HC}$ emission from this engine. Data for xylene at all four operating conditions shows no effect of $\mathrm{CCD}$ s on $\mathrm{HC}$ emission from xylene. There is no plausible explanation for this result. Xylene like benzene belongs to the aromatics group of hydrocarbons. So, its oxidation characteristics in the cylinder head and exhaust port and other physical characteristics (adsorption on deposit surface and diffusion in deposit pores) are expected to be similar to those of benzene. In fact, the data presented later from the 35-hour test will show an effect of the CCDs on the $\mathrm{HC}$ emission from xylene comparable to that of the other $\mathrm{HCs}$ tested.

\section{Single-component HC Emission from 35-hour Test}

As mentioned above, the $\mathrm{HC}$ emissions were measured with both the EGR valve on and off. For the case when the EGR was on, the HC data at the four operating conditions is also shown in Figure 3.29 and a summary is in Tables B1 through B4 in appendix B. The HC data with the EGR off is in Figures 3.29 and in Tables B5 through B8 in appendix B. A few words should be said about how the engine control unit (ECU) reacts to disabling the electronic EGR valve. Once the EGR valve is disabled, the ECU retards the spark timing for the operating conditions where EGR is introduced. EGR is typically introduced for intake manifold pressures higher than about $40 \mathrm{kPa}$. For operating conditions where the intake manifold pressure is less than $40 \mathrm{kPa}$, the spark timing is not affected. Among the operating conditions where $\mathrm{HC}$ emission measurements are taken, the two operating conditions that are affected are the $1500 \mathrm{rpm}$ and $2200 \mathrm{rpm}$ and bmep= $318 \mathrm{kPa}$. The $1500 \mathrm{rpm}$ and bmep= $262 \mathrm{kPa}$ has an intake pressure of about $40 \mathrm{kPa}$, which places it at the threshold of EGR introduction. 
Looking at the HC data with the EGR on first, a few conclusions can be drawn. At all operating conditions and for all fuels, the $\mathrm{HC}$ emissions decrease with CCD removal indicating that CCDs cause an increase in the $\mathrm{HC}$ emissions. The $\mathrm{HC}$ increase due to CCDs ranges from 11 to $15 \%$ of the total HC emission for isooctane, 14 to $24 \%$ for benzene, 16 to $22 \%$ for toluene, and 10 to $12 \%$ for xylene. This indicates that $\mathrm{CCDs}$ are a significant $\mathrm{HC}$ emission source. Because the total $\mathrm{HC}$ emission levels are different for different fuels, a better way of comparing fuels is to compare the $\%$ of the mass of injected per cycle due to CCDs, which are shown in the tables also. At all operating conditions, the increase in engine-out HC emissions due to CCDs is largest for toluene, followed by isooctane, benzene and finally xylene. M. Norris et al. [19] doped lubricating oil with isooctane, xylene, and toluene and estimated the fraction of the desorbed fuel that escapes oxidation in the cylinder and exhaust ports. He found that toluene had the largest surviving fraction at 0.33 followed by xylene at 0.29 and finally isooctane at 0.23 . This indicates that the CCD source for the three fuels isooctane, benzene and toluene might be about the same while it could be smaller than the other three fuels for xylene. The difference that is seen among the three fuels is due in part to the difference in the oxidation rates among the fuels. In addition, the surviving fraction is a function of the operating conditions. Adding to that the experimental uncertainties, no significant differences in the effect of CCDs on HC emissions from the three fuels could be seen. CCDs cause an $\mathrm{HC}$ increase equal to 0.2 to $0.5 \%$ of the mass of injected fuel, depending on the operating condition and fuel.

Looking at the $\mathrm{HC}$ emission data with the EGR off at the two operating conditions where EGR is introduced when the EGR valve is on $(1500 \mathrm{rpm} @$ bmep $=318 \mathrm{kPa}$ and $2200 \mathrm{rpm} @$ bmep= $318 \mathrm{kPa}$ ), it can be clearly seen that the CCD $\mathrm{HC}$ emission source ranges from 15 to $29 \%$. CCDs cause an increase equal to about $0.5 \%$ of the mass of fuel injected.

\section{4 $\mathrm{NO}_{\mathrm{x}}$ Emission Data}

Due to their low thermal conductivity, it is believed that CCDs raise the peak cylinder temperature. Since $\mathrm{NO}_{\mathrm{x}}$ formation is strongly temperature dependent, it is believed that CCDs increase $\mathrm{NO}_{x}$ emissions through this thermal process. In order to verify this hypothesis, the $\mathrm{NO}_{\mathrm{x}}$ emission was collected along with the $\mathrm{HC}$ emission during the deposit accumulation tests and at the two additional operating conditions listed above every 2 hours. Figures 3.30 and 3.31 show the $\mathrm{NO}_{\mathrm{x}}$ emission as a function of engine hours at three operating conditions from the 25-hour deposit accumulation test. During the 25 -hour deposit build-up test, the old passive EGR system was still in operation.

Looking at Figure 3.30, it is clear that the $\mathrm{NO}_{\mathrm{x}}$ emission data has significant scatter (as large as $400 \mathrm{ppm}$ ) at both operating conditions. It is clear that the data shows no clear pattern and it can be concluded that CCDs show no effect on the $\mathrm{NO}_{x}$ emission at these operating conditions. Figure 2.45 shows the $\mathrm{NO}_{\mathrm{x}}$ emission at $2200 \mathrm{rpm}$ and bmep $=318 \mathrm{kPa}$, one of the deposit build-up cycle operating conditions. There is 
significant scatter in the data. This scatter in the data can be attributed to variability in the EGR amounts provided by the EGR valve at the same operating condition. The $\mathrm{NO}_{\mathrm{x}}$ emission is very sensitive to variations in the EGR amounts. Again, the data is inconclusive on the effect of CCDs on the $\mathrm{NO}_{\mathrm{x}}$ emissions.

\subsection{Conclusions}

Four deposit build-up tests were conducted. In the first test (110 hours long) the $\mathrm{HC}$ emissions were measured with the deposit build-up fuel and indolene. Two more tests, 50 and 25-hour long were conducted. The $\mathrm{HC}$ emissions were measured with the deposit build-up fuel. At the end of the 50-hour test and after CCD removal, the $\mathrm{HC}$ emissions were measured with isooctane, benzene and xylene to quantify the effect of $\mathrm{CCDs}$ on the $\mathrm{HC}$ emissions from single-component fuels. Finally, after installing a new electronic EGR valve was installed, a 35-hour deposit accumulation test was conducted. At the end of that test and after $\mathrm{CCD}$ removal, the $\mathrm{HC}$ emissions were again measured with isooctane, benzene, toluene, and xylene. Because the $\mathrm{HC}$ emissions data did not confirm the conclusions of the previous 3 tests, it was decided to disable the new electronic EGR valve because it was thought to be the reason behind the inconsistency in the data. After disabling the EGR valve, the HC emission was measured with the deposit build-up fuel and the four single-component fuels with the deposited engine and after engine clean-up. The new data confirmed the conclusions of the previous three tests. The conclusions from all four tests can be summarized in the following points:

1. The deposit thickness keeps growing long after the HC emission has stabilized. Even after 110 hours of deposit accumulation, the deposit thickness on the cylinder head and piston top continues to grow, though at a slower rate.

2. The average deposit thickness is about half of that on the cylinder head. This is due to the higher piston surface temperature, which reduces the amount of deposits that accumulates on its surface.

3. The HC emissions increase rapidly in the first 10 hours of deposit accumulation and stabilize after about 25 hours, corresponding to a deposit thickness of about 50 and $100 \mu \mathrm{m}$ on the piston top and cylinder head. Additional deposit accumulation does not affect the $\mathrm{HC}$ emission.

4. CCDs contributed to about a $15 \%$ of the total engine-out $\mathrm{HC}$ emission making them a significant source of HC emissions. There was no significant difference between the $\mathrm{HC}$ emissions of the deposit build-up fuel and indolene.

5. CCDs affected the $\mathrm{HC}$ emissions from all four single-component fuels (isooctane, benzene, toluene, and xylene). The CCD contribution ranged from 5 to $30 \%$ depending on the fuel and operating condition. This translates into 0.1 to $0.5 \%$ of the mass of fuel injected per cycle. There was no significant in the effect of CCDs on the $\mathrm{HC}$ emissions from the different fuels. 
6. Due to the large scatter in the data, no conclusion on the effect of $\mathrm{CCD}$ on the $\mathrm{NO}_{\mathrm{x}}$ emission could be drawn. 


\begin{tabular}{|l|l|l|l|l|}
\hline Operating Condition & $\begin{array}{l}{[\mathrm{HC}]_{\text {deposit }}} \\
(\mathrm{ppm} \mathrm{Cl})\end{array}$ & $\begin{array}{l}{[\mathrm{HC}]_{\text {clean }}} \\
(\mathrm{ppm} \mathrm{C1})\end{array}$ & $\begin{array}{l}\Delta[\mathrm{HC}] \\
(\mathrm{ppm} \mathrm{C} 1)\end{array}$ & $\begin{array}{l}\Delta[\mathrm{HC}] /[\mathrm{HC}]_{\text {deposit }} \\
\%\end{array}$ \\
\hline $1500 \mathrm{rpm}, \mathrm{bmep}=262 \mathrm{kPa}$ & 2667 & 2273 & 394 & 15 \\
\hline $1600 \mathrm{rpm}, \mathrm{bmep}=411 \mathrm{kPa}$ & 2491 & 2066 & 425 & 17 \\
\hline $1800 \mathrm{rpm}, \mathrm{bmep}=511 \mathrm{kPa}$ & 2333 & 1971 & 362 & 15 \\
\hline $2000 \mathrm{rpm}, \mathrm{bmep}=625 \mathrm{kPa}$ & 2213 & 1928 & 285 & 13 \\
\hline
\end{tabular}

Table 3.1 Summary of the effect of CCD on HC emission from deposit build-up fuel. Data from 110-hour run

\begin{tabular}{|l|l|l|l|l|}
\hline Operating Condition & $\begin{array}{l}{[\mathrm{HC}]_{\text {deposit }}} \\
(\mathrm{ppm} \mathrm{C1})\end{array}$ & $\begin{array}{l}{[\mathrm{HC}]_{\text {clean }}} \\
(\mathrm{ppm} \mathrm{C1})\end{array}$ & $\begin{array}{l}\Delta[\mathrm{HC}] \\
(\mathrm{ppm} \mathrm{C} 1)\end{array}$ & $\begin{array}{l}\Delta[\mathrm{HC}] /[\mathrm{HC}]_{\text {deposit }} \\
\%\end{array}$ \\
\hline $1500 \mathrm{rpm}, \mathrm{bmep}=262 \mathrm{kPa}$ & 2715 & 2284 & 431 & 16 \\
\hline $1600 \mathrm{rpm}, \mathrm{bmep}=411 \mathrm{kPa}$ & 2559 & 2073 & 486 & 19 \\
\hline $1800 \mathrm{rpm}, \mathrm{bmep}=511 \mathrm{kPa}$ & 2419 & 1981 & 438 & 18 \\
\hline $2000 \mathrm{rpm}, \mathrm{bmep}=625 \mathrm{kPa}$ & 2227 & 1859 & 368 & 16 \\
\hline
\end{tabular}

Table 3.2 Summary of the effect of CCD on HC emission from indolene. Data from 110hour run 


\begin{tabular}{|l|l|l|l|l|}
\hline Operating Condition & $\begin{array}{l}{[\mathrm{HC}]_{\text {deposit }}} \\
(\mathrm{ppm} \mathrm{C1})\end{array}$ & $\begin{array}{l}{[\mathrm{HC}]_{\text {clean }}} \\
(\mathrm{ppm} \mathrm{C1})\end{array}$ & $\begin{array}{l}\Delta[\mathrm{HC}] \\
(\mathrm{ppm} \mathrm{C1})\end{array}$ & $\begin{array}{l}\Delta[\mathrm{HC}] /[\mathrm{HC}]_{\text {deposit }} \\
\%\end{array}$ \\
\hline $1400 \mathrm{rpm}, \mathrm{bmep}=106 \mathrm{kPa}$ & 2716 & 2878 & -162 & -6 \\
\hline $1500 \mathrm{rpm}, \mathrm{bmep}=262 \mathrm{kPa}$ & 2579 & 2517 & 62 & 2 \\
\hline $1500 \mathrm{rpm}, \mathrm{bmep}=318 \mathrm{kPa}$ & 2605 & 2293 & 312 & 12 \\
\hline $2200 \mathrm{rpm}, \mathrm{bmep}=318 \mathrm{kPa}$ & 2230 & 2033 & 197 & 9 \\
\hline
\end{tabular}

Table 3.3 Summary of the effect of CCD on HC emission from deposit build-up fuel. Data from 50-hour run

\begin{tabular}{|l|l|l|l|l|}
\hline Operating Condition & $\begin{array}{l}{[\mathrm{HC}]_{\text {deposit }}} \\
(\mathrm{ppm} \mathrm{C1})\end{array}$ & $\begin{array}{l}{[\mathrm{HC}]_{\text {clean }}} \\
(\mathrm{ppm} \mathrm{C1})\end{array}$ & $\begin{array}{l}\Delta[\mathrm{HC}] \\
(\mathrm{ppm} \mathrm{C1})\end{array}$ & $\begin{array}{l}\Delta[\mathrm{HC}] /[\mathrm{HC}]_{\text {deposit }} \\
\%\end{array}$ \\
\hline $1400 \mathrm{rpm}, \mathrm{bmep}=106 \mathrm{kPa}$ & 2834 & 2771 & 63 & 2 \\
\hline $1500 \mathrm{rpm}, \mathrm{bmep}=262 \mathrm{kPa}$ & 2833 & 2458 & 375 & 13 \\
\hline $1500 \mathrm{rpm}, \mathrm{bmep}=318 \mathrm{kPa}$ & 2699 & 2321 & 378 & 14 \\
\hline $2200 \mathrm{rpm}, \mathrm{bmep}=318 \mathrm{kPa}$ & 2196 & 1959 & 237 & 11 \\
\hline
\end{tabular}

Table 3.4 Summary of the effect of CCD on HC emission from deposit build-up fuel. Data from 25-hour run 


\section{EGR OFF}

\begin{tabular}{|l|l|l|l|l|}
\hline Operating Condition & $\begin{array}{l}{[\mathrm{HC}]_{\text {deposit }}} \\
(\mathrm{ppm} \mathrm{C1})\end{array}$ & $\begin{array}{l}{[\mathrm{HC}]_{\text {clean }}} \\
(\mathrm{ppm} \mathrm{C1})\end{array}$ & $\begin{array}{l}\Delta[\mathrm{HC}] \\
(\mathrm{ppm} \mathrm{C1})\end{array}$ & $\begin{array}{l}\Delta[\mathrm{HC}] /[\mathrm{HC}]_{\text {deposit }} \\
\%\end{array}$ \\
\hline $1400 \mathrm{rpm}, \mathrm{bmep}=106 \mathrm{kPa}$ & 2613 & 2425 & 188 & 7 \\
\hline $1500 \mathrm{rpm}, \mathrm{bmep}=262 \mathrm{kPa}$ & 2822 & 2252 & 570 & 20 \\
\hline $1500 \mathrm{rpm}, \mathrm{bmep}=318 \mathrm{kPa}$ & 2756 & 2300 & 456 & 16.5 \\
\hline $1600 \mathrm{rpm}, \mathrm{bmep}=411 \mathrm{kPa}$ & 2530 & 2054 & 476 & 18.8 \\
\hline $1800 \mathrm{rpm}, \mathrm{bmep}=511 \mathrm{kPa}$ & 2306 & 2022 & 284 & 12.3 \\
\hline $2200 \mathrm{rpm}, \mathrm{bmep}=318 \mathrm{kPa}$ & 2335 & 2022 & 313 & 13 \\
\hline
\end{tabular}

Table 3.5 Summary of the effect of CCD on HC emission from deposit build-up fuel. Data from 35-hour run with the EGR off. 


\section{Average Deposit Thickness at Center of Pistons}

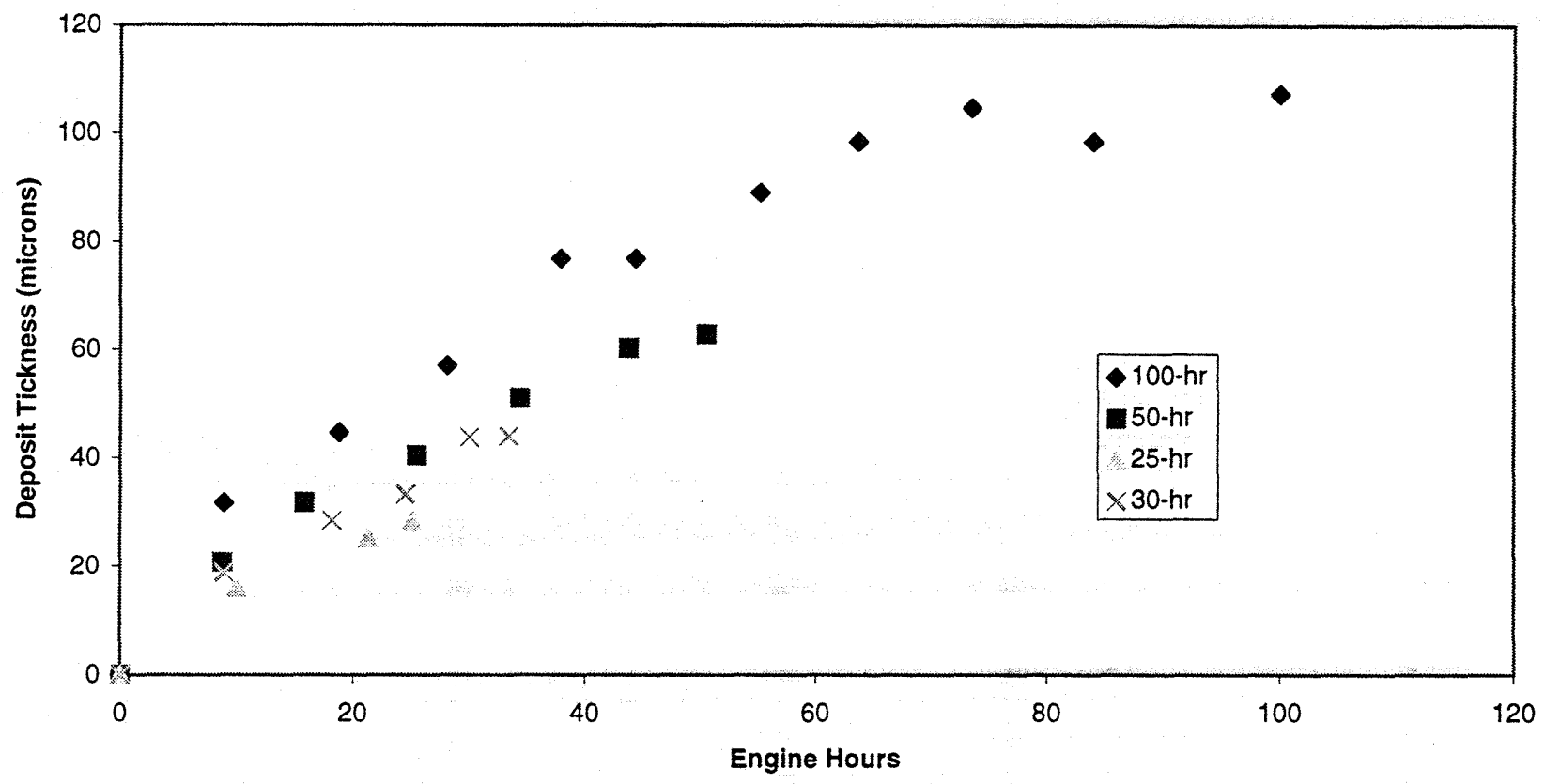

Figure 3.1 Average deposit thickness at the center of the pistons from 100-hr, 50-hour, 30-hr and 25-hr deposit accumulation tests. 


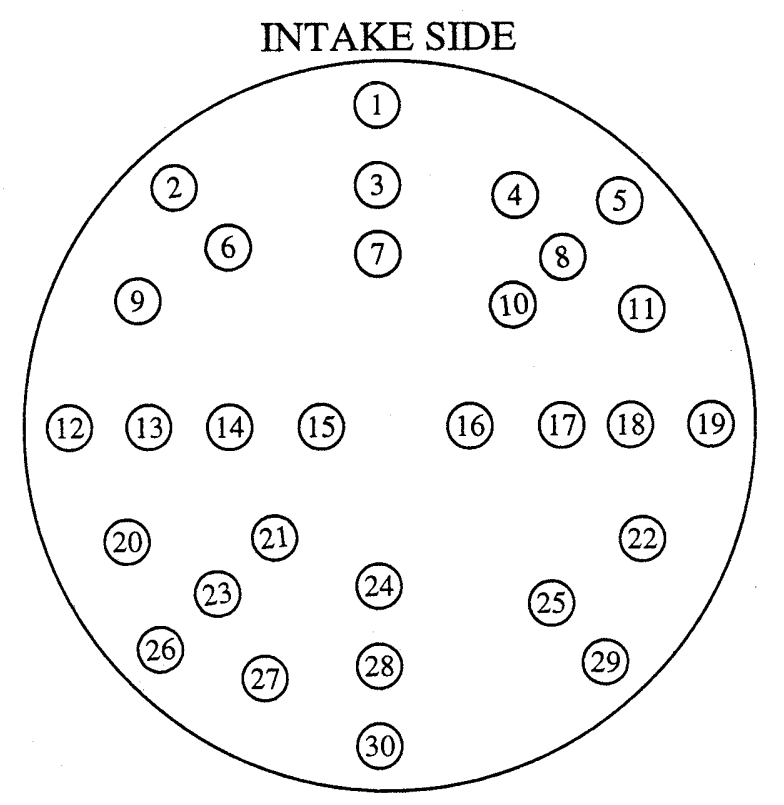

Figure 3.2 Deposit thickness measurement locations on top of the piston.

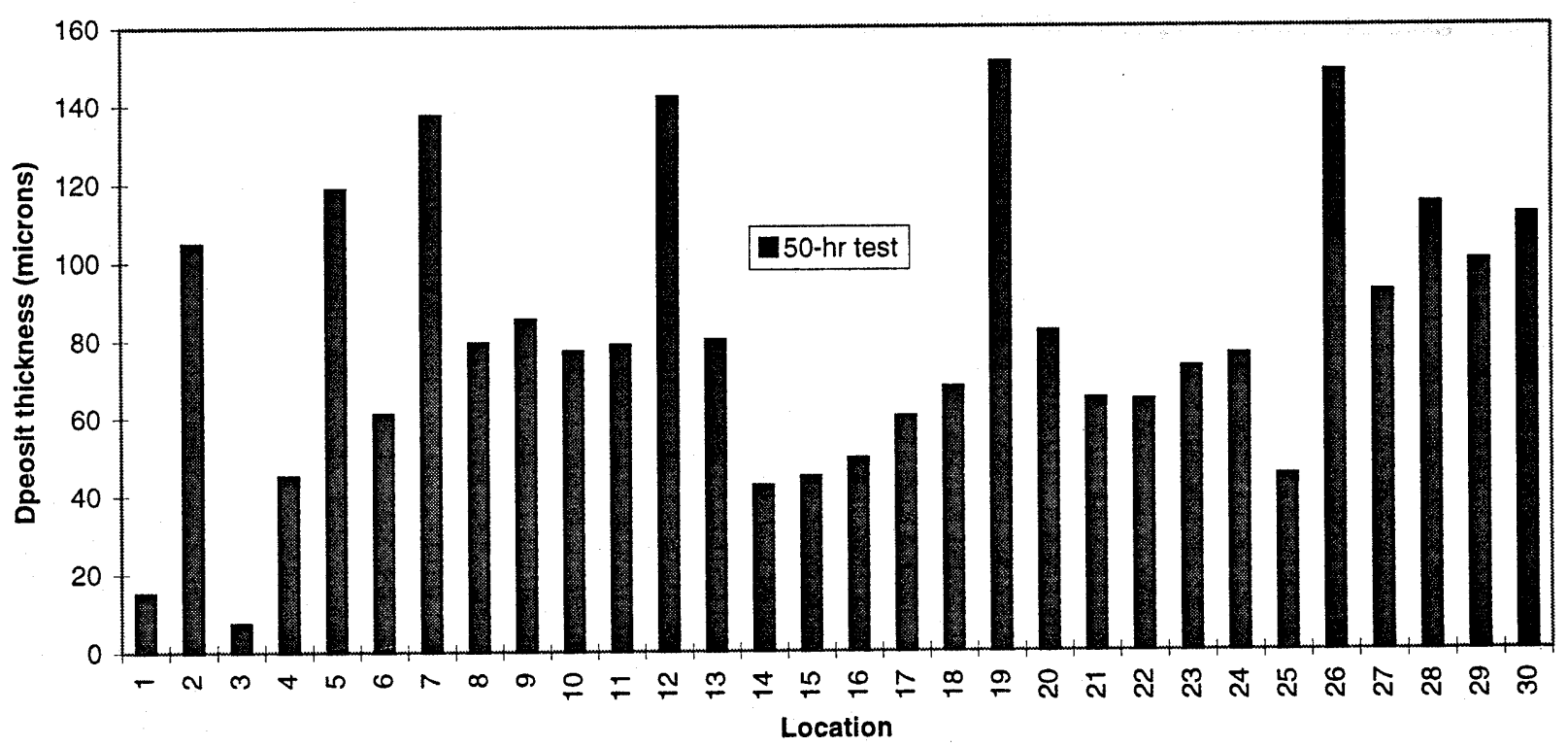

Figure 3.3 Deposit thickness measurements at specified locations on piston top from 50-hour deposit accumulation test. 


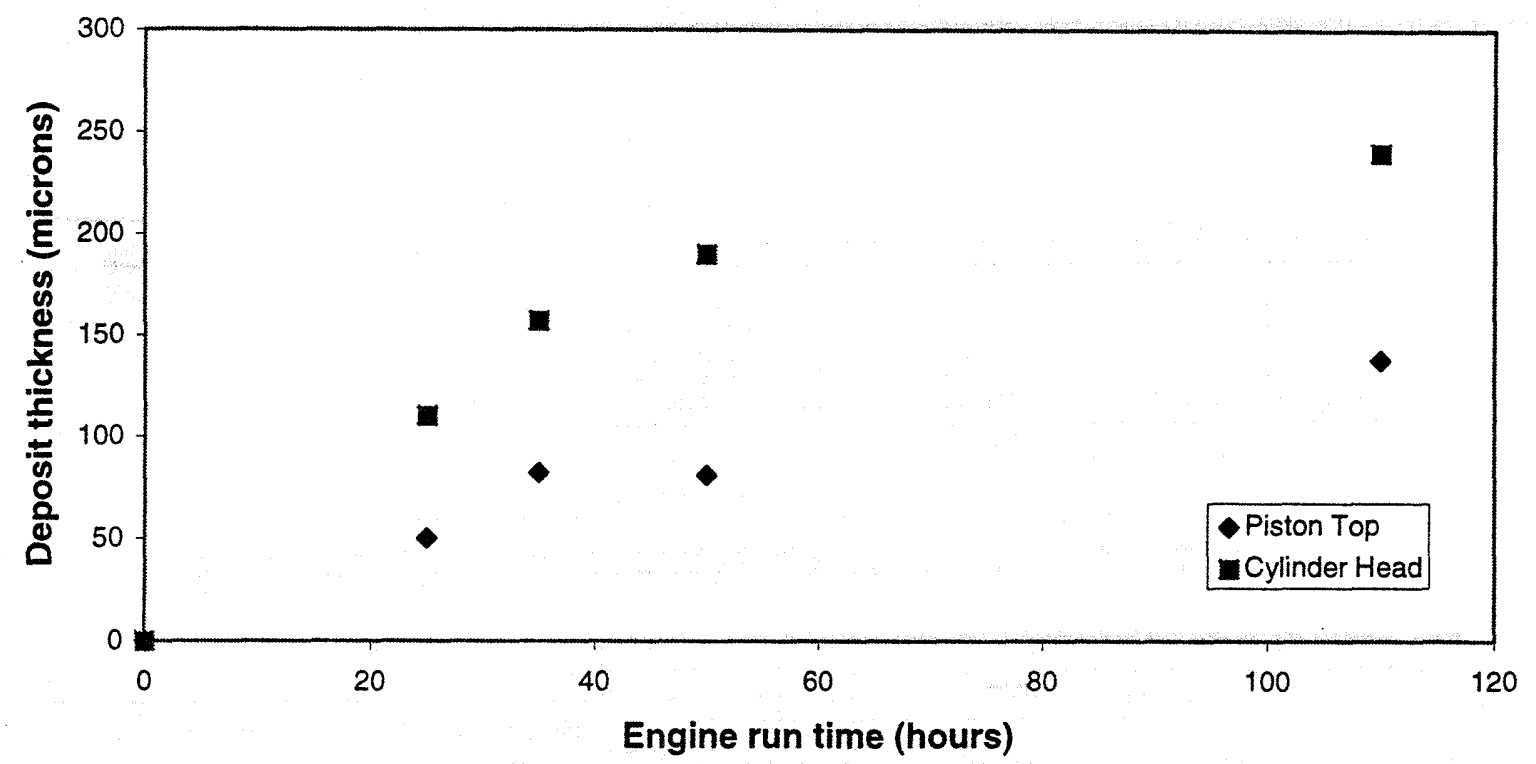

Figure 3.4 Average deposit thickness over four cylinder heads and piston tops measured at the end of each of the four deposit accumulation tests after engine disassembly.

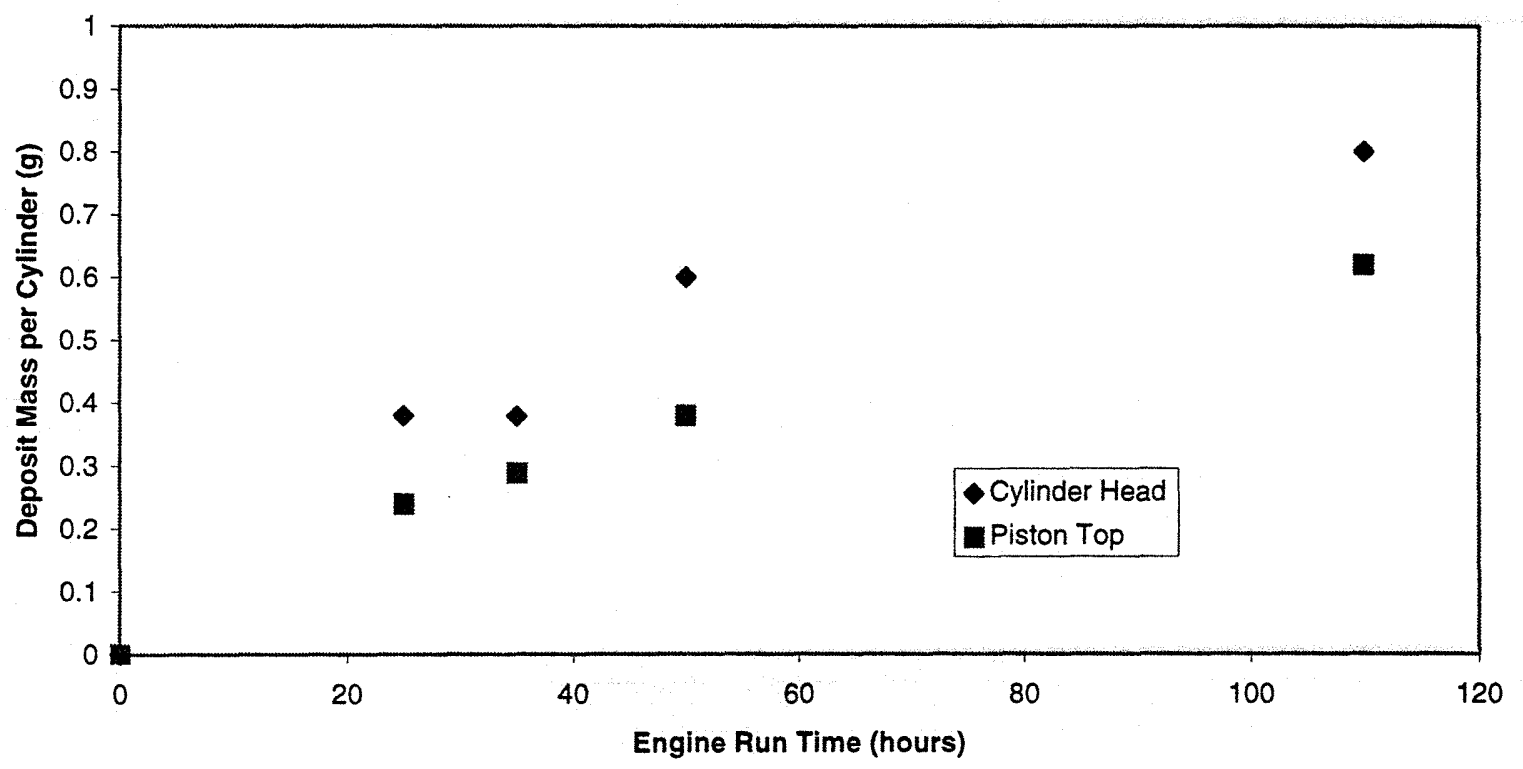

Figure 3.5 Average deposit mass over four cylinder heads and piston tops measured at the end of each of the four deposit accumulation tests after engine disassembly. 


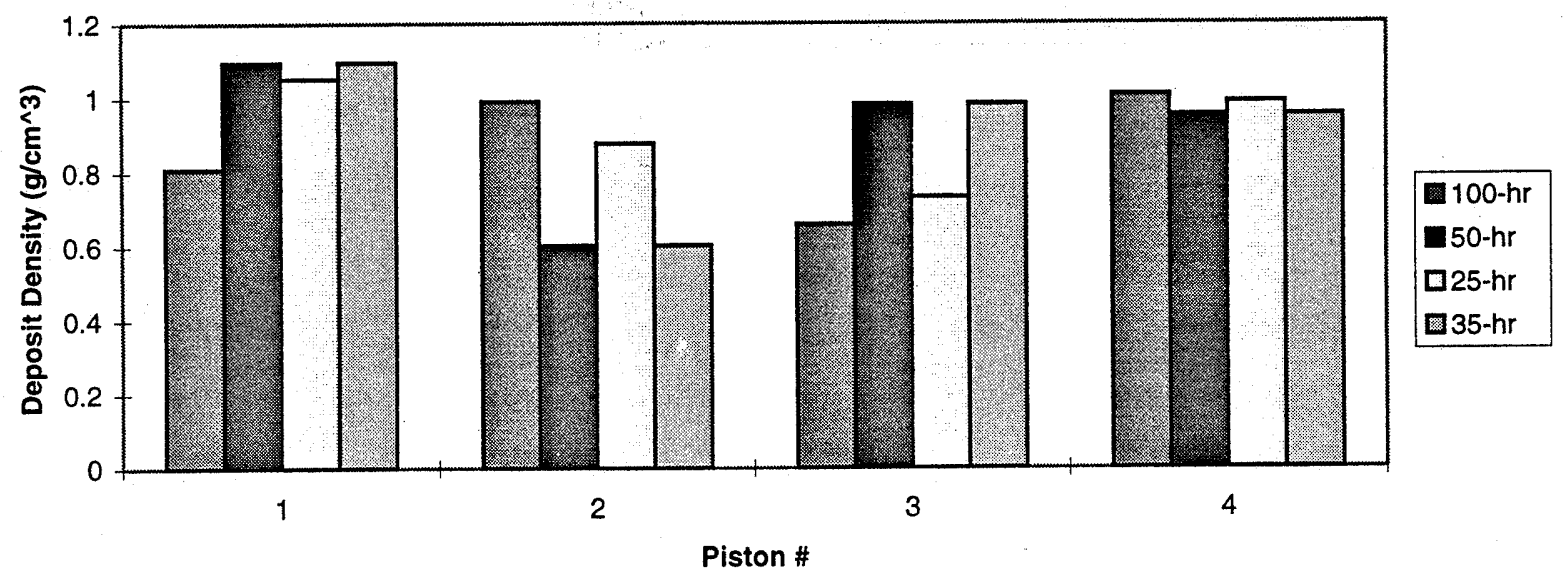

Figure 3.6 Calculated deposit density on all four pistons from all four deposit accumulation tests.

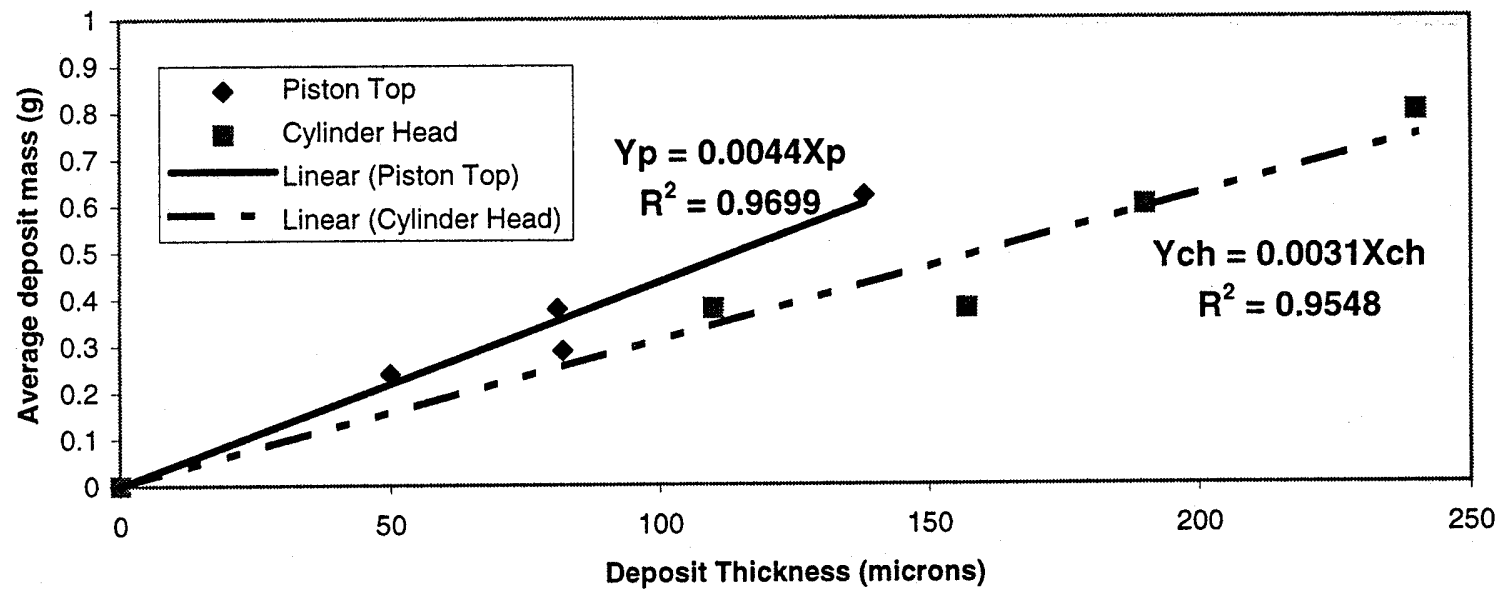

Figure 3.7 Average deposit mass on cylinder head and piston top vs. average deposit thickness on the cylinder head and piston top. Data taken at the end of the four deposit build-up tests. 


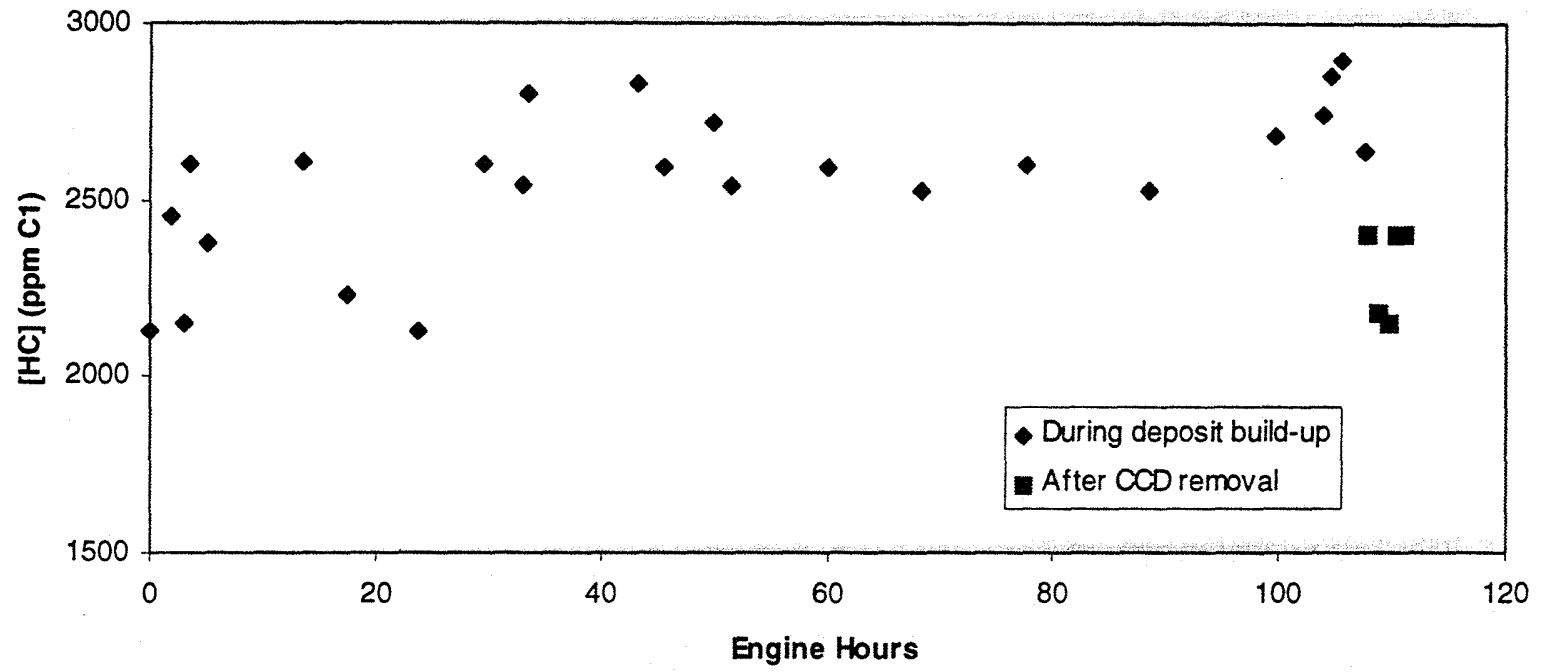

Figure 3.8 HC emissions from the deposit build-up fuel vs. engine hours at $1500 \mathrm{rpm}, \mathrm{bmep}=$ $262 \mathrm{kPa}$. Data from 110-hour deposit build-up test

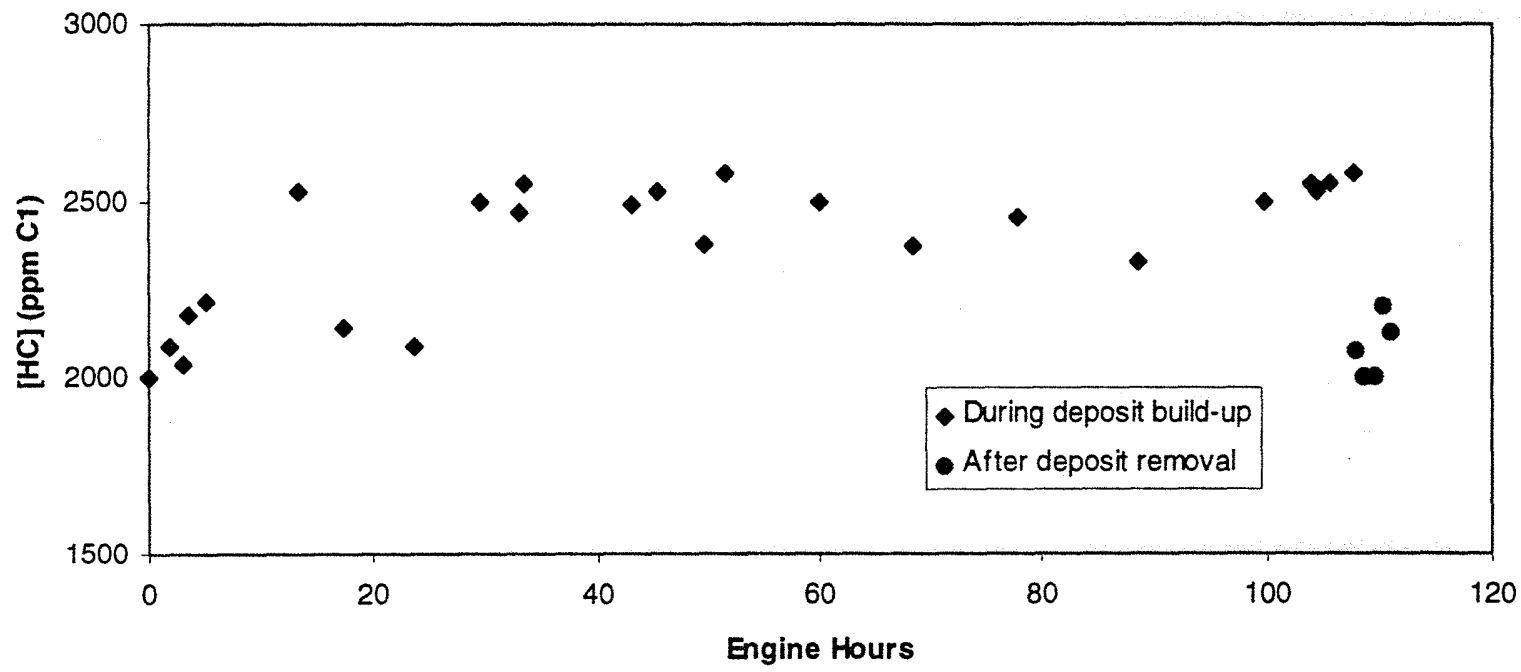

Figure $3.9 \mathrm{HC}$ emissions from the deposit build-up fuel vs. engine hours at $1600 \mathrm{rpm}$, bmep= $411 \mathrm{kPa}$. Data from 110-hour deposit build-up test 


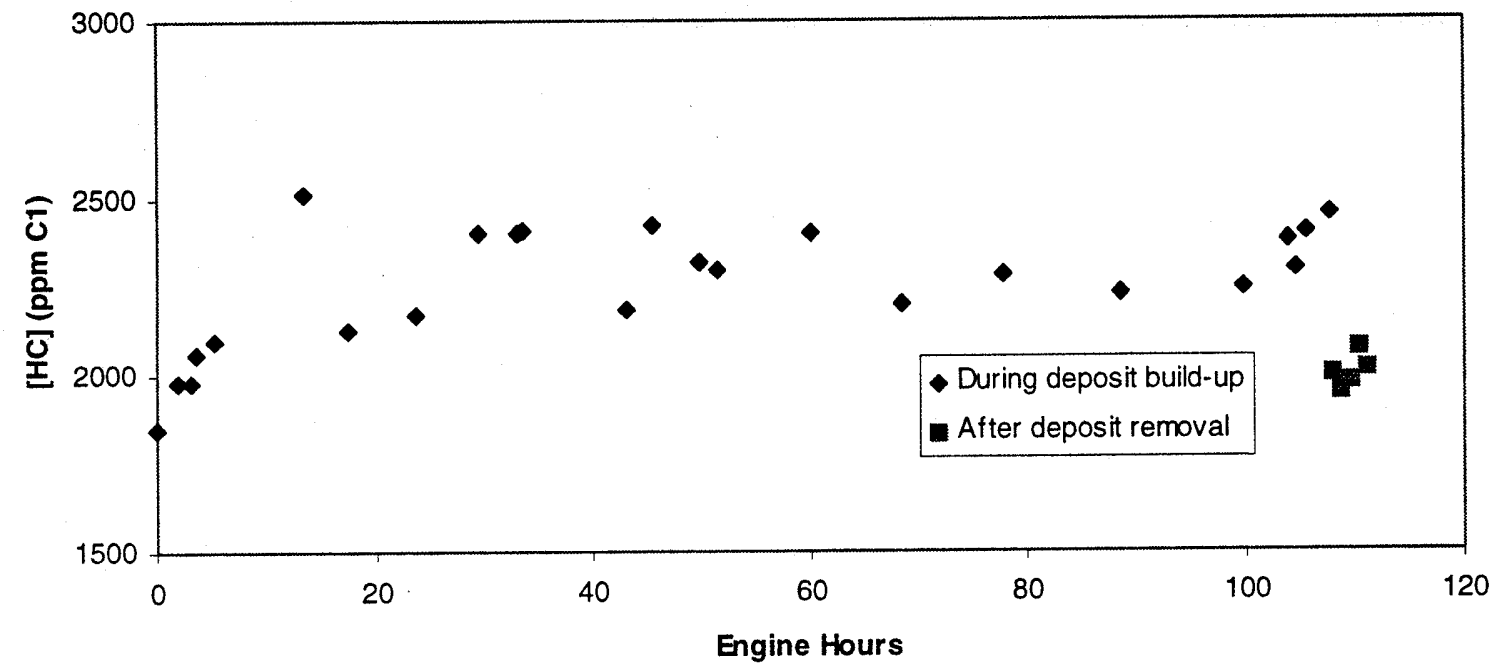

Figure $3.10 \mathrm{HC}$ emissions from the deposit build-up fuel vs. engine hours at $1800 \mathrm{rpm}, \mathrm{bmep}=$ $511 \mathrm{kPa}$. Data from 110-hour deposit build-up test

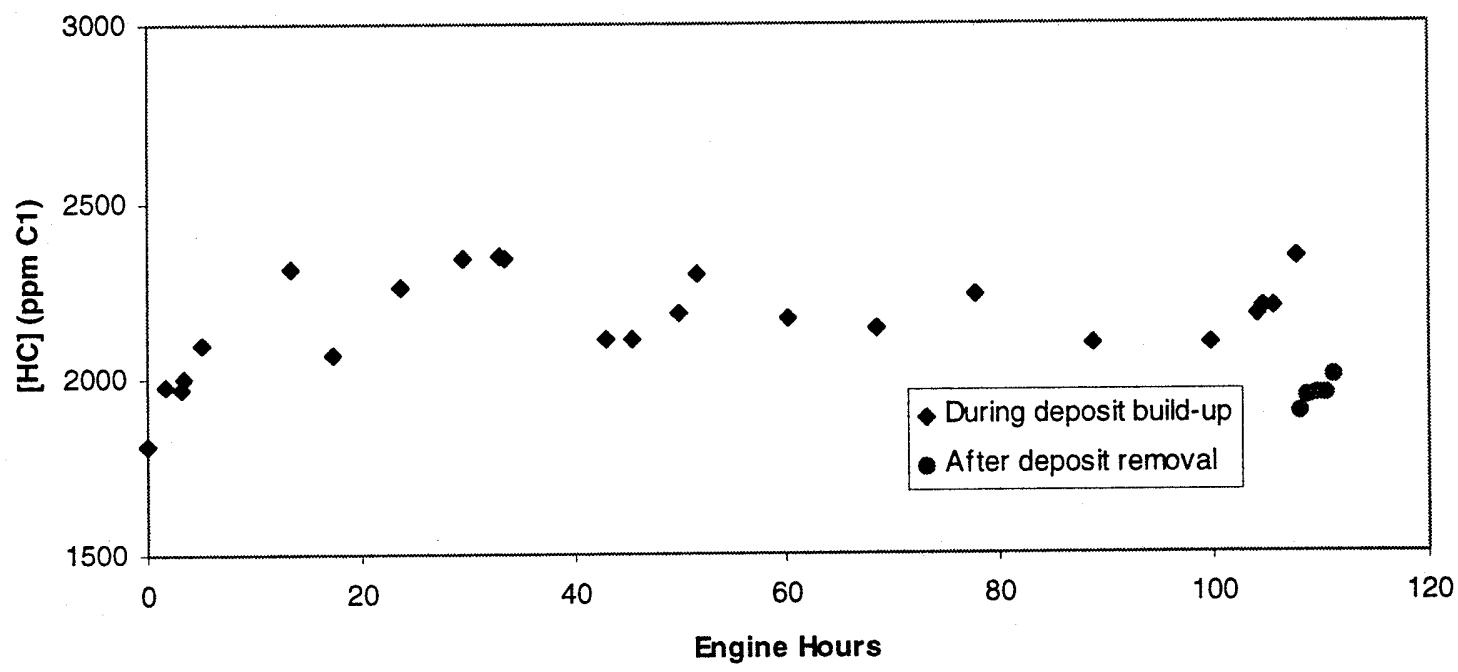

Figure $3.11 \mathrm{HC}$ emissions from the deposit build-up fuel vs. engine hours at $2000 \mathrm{rpm}$, bmep= $625 \mathrm{kPa}$. Data from 110-hour deposit build-up test 


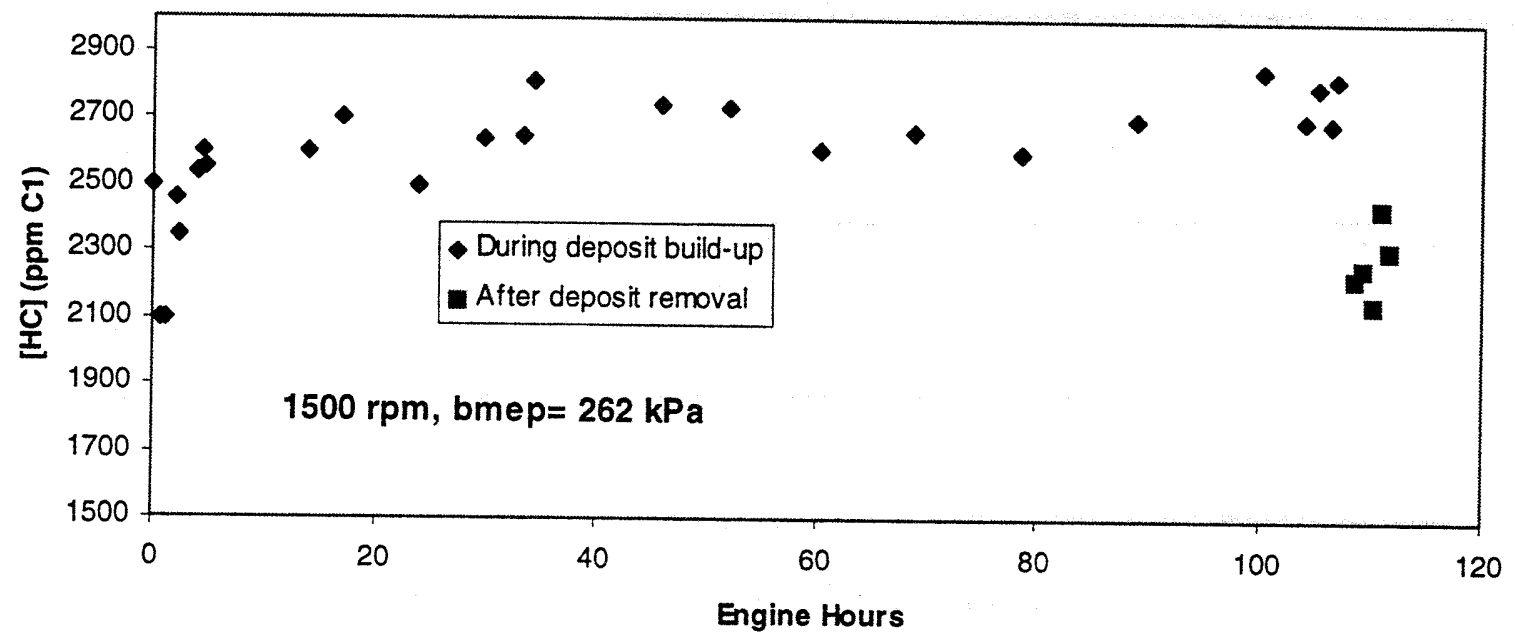

Figure $3.12 \mathrm{HC}$ emissions from indolene vs. engine hours at $1500 \mathrm{rpm}, \mathrm{bmep}=262 \mathrm{kPa}$. Data from 110-hour deposit build-up test

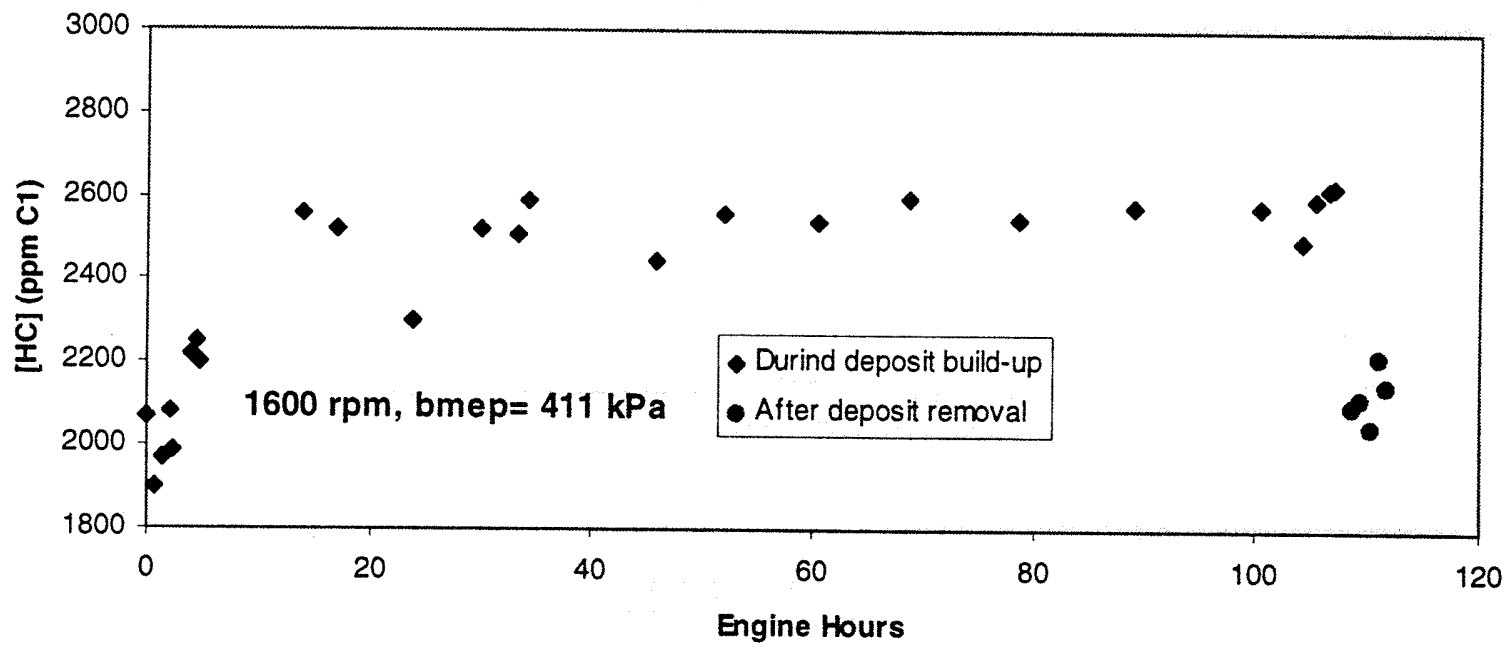

Figure $3.13 \mathrm{HC}$ emissions from indolene vs. engine hours at $1600 \mathrm{rpm}, \mathrm{bmep}=411 \mathrm{kPa}$. Data from 110-hour deposit build-up test. 


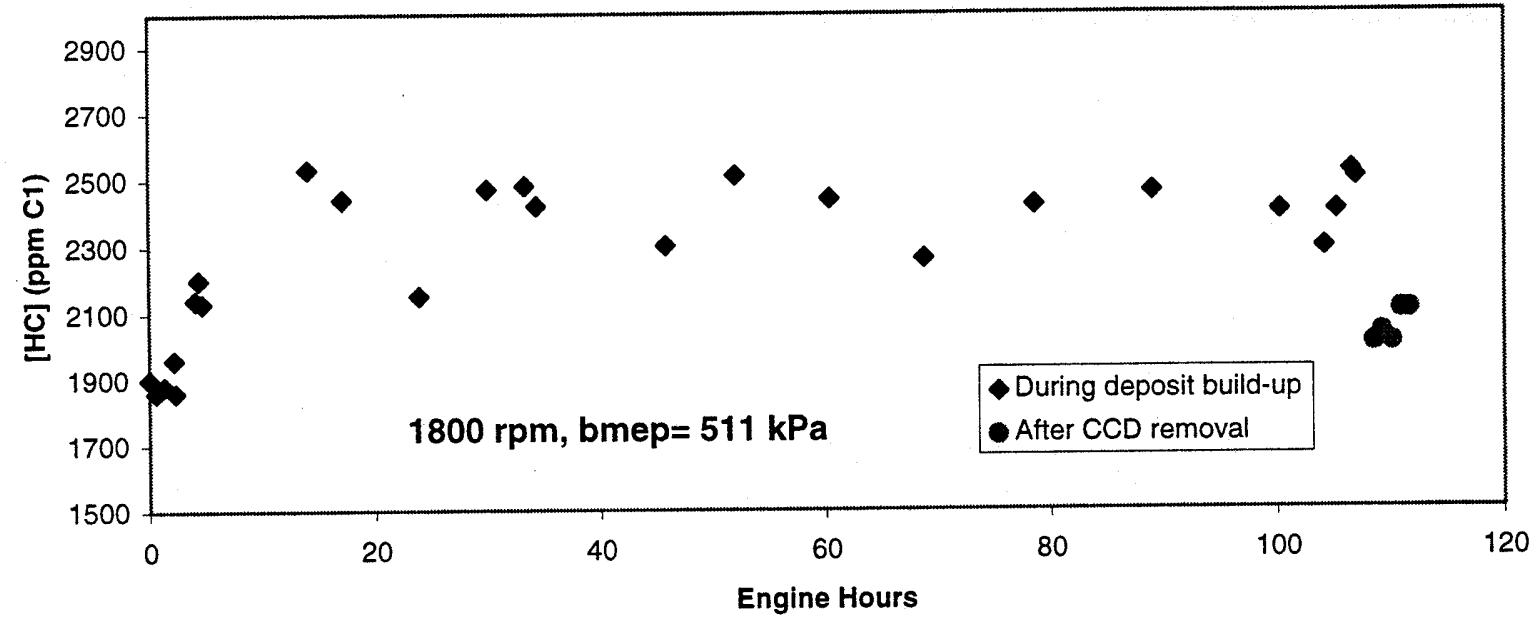

Figure $3.14 \mathrm{HC}$ emissions from indolene vs. engine hours at $1800 \mathrm{rpm}, \mathrm{bmep}=511 \mathrm{kPa}$. Data from 110-hour deposit build-up test.

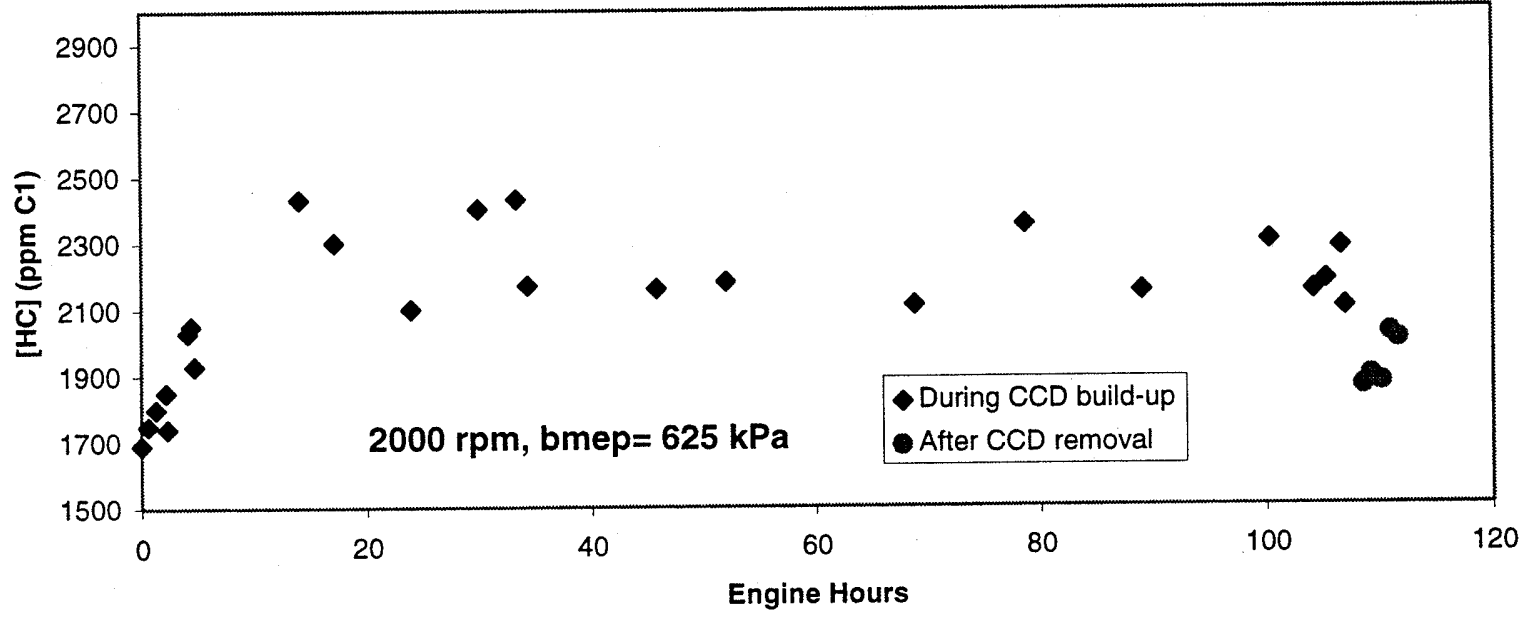

Figure $3.15 \mathrm{HC}$ emissions from indolene vs. engine hours at $2000 \mathrm{rpm}$, bmep= $625 \mathrm{kPa}$. Data from 110-hour deposit build-up test. 


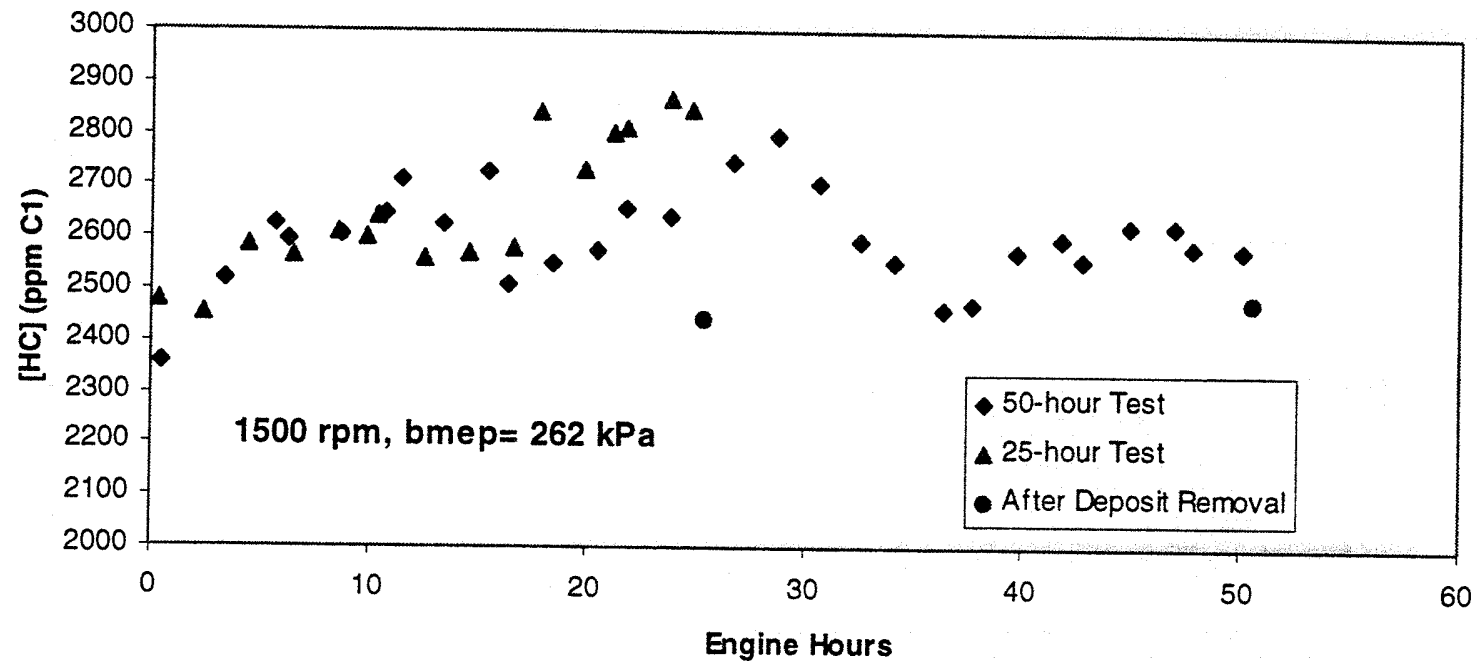

Figure 3.16 HC emissions vs. engine hours with deposit build up fuel at $1500 \mathrm{rpm}, \mathrm{bmep}=262$ $\mathrm{kPa}$. Data from 50 and 25-hour tests.

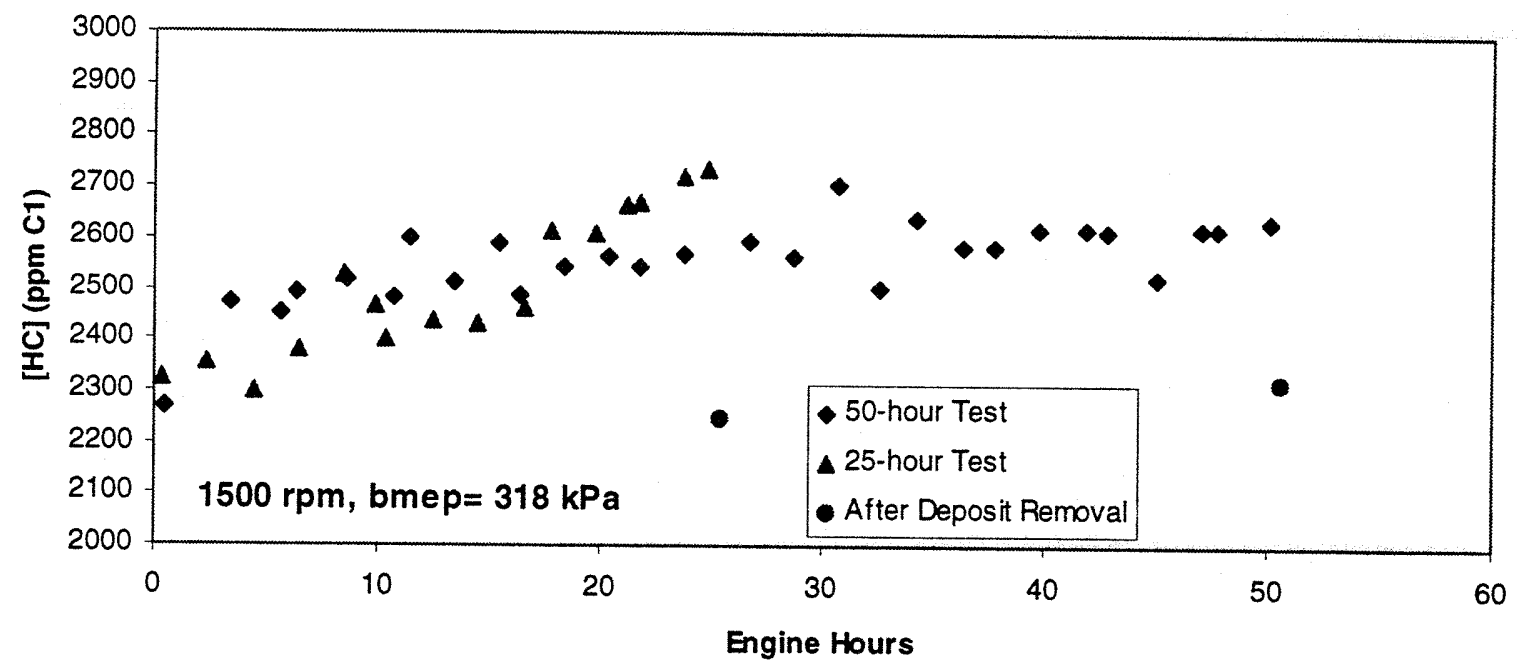

Figure $3.17 \mathrm{HC}$ emissions vs. engine hours with deposit build up fuel at $1500 \mathrm{rpm}, \mathrm{bmep}=318$ $\mathrm{kPa}$. Data from 50 and 25-hour tests. 


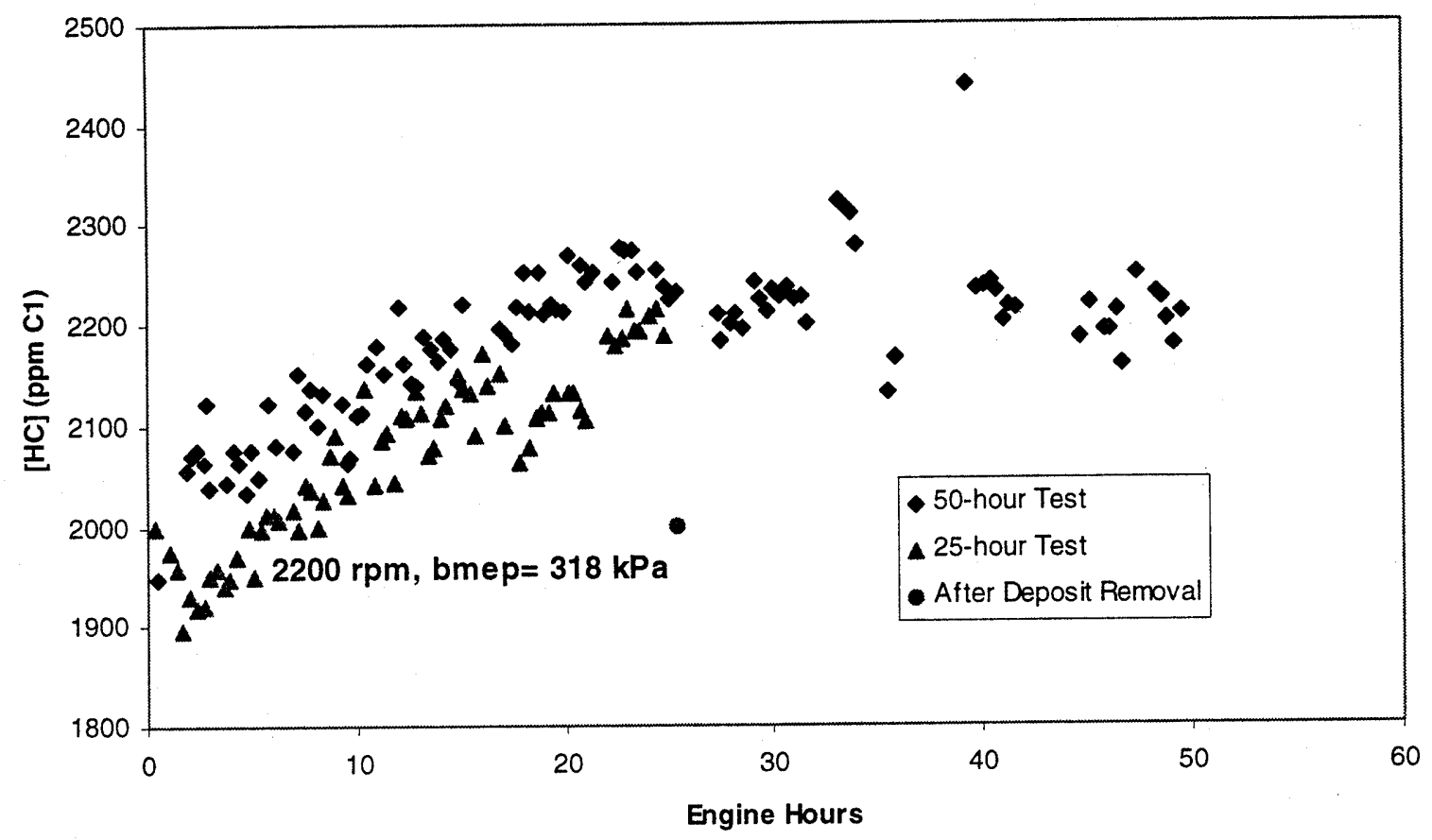

Figure $3.18 \mathrm{HC}$ emissions vs. engine hours with deposit build up fuel at $2200 \mathrm{rpm}$, bmep= 318 $\mathrm{kPa}$. Data from 50 and 25-hour tests. 


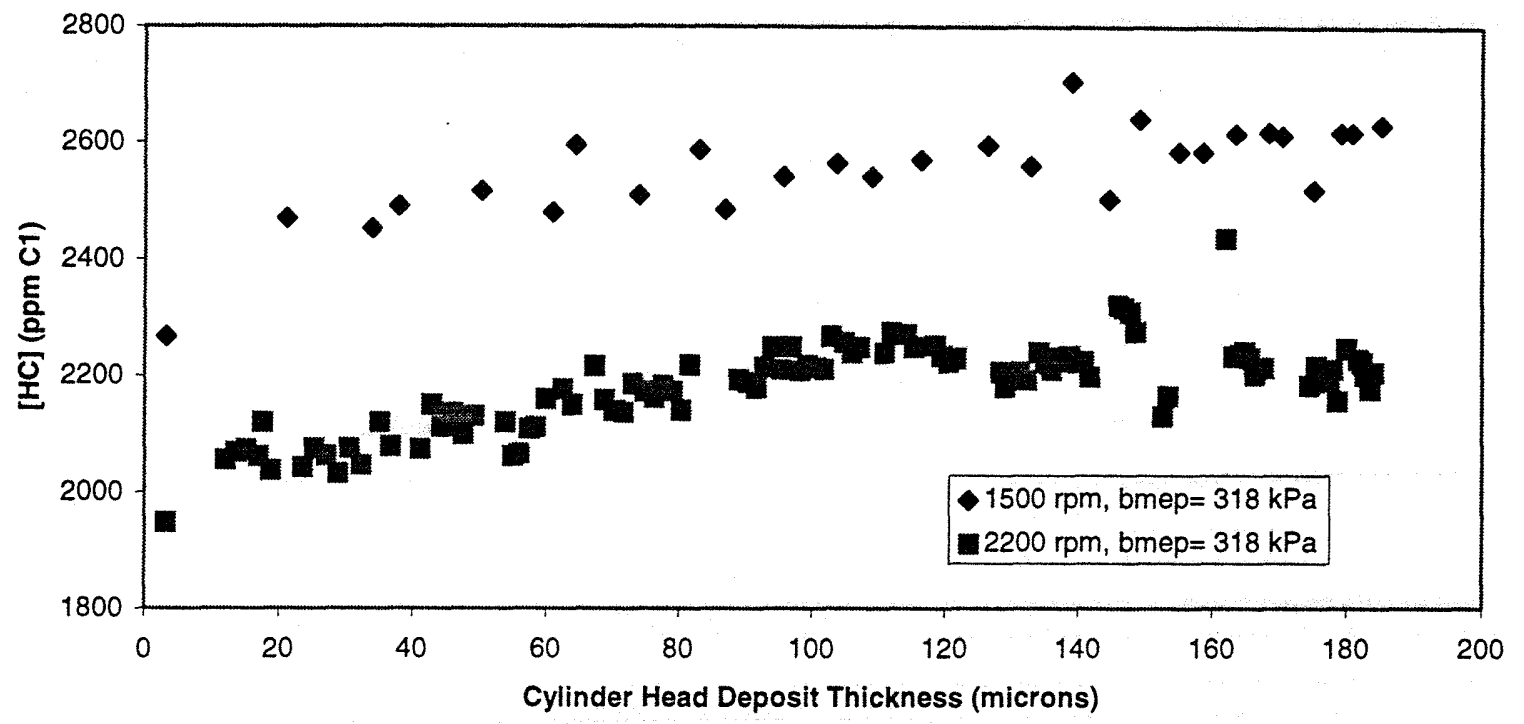

Figure 3.19 Effect of cylinder head deposits on $\mathrm{HC}$ emissions at $1500 \mathrm{rpm}$, bmep= $318 \mathrm{kPa}$ and $2200 \mathrm{rpm}, \mathrm{bmep}=318 \mathrm{kPa}$. Data from 50-hour deposit accumulation test

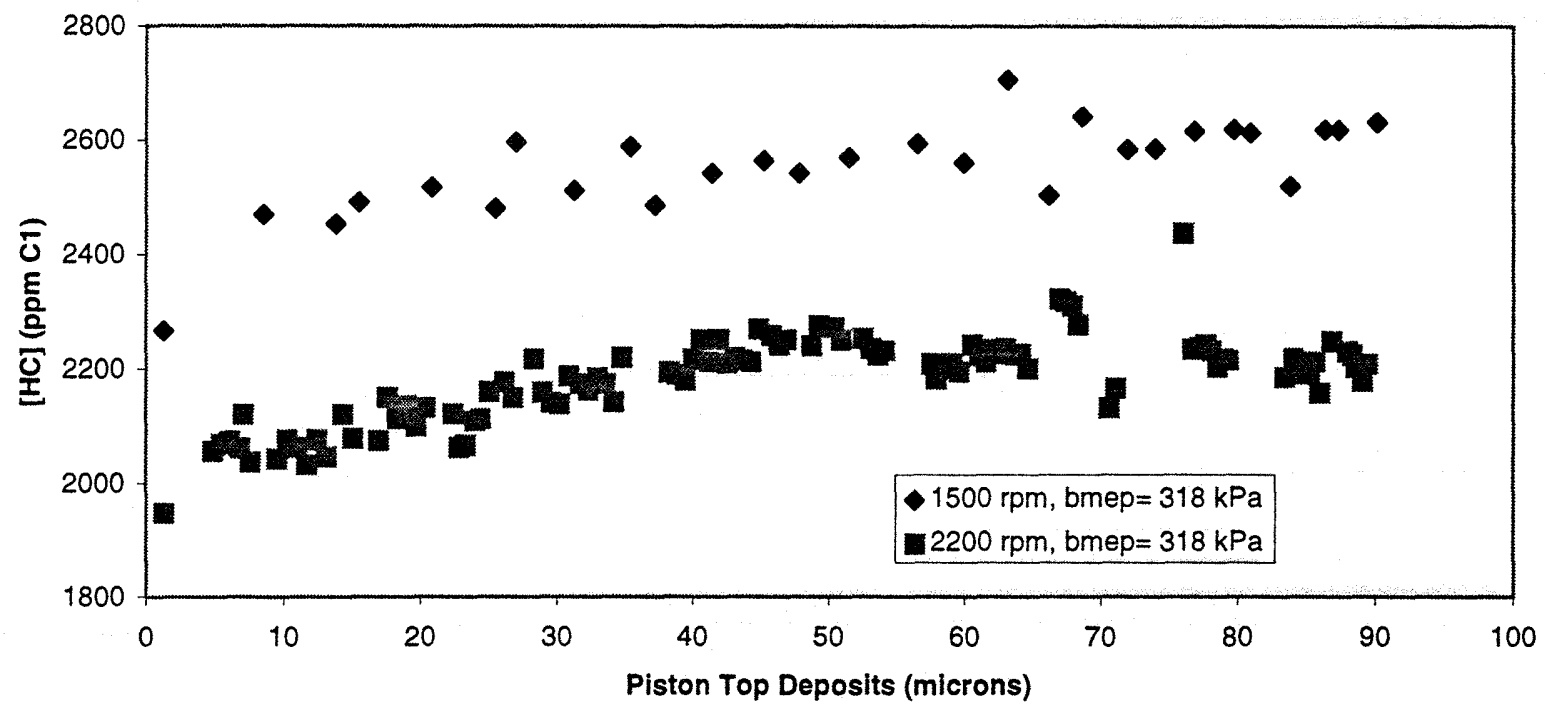

Figure 3.20 Effect of piston top deposits on $\mathrm{HC}$ emissions at $1500 \mathrm{rpm}$, bmep= $318 \mathrm{kPa}$ and 2200 $\mathrm{rpm}, \mathrm{bmep}=318 \mathrm{kPa}$. Data from 50-hour deposit accumulation test 


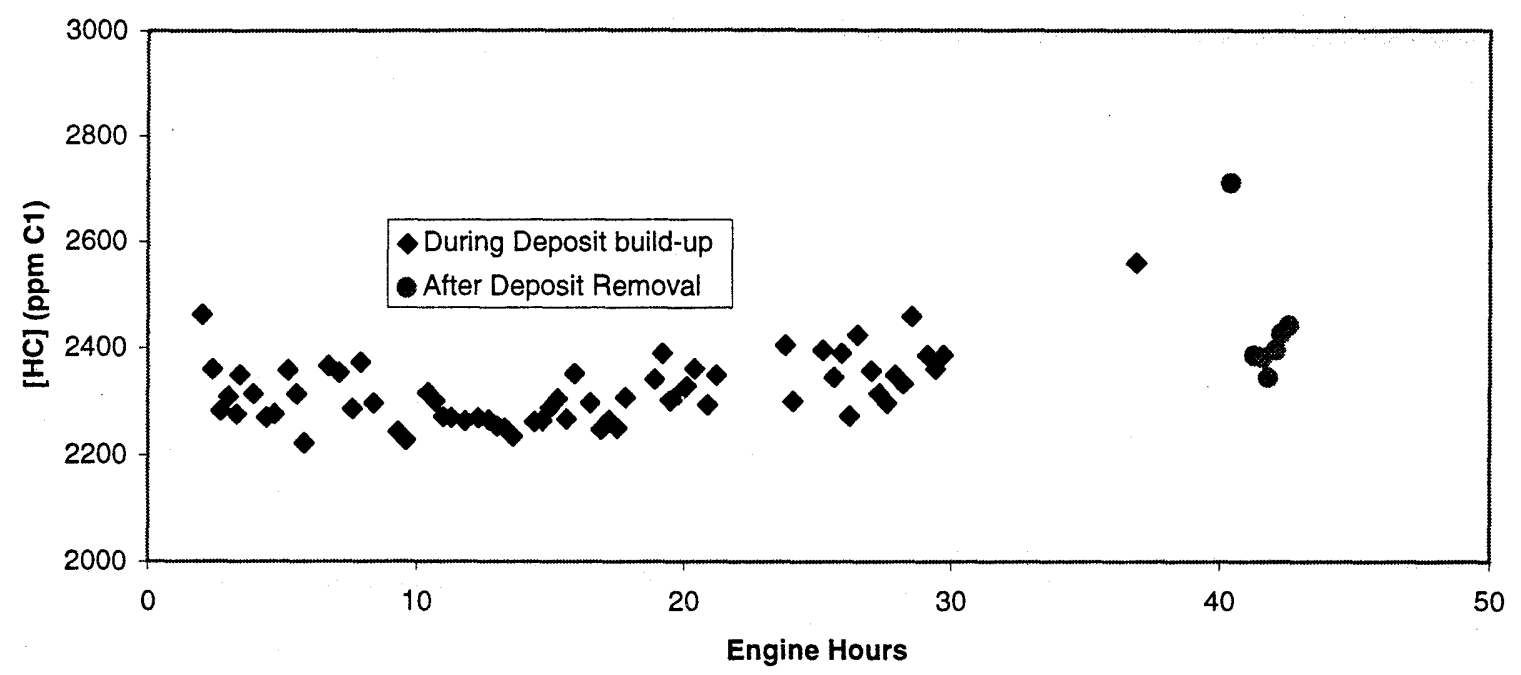

Figure $3.21 \mathrm{HC}$ emissions vs. engine hours with deposit build up fuel at $1400 \mathrm{rpm}, \mathrm{bmep}=106$ $\mathrm{kPa}$. Data from 35 -hour test.

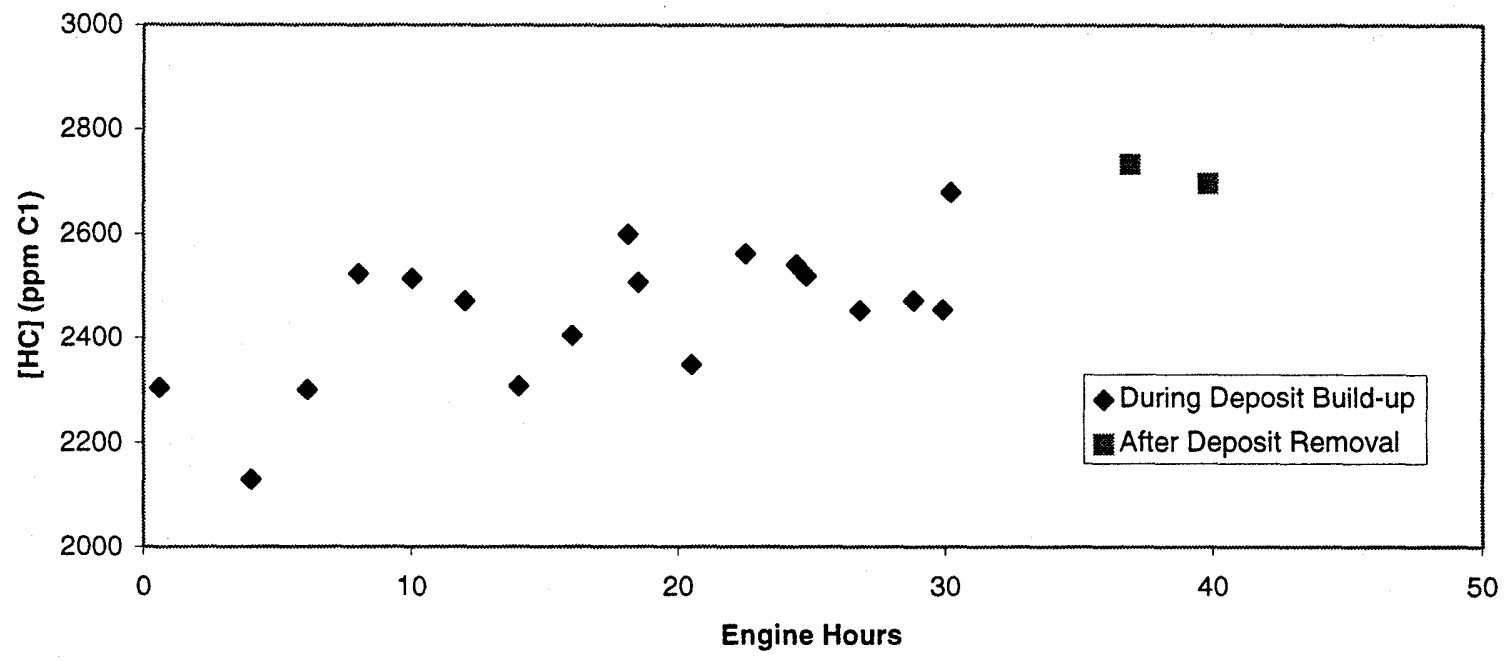

Figure $3.22 \mathrm{HC}$ emissions vs. engine hours with deposit build up fuel at $1500 \mathrm{rpm}, \mathrm{bmep}=262$ $\mathrm{kPa}$. Data from 35-hour test. 


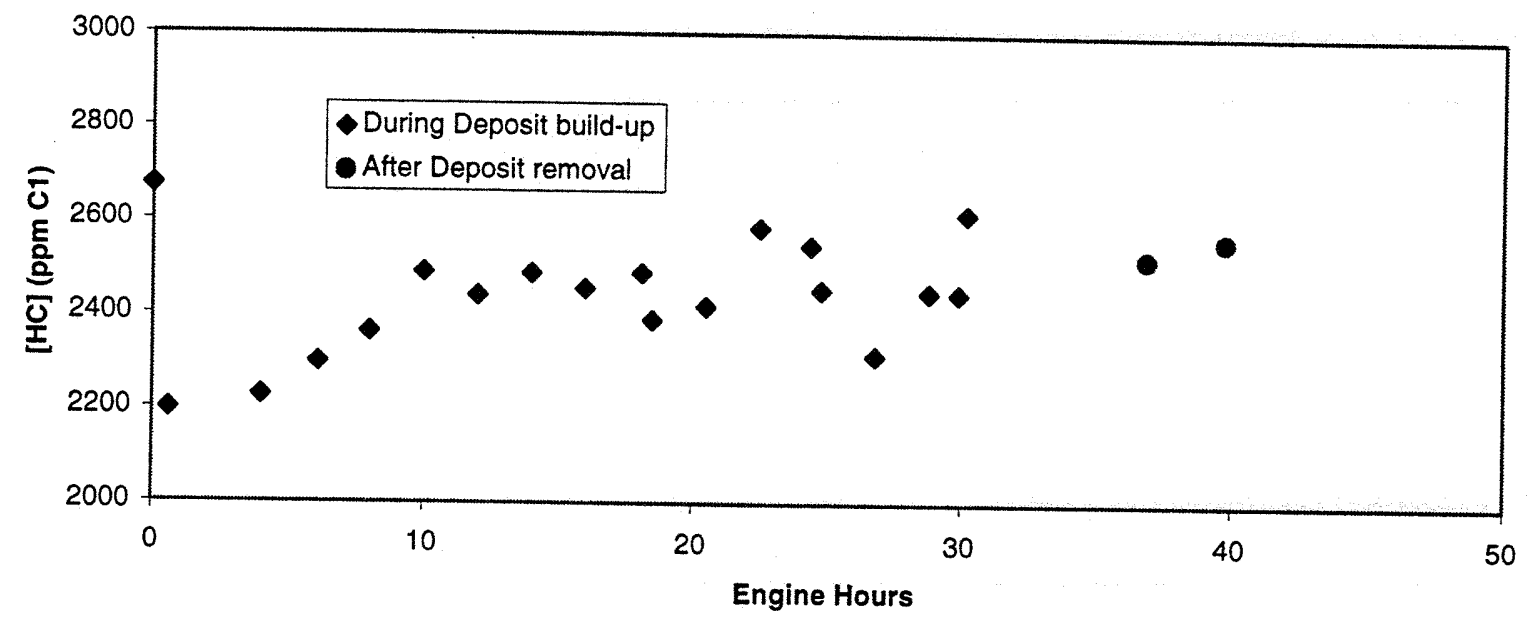

Figure $3.23 \mathrm{HC}$ emissions vs. engine hours with deposit build up fuel at $1500 \mathrm{rpm}$, bmep $=318$ $\mathrm{kPa}$. Data from 35-hour test.

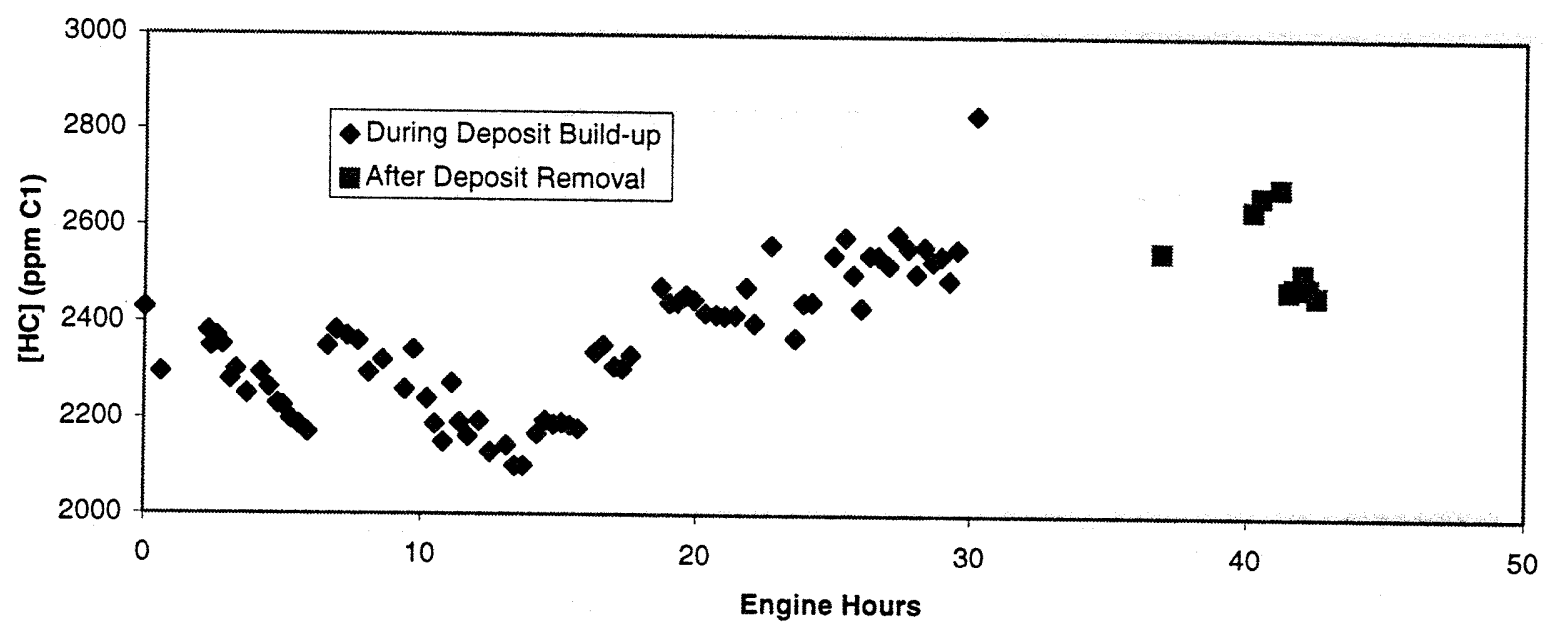

Figure $3.24 \mathrm{HC}$ emissions vs. engine hours with deposit build up fuel at $2200 \mathrm{rpm}, \mathrm{bmep}=318$ $\mathrm{kPa}$. Data from 35-hour test. 


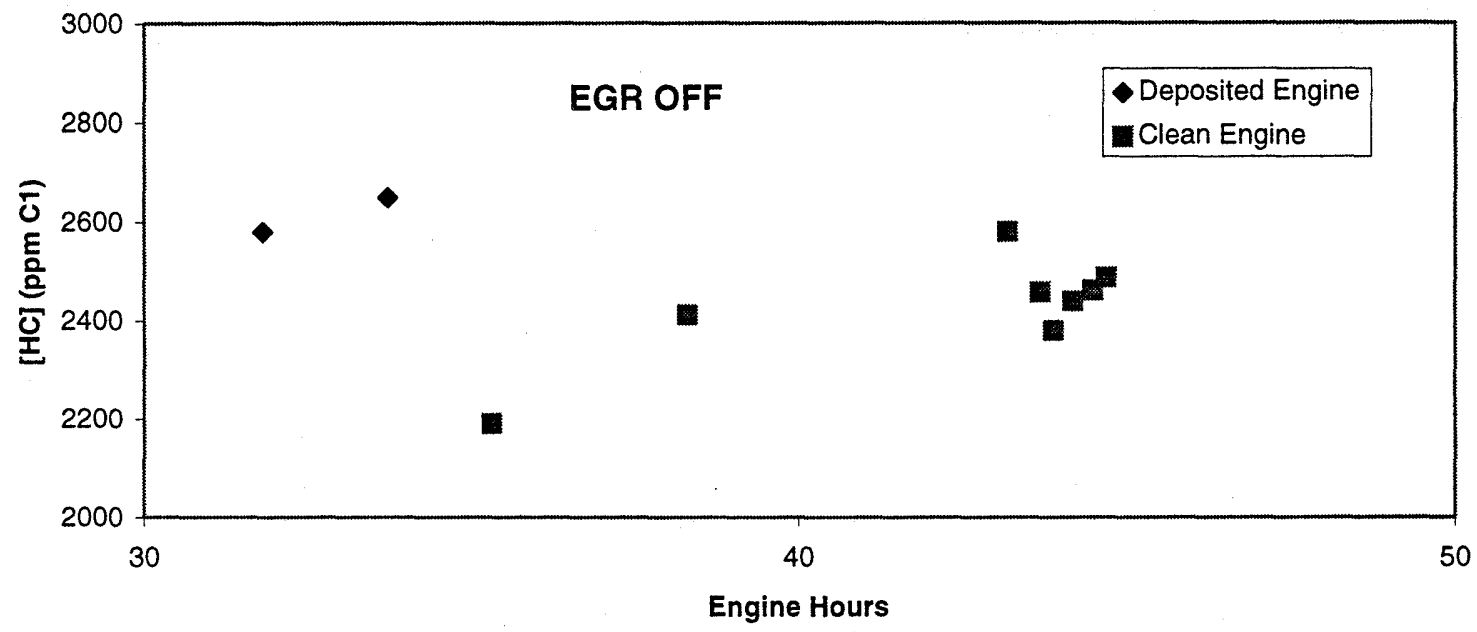

Figure $3.25 \mathrm{HC}$ emissions with EG R off with the deposited engine and after deposit removal at $1400 \mathrm{rpm}$, bmep $=106 \mathrm{kPa}$. Data from 35-hour test

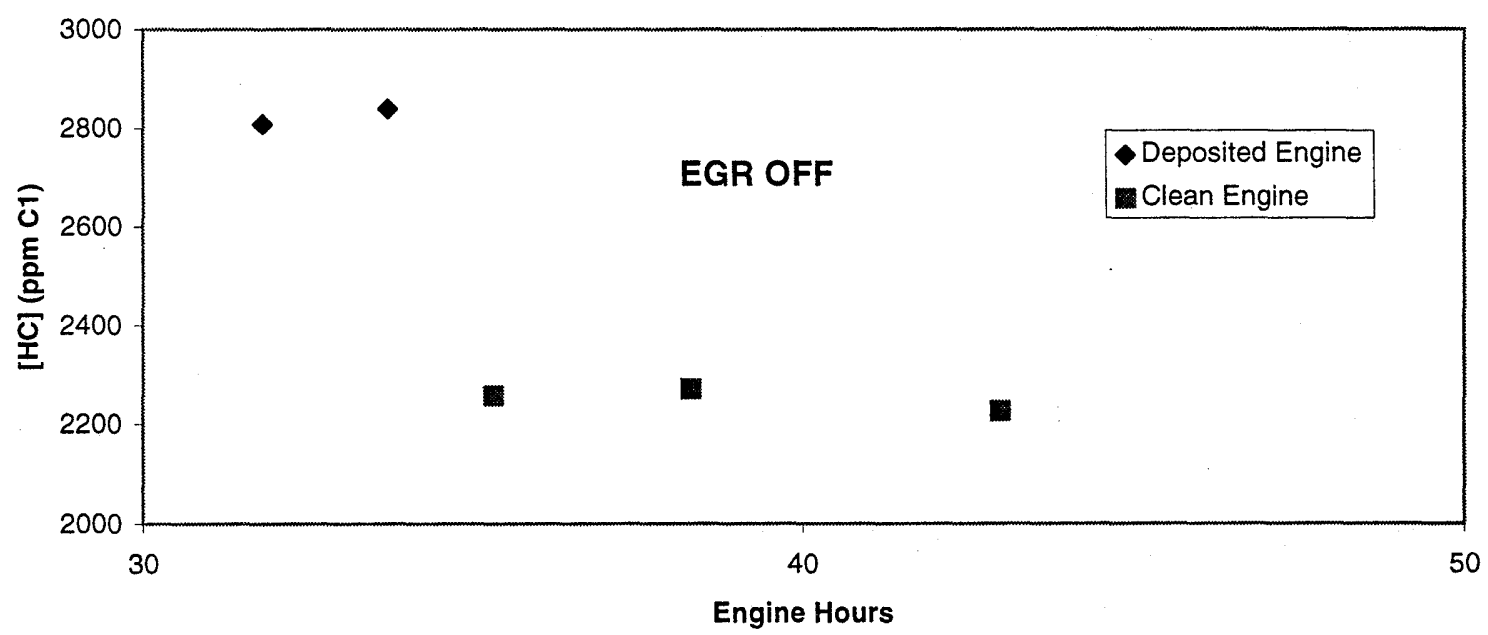

Figure 3.26 HC emissions with EG R off with the deposited engine and after deposit removal at $1500 \mathrm{rpm}, \mathrm{bmep}=262 \mathrm{kPa}$. Data from 35-hour test 


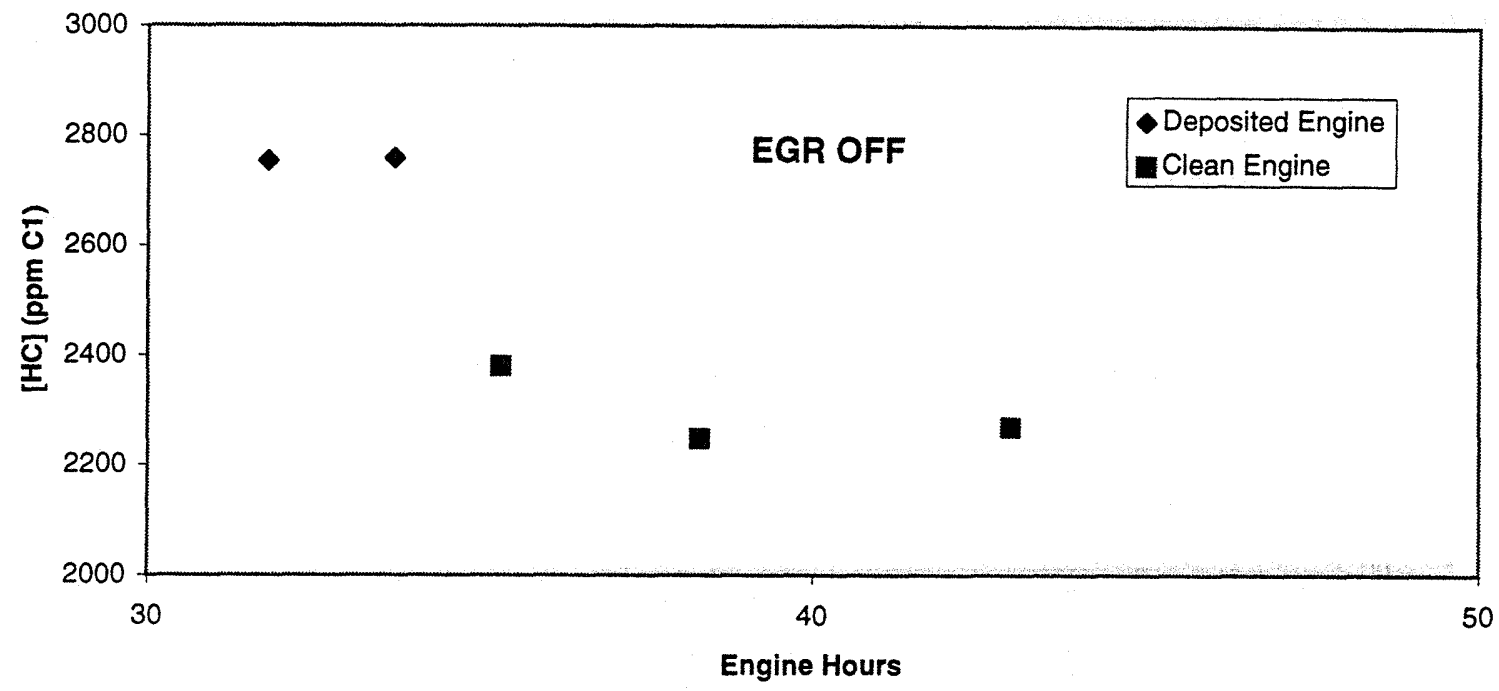

Figure $3.27 \mathrm{HC}$ emissions with EG R off with the deposited engine and after deposit removal at $1500 \mathrm{rpm}, \mathrm{bmep}=318 \mathrm{kPa}$. Data from 35-hour test

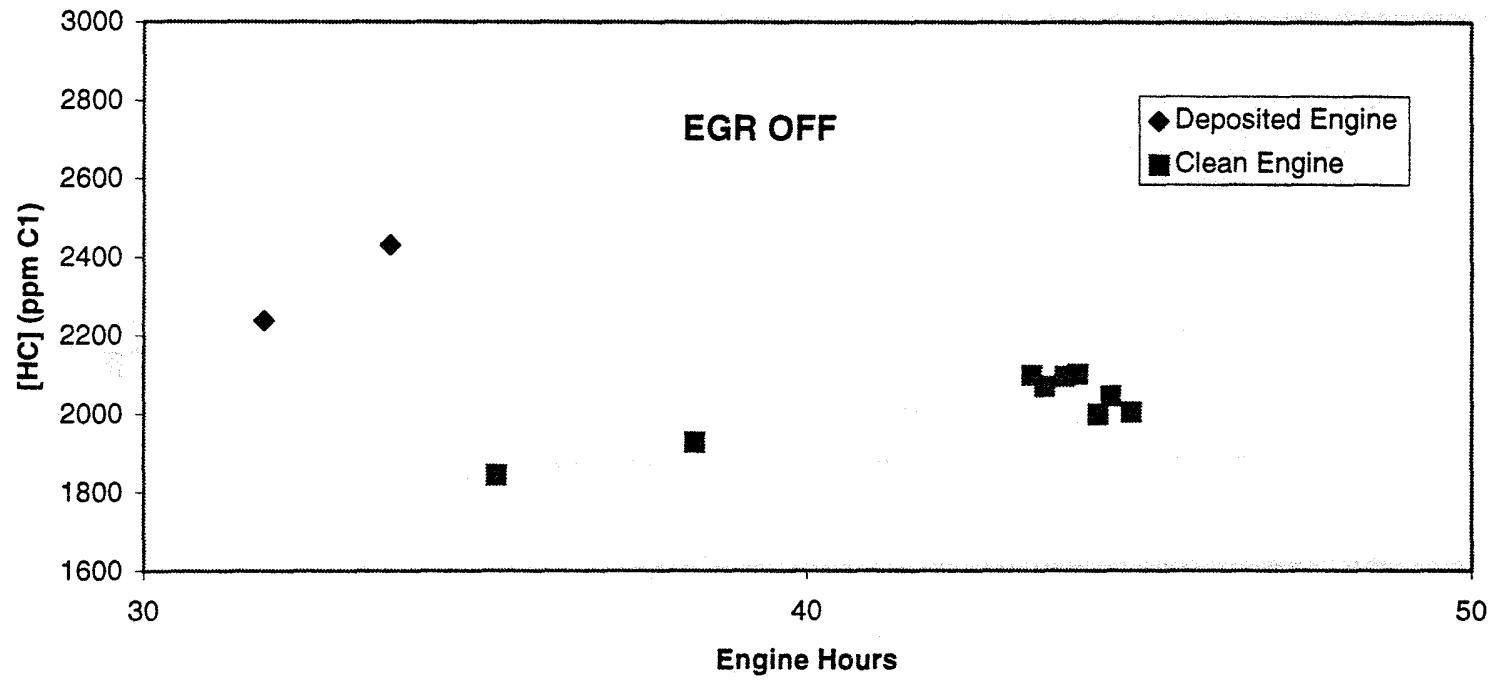

Figure 3.28 HC emissions with EG R off with the deposited engine and after deposit removal at $2200 \mathrm{rpm}$, bmep $=318 \mathrm{kPa}$. Data from 35 -hour test 

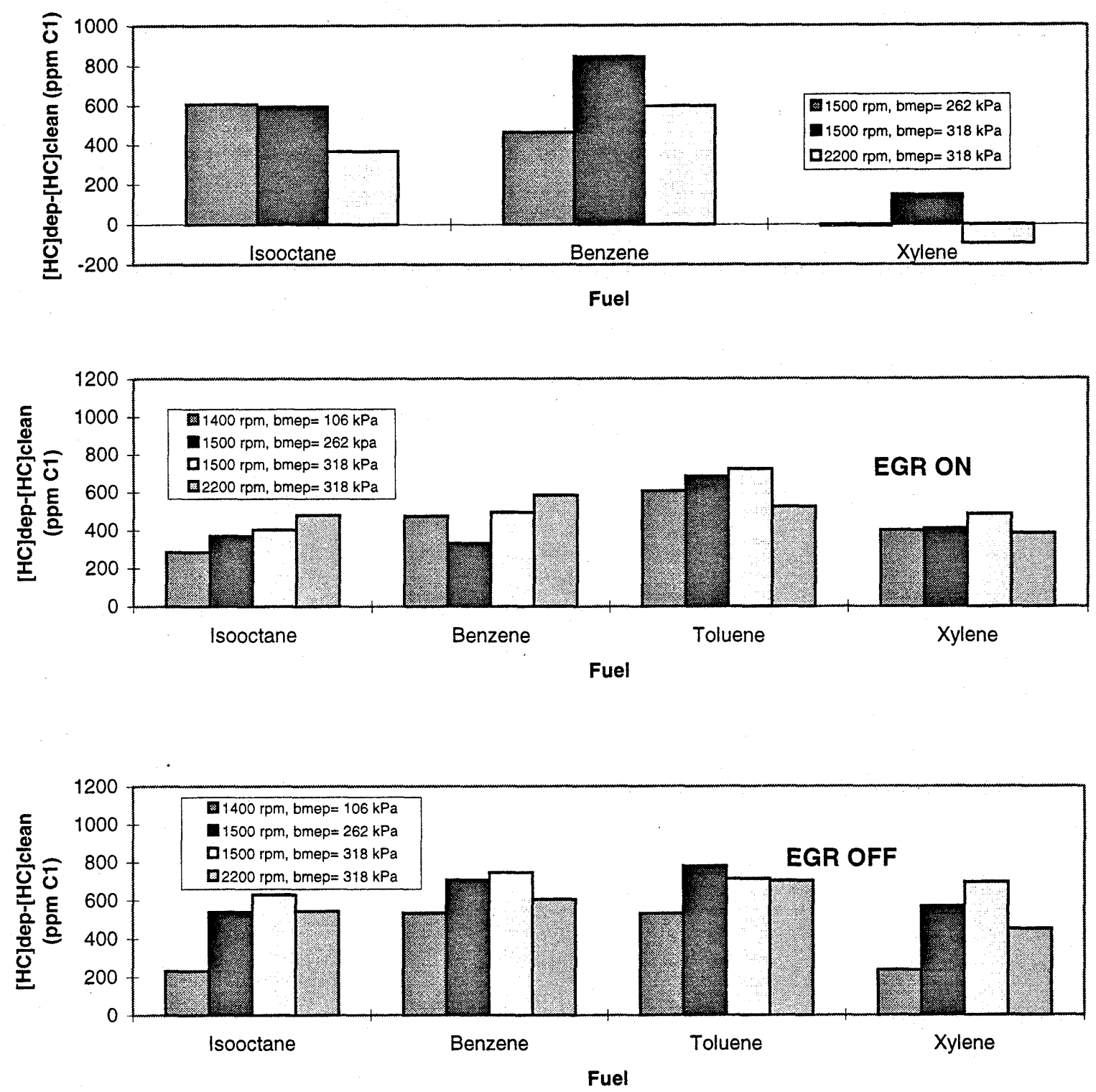

Figure 3.29 Effect of combustion chamber deposit removal on HC emissions from singlecomponent fuels at various operating conditions. Top graph is from 50-hour test with old mechanical EGR valve. Middle and bottom graphs are data from 35-hr test with new electronic EGR system on and off respectively. 


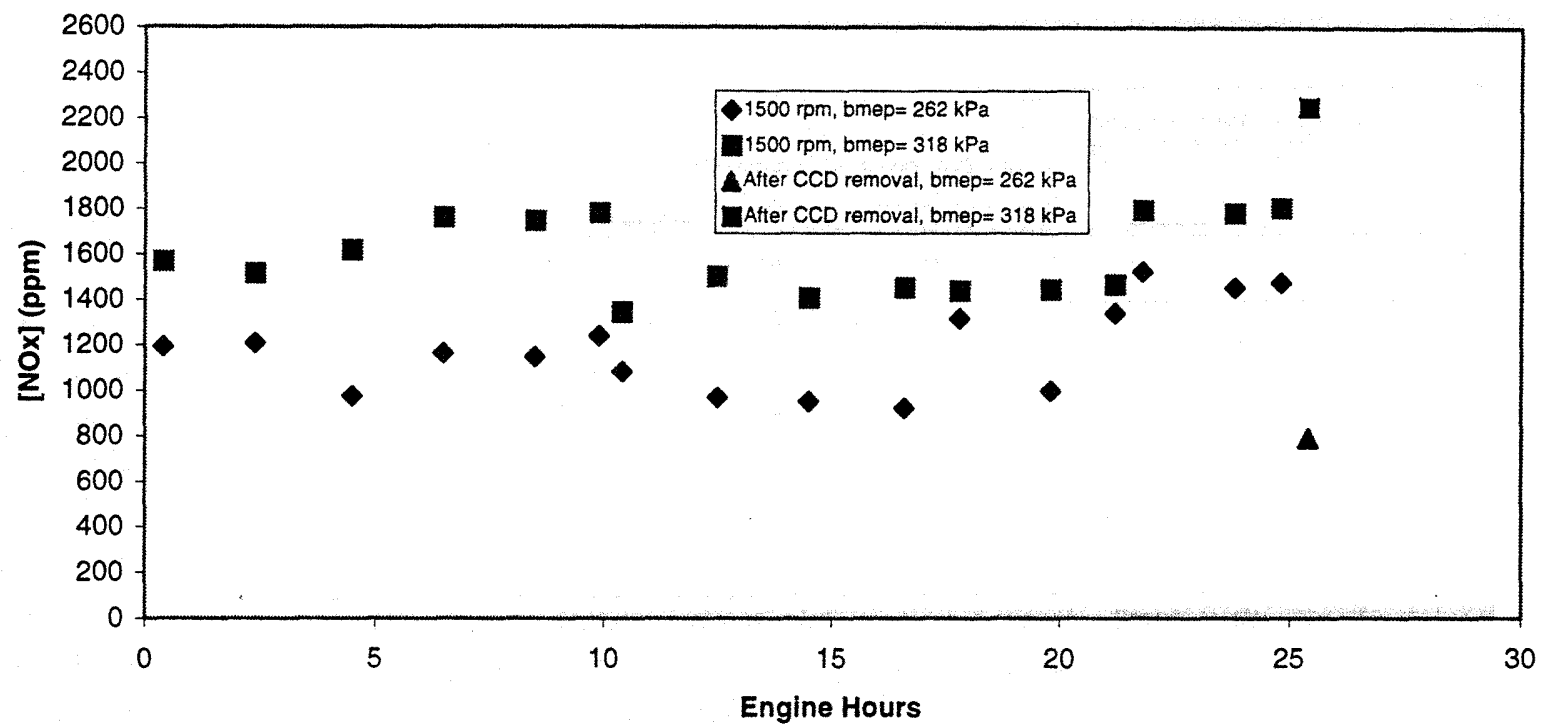

Figure $3.30 \mathrm{NO}_{\mathrm{x}}$ emissions with deposit build-up fuel at $1500 \mathrm{rpm}, \mathrm{bmep}=262 \mathrm{kPa}$ and bmep= $318 \mathrm{kPa}$. Data from 25-hour deposit accumulation test

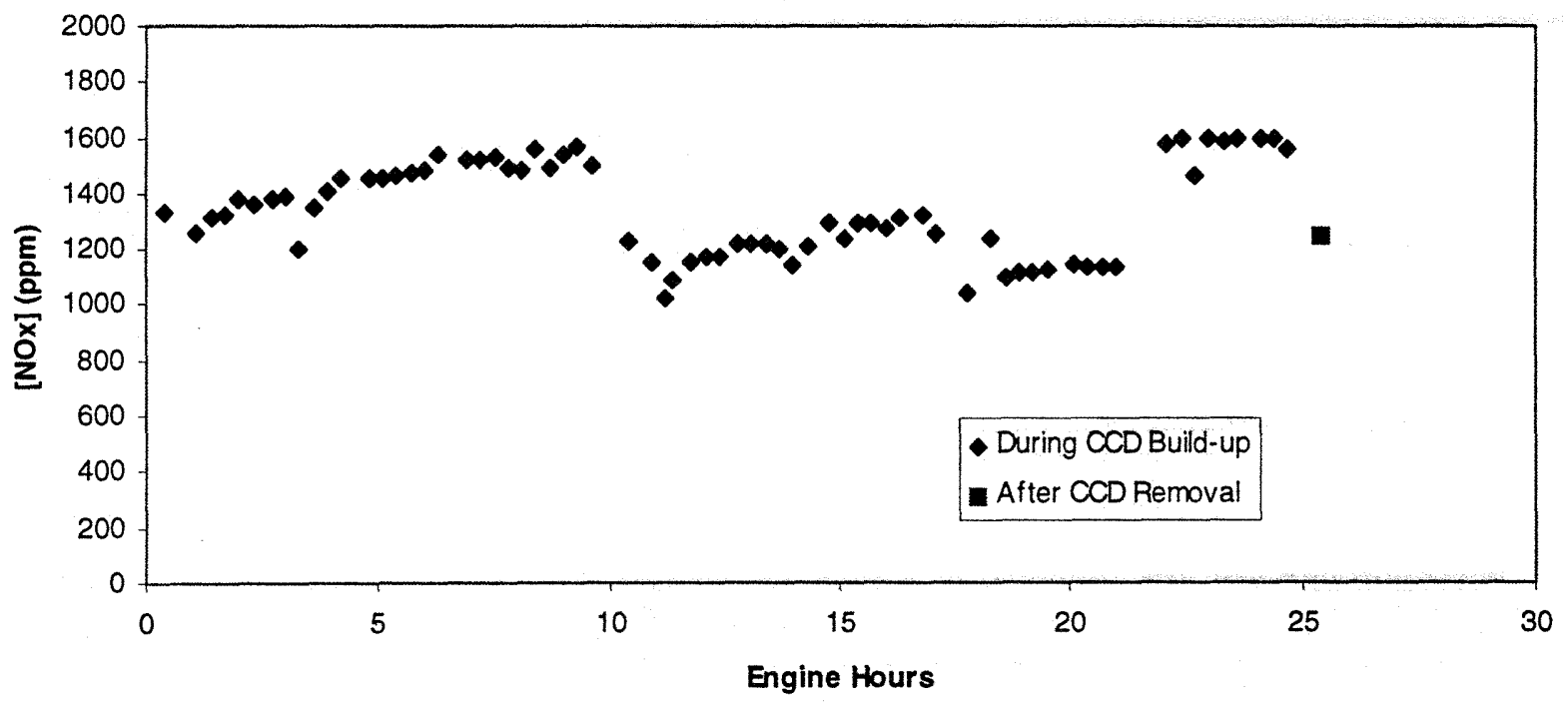

Figure $3.31 \mathrm{NO}_{\mathrm{x}}$ emissions with deposit build-up fuel at $2200 \mathrm{rpm}, \mathrm{bmep}=318 \mathrm{kPa}$. Data from 25-hour deposit accumulation test. 


\section{CHAPTER 4: MODELING OF THE EFFECT OF CCD ON HC EMISSIONS}

\section{4-1 Introduction}

In the last chapter, we established through the presentation of the $\mathrm{HC}$ data that CCDs significantly increase the $\mathrm{HC}$ emissions from our spark-ignition engine. The $\mathrm{HC}$ emission source from CCDs ranged between 0 and $30 \%$ of the total $\mathrm{HC}$ emission level (depending on the fuel and operating conditions), making it a significant source of $\mathrm{HC}$ emissions from this sparkignition engine. In the following sections, we will develop physically-based models that identify the possible mechanisms by which combustion chamber deposits lead to additional HC emissions. It turns out that there are four possible mechanisms by which CCDs contribute to additional $\mathrm{HC}$ emissions. The first one is the filling of the deposit pores with fuel- air mixture as the pressure rises in the cylinder. This will be called the deposit crevice model. This mechanism occurs for pores with large diameters that offer little resistance to the flow into and out of the deposit pores. The second mechanism is based on the Darcy flow model. As pore diameters get smaller (which will be defined later), they offer viscous resistance to the flow of fuel-air mixture into and out of the pores and thus do not allow the flow to fully penetrate into the deposit pores. The third mechanism which might occur simultaneously with the Darcy flow is ordinary diffusion of fuel molecules in the gas in the deposit pores and their adsorption on active adsorption sites on the pore walls. As the cylinder pressure rises, the in-cylinder fuel concentration increases creating a concentration gradient and causing the fuel molecule to diffuse in the deposit pores. Once these fuel molecules diffuse deep into the pores, they also get adsorbed on active adsorption sites on the deposit pores. Finally, for very small pores with sizes of the order or less than the mean-free-path of the fuel molecule $(r<50 \AA)$ Knudsen diffusion takes over. In Knudsen diffusion the collisions between the fuel molecules are less important than the collisions between the fuel molecules and the deposit pore surfaces. The diffusion process is then dependent on the pore diameter and the temperature in the pores. Again, adsorption on the deposit walls takes place simultaneously with the Knudsen diffusion process. These four mechanisms will be discussed in great detail in the following sections. The deposit pore structure (mainly pore size distribution) is an important factor in determining which of these four mechanisms dominates the transport of the fuel molecules into and out of the deposit pores. In the following sections, the mathematical formulation of each of the four mechanisms will be presented. After presenting these mechanisms, the illustrative simulation results will be shown using the pore size distribution data from the mercury porosimetry measurements.

It is worthwhile to devote the next section to discussing the deposit pore structure and mercury porosimetry, the method by which the deposit pore size distribution was determined. The sections following that will be used to describe in detail the four physical mechanisms by which CCDs lead to additional HC emissions.

\section{4-2 Combustion Chamber Deposit Pore Structure}


Before getting into a detailed description of the different $\mathrm{HC}$ mechanisms, it is useful to talk a little about CCDs and their pore structure. Combustion chamber deposits can be thought as solid carbonaceous materials which are porous. A pore is a void occupying the space between the solid material. It extends into the CCD structure and can be characterized by a length and a diameter which vary along the length of the pore. These pores can be interconnected and form what is called a pore network. The pores have a wide range of sizes that spans four orders of magnitudes as will be seen later. It is in these pores that the fuel molecules get stored via the different mechanisms during the compression and combustion processes allowing them to escape the main combustion event. During the expansion and exhaust processes, the fuel stored in these pores gets released into the combustion products. While a fraction of the fuel gets oxidized, much of the rest gets released with the exhaust products leading to higher HC emissions.

\section{4-2-1 Mercury Porosimetry}

Deposit pore sizes (diameters) range from more than about $20 \mu \mathrm{m}$ to $0.003 \mu \mathrm{m}$. The pore size is an important parameter that determines which mechanism dominates the process of the storage of the fuel molecules in these deposit pores. So, it is important to be able to get a pore size distribution of the deposit pores. This is achieved with an experimental method called mercury porosimetry. A detailed description of the apparatus used for this measurement is provided in R.L. Bond's work [20]. This measurement is based on forcing mercury into pores under pressure in a chamber. The pressure is raised in small increments inside the chamber. The volume of mercury intruding in the pores due to this pressure step rise is measured, allowing the measurement of the pore volume in this small pressure range. Due to its high contact angle $(\theta=$ $130^{\circ}$ ), mercury does not wet the surface of the deposit making it necessary to use pressure to force the mercury in the deposit pores. The Washburn equation is the basis for calculating the pore radii from the mercury intrusion data [21]:

$$
r=\frac{-2 \gamma \cos \theta}{P}
$$

where:

$\mathrm{r}=$ pore radius $(\mathrm{m})$

$\gamma=$ surface tension of mercury $(0.485 \mathrm{~N} / \mathrm{m})$

$\theta=$ contact angle $\left(130^{\circ}\right)$

$\mathrm{P}=$ applied pressure $(\mathrm{Pa})$

Mercury porosimetry is used to measure pore radii in the range of $3.5 \mathrm{~nm}-7.5 \mathrm{~mm}$ [22]. It is not suited for measurement of smaller pore sizes because the high pressure required for these measurements can damage the pore structures. To measure larger pore sizes, the pressure inside the chamber is dropped to below atmospheric levels $(\mathrm{P}=0.11 \mathrm{~atm}$ for $\mathrm{r}=56 \mu \mathrm{m})$. It is important to realize the assumptions involved in interpreting the mercury porosimetry measurements. The 
method assumes that the pores are cylindrical of uniform diameter throughout their lengths and that the pores do not intersect. In addition, the method requires the scraping of the deposits off the surfaces on which they form, which might disturb their pore structure by creating cracks and exposing isolated pores, which would not be exposed to the mercury if the deposits were left in their undisturbed state. In addition, scraping off the deposits creates flakes which when put together, create spaces between them that are of the order of the deposit thickness of $100 \mu \mathrm{m}$. These inter-particle spaces show up in the mercury porosimetry measurements and either falsely indicating the existence of pores in those sizes or add to the contribution of the pore sizes in that range. But, the method is widely used and fairly accurate if its use is restricted to the pore size range listed above.

Figures 4.1 through 4.4 show the results of the mercury porosimetry measurements on cylinder head and piston top deposits. Each of these graphs will be examined in detail later. Because piston top deposits are exposed to higher temperatures than those on the cylinder head, it was thought that their pore structure might be different than cylinder head deposits. It is noteworthy to explain the variables in the graphs first, namely the cumulative and the incremental intrusion volumes. Note that both intrusion volumes are given per unit mass of deposits. Figures 4.1 and 4.3 show the cumulative intrusion volume vs. pore diameter. What is meant by cumulative intrusion volume is the volume of mercury that has intruded into the deposit pores up to a certain pore diameter. It is basically an integrated volume from the largest pore diameter down to a pore diameter, $d$. While the cumulative pore volume gives an indication of the pore sizes where the volume is concentrated, a better indicator of the concentration of pore sizes is the incremental intrusion volume shown in Figures 4.2 and 4.4.

A first glance at those figures indicates no significant difference between the piston and cylinder head deposits. All graphs show the same trends. The total cumulative volumes are 0.6802 and $0.7455 \mathrm{~cm}^{3} / \mathrm{g}$ for cylinder head and piston top deposits respectively. Both deposits have a significant pore volume in pores smaller than $100 \AA$. Finally, both incremental pore volumes show a peak at about $58 \mu \mathrm{m}$. B.S. Wood et al. [23] examined undisturbed combustion chamber deposits from a single-cylinder two-stroke research engine, collected on a removable plug, under a scanning electron microscope (SEM). They found the pore sizes to range from 20 to $1 \mu \mathrm{m}$. It was then thought that the larger pore sizes showing up in the mercury porosimetry measurements might just be spaces between deposit flakes (the deposits are scraped off the cylinder head and the piston top surfaces) and not actual pores. To examine this hypothesis, the cylinder head and piston top deposits were studied under an optical microscope, which has a resolution of about $10 \mu \mathrm{m}$. There were clear differences between the piston top and cylinder head deposits. First, the piston top deposit flakes were all in the form of planar slabs while cylinder head deposit flakes had more irregular and 3-dimensional corrugations. The cylinder head deposits seemed to have been formed by these corrugations coagulating together. These corrugations ranged in size from about $150 \mu \mathrm{m}$ down to the resolution of the microscope. The average size of these corrugations was about $70 \mu \mathrm{m}$. There were some corrugations that were about $500 \mu \mathrm{m}$ in size. The details of the corrugated surfaces (i.e. smaller pore sizes) could not be resolved using the optical microscope. Looking at a cylinder head deposit flake about $1.5 \times 3 \mathrm{~mm}$ 
in size, pores ranging in size from about $100 \mu \mathrm{m}$ down to the resolution of the microscope $(\sim 10$ $\mu \mathrm{m})$ could be seen and about half of the surface area was porous, which we will see is consistent with the mercury porosimetry measurement. It can be concluded that at least a part of the pore sizes larger than $20 \mu \mathrm{m}$ that showed up in the mercury porosimetry measurement on the cylinder head deposits are likely due to actual pores. In fact, mercury porosimetry as used measures pores up to a $112 \mu \mathrm{m}$ in sizes only. The larger pores which were detected with the microscope, do not show up in the mercury porosimetry measurement. Thus the porosimetry measurement may underestimate the porosity of cylinder head deposits. The piston top deposit had thin flakes ( thickness about the thickness of deposit on piston) with smoother surfaces. They did not show a well developed surface as the cylinder head deposits did. This might be due to the fact that piston top deposits are formed under higher temperatures than cylinder head deposits. The piston top deposit flakes $(420 \times 420 \times 70 \mu \mathrm{m})$ were much smaller in size that cylinder head deposit flakes. Due to their drier nature, it seems that the scraping process broke them in smaller pieces. Isolating a piston top deposit flake $(420 \times 420 \times 70 \mu \mathrm{m})$, the surface had a significant number of pores of about $15 \mu \mathrm{m}$ size although there were a few pores $70 \mu \mathrm{m}$ and larger. The piston deposits had much fewer larger pores than the cylinder head deposits. It seems that for piston top deposits, the pore sizes over $20 \mu \mathrm{m}$ which are showing up in the mercury porosimetry measurements are mostly due to inter-flake spacing and not actual pores. This suggests that only pores smaller than about $20 \mu \mathrm{m}$ should be considered for piston top deposits. It should be kept in mind that scraping may have affected the pore structure of the deposits by creating cracks and opening up the dead pores (enclosed empty volumes not connected to other pores) which would not be detectable if the deposits were in their undisturbed state. This would falsely add the contribution of these pores to the total pore volume.

\section{4-3 Heat Transfer Model}

\section{4-3-1 Mathematical Formulation}

All the four mechanisms described above require the knowledge of the deposit temperature. So, it was necessary to be able to predict the deposit temperature throughout the engine cycle. A 1-dimensional unsteady heat transfer model was developed for this purpose. The geometry of the problem is defined in Figure 4.5. It consists of two parallel layers, a thin deposit layer of thickness $L_{1}$ and an aluminum layer of thickness $L_{2}$ (because $L_{1}<<L_{2}$, the curvature in the cylinder head surface is neglected and the problem is treated as 1-dimensional). As indicated in Figure 4.5, the interface between the deposit-aluminum layers is taken as the origin of the $x$-axis. The solution to this problem was included in D.N. Assanis's work [24]. The basic assumptions in the model is that the combustion chamber side heat transfer coefficient, $h_{\mathrm{g}}$, the coolant side heat transfer coefficient and temperature, $h_{c}$ and $T_{c}$, and that the thermal properties of the deposits and aluminum, are all constant. Under these simplifying assumptions, a closed solution to this problem is attainable. The solution was implemented in a MATLAB program listed in Appendix C. 
The gas temperature, $\mathrm{T}_{\mathrm{g}}$, is calculated as follows:

$$
T_{g}=x_{b} T_{b}+\left(1-x_{b}\right) T_{u}
$$

where:

$\mathrm{x}_{\mathrm{b}}=$ burned gas fraction

$\mathrm{T}_{\mathrm{b}}=$ burned gas temperature $(\mathrm{K})$

$\mathrm{T}_{\mathrm{u}}=$ unburned gas temperature $(\mathrm{K})$

$\mathrm{x}_{\mathrm{b}}, \mathrm{T}_{\mathrm{b}}$ and $\mathrm{T}_{\mathrm{u}}$ are obtained from a quasi-steady cycle simulation program developed at MIT [25]. Given the engine geometric parameters, intake pressure, and spark timing, the cycle simulation program predicts the cylinder pressure, the burned gas fraction, the burned and unburned gas temperatures, among other things. $x_{b}$ is used in calculating $T_{g}$ to account for the fact that not all the deposit surface is exposed to either the burned and unburned gas throughout the cycle. A Fourier series expansion of $\mathrm{T}_{\mathrm{g}}$ is then calculated:

$$
T_{g}=T_{g m}+\sum_{n=1}^{k} \Delta T_{g}(n) e^{i \omega_{n} t}
$$

where $T_{g m}$ is the mean gas temperature and $\omega_{n}$ is the frequency of the oscillations. Since the governing differential equations are linear, we find a solution to each harmonic. By the superposition principle, the total temperature at each location and at any instant is the sum of the temperatures due to each harmonic. In what follows, we drop the subscript $n$ from all variables, and develop a solution for one harmonic $\omega$.

The temperature in each layer consists of a steady component (easily calculated and superimposed on the unsteady harmonic component) and an unsteady harmonic component (due to the harmonically varying part of $\mathrm{T}_{\mathrm{g}}$ ). The unsteady harmonic temperature in each slab obeys the unsteady heat conduction equations:

$$
\begin{aligned}
& \frac{1}{\alpha_{1}} \frac{\partial T_{1}}{\partial t}=\frac{\partial^{2} T_{1}}{\partial x^{2}} \\
& \frac{1}{\alpha_{2}} \frac{\partial T_{2}}{\partial t}=\frac{\partial^{2} T_{2}}{\partial x^{2}}
\end{aligned}
$$

$\alpha_{1}$ and $\alpha_{2}$ are the thermal diffusivities of layers 1 and 2 .

Using the separation of variables method, we break the temperatures into a time-periodic part and position-dependent parts, $\theta_{1}$ and $\theta_{2}$ :

$$
\begin{aligned}
& T_{1}(x, t)=\theta_{1}(x) e^{i \omega t} \\
& T_{2}(x, t)=\theta_{2}(x) e^{i \omega t}
\end{aligned}
$$


Differentiating and substituting in eqs. (4.5) and (4.6) we get:

$$
\begin{aligned}
& \frac{i \omega}{\alpha_{1}} \theta_{1}=\frac{d^{2} \theta_{1}}{d x^{2}} \\
& \frac{i \omega}{\alpha_{2}} \theta_{2}=\frac{d^{2} \theta_{2}}{d x^{2}}
\end{aligned}
$$

The solutions to the above ordinary equations are of the form:

$$
\begin{aligned}
& \theta_{1}(x)=A_{1} e^{d_{1} x}+B_{1} e^{-d_{1} x} \\
& \theta_{2}(x)=A_{2} e^{d_{2} x}+B_{2} e^{-d_{2} x} \\
& d_{1}=\sqrt{\frac{i \omega}{\alpha_{1}}} \\
& d_{2}=\sqrt{\frac{i \omega}{\alpha_{2}}}
\end{aligned}
$$

The four boundary conditions are:

At the combustion chamber side $\left(x=-L_{1}\right)$

$$
-k_{1} \frac{d \theta_{1}}{d x}=h_{g}\left(\Delta T_{g}-\theta_{1}\right)
$$

At the coolant side $\left(x=L_{2}\right)$

$$
-k_{2} \frac{d \theta_{2}}{d x}=h_{c} \theta_{2}
$$

$\mathrm{k}_{1}$ and $\mathrm{k}_{2}$ are the thermal conductivities in layers 1 and 2. A reminder that eqs. (4.14) and (4.15) do not contain $T_{g m}$ and $T_{c}$ because we are only interested in the time-periodic part of the solution, not the steady state solution.

At the interface between the two layers $(x=0)$, the continuity of temperature and heat flux give:

$$
\begin{aligned}
& A_{1}+B_{1}=A_{2}+B_{2} \\
& k_{1} d_{1}\left(A_{1}-B_{1}\right)=k_{2} d_{2}\left(A_{2}-B_{2}\right)
\end{aligned}
$$

Substituting eqs. (4.10) into (4.14) and (4.11) into (4.15) and manipulating the equations we obtain:

where

$$
\begin{aligned}
& B_{1}=S_{1} A_{1}+S_{2} \\
& B_{2}=S_{3} A_{2} \\
& S_{1}=\frac{k_{1} d_{1}-h_{g}}{k_{1} d_{1}+h_{g}} e^{-2 L_{1} d_{1}}
\end{aligned}
$$




$$
\begin{aligned}
& S_{2}=\frac{h_{g} \Delta T_{g}}{k_{1} d_{1}+h_{g}} e^{-L_{1} d_{1}} \\
& S_{3}=\frac{k_{2} d_{2}+h_{c}}{k_{2} d_{2}-h_{c}} e^{2 L_{2} d_{2}}
\end{aligned}
$$

$A_{1}, A_{2}, B_{1}$, and $B_{2}$ can be calculated from eqs. (4.16), (4.17), (4.18), and (4.19) to give the temperature distribution anywhere in both layers and at any instant. The thermophysical properties of combustion chamber deposits [26] and aluminum [27] are listed in Table 4.1.

\section{Estimation of Heat Transfer Coefficients}

The gas-side heat transfer coefficient, $\mathrm{h}_{\mathrm{g}}$ is calculated from Annand's correlation[28]:

$$
\begin{aligned}
& \frac{h_{g} B}{k}=a\left(\frac{S_{P} B}{v}\right)^{b} \\
& \bar{S}_{P}=2 L N
\end{aligned}
$$

where:

$\mathrm{B}=$ piston bore $(\mathrm{m})$

$\mathrm{k}=$ thermal conductivity of air at the cylinder-average charge temperature $(\mathrm{W} / \mathrm{m} \mathrm{K})$

$\mathrm{a}=$ experimental constant $=0.6$

$\mathrm{b}=$ experimental exponent $=0.7$

$v=$ kinematic viscosity at the cylinder-average charge temperature $\left(\mathrm{m}^{2} / \mathrm{s}\right)$

$\mathrm{S}_{\mathrm{P}}=$ mean piston speed $(\mathrm{m} / \mathrm{s})$

$\mathrm{L}=$ engine stroke $(\mathrm{m})$

$\mathrm{N}=$ engine speed $(\mathrm{rev} / \mathrm{s})$

The coolant-side heat transfer coefficient $h_{c}$ (water) for the cylinder head and oil for piston), is calculated from the following correlation, evaluating the water or oil properties at 365 $\mathrm{K}$. The same relationship was used to estimate an average heat transfer coefficient for the piston.

$$
\frac{h_{c} B}{k_{c}}=0.023\left(\frac{V_{c} B}{v_{c}}\right)^{0.8} \operatorname{Pr}^{0.4}
$$

$\mathrm{k}_{\mathrm{c}}=$ thermal conductivity of coolant $(\mathrm{W} / \mathrm{m} . \mathrm{K}$.

$\mathrm{V}_{\mathrm{c}}=$ measured water velocity in coolant jacket $[29](0.3 \mathrm{~m} / \mathrm{s})$

$=$ mean piston speed for piston heat transfer

$v_{c}=$ kinematic viscosity of coolant $\left(\mathrm{m}^{2} / \mathrm{s}\right)$

$\operatorname{Pr}=$ Prandtl number of coolant.

\section{4-3-2 Heat Transfer Model Results}

In this section, we will present some of the results of the heat transfer model for illustrative purposes. As we mentioned above, the deposit temperature is of interest to us because of its use in all four models for predicting the effect of CCDs on the HC emissions. Figure 4.6 shows the temperature $T_{g}$ at $1500 \mathrm{rpm}$ and $\mathrm{bmep}=318 \mathrm{kPa}$, as calculated from the 
cycle simulation program, and a 10-harmonic Fourier series representation of $\mathrm{T}_{\mathrm{g}}$. It is apparent that the Fourier series expansion does a good job of capturing the main features of $T_{\mathrm{g}}$. Figure 4.7 shows the predicted deposit temperature variation throughout the engine cycle, at different $\mathrm{x}$ locations in the cylinder head deposits, while Figure 4.8 presents the deposit temperature at different locations in the piston top deposits. $\mathrm{x}=-\mathrm{L}_{1}$ corresponds to the deposit-combustion chamber interface and $x=0$ the deposit-aluminum interface. In both graphs, the deposit thickness used is $120 \mu \mathrm{m}$. At $\mathrm{x}=-\mathrm{L}_{1}$, the largest swing in the deposit thickness throughout the cycle occurs. This is due to the proximity of the location to the combustion gases. As we move closer to the aluminum, the effect of the variation in $T_{\mathrm{g}}$ are damped out due to the small thermal diffusivity of the deposits. So, the effect is restricted to a small penetration depth estimated to be about $100 \mu \mathrm{m}$. Because the piston is only cooled by the splashing of oil, the deposit temperature on the piston is higher than that on the cylinder head. Taking the average temperature (over the whole cycle) at $\mathrm{x}=-\mathrm{L}_{1} / 2$ (which is the temperature used in the models), the piston deposit temperature is $42 \mathrm{~K}$ higher than that of the cylinder head ( $451 \mathrm{~K}$ compared to $409 \mathrm{~K}$ ).

\section{4-4 Deposit Crevice Model}

The simplest of all four models is the deposit crevice model. The basic assumptions in this model is that the deposit pore sizes are sufficiently large that they offer no resistance to the flow of fuel-air mixture. As the pressure rises in the cylinder, it forces the fuel-air mixture into the deposit pores during the compression and combustion processes. During the expansion and exhaust processes when the cylinder pressure drops, the fuel-air mixture exits the deposit pores into the combustion products where a fraction of the fuel oxidizes in the hot combustion gases in the cylinder. Another fraction of the fuel oxidizes in the exhaust port and the surviving fraction of the fuel escapes as $\mathrm{HC}$ emission.

The mass of fuel trapped in the deposit pores is given by:

$$
m_{\text {crev }}=\frac{X_{f} P_{10 A T C} V_{d e p} \theta}{R T_{\text {dep }}}
$$

where:

$\mathrm{X}_{\mathrm{f}}=$ fuel mole fraction in the fuel-air mixture

$\mathrm{P}_{10 \mathrm{ATC}}=$ cylinder pressure at $10^{\circ}$ after top center $(\mathrm{ATC})$ from the cycle simulation program

$\mathrm{V}_{\text {dep }}=$ deposit volume calculated from deposit thickness data

$\theta=$ deposit porosity or deposit void fraction calculated from mercury porosimetry measurement

$\mathrm{R}=\mathrm{R}_{\mathrm{u}} / \mathrm{M}_{\mathrm{f}}$

$\mathrm{T}_{\text {dep }}=$ average (over whole cycle) deposit temperature from heat transfer model

At about $10^{\circ} \mathrm{ATC}$, about $80 \%$ of the volume of the combustion chamber has been covered with burned gas. This corresponds to about $50 \%$ of the mass of fuel-air mixture. From 
the deposit thickness data on the cylinder head and piston top and the deposit temperature from the heat transfer model, the amount of fuel stored in the deposit pores can be calculated.

\section{4-5 Darcy Flow Model in Deposit Pores}

As pores get smaller, viscous resistance prevents the fuel-air mixture from easily flowing into and filling the deposit pores and has to be taken into account. To account for the viscous resistance, an empirically determined relation for flow in a porous system, called Darcy's law, is used:

$$
q=\frac{-k}{\mu} \nabla P
$$

where:

$q=$ superficial velocity in the porous medium

$\mathrm{k}=$ an empirical constant called permeability of porous medium

$\mu=$ viscosity of the fluid in the porous medium

$\mathrm{P}=$ pressure in pore

The conservation of mass equation in the porous medium is:

$$
\theta \frac{\partial \rho}{\partial t}+(\nabla \cdot \rho q)=0
$$

where:

$\theta=$ porosity of porous medium

$\rho=$ density of fluid

For a homogeneous and isotropic medium ( $\mathrm{k}$ is constant), substituting for $\mathrm{q}$ from eq. 4.27 into 4.28, we get:

$$
\begin{aligned}
& \theta \mu C_{l} \frac{\partial \rho}{\partial t}=k \nabla \cdot \nabla \rho \\
& C_{l}=\frac{1}{\rho} \frac{\partial \rho}{\partial P}=\frac{1}{P} \text { for and ideal gas }
\end{aligned}
$$

To simplify the differential equation and get an analytical solution, it is assumed that the pressure changes inside the pores are small, i.e. $C_{1}$ is constant $\left(C_{1}=\right.$ constant is a good assumption in small pores ) and that the term involving $(\nabla \mathrm{P})^{2}$ is negligible. Eq. 4.29 reduces to the well-known diffusion equation: 


$$
\frac{\partial P}{\partial t}=\frac{k}{\theta \mu C_{l}} \frac{\partial^{2} P}{\partial x^{2}}=\alpha \frac{\partial^{2} P}{\partial x^{2}}
$$

A more expansive treatment of flow phenomena in porous media can be found in the work of R.A. Greenkorn [30]. Assuming the pores are circular in shape, the permeability of the porous medium can be estimated from the following equation:

$$
k=\frac{\theta}{\tau} \frac{D_{p}^{2}}{32}
$$

where:

$\theta=$ porosity of the medium

$\tau=$ tortuosity factor, an empirical constant accounting for the change in the pore diameter along its length and for the deviation of its direction from the general direction of the flow $=1-10$ $\mathrm{D}_{\mathrm{p}}=$ pore diameter

In order to get a solution for the pressure distribution in the deposit pores, the same procedure used to get the temperature distribution is followed. A Fourier series expansion of the cylinder pressure is obtained:

$$
P_{c y l}=\left(P_{c y l}\right)_{m}+\sum_{j=1}^{n} \Delta P_{c y l}(j) e^{i \omega_{j} t}
$$

Using separation of variables, the pressure inside the pores is expressed as:

$$
P=P_{s}+\sum_{j=1}^{n} X_{j}(x) e^{i \omega_{j} t}
$$

$\mathrm{X}(\mathrm{x})$ is only a function of position $\mathrm{x}$. The subscript $\mathrm{j}$ designating the $\mathrm{j}^{\text {th }}$ harmonic is dropped and a solution for one harmonic, $\omega$, is developed. Using the superposition principle, the solution to all harmonics are added to give the total response. Substituting for $\mathrm{P}$ in eq. 4.31, 4.31 reduces to an ordinary diffusion equation in $\mathrm{X}$ :

$$
\alpha \frac{d^{2} X}{d x^{2}}-i \omega X=0
$$

The solution to this equation takes the form:

$$
\begin{aligned}
& X(x)=A e^{-d x}+B e^{d x} \\
& d=\sqrt{\frac{i \omega}{\alpha}}
\end{aligned}
$$

Applying the two boundary conditions: 
At $x=0$ (deposit-aluminum interface),

$$
\frac{\partial X}{\partial x}=0
$$

At $\mathrm{x}=\mathrm{L}$ (deposit-combustion chamber interface),

$$
X=\Delta P_{c y l}
$$

Solving for $\mathrm{A}$ and $\mathrm{B}$, we get:

$$
\begin{aligned}
& A=B=\frac{\Delta P_{c y l}}{e^{-d L}+e^{d L}} \\
& X(x)=\Delta P_{c y l}\left(\frac{e^{-d x}+e^{d x}}{e^{-d L}+e^{d L}}\right)
\end{aligned}
$$

The pressure and velocity at any location and at any instant can be calculated from the above response. The results from this model in conjunction with the mercury porosimetry measurements, will determine which of the mechanisms dominates the transport of the fuel into and out of the deposit pores. The results from this model will be presented later. The above solution was implemented in a MATLAB program listed in Appendix C.

\section{4-6 Ordinary and Knudsen Diffusion Models with Adsorption}

When the flow into the pores is negligible, transport of fuel into the deposit pores occurs through the diffusion mechanism. For large pores (defined later), the deposit pores are filled with fuel-air mixture or combustion products at low pressure the start of the intake process. Under certain circumstances (large pores with small entrances or for small pores ), the air-fuel mixture is restricted from simply filling the pores. Then, the transport of fuel into and out of the pores occurs through the process of ordinary diffusion or Knudsen diffusion of fuel molecules into the gases (air and combustion products) trapped inside the pores. It is worthwhile to expand on the differences between ordinary and Knudsen diffusion. Ordinary diffusion takes place when the pore size is much larger than the mean free path of fuel molecules. In this case, the collision among the fuel molecules themselves is more important than the collisions between the fuel molecules and the walls of the pore. When the mean free path is of the same order as the pore size, the collisions among the molecules themselves become unimportant in comparison to those occurring between the pore walls and the molecules. Under the temperature and pressure conditions inside the deposit pores, the mean free path was estimated to be about $100 \AA$. So, for pores smaller than $100 \AA$ in diameter, Knudsen diffusion takes place.

As the pressure inside the cylinder rises, so does the fuel concentration in the fuel-air mixture. Using the pressure and unburned gas temperature from the cycle simulation program, the in-cylinder concentration of fuel is calculated at each instant throughout the cycle: 


$$
C_{f}=\frac{X_{f} P}{R_{u} T_{u}}
$$

where:

$\mathrm{C}_{\mathrm{f}}=$ the in-cylinder fuel concentration

$\mathrm{X}_{\mathrm{f}}=$ the fuel mole-fraction in the cylinder, assuming stoichiometric mixture of fuel and air

$P=$ cylinder pressure

$\mathrm{R}_{\mathrm{u}}=$ universal gas constant

$\mathrm{T}_{\mathrm{u}}=$ unburned gas temperature from the cycle simulation program

Figure 4.9 shows the calculated fuel concentration and its 40-harmonic Fourier series representation as a function of crank angle (CA). It is apparent that the Fourier series adequately represents the actual fuel concentration. As the pressure inside the cylinder rises during the compression and combustion processes, the fuel concentration also rises. By the end of combustion (around $\mathrm{CA}=380$ ), most of the fuel, except what is stored in the cold quench layers close to the walls, in the deposits or in the piston and cylinder head crevices, has been consumed by the flame. For this reason, the fuel concentration is forced to go to zero at the end of combustion.

After the start of the intake process and during the compression and combustion processes, the existence of a fuel concentration in the cylinder forces the fuel molecules to diffuse in the deposit pores, which contain no fuel at the beginning of the intake process. As the fuel molecules penetrate into the deposit pores, they encounter active adsorption sites on the surface of the pores. These adsorption sites exert strong attractive forces forcing the fuel molecules to stick to these sites. For small surface coverage, the amount adsorbed is proportional to the fuel concentration. So, the deeper points in the pores adsorb less because the fuel concentration drops with distance into the pores. At the end of the combustion process, the diffusion process occurs in the opposite direction, out of the deposit pores and into the cylinder. As the concentration in the pores drops, desorption takes place and the adsorbed fuel molecules escape the adsorption sites and exit the pores. As mentioned before, a fraction of this fuel gets oxidized or retained in the cylinder or oxidized in the exhaust port, and the remaining fraction contributes to the $\mathrm{HC}$ emission from the engine.

\section{4-6-1 Mathematical Formulation}

In this section, the mathematical formulation of the diffusion (ordinary and Knudsen) and adsorption of fuel molecules into the deposit pores will be presented here. First, expressions for the ordinary and Knudsen diffusion coefficients are shown. Using the kinetic theory of gases, the binary diffusion coefficient of a gas 1 into a gas 2 is given by the following expression [31]: 


$$
\begin{aligned}
& D_{12}=\frac{0.001858 T^{\frac{3}{2}}\left[\left(M_{1}+M_{2}\right) / M_{1} M_{2}\right]^{\frac{1}{2}}}{P \sigma_{12}{ }^{2} \Omega_{D}} \\
& \sigma_{12}=\frac{1}{2}\left(\sigma_{1}+\sigma_{2}\right)
\end{aligned}
$$

where:

$D_{12}=$ diffusion coefficient of species 1 intc species $2\left(\mathrm{~cm}^{2} / \mathrm{s}\right)$

$\mathrm{T}=$ temperature in $\mathrm{K}$

$\mathrm{M}_{1}, \mathrm{M}_{2}=$ molecular weights of species 1 and 2

$\mathrm{P}=$ absolute pressure (atm)

$\sigma_{1}, \sigma_{2}=$ force constants

$\Omega_{\mathrm{D}}=$ "collision integral", a known function of temperature

As seen before, the deposit temperature varies slightly throughout the cycle. An average deposit temperature is then used in the calculation of $D_{12}$. The other assumption in the model is that the pressure inside the deposit pore does not vary as much as the cylinder pressure ( small entrance effects that dampen the pressure variation in the pores are a plausible explanation). An average cylinder (over the whole cycle) is used in calculating $D_{12}$. The above two assumptions imply that a constant $D_{12}$ is used throughout the cycle.

The Knudsen diffusion coefficient of a fuel molecule in a small pore is given by the knietic theory of gases [31]:

$$
D_{K}=\frac{d_{p}}{3} \sqrt{\frac{8 R_{u} T}{\pi M}}
$$

where:

$D_{\mathrm{K}}=$ Knudsen diffusion coefficient

$\mathrm{d}_{\mathrm{p}}=$ pore diameter

$\mathrm{R}_{\mathrm{u}}=$ universal gas constant

$\mathrm{T}=$ temperature

$M=$ molecular weight

In both ordinary and Knudsen diffusion in porous media, an empirical constant called a tortuosity factor $\tau$, is used to scale the diffusion coefficients calculated above. This tortuosity factor accounts for the varying pore cross section and the tortuous path (length of pore is different than the solid thickness). In addition, in order to calculate fluxes based on the solid cross section and not just the pore cross section, the porosity $\theta$, is also used to scale the diffusion coefficients [31]. The result of these two scaling constants is an effective diffusion coefficient:

$$
D_{12, e f f}=\frac{D_{12} \theta}{\tau}
$$




$$
D_{K, e f f}=\frac{D_{K} \theta}{\tau}
$$

It is obvious that the effect of including $\theta(\theta<1)$ and $\tau(\tau>1)$ is to reduce the diffusion coefficient. For a flat plate geometry, the diffusion of fuel (ordinary or Knudsen) in a porous medium is governed by the diffusion equation:

$$
\frac{\partial C}{\partial t}=\left[\frac{D_{e f f}}{\theta+K_{H} \rho_{p} S_{p}}\right] \frac{\partial^{2} C}{\partial x^{2}}=D_{e} \frac{\partial^{2} C}{\partial x^{2}}
$$

where:

$C=$ concentration of fuel in pores $\left(\mathrm{mole} / \mathrm{m}^{3}\right)$

$D_{\text {eff }}=D_{12, \text { eff }}$ or $D_{K, \text { eff }}$ depending on what diffusion regime is taking place

$\theta=$ porosity of the medium

$\mathrm{K}_{\mathrm{H}}=$ adsorption equilibrium constant calculated from the adsorption isotherm (m)

$\rho_{\mathrm{p}}=$ density of porous medium $\left(\mathrm{kg} / \mathrm{m}^{3}\right)$

$\mathrm{S}_{\mathrm{p}}=$ specific surface area of porous medium $\left(\mathrm{m}^{2} / \mathrm{kg}\right.$ of porous material)

The product $\rho_{p} S_{p}$ is the adsorbent surface area per unit adsorbent volume. $K_{H} \rho_{p} S_{p}$ represents the effect of the accumulation (or depletion) of adsorbed material. Looking at the above equation is to reduce the effective diffusion coefficient, $D_{e}$. The physical explanation to this effect is the following. As the fuel molecules diffuse into the pores, they are picked up the adsorption sites, leading to a shorter penetration depth in the pores than if adsorption was not taking place.

The specific surface area of a porous materials is a measure of the surface area available for molecules to be adsorbed. It usually indicates the surface area of the smallest pores (micropores) which exert the strongest attractive force on the molecules being adsorbed. The surface area of deposits was measured using the standard BET technique. This method uses nitrogen gas as the adsorbate because of the small size of its molecule, which allows it to penetrate to the smallest pores. The surface area of deposits ranged between 0.5 and $0.8 \mathrm{~m}^{2} / \mathrm{g}$. As a comparison, the surface area of activated carbon which is widely used as an adsorbent, is of the order of a few hundred $\mathrm{m}^{2} / \mathrm{g}$ of activated carbon. Clearly, the deposits do not have a lot of surface area available for adsorption relative to activated carbon.

\section{Adsorption Isotherms on CCDs}

Pore walls on solid surfaces exert attractive forces on gas molecules in their neighborhood, causing them to get adsorbed on the pore walls. The energy required to transfer a molecule from the gaseous state to the adsorbed state (called Polanyi adsorption potential) can be considered, in the first approximation, equal to the energy required to transfer the molecule from the gaseous state to the saturated liquid state at the adsorption temperature: 


$$
\varepsilon=R_{u} T \ln \left(\frac{P_{s}}{P}\right)
$$

where:

$\varepsilon=$ Polanyi adsorption potential

$\mathrm{R}_{\mathrm{u}}=$ universal gas constant

$\mathrm{T}=$ temperature at which adsorption is taking place (i.e. adsorbent temperature)

$\mathrm{P}_{\mathrm{s}}=$ saturation pressure of the adsorbate at the adsorption temperature $\mathrm{T}$

$\mathrm{P}=$ adsorbate pressure

For nonporous carbonaceous adsorbents like CCDs, the amount adsorbed per unit mass of adsorbent is given by [32]:

$$
a=\rho_{s} W_{o} e^{-m \frac{\varepsilon}{\beta}}=\rho_{s} W_{o} e^{-\frac{m}{\beta} R_{u} T \ln \left(\frac{P_{s}}{P}\right)}
$$

where:

$\mathrm{a}=$ mass adsorbed per unit mass of adsorbent( $\mathrm{g}$ of adsorbate/g adsorbent)

$\rho_{\mathrm{s}}=$ density of saturated liquid at adsorption temperature $\left(\mathrm{g} / \mathrm{cm}^{3)}\right.$

$\mathrm{W}_{\mathrm{o}}=$ maximum volume available for adsorption per unit mass of adsobent $\left(\mathrm{cm}^{3} / \mathrm{g}\right.$ of adsorbent $)$

$\mathrm{m}=$ an empirical parameter related to adsorbent pore structure

$\beta=$ affinitiy coefficient describing the strength of interaction of an adsorbate with the adsorbent

The adsorption theory developed above is called the potential theory of adsorption. An adsorption isotherm is obtained when the temperature is maintained constant, while the pressure is varied up to the saturation pressure corresponding to the adsorption temperature. At the maximum amount of gas is adsorbed and the adsorbed fills the whole volume $\mathrm{W}_{\mathrm{o}}$. According to the above theory, once an adsorption isotherm is measured, any other isotherm at any other temperature can then be calculated simply through the use of saturated pressure and density tables.

Several adsorption isotherms were measured on CCDs using isooctane, toluene, xylene, and benzene at an adsorption temperature of $313 \mathrm{~K}$. The purpose of these adsorption isotherm measurements was to be able to calculate the adsorption equilibrium constant $\mathrm{K}_{\mathrm{H}}$, used in the diffusion model above. The measurement apparatus is called a static gravimetric adsorption apparatus [33]. It consists of a microbalance on which a small adsorbent sample $(\sim 20$ $\mathrm{mg}$ ). The microbalance hangs inside a vacuum chamber where the pressure is measured. The microbalance and vacuum chamber are enclosed in a thermostat that maintains the whole system at the adsorption temperature. Before introducing the adsorbate into the vacuum chamber, the adsorbent sample is outgassed under vacuum at $200^{\circ} \mathrm{C}$. This ensures that any moisture trapped in the adsorbent pores is removed. Once the outgassing process is complete, the vacuum chamber is evacuated down to almost zero pressure. The pressure is then raised in small steps by introducing a small amount of adsorbate into the chamber. The pressure is maintained at that 
level until the sample weight stops increasing (adsorption equilibrium has been reached). The pressure is then increased by another step and the process repeated until the desired maximum pressure is reached.

The measured adsorption isotherms of isooctane, benzene, toluene, and xylene on CCDs are shown in Figure 4.10 at an adsorption temperature of $313 \mathrm{~K}$. The amount adsorbed per unit deposit mass $\mathrm{a}$, is plotted against $\mathrm{P} / \mathrm{P}_{\mathrm{s}}$. Using the potential theory of adsorption described above, the adsorption isotherms of the four hydrocarbons are calculated at $450 \mathrm{~K}$, the deposit temperature predicted by the heat transfer model. The calculated isotherms are shown in Figure 4.11. In Figure 4.11, $\mathrm{a}$ is plotted against the adsorption pressure $\mathrm{P}$ and not $\mathrm{P} / \mathrm{P}_{\mathrm{s}}$. This is done because these isotherms will be used to calculate $\mathrm{K}_{\mathrm{H}}$, the adsorption equilibrium constant. $\mathrm{K}_{\mathrm{H}}$ is defined by the following expression:

$$
K_{H}=\frac{d C_{s}}{d C_{g}}
$$

where:

$\mathrm{C}_{\mathrm{s}}=$ adsorbate surface concentration $\left(\mathrm{mole} / \mathrm{m}^{2}\right)$

$\mathrm{C}_{\mathrm{g}}=$ adsorbate concentration in the gas phase $\left(\mathrm{mole} / \mathrm{m}^{3}\right)$

Converting the amount adsorbed per unit mass a, to a surface concentration and $\mathrm{P}$ to $\mathrm{C}_{\mathrm{g}}$ using the ideal gas law, $\mathrm{K}_{\mathrm{H}}$ is then given by:

$$
K_{H}=\frac{d a /\left(M S_{p}\right)}{d P /\left(R_{u} T\right)}=\left(\frac{d a}{d P}\right) \frac{R_{u} T}{M S_{p}}
$$

where:

$\mathrm{da} / \mathrm{dP}=$ slope of adsoprtion isotherms in Figure 4.11

$\mathrm{T}=$ adsorption temperature

$\mathrm{M}=$ Fuel molecular weight

$S_{p}=$ specific surface area of deposit

Using a linear least square fit to each of the adsorption isotherms shown in Figure 4.11, the slope da/dP is calculated. Table 4.2 shows the $\mathrm{K}_{\mathrm{H}}$ values for all fuels at 313 and $450 \mathrm{~K}$. Obviously, $\mathrm{K}_{\mathrm{H}}$ goes down with temperature because the amount adsorbed goes down with temperature. It takes more energy to restrain a fuel molecule to a surface when it is at higher temperature. 


\section{Solution to the Diffusion Equation}

We devote this section to developing a solution to eq. 4.48 , the diffusion equation of fuel into the deposit pores with the appropriate boundary conditions. As mentioned above, the in-cylinder fuel concentration $\mathrm{C}_{\mathrm{f}}$ throughout the cycle is calculated from the pressure and unburned gas temperature data from the cycle simulation program as eq. 4.42 shows. A Fourier series expansion of $C_{f}$ is then obtained:

$$
C_{f}=C_{f s}+\sum_{j=1}^{n} \Delta C_{f}(j) e^{i \omega_{j} t}
$$

where:

$\mathrm{C}_{\mathrm{fs}}=$ steady component of $\mathrm{C}_{\mathrm{f}}$

$\Delta \mathrm{C}_{\mathrm{f}}(\mathrm{j})=$ amplitude of the $\mathrm{jth}$ harmonic of $\mathrm{C}_{\mathrm{f}}$

Using separation of variable, the fuel concentration in the deposit pores can be written as:

$$
C(x, t)=C_{s}+\sum_{j=1}^{n} G_{j}(x) e^{i \omega_{j} t}
$$

We know obtain a solution to one harmonic $\omega$, subject to the appropriate conditions. We drop the subscript $j$ in what follows with the assumption that the solution pertains to a harmonic $\omega_{j}$. Differentiating and substituting in eq. 4.48 we get:

$$
\frac{d^{2} G(x)}{d x^{2}}=\frac{i \omega}{D_{e}} G(x)=G(x) d^{2}
$$

The solution to the above differential equation is of the form:

$$
G(x)=A e^{d x}+B e^{-d x}
$$

Applying the boundary conditions:

At $\mathrm{x}=0$ (the deposit-combustion gases interface)

$$
J_{0}=-D_{e} \frac{d G}{d x}=h_{m}\left(\Delta C_{f}-G\right)
$$

At $\mathrm{x}=\mathrm{L}$ (the deposit-aluminum interface)

$$
\frac{d G}{d x}=0
$$

$h_{m}$ is the mass transfer coefficient calculated from a flat-plate correlation [27]: 


$$
\frac{h_{m} B}{D_{12}}=0.664 \operatorname{Re}_{B}^{1 / 2} S c^{1 / 3}=0.664\left(\frac{S_{p} B}{v}\right)^{1 / 2}\left(\frac{v}{D_{12}}\right)^{1 / 3}
$$

where:

$\mathrm{h}_{\mathrm{m}}=$ mass transfer coefficient $(\mathrm{m} / \mathrm{s})$

$\mathrm{B}=$ cylinder bore $(\mathrm{m})$

$\mathrm{S}_{\mathrm{p}}=$ mean piston speed $(\mathrm{m} / \mathrm{s})$

$v=$ kinematic viscosity of air calculated at the mean unburned gas temperature

$D_{12}=$ binary diffusion coefficient of species 1 in 2 at the mean unburned gas temperature $\left(\mathrm{m}^{2} / \mathrm{s}\right)$

Substituting for the boundary conditions and solving for A and B we get:

$$
\begin{aligned}
& A=\frac{h_{m} \Delta C_{f} e^{-2 d L}}{\left[\left(h_{m}+D_{e} d\right)+\left(h_{m}-D_{e} d\right) e^{-2 d L}\right]} \\
& B=\frac{h_{m} \Delta C_{f}}{\left[\left(h_{m}+D_{e} d\right)+\left(h_{m}-D_{e} d\right) e^{-2 d L}\right]}
\end{aligned}
$$

The molar flux at the deposit-combustion chamber interface $\mathrm{J}_{0}$ can then be calculated. The amount of fuel per unit deposit area that has diffused through the deposit pores during a cycle can be evaluated by integrating $\mathrm{J}_{0}$ from intake valve opening (IVO) until the end of combustion (EOC):

$$
n_{0}=\int_{I V O}^{E O C} J_{o}(C A) d(C A)
$$

where:

$\mathrm{n}_{0}=$ moles of fuel per unit deposit area that has diffused into deposits through a cycle (mole $/ \mathrm{m}^{2}$ ) $\mathrm{CA}=$ engine crank angle

Knowing the response to one harmonic, the pressure at any location and any instant is calculated by adding the pressures due to each harmonic. The above solution was implemented in a MATLAB program listed in Appendix D.

\section{4-7 Model Results}

Before discussing the model results, it's helpful to describe the physical processes in "small" and "large" pores. What is meant by "small" and "large" pores will be quantified later in this section. All pores are subjected to the time-varying pressure inside the cylinder. For large pores, the resistance to the flow of fuel-air mixture into the pores is insignificant. As the 
pressure rises inside the cylinder, the fuel-air mixture simply starts filling the large pore volume until the pressure reaches the value at which the burned gases cover the pore entrance. That's when the maximum amount of fuel-air mixture is stored in the pore volume. The gas initially in the pore, which could be a combination of air-fuel vapor and combustion products gets compressed and occupies a small fraction of the pore volume. In the case of large pores, the pores simply act as crevices that store the fuel-air mixture during the compression and combustion processes. As the cylinder pressure drops inside the cylinder, the fuel-air mixture exits the pores. A fraction of that fuel gets oxidized in the cylinder and exhaust port while the surviving fraction exits the engine. For the case of large pores, the main mechanism for transport of fuel into the pores is this deposit crevice mechanism. Since the filling process occurs at uniform pressure it does not create a fuel concentration gradient which is essential for diffusion to take place. This renders the diffusion (ordinary or Knudsen) mode of fuel transport negligible compared to the filling process. As the pore diameter gets smaller, the resistance to the flow of fuel-air mixture into the pore becomes significant and the rising pressure inside the cylinder only penetrates a small fraction of the pore length. In this case, the transport of fuel through the pores is mainly due to diffusion of fuel molecules into the "old" or residual gas in the pores. As the cylinder pressure rises during the compression and combustion processes, the in-cylinder fuel concentration rises creating a concentration gradient which drives the diffusion process of fuel molecules into the pores. When the in-cylinder fuel concentration drops to zero (around the end of the combustion process), the diffusion process occurs in the opposite direction, from the deposit pores into the combustion chamber.

\section{4-7-1 Darcy Flow Model Results}

As mentioned above, the pore size determines what mechanism of fuel transport is taking effect. In this section, the Darcy flow model is used to break down the pore size spectrum into ranges for which each mechanism takes place. Figure 4.12 shows the pressure at three locations in the deposit pores as a function of engine crank angle at a uniform pore size of 1 $\mu \mathrm{m} . \mathrm{x}=\mathrm{L}_{1}$ corresponds to the deposit-combustion gases interface. So, the pressure at $x=L_{1}$ corresponds to the cylinder pressure. $\mathrm{x}=0$ corresponds to the deposit-aluminum interface. It is clear that except for a small time lag, the cylinder pressure fully penetrates into the deposit pores. This suggests that for pore sizes larger than $1 \mu \mathrm{m}$, the deposits offer little resistance to the flow of the fuel-air mixture and the mechanism of transport of fuel is through the simple filling of the deposit pores with the fuel-air mixture at uniform pressure (deposit crevice model). The flux due to the flow of fuel-air mixture is much larger than the diffusional flux (ordinary diffusion). At a pore diameter of $0.4 \mu \mathrm{m}$ (Figure 4.13), the peak pressure drops to about 15 atm at $\mathrm{x}=0.2 \mathrm{~L}_{1}$, suggesting a transition to the Darcy flow regime. Reducing the pore diameter to $0.1 \mu \mathrm{m}$, the pressure distribution in the deposits is shown in Figure 4.14. As expected, as the pore size is decreased, the resistance to the flow increases and the cylinder pressure does not diffuse fully into the deposit pores. In this case, Darcy flow dominates in the top half of the deposit thickness. In the bottom half, ordinary diffusion takes over. At this pore size, a transition from the Darcy flow mechanism to the ordinary diffusion mechanism takes place. Figure 4.15 shows the pressure distribution at a pore diameter of $0.01 \mu \mathrm{m}$. It is apparent that the cylinder pressure does not penetrate very far into the deposit pores. At $\mathrm{x}=0.9 \mathrm{~L}_{1}$, the peak pressure is already about one 
tenth the peak cylinder pressure. Here, little fuel air-mixture will flow into the deposit pores. This could be better seen by looking at Figures 4.16 through 18 which show the flow velocity at different locations in the deposit pores as a function of crank angle (CA). A negative velocity value indicates a flow direction into the deposit pores and a positive value a flow direction out of the pores. Looking at Figure $4.16(\mathrm{Dp}=1 \mu \mathrm{m})$, the velocity reaches a maximum at $x=L_{1}$ (the deposit-combustion gases interface) where the pressure gradient is largest. As the pressure gradient decreases moving deeper into the pores, the velocity goes down until it reaches zero at the deposit-aluminum interface. Comparing the velocities at the same deposit location $x=L_{1} / 2$ for the three different pore sizes, the velocity drops quickly until it reaches zero at $D_{p}=0.01 \mu \mathrm{m}$. At $D_{p}=0.01 \mu \mathrm{m}$, moving even slightly into the pores to $x=0.9 \mathrm{~L}_{1}$, the velocity almost drops to zero. Very little fuel-air mixture flows into the deposit pores. For pore sizes smaller than $0.1 \mu \mathrm{m}$, the ordinary diffusion mechanism for fuel transport becomes important. The next step is to determine which diffusion regime (ordinary or Knudsen) is taking place. With the aid of the kinetic theory of gases, the mean free path is determined at the pressure and temperature conditions of the deposits. It coincidentally turns out to be about $0.01 \mu \mathrm{m}$. Thus, Knudsen diffusion takes place in pores smaller than $0.01 \mu \mathrm{m}$ in diameter.

In summary, the pore size spectrum can be broken into four regions in terms of transport mechanisms of fuel into the pores. It is apparent that for pore sizes larger than about $0.4 \mu \mathrm{m}$, the deposits act as crevices that get filled with fuel-air mixture at uniform pressure as the cylinder pressure rises. The Darcy flow regime occurs between 0.4 and $0.1 \mu \mathrm{m}$. Between 0.1 and 0.01 $\mu \mathrm{m}$ pore sizes, the ordinary diffusion mechanism takes place. As the pore size approaches 0.01 $\mu \mathrm{m}$, another transition takes place, between ordinary and Knudsen diffusion. For pore sizes smaller than $0.01 \mu \mathrm{m}$, Knudsen diffusion is the only mechanism which can occur. Two points have to be kept in mind. First, ordinary diffusion occurs simultaneously with the filling of the pores. It is just not important for larger pores. Second, these boundaries for the different transport mechanisms are only approximate due to the inherent simplifying assumptions in the Darcy flow model and due to the simultaneous occurrence of different mechanisms.

Table 4.3 shows the porosity of the piston and cylinder head deposits and the fraction of the pore volume between the above pore size ranges, corresponding to the different fuel transport mechanisms. For the piston top deposits, only pore sizes smaller than $20 \mu \mathrm{m}$ were included from the mercury porosimetry measurements because the optical microscope observations did not reveal many pore sizes larger than $20 \mu \mathrm{m}$ in the piston top deposit flakes. This is why the porosity of piston top deposits is less than one third that of the cylinder head deposits. For the cylinder head deposits, the crevice mechanism dominates the transport of fuel into the pores (about $91 \%$ of the pore volume) while the two diffusion mechanisms are insignificant. The crevice mechanism occurs in a large fraction of the piston top deposits also (about $65 \%$ of the pore volume). The results from Table 4.3 will be used in quantifying the contribution of each mechanism to the deposit-related $\mathrm{HC}$ emissions.

\section{4-7-2 Deposit Crevice and Diffusion Model Results}


Table 4.3 gives a concise summary of the breakdown of the pore size spectrum into four ranges where one transport mechanism dominates. Because the Darcy flow takes place in a small fraction of the pore volume, it is assumed that the deposit crevice mechanism also takes place in that small fraction to simplify the analysis. This has little effect on the final results because, as will be seen, the deposit crevice mechanism dominates all the other three mechanisms in the transport of fuel into and out of the deposit pores. Before being able to interpret the data in Table 4.3 , a pore structure model needs to be postulated. The simplest model used in the literature on porous material is the parallel port model. As the name suggests, the parallel port model assumes that the deposit pores of different sizes extend parallel to each other into the deposit structure. The assumption of this pore model simplifies the analysis of the model results because each mechanism takes place independently of the other in the pore size range where it dominates. Each mechanism then takes place in a fraction of the deposit cross section that is equal to the fraction of the pore volume where it takes place. In actuality, the deposit pores are interconnected to form complicated networks. In what follows, results from the three mechanisms will be shown separately. The contribution of all three mechanisms will then be combined to give the total contribution of the three mechanisms to the deposited related $\mathrm{HC}$ emission. Finally, after including a simple oxidation model, this total contribution will be compared to the experimental data from isooctane, benzene, toluene and xylene.

\section{Deposit Crevice Model Results}

Figures 4.19 shows the contribution of the deposit crevice model to the CCD-related HC emissions from isooctane, benzene, and toluene. In those graphs, the $\%$ of the mass of the fuel injected per cycle that is stored in the deposit is shown as a function of deposit thickness on the cylinder head and piston top at two operating conditions $(1500 \mathrm{rpm}$, bmep $=318 \mathrm{kPa}$ and 2200 rpm bmep $=318 \mathrm{kPa}$ ). The deposit thickness values used in generating these graphs are actual deposit thickness data on the cylinder head and piston top from all four deposit accumulation tests. The thickness data is shown in Figure 3.4. Surface adsorption of fuel molecules on the pore walls is not included in the calculation Not surprisingly, the amount of fuel stored in the deposits increases linearly with deposit thickness because the amount stored is proportional to the volume of the deposits. This trend does not agree with that observed in the experiments where the HC emissions stabilize after about 25 hours, corresponding to a thickness of $50 \mu \mathrm{m}$ on the piston top and $110 \mu \mathrm{m}$ on the cylinder head. The model assumes that all the deposit pores, even the ones in the bottom layers are accessible to the fuel-air mixture. This may not be true since the deposits appear to form in layers, which may make the pores in the bottom layers inaccessible to the fuel-air mixture. If this is so, the data suggest that the maximum volume of accessible pores is that of the pores accumulated after 25 hours. In fact, this will be the number used in comparing the deposit crevice model predictions to the experimental data. Another mechanism that was not accounted for in the deposit crevice model and that would explain the stabilization of the $\mathrm{HC}$ emissions after a certain thickness is adsorption of fuel molecules on small pores as the larger pores are being filled. As the pressure rises in the cylinder head, fuel-air mixture is forced into the deposit pores. As a lump of fuel-air mixture moves into the pores, fuel molecules are adsorbed by the active adsorption sites on the pore walls until the lump is emptied of its fuel content. The fuel in the next lump that enters the pore needs to penetrate a little deeper 
into the pores to be adsorbed. During the compression and combustion processes, there is limited time for this process to take place and the last lump of fuel-air mixture will only penetrate a finite thickness. Using the potential theory of adsorption, the amount of fuel stored per unit deposit surface area at the deposit temperature is calculated using a mean fuel concentration in the deposit pores. Knowing the amount of fuel stored in the deposit crevices, the total surface area of deposits to adsorb the fuel stored in these crevices is evaluated. From the measured specific surface area of the deposits, the deposit thickness needed to provide this total surface area is estimated. This simple calculation to estimate the thickness of deposits required to adsorb the amount of fuel entering the deposit crevices based on the mean fuel concentration in the pores gives a penetration depth of about $150 \mu \mathrm{m}$. This compares favorably with the experimental data which gives a thickness of about $100 \mu \mathrm{m}$ at 25 hours when the HC emissions stabilize.

As the graphs indicate, there is no significant difference in the amount of stored fuel between the two operating conditions and among the fuels themselves. This is expected because the pressures used in calculating the amount of fuel stored at each operating condition are close in value. The amount of fuel stored in the piston top deposits is about one tenth of that stored in the piston top deposits. Three factors contribute to this. First, the piston top deposit porosity is less than one third of the cylinder head deposit porosity, thus providing less pore volume for fuel storage. Second, the piston top deposit thickness is about one half of the cylinder deposits giving less pore depth. Finally, the piston top deposits are typically about $40 \mathrm{~K}$ hotter than cylinder head deposits, thus reducing the density of the fuel-air mixture stored in piston top deposits. The first two causes affect the difference between the cylinder head and piston top contribution the most. In fact, accounting for the difference in porosity and thickness leads to the fuel stored in the piston top deposits being about 0.14 that stored in the cylinder head. Another factor that would make the contribution of the piston top deposits less significant is that a larger fraction of fuel stored in the piston top deposits is more likely to oxidize than that stored in the cylinder head deposits because it is exposed to the hot combustion products for longer periods of time before it exits the cylinder. J.T. Wentworth [34] placed a porous material (to simulate deposits) on the piston and cylinder head surfaces and found that the simulated piston top deposits contributed about one half the simulated cylinder head deposits to the engine-out HC emissions. The comparison between the deposit crevice model predictions and the experimental data will be done later. The experimental data predicts that the engine-out HC emission due to CCDs is between 0.2 and $0.5 \%$ of the mass of the fuel injected. Taking the value for the fuel stored in the deposits corresponding to the thickness at the end of the 25-hour test gives the combined contribution of the piston top and cylinder head deposits to be about $2 \%$.

\section{Diffusion Model Results}

Figures 4.20 through 4.25 show the results of the diffusion models with adsorption (ordinary and Knudsen) for all three fuels at the two operating conditions. The number of moles of fuel per unit deposit area $n_{0}$ is plotted against the deposit thickness. Then, the stabilized value of the number of moles per unit area is scaled by the fraction of the deposit pore volume that falls in each diffusion regime. The interesting feature about these graphs is that they predict the experimental rapid rise in the $\mathrm{HC}$ emission data with engine run time (i.e. deposit thickness). 
The experimental data shows that the $\mathrm{HC}$ emission stabilize at a thickness of about $100 \mu \mathrm{m}$ for cylinder head deposits and $50 \mu \mathrm{m}$ for piston top deposits. The ordinary diffusion model predicts the $\mathrm{HC}$ emission would stabilize at a thickness of about $70 \mu \mathrm{m}$ while the Knudsen diffusion model predicts stabilization at a thickness of $50 \mu \mathrm{m}$. Even though they predict the stabilization of the HC emission with thickness, the contribution of the diffusion mechanisms are too small to affect the trend of linear increase with deposit thickness that shows up in the simple deposit crevice model. Tables 4.4 through 4.7 show the contributions of the three mechanisms to the deposit-related (cylinder head and piston top) $\mathrm{HC}$ emissions at the two operating conditions for the three fuels (isooctane, benzene, and toluene). It is apparent that the contribution from the ordinary and diffusion mechanisms is very small compared to that from the deposit crevice model. At $1500 \mathrm{rpm}$ and bmep $=318 \mathrm{kPa}$, the contribution of both diffusion regimes on the cylinder head and piston top deposits is about $0.1 \%$ of the mass of the fuel injected, a negligible contribution compared to that of the deposit crevice model. When comparing the experimental data to the model predictions, the contribution from the diffusion model will be added to that of the deposit crevice model, even though the deposit crevice model contribution is much larger. Both diffusion models predict little difference among all four fuels. This is due to the fact that all four fuel molecules are similar in size resulting in little difference in the diffusion coefficients among the four fuels.

\section{Comparison between the Models and the experimental data}

In this section, the model predictions will be compared to the experimental data of the four single-component fuels from the 50-hour and 35-hour deposit accumulation tests shown in the previous chapter. At each operating condition, the data as a percent of the mass of fuel injected per cycle from the two deposit accumulation tests will be averaged for each fuel. The results are shown in Tables 4.8 and 4.9 at two operating conditions (1500 rpm @ bmep $=318$ $\mathrm{kPa}$ and $2200 \mathrm{rpm} @$ bmep $=318 \mathrm{kPa}$ ). The predictions from the three mechanisms are then added. After estimating the fraction of the fuel that is oxidized in the cylinder, retained in the cylinder, or then oxidized in the port, the model predictions are reduced by this fraction and compared to the experimental data.

After escaping the main combustion event through any of the three mechanisms listed above, the fuel-air mixture exits the deposit pores during the expansion and exhaust processes and mixes in with the hot combustion gases. A fraction of the fuel that mixes with the combustion product oxidizes in the cylinder $\left(f_{\text {oxid,cyl }}\right)$, another fraction leaves the cylinder with the combustion gases during the exhaust process, while the remaining fraction stays in the cylinder $\left(f_{\text {retained,cyl }}\right)$ where it mixes with the residual gas and participates in the combustion process of the next cycle. Of the unburned HC that leave the cylinder, some oxidize in the exhaust port $\left(f_{\text {oxid,port }}\right)$. Using the amount of fuel predicted by the model through the three mechanisms, the amount of fuel emitted due to CCDs can be calculated if $\mathrm{f}_{\text {oxid,cyl}}, \mathrm{f}_{\text {retained,cyl }}$ and $\mathrm{f}_{\text {oxid,port }}$ are known. W.K. Cheng et al [35] in their paper on the overview of HC emissions mechanisms in sparkignition engines estimated these fractions. They found $f_{\text {oxid,cyl }}, f_{\text {retained,cyl }}$ and $f_{\text {oxid,port }}$ to be respectively equal to about $0.33,0.33$, and 0.33 . Then, the amount of fuel emitted due to CCDs 
as a function of the amount of fuel stored in the deposits through the three mechanism is given by:

$m_{\text {emitted }, C C D}=\left(1-f_{\text {oxid,cyl }}\right)\left(1-f_{\text {retained, }, y l}\right)\left(1-f_{\text {oxid,port }}\right) m_{\text {stored }, C C D}$

where:

$m_{\text {emitted,CCD }}=$ mass of fuel emitted due to CCDs

$\mathrm{m}_{\text {stored,CCD }}=$ mass of fuel stored in the deposit pores through the three mechanisms

Using these values for the three fractions gives the mass of fuel emitted due to CCDs as about $30 \%$ of the fuel stored in the deposits. It should be kept in mind that the purpose of this exercise is to show that the model predictions are reasonably close to the experimental data. Obviously, the oxidized fractions in the cylinder and exhaust ports may be different for the different fuels if these fuels oxidize at different rates. In addition, all three fractions vary with the operating conditions.

At the two operating conditions and for all four fuels, the contribution of the three mechanisms ( deposit crevice, ordinary and Knudsen diffusion with adsorption) on the piston top and cylinder head deposits are added up and compared to the experimental data after accounting for the oxidation and retention of the fuel stored in the deposits, as was shown above. The results are shown in Table 4.8 and 4.9. In all cases, the model overestimates the experimental data by about $65 \%$. This is an acceptable result considering the many simplifying assumptions made in arriving at the results. There are uncertainties involved in estimating the oxidized fractions in the cylinder and exhaust port and the retained fraction in the cylinder which would affect the surviving fraction of the fuel in the exhaust. Another possible source of this discrepancy is in overestimating the porosities of the cylinder head and piston top deposits by scraping them off and exposing the closed pores which would not be accessible in the deposit undisturbed state. The model predicts no significant differences among the four fuels and the two operating conditions, which is in agreement with the experimental data.

\section{4-8 Conclusions}

Using the Darcy flow model, the deposit pore size spectrum was divided into four regions where one of four mechanisms of fuel transport into and out of the deposit pores dominates: deposit crevice mechanism, Darcy flow, ordinary diffusion with adsorption and Knudsen diffusion with adsorption (see Table 4.3 for pore size range for each mechanism). The contribution of each of these mechanisms to the deposit-related $\mathrm{HC}$ emission. It turns out that the deposit crevice mechanism dominates all the three other mechanisms. The deposit crevice mechanism HC emission predictions are proportional to the pore volume. At first glance, this does not agree with the experimental data which shows that the HC emission stabilizes after about 25 hours of deposit accumulation, corresponding to a thickness of about 50 and $100 \mu \mathrm{m}$ on the piston and cylinder head respectively. Since the deposit thickness continues to grow well beyond the point where $\mathrm{HC}$ emissions stabilize, this suggests that the pores in the lower layers of the deposits are not accessible to the fuel-air mixture. This may be a physical limitation, or 
adsorption on the pore walls may limit the penetration of the fuel species into the pores as gas flows into the pores. An estimate of this adsorption shows that this may be the limiting factor. Adding the contributions of the four mechanisms to the CCD-related $\mathrm{HC}$ emissions, the model overpredicts the experimental HC emission data from the four single-component fuels by about $65 \%$. This is an acceptable result considering the simplifying assumptions used in the model and in estimating the oxidation fractions in the cylinder and exhaust port. Finally, the model successfully predicts no difference in the effect of CCDs on the HC emissions from all four single-component fuels. 


\begin{tabular}{|l|l|l|}
\hline Material & $\begin{array}{l}\text { Thermal Conductivity, } \\
\mathrm{K}(\mathrm{W} / \mathrm{m} . \mathrm{K} .)\end{array}$ & $\begin{array}{l}\text { Thermal Diffusivity } \\
\alpha\left(\mathrm{m}^{2} / \mathrm{s}\right)\end{array}$ \\
\hline Combustion Chamber Deposits & 0.5 & $2 \times 10^{-7}$ \\
\hline Aluminum & 180 & $10^{-4}$ \\
\hline
\end{tabular}

Table 4.1 Thermophysical properties of combustion chamber deposits and Aluminum used in the heat transfer model.

\begin{tabular}{|l|l|l|l|l|}
\hline Fuel & Isooctane & Benzene & Toluene & Xylene \\
\hline $\mathrm{K}_{\mathrm{H}}$ at $313 \mathrm{~K}(\mathrm{~m})$ & $364 \times 10^{-6}$ & $466 \times 10^{-6}$ & $565 \times 10^{-6}$ & $1471 \times 10^{-6}$ \\
\hline $\mathrm{K}_{\mathrm{H}}$ at $450 \mathrm{~K}(\mathrm{~m})$ & $6.5 \times 10^{-6}$ & $9.6 \times 10^{-6}$ & $8 \times 10^{-6}$ & $14 \times 10^{-6}$ \\
\hline
\end{tabular}

Table 4.2 The adsorption equilibrium constant of isooctane, benzene, toluene and Xylene calculated from adsorption isotherms of the four fuels on combustion chamber deposits.

\begin{tabular}{|l|l|l|l|l|l|}
\hline $\begin{array}{l}\text { Fuel Transport } \\
\text { Mechanism }\end{array}$ & $\begin{array}{l}\text { Deposit } \\
\text { Crevice }\end{array}$ & Darcy Flow & $\begin{array}{l}\text { Ordinary } \\
\text { Diffusion and } \\
\text { Adsorption }\end{array}$ & $\begin{array}{l}\text { Knudsen } \\
\text { Diffusion and } \\
\text { Adsorption }\end{array}$ & Porosity \\
\hline $\begin{array}{l}\text { Pore Size Range } \\
(\mu \mathrm{m})\end{array}$ & $100-0.4$ & $0.4-0.1$ & $0.1-0.01$ & $<0.01$ & N/A \\
\hline $\begin{array}{l}\% \text { of Total Pore } \\
\text { Volume in size } \\
\text { Range }\end{array}$ & & & & & \\
\hline $\begin{array}{l}\text { Cylinder Head } \\
\text { Deposits }\end{array}$ & 91 & 1 & 3 & 5 & 0.46 \\
\hline Piston Top Deposits & 65 & 6 & 13 & 16 & 0.13 \\
\hline
\end{tabular}

Table 4.3 Breakdown of deposit pore size spectrum into size ranges for four fuel transport mechanisms. Also, porosity of cylinder head and piston top deposits and \% of total pore volume falling in each pore size range. 
Cylinder Head Deposits. $1500 \mathrm{rpm}$, bmep $=318 \mathrm{kPa}$

\begin{tabular}{|l|l|l|l|l|}
\hline Mechanism & Deposit crevice & $\begin{array}{l}\text { Ordinary } \\
\text { Diffusion and } \\
\text { Adsorption }\end{array}$ & $\begin{array}{l}\text { Knudsen } \\
\text { Diffusion and } \\
\text { Adsorption }\end{array}$ & Total \\
\hline Fuel & $\begin{array}{l}\text { \% of Mass of } \\
\text { Injected Fuel }\end{array}$ & $\begin{array}{l}\text { \% of Mass of } \\
\text { Injected Fuel }\end{array}$ & $\begin{array}{l}\text { \% of Mass of } \\
\text { Injected Fuel }\end{array}$ & $\begin{array}{l}\text { \% of Mass of } \\
\text { Injected Fuel }\end{array}$ \\
\hline Isooctane & 1.75 & 0.019 & 0.009 & 1.78 \\
\hline Benzene & 1.97 & 0.023 & 0.009 & 2.00 \\
\hline Toluene & 1.95 & 0.022 & 0.009 & 1.98 \\
\hline Xylene & 1.92 & 0.017 & 0.007 & 2.01 \\
\hline
\end{tabular}

Table 4.4 Contribution of each fuel transport mechanism to the $\mathrm{HC}$ emission increase due to CCDs for all four single-component fuels. Cylinder head deposits at $1500 \mathrm{rpm}$, bmep= $318 \mathrm{kPa}$

Piston Top Deposits. $1500 \mathrm{rpm}, \mathrm{bmep}=318 \mathrm{kPa}$

\begin{tabular}{|l|l|l|l|l|}
\hline Mechanism & Deposit crevice & $\begin{array}{l}\text { Ordinary } \\
\text { Diffusion and } \\
\text { Adsorption }\end{array}$ & $\begin{array}{l}\text { Knudsen } \\
\text { Diffusion and } \\
\text { Adsorption }\end{array}$ & Total \\
\hline Fuel & $\begin{array}{l}\text { \% of Mass of } \\
\text { Injected Fuel }\end{array}$ & $\begin{array}{l}\text { \% of Mass of } \\
\text { Injected Fuel }\end{array}$ & $\begin{array}{l}\text { \% of Mass of } \\
\text { Injected Fuel }\end{array}$ & $\begin{array}{l}\text { \% of Mass of } \\
\text { Injected Fuel }\end{array}$ \\
\hline Isooctane & 0.16 & 0.058 & 0.017 & 0.23 \\
\hline Benzene & 0.18 & 0.067 & 0.018 & 0.26 \\
\hline Toluene & 0.18 & 0.066 & 0.018 & 0.26 \\
\hline Xylene & 0.17 & 0.05 & 0.013 & 0.23 \\
\hline
\end{tabular}

Table 4.5 Contribution of each fuel transport mechanism to the $\mathrm{HC}$ emission increase due to CCDs for all four single-component fuels. Piston top deposits at $1500 \mathrm{rpm}$, bmep= 318 $\mathbf{k P a}$ 
Cylinder Head Deposits. $2200 \mathrm{rpm}$, bmep $=318 \mathrm{kPa}$

\begin{tabular}{|l|l|l|l|l|}
\hline Mechanism & Deposit crevice & $\begin{array}{l}\text { Ordinary } \\
\text { Diffusion and } \\
\text { Adsorption }\end{array}$ & $\begin{array}{l}\text { Knudsen } \\
\text { Diffusion and } \\
\text { Adsorption }\end{array}$ & Total \\
\hline Fuel & $\begin{array}{l}\text { \% of Mass of } \\
\text { Injected Fuel }\end{array}$ & $\begin{array}{l}\text { \% of Mass of } \\
\text { Injected Fuel }\end{array}$ & $\begin{array}{l}\text { \% of Mass of } \\
\text { Injected Fuel }\end{array}$ & $\begin{array}{l}\text { \% of Mass of } \\
\text { Injected Fuel }\end{array}$ \\
\hline Isooctane & 1.68 & 0.016 & 0.008 & 1.7 \\
\hline Benzene & 1.89 & 0.019 & 0.008 & 1.92 \\
\hline Toluene & 1.87 & 0.019 & 0.008 & 1.9 \\
\hline Xylene & 1.85 & 0.014 & 0.006 & 1.87 \\
\hline
\end{tabular}

Table 4.6 Contribution of each fuel transport mechanism to the HC emission increase due to CCDs for all four single-component fuels. Cylinder head deposits at $2200 \mathrm{rpm}$, bmep= $318 \mathrm{kPa}$

Piston Top Deposits. $2200 \mathrm{rpm}$, bmep $=318 \mathrm{kPa}$

\begin{tabular}{|l|l|l|l|l|}
\hline Mechanism & Deposit crevice & $\begin{array}{l}\text { Ordinary } \\
\text { Diffusion and } \\
\text { Adsorption }\end{array}$ & $\begin{array}{l}\text { Knudsen } \\
\text { Diffusion and } \\
\text { Adsorption }\end{array}$ & Total \\
\hline Fuel & $\begin{array}{l}\text { \% of Mass of } \\
\text { Injected Fuel }\end{array}$ & $\begin{array}{l}\text { \% of Mass of } \\
\text { Injected Fuel }\end{array}$ & $\begin{array}{l}\text { \% of Mass of } \\
\text { Injected Fuel }\end{array}$ & $\begin{array}{l}\text { \% of Mass of } \\
\text { Injected Fuel }\end{array}$ \\
\hline Isooctane & 0.15 & 0.051 & 0.015 & 0.22 \\
\hline Benzene & 0.17 & 0.058 & 0.015 & 0.24 \\
\hline Toluene & 0.17 & 0.058 & 0.016 & 0.24 \\
\hline Xylene & 0.16 & 0.044 & 0.012 & 0.22 \\
\hline
\end{tabular}

Table 4.7 Contribution of each fuel transport mechanism to the $\mathrm{HC}$ emission increase due to CCDs for all four single-component fuels. Piston top deposits at $2200 \mathrm{rpm}$, bmep= $\mathbf{3 1 8}$ $\mathbf{k P a}$ 
$1500 \mathrm{rpm}, \mathrm{bmep}=318 \mathrm{kPa}$

\begin{tabular}{|l|l|l|l|}
\hline & $\begin{array}{l}\text { Model Prediction with no } \\
\text { Oxidation }\end{array}$ & $\begin{array}{l}\text { Model Prediction after } \\
\text { Oxidation }\end{array}$ & Experiment \\
\hline Fuel & $(\%$ mass of injected fuel $)$ & $(\%$ mass of injected fuel $)$ & $(\%$ mass of injected fuel $)$ \\
\hline Isooctane & 2.01 & 0.6 & 0.43 \\
\hline Benzene & 2.26 & 0.68 & 0.45 \\
\hline Toluene & 2.24 & 0.67 & 0.47 \\
\hline Xylene & 2.24 & 0.67 & 0.39 \\
\hline
\end{tabular}

Table 4.8 Comparison between the model predictions with and without oxidation and the experimental data for all four single-component fuels at $1500 \mathrm{rpm}, \mathrm{bmep}=318 \mathrm{kPa}$

$2200 \mathrm{rpm}, \mathrm{bmep}=318 \mathrm{kPa}$

\begin{tabular}{|l|l|l|l|}
\hline & $\begin{array}{l}\text { Model Prediction with no } \\
\text { Oxidation }\end{array}$ & $\begin{array}{l}\text { Model Prediction after } \\
\text { Oxidation }\end{array}$ & Experiment \\
\hline Fuel & $(\%$ mass of injected fuel $)$ & $(\%$ mass of injected fuel $)$ & $(\%$ mass of injected fuel $)$ \\
\hline Isooctane & 1.99 & 0.6 & 0.37 \\
\hline Benzene & 2.16 & 0.65 & 0.38 \\
\hline Toluene & 2.14 & 0.64 & 0.4 \\
\hline Xylene & 2.09 & 0.63 & 0.28 \\
\hline
\end{tabular}

Table 4.9 Comparison between the model predictions with and without oxidation and the experimental data for all four single-component fuels at $2200 \mathrm{rpm}$, bmep= $318 \mathrm{kPa}$ 


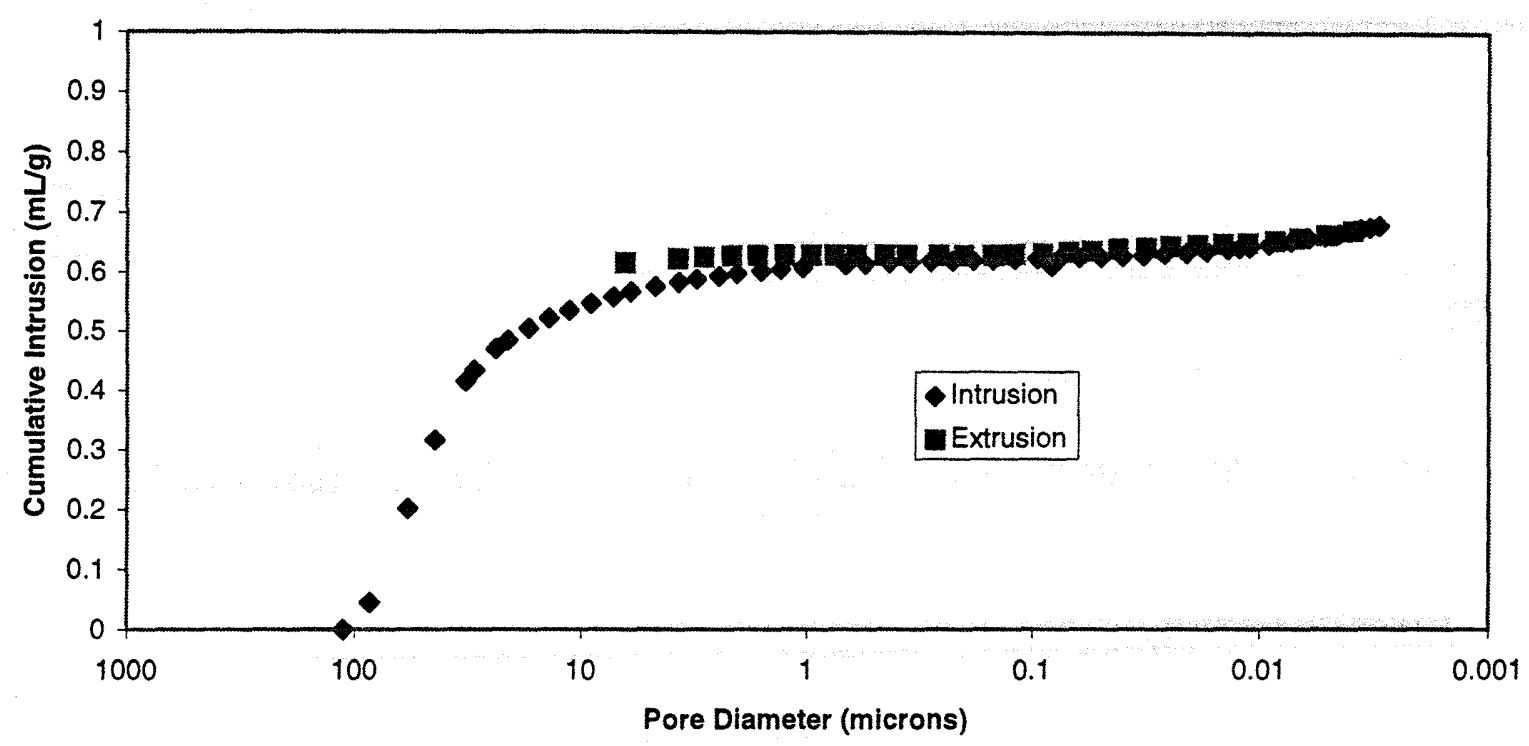

Figure 4.1 Pore size distribution of cylinder head deposits using mercury porosimetry. Cumulative intrusion volume vs. pore diameter

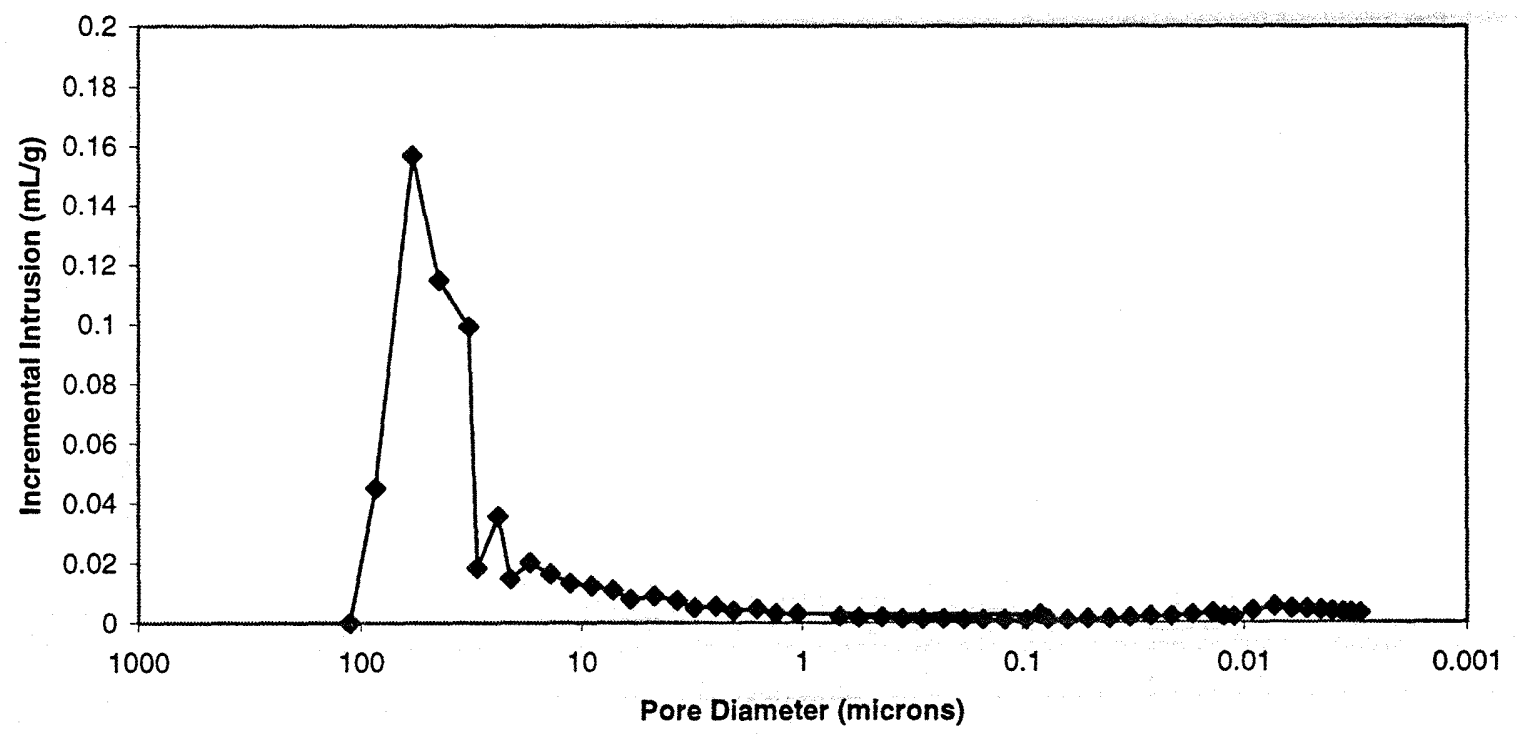

Figure 4.2 Pore size distribution of cylinder head deposits using mercury porosimetry. Incremental intrusion volume vs. pore diameter 


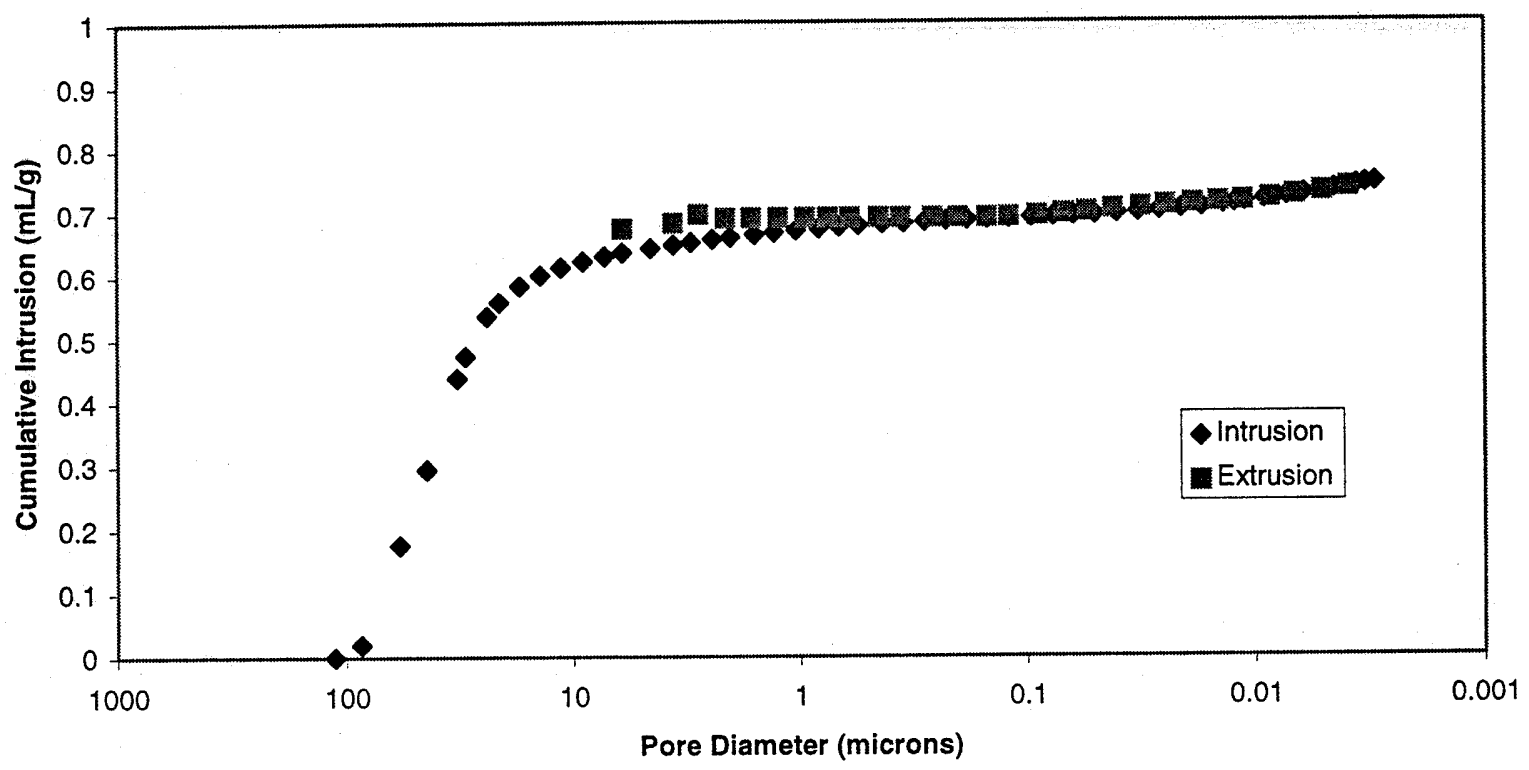

Figure 4.3 Pore size distribution of piston top deposits using mercury porosimetry. Cumulative intrusion volume vs. pore diameter

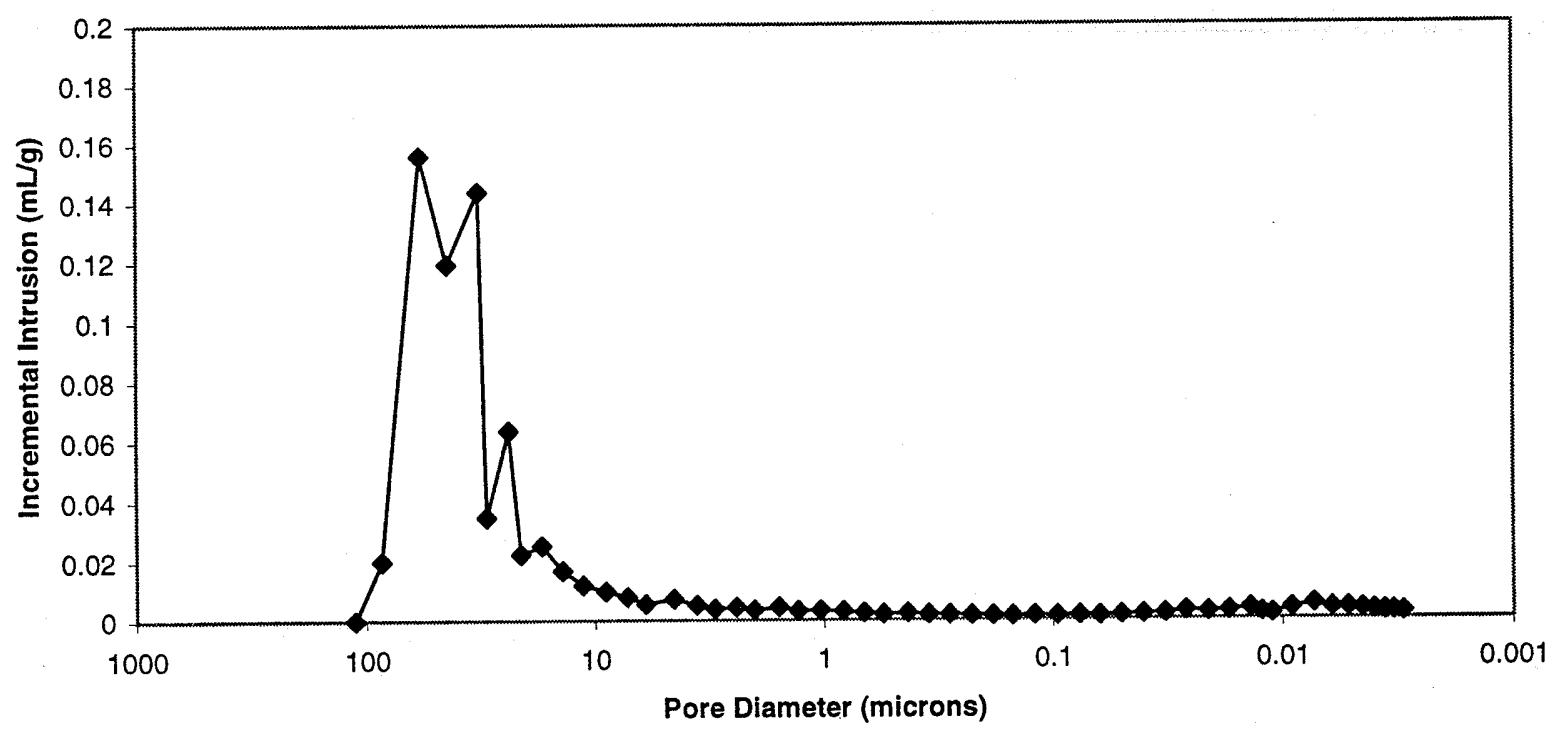

Figure 4.4 Pore size distribution of piston top deposits using mercury porosimetry. Incremental intrusion volume vs. pore diameter 


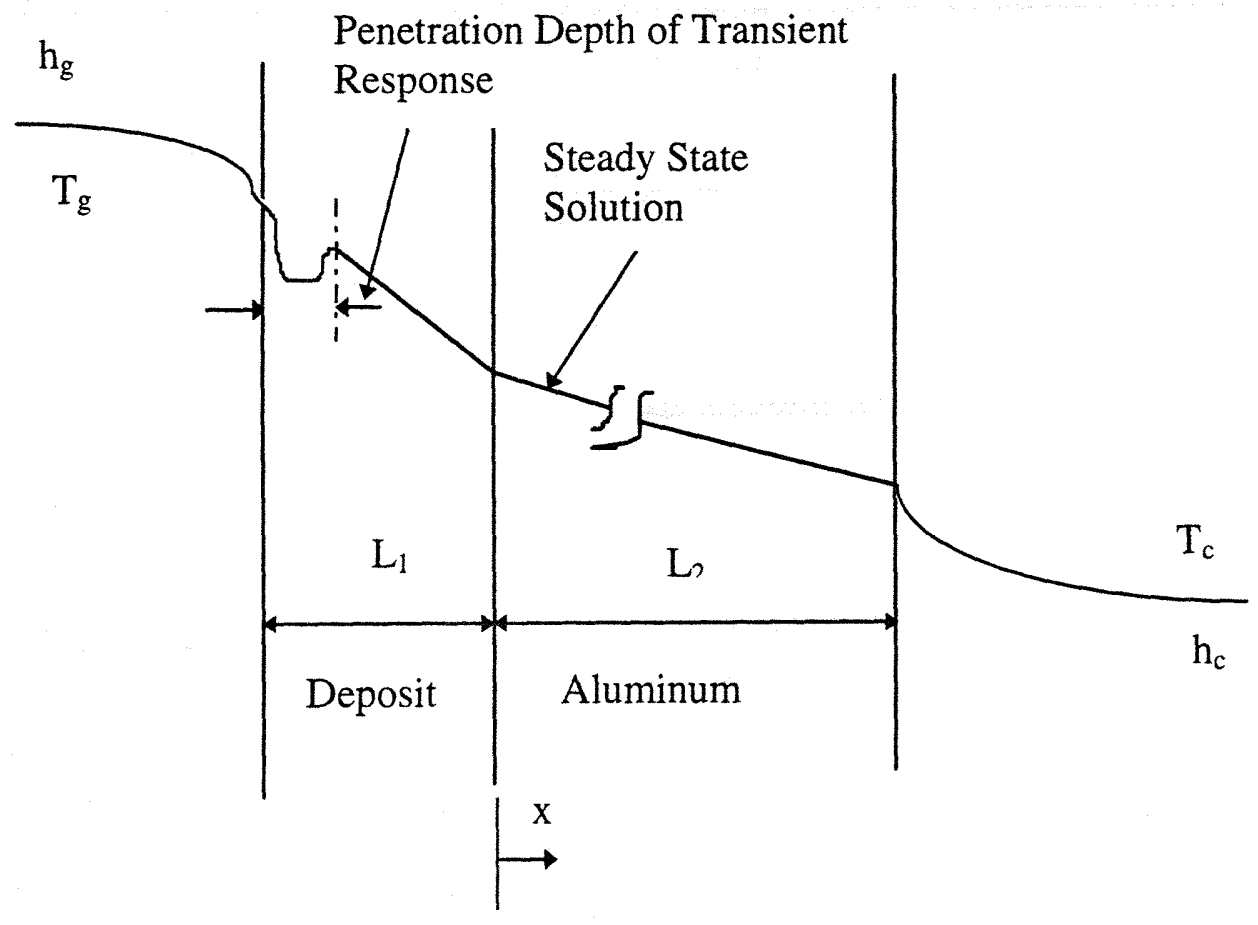

Figure 4.5 Temperature distribution in the deposit and aluminum layers in the combustion chamber 


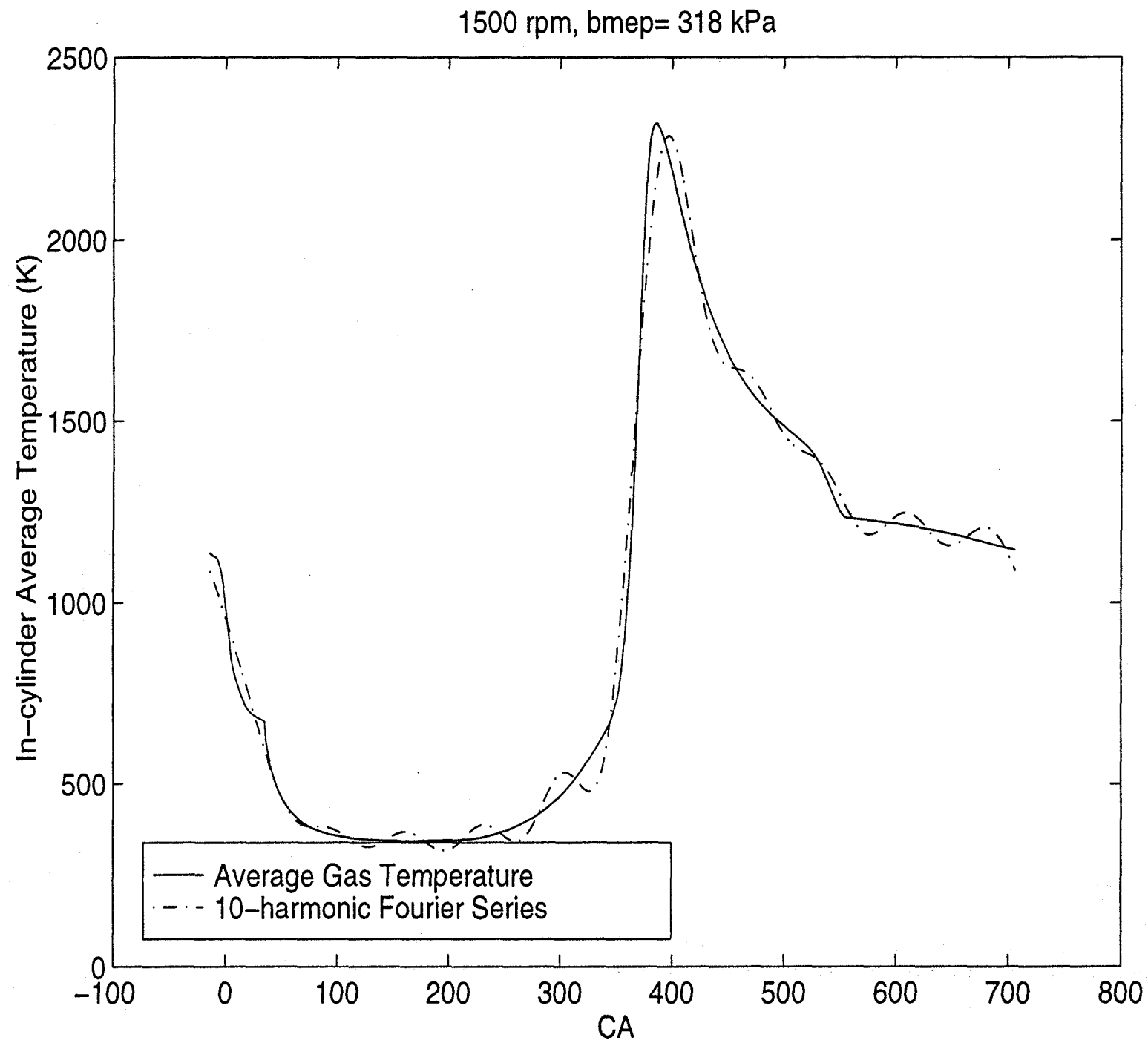

Figure 4.6 Average in-cylinder gas temperature and its 10-harmonic Fourier series representation vs. crank angle (CA) at $1500 \mathrm{rpm}$, bmep $=318 \mathrm{kPa}$. 


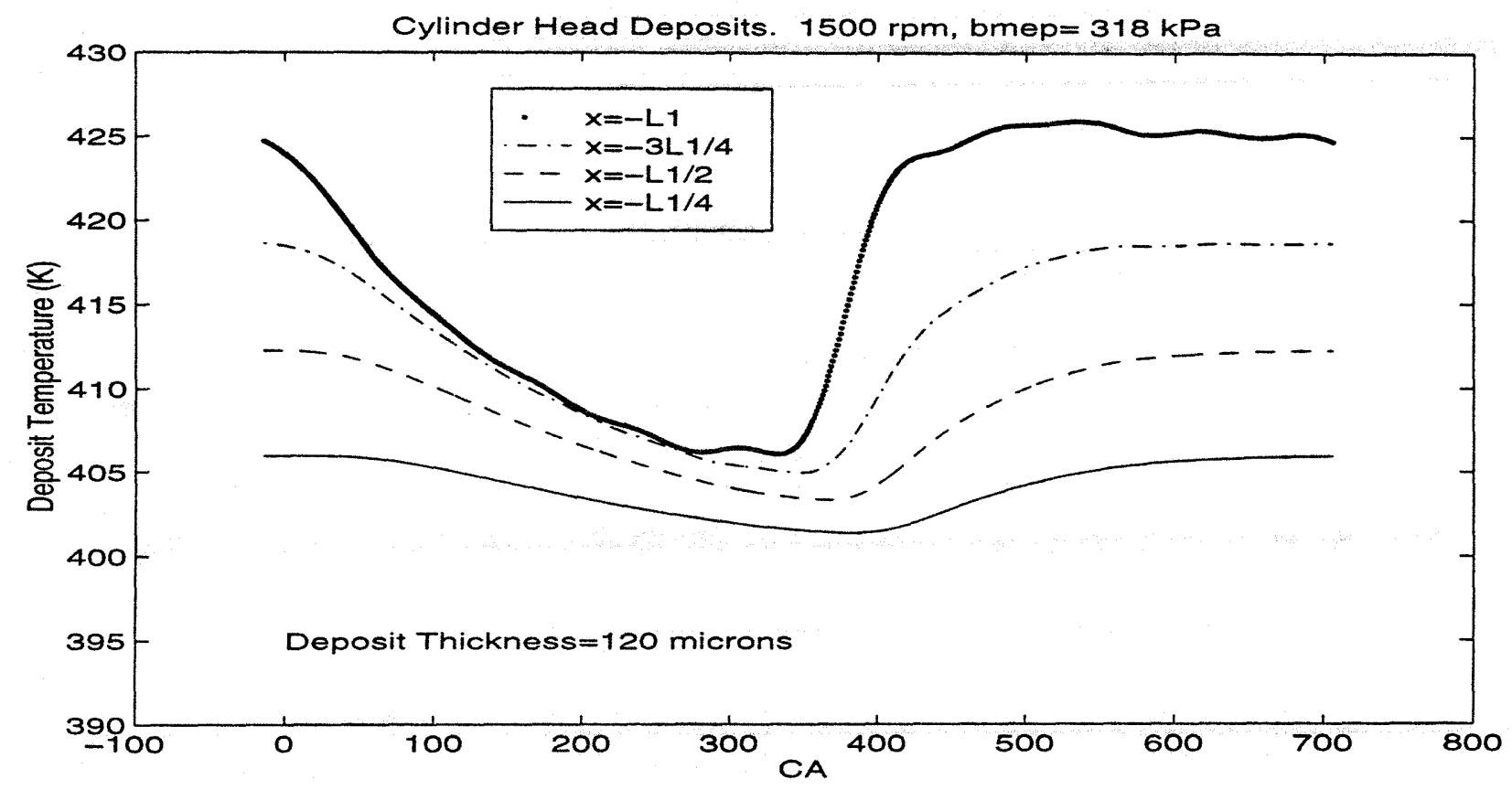

Figure 4.7 Temperature at different cylinder head deposit locations vs. CA at $1500 \mathrm{rpm}, \mathrm{bmep}=$ $318 \mathrm{kPa}$. Deposit thickness $=120 \mu \mathrm{m}$.

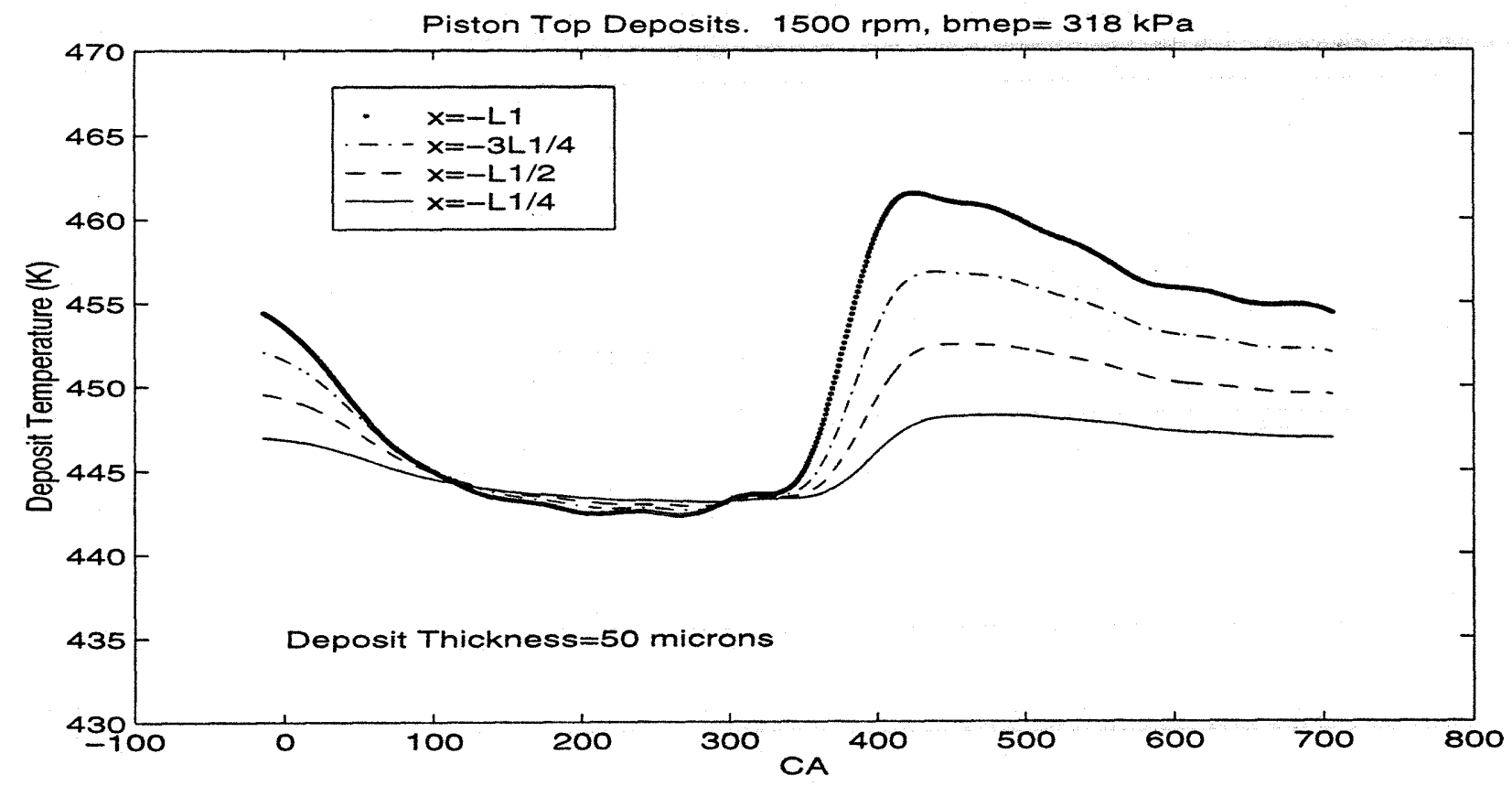

Figure 4.8 Temperature at different piston top deposit locations vs. CA at $1500 \mathrm{rpm}, \mathrm{bmep}=318$ $\mathrm{kPa}$. Deposit thickness $=120 \mu \mathrm{m}$. 


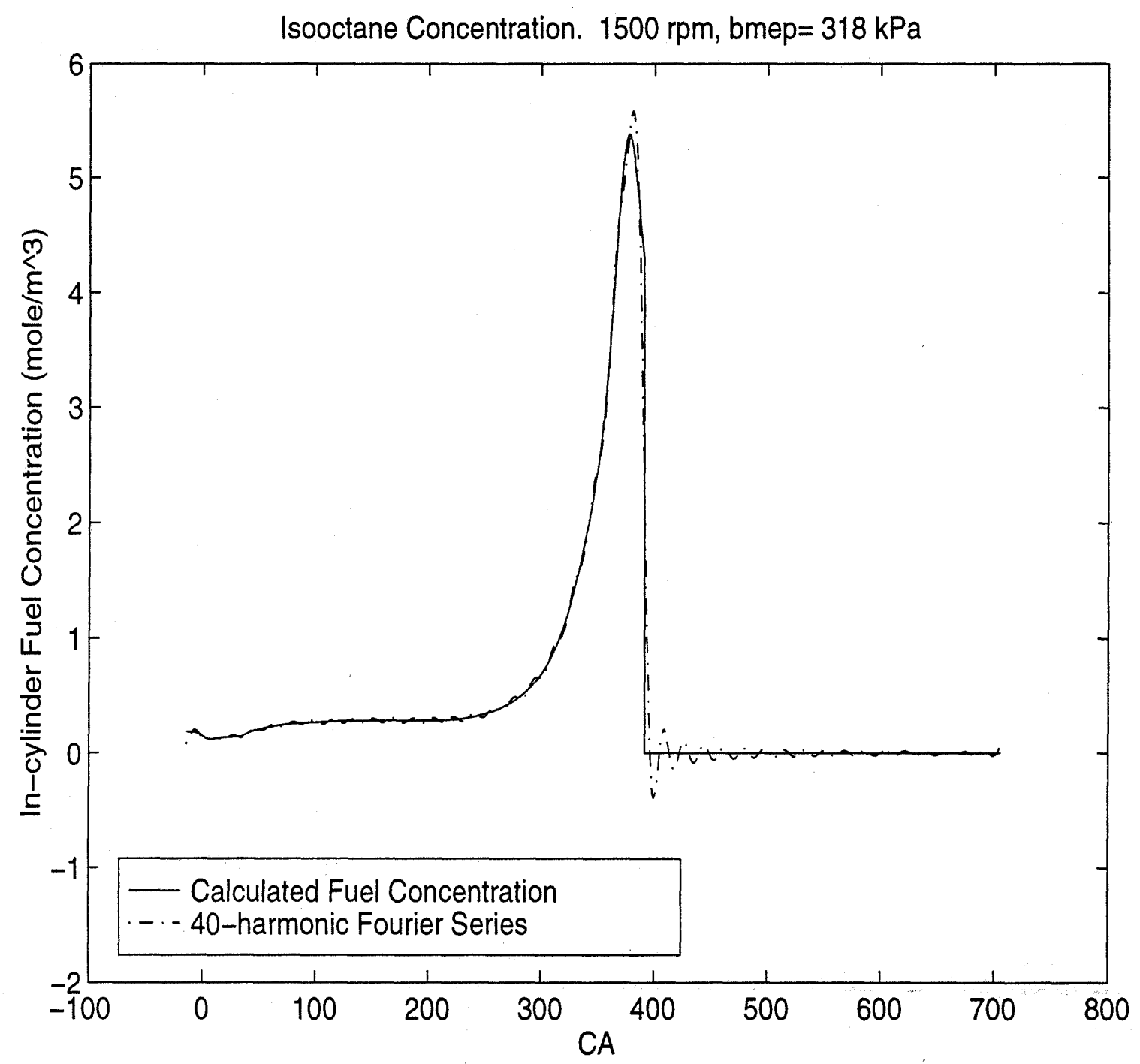

Figure 4.9 In-cylinder isooctane concentration vs. CA and its 40-term Fourier series representation at $1500 \mathrm{rpm}, \mathrm{bmep}=318 \mathrm{kPa}$. 


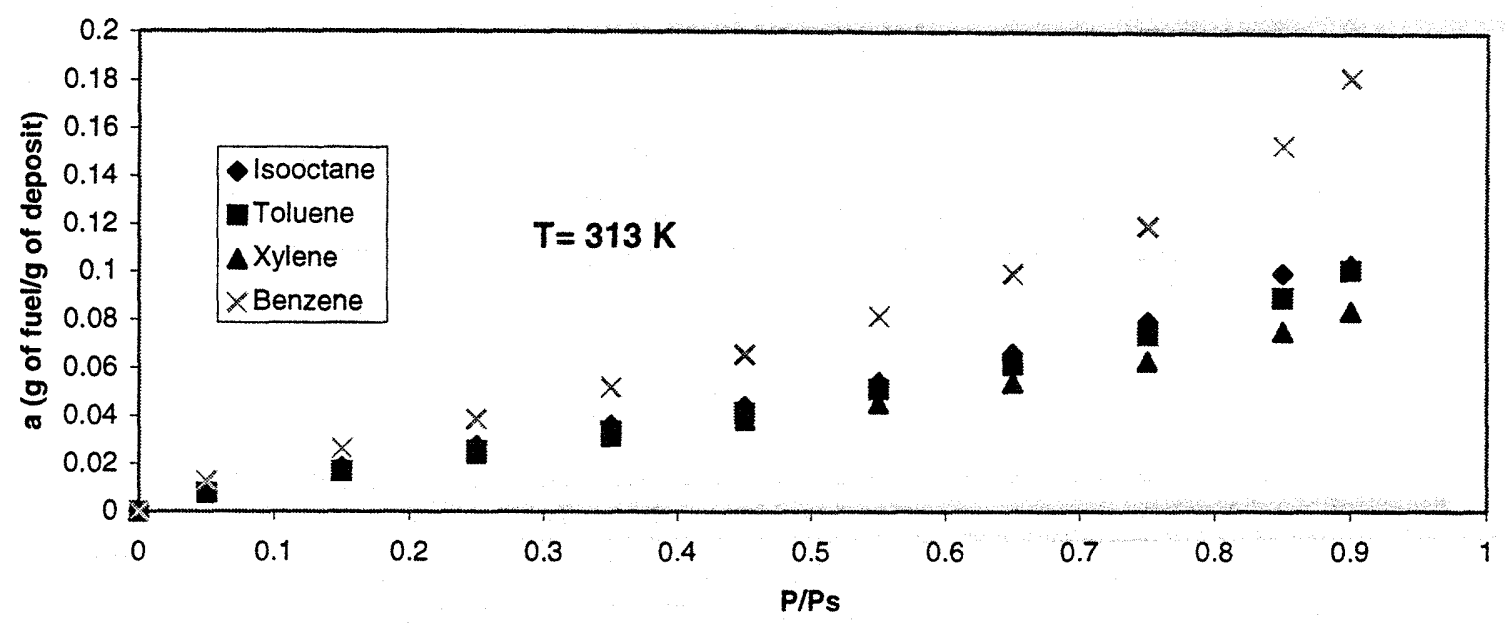

Figure 4.10 Measured adsorption isotherm of isooctane, benzene, toluene and xylene on combustion chamber deposits at $313 \mathrm{~K}$. a mass of fuel adsorbed per unit deposit mass vs. relative pressure.

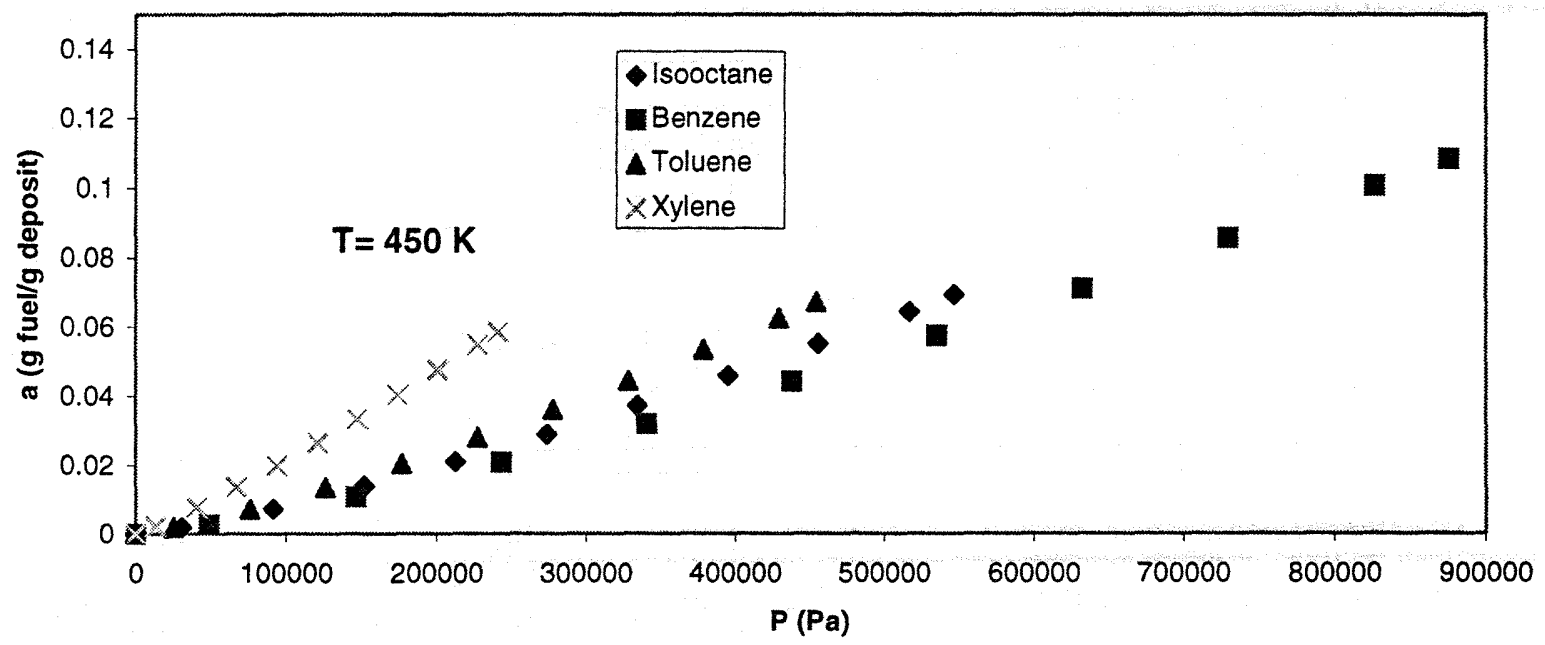

Figure 4.11 Calculated adsorption isotherm of isooctane, benzene, toluene and xylene on combustion chamber deposits at $450 \mathrm{~K}$. a mass of fuel adsorbed per unit deposit mass vs. relative pressure. 


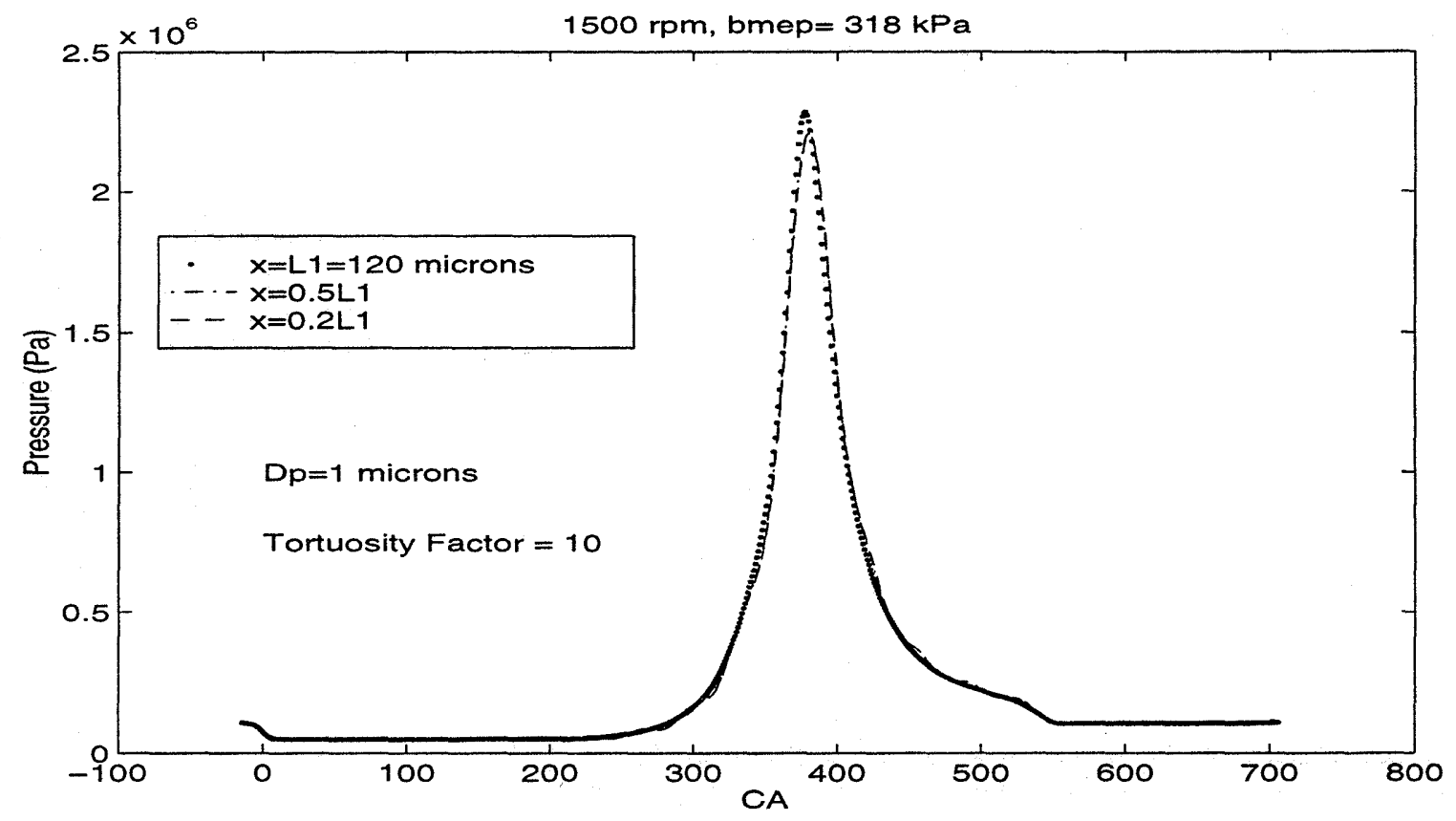

Figure 4.12 Pressure at different locations in the cylinder head deposit pores vs. CA at 1500 $\mathrm{rpm}$, bmep $=318 \mathrm{kPa} . \mathrm{D}_{\mathrm{p}}=1 \mu \mathrm{m}, \tau=10$.

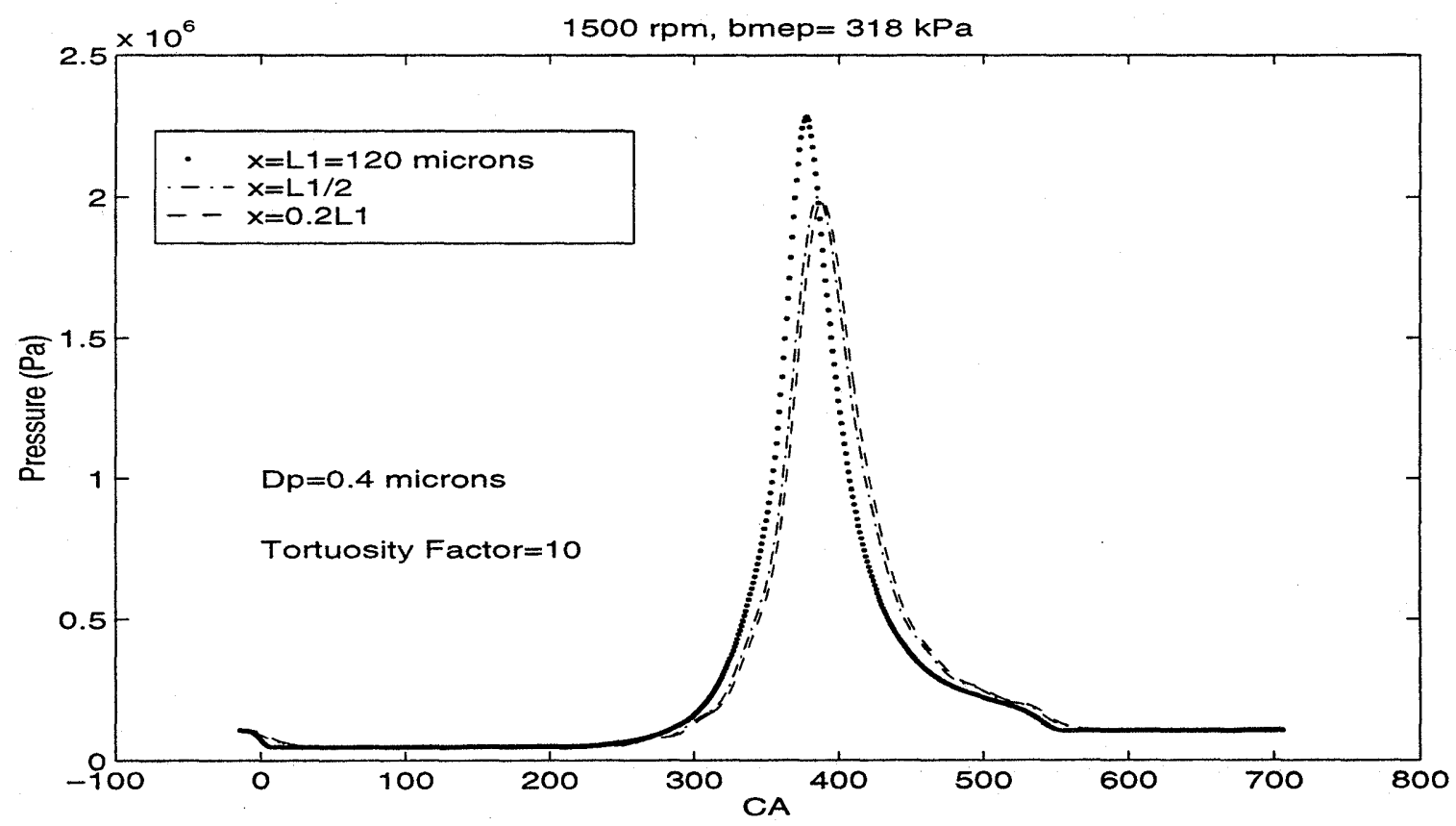

Figure 4.13 Pressure at different locations in the cylinder head deposit pores vs. CA at 1500 $\mathrm{rpm}, \mathrm{bmep}=318 \mathrm{kPa} . \mathrm{D}_{\mathrm{p}}=0.4 \mu \mathrm{m}, \tau=10$. 


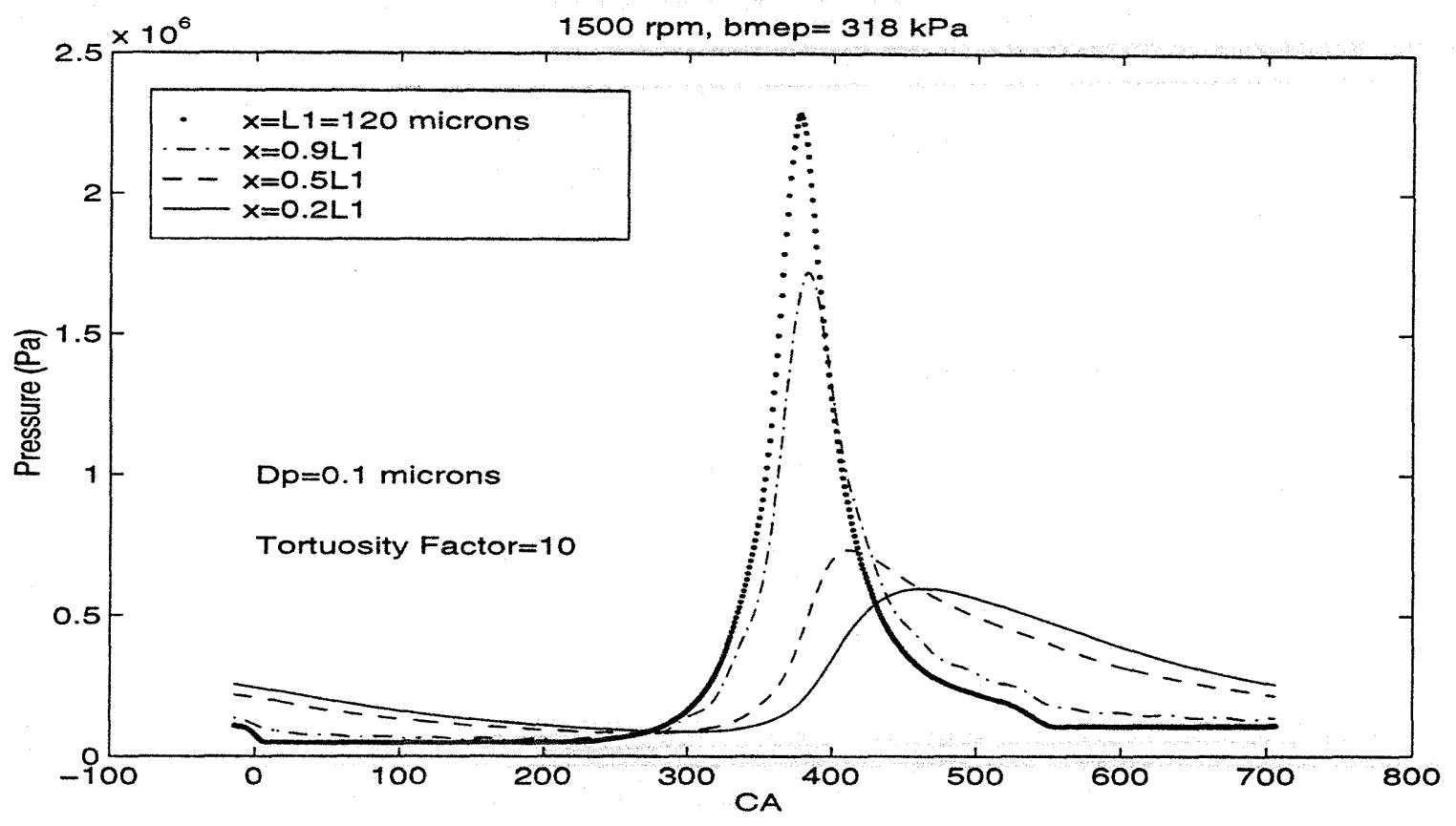

Figure 4.14 Pressure at different locations in the cylinder head deposit pores vs. CA at 1500 $\mathrm{rpm}, \mathrm{bmep}=318 \mathrm{kPa} . \mathrm{D}_{\mathrm{p}}=0.1 \mu \mathrm{m}, \tau=10$.

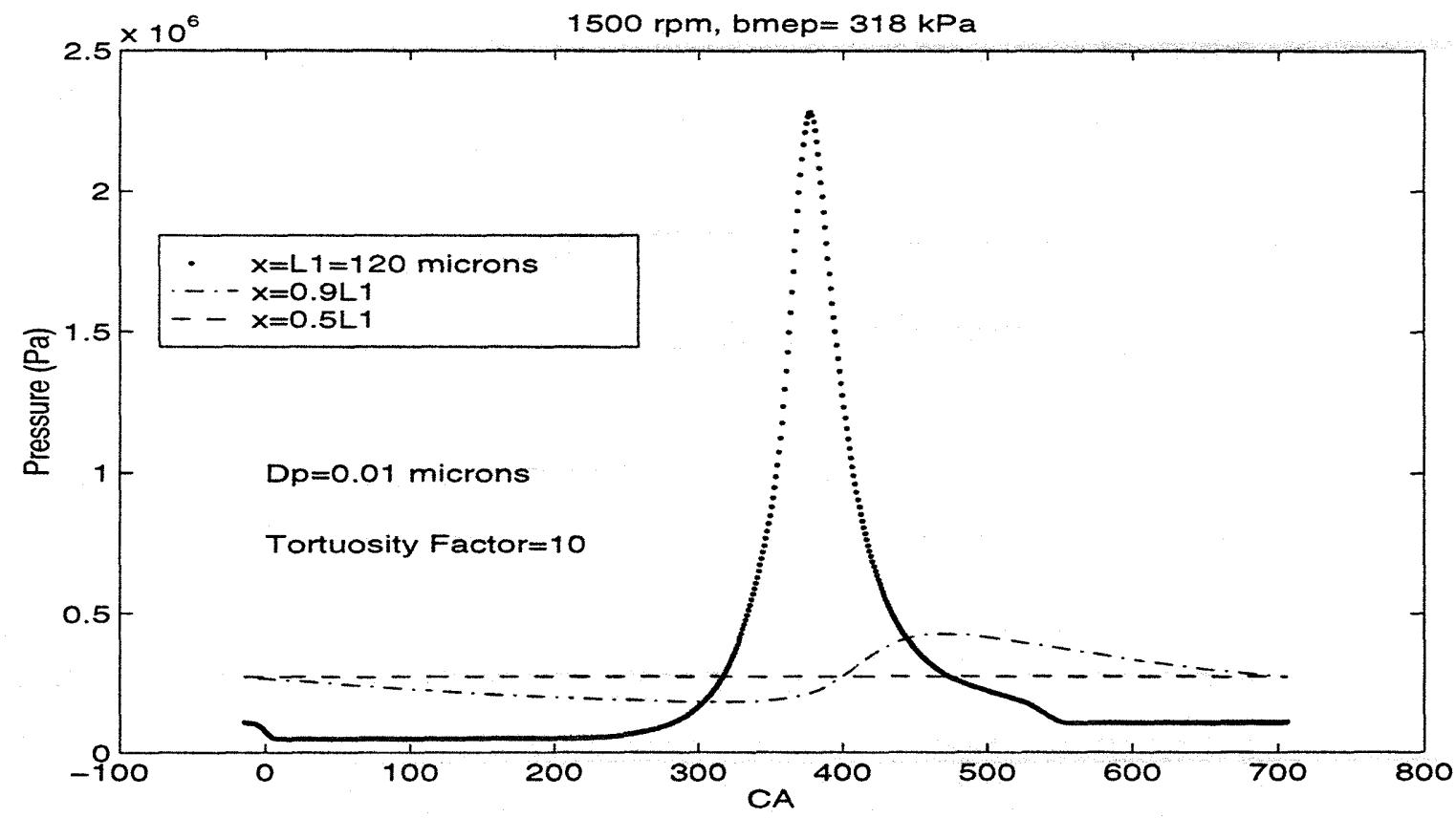

Figure 4.15 Pressure at different locations in the cylinder head deposit pores vs. CA at 1500 rpm, bmep $=318 \mathrm{kPa} . \mathrm{D}_{\mathrm{p}}=0.01 \mu \mathrm{m}, \tau=10$. 


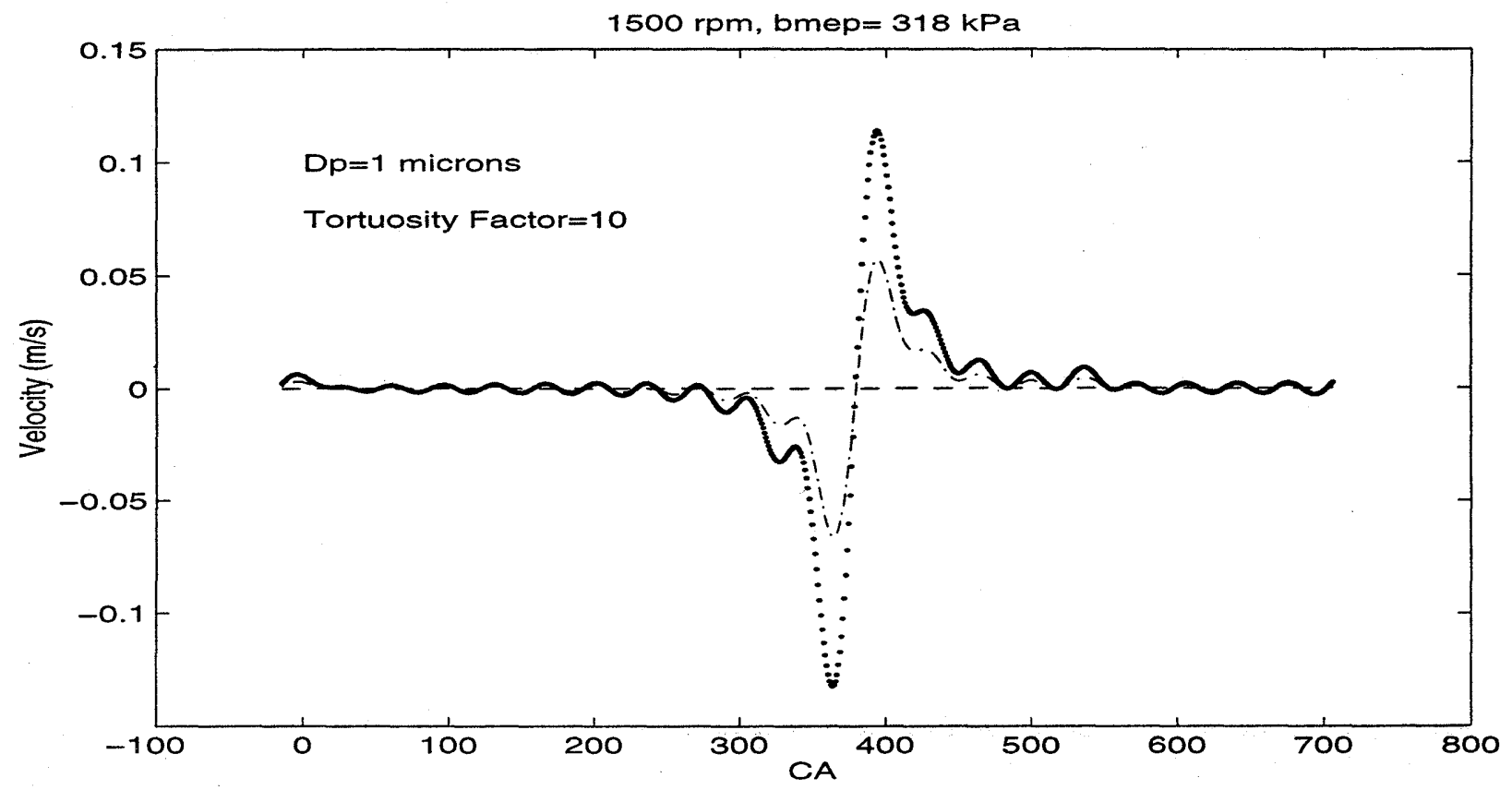

Figure 4.16 Velocity at different locations in the cylinder head deposit pores vs. CA at 1500 $\mathrm{rpm}, \mathrm{bmep}=318 \mathrm{kPa} . \mathrm{D}_{\mathrm{p}}=1 \mu \mathrm{m}, \tau=10$.

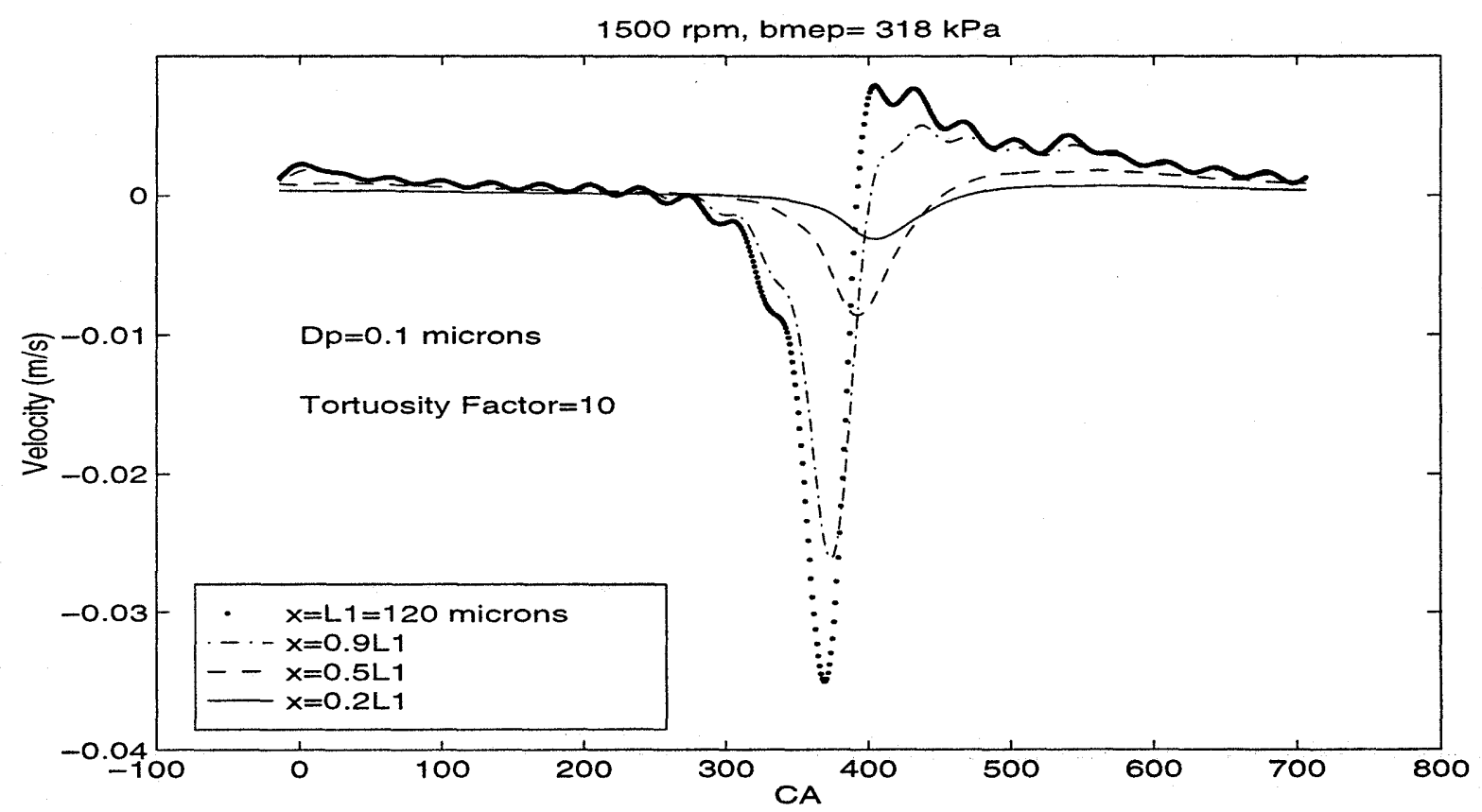

Figure 4.17 Velocity at different locations in the cylinder head deposit pores vs. CA at 1500 $\mathrm{rpm}, \mathrm{bmep}=318 \mathrm{kPa} . \mathrm{D}_{\mathrm{p}}=0.1 \mu \mathrm{m}, \tau=10$. 


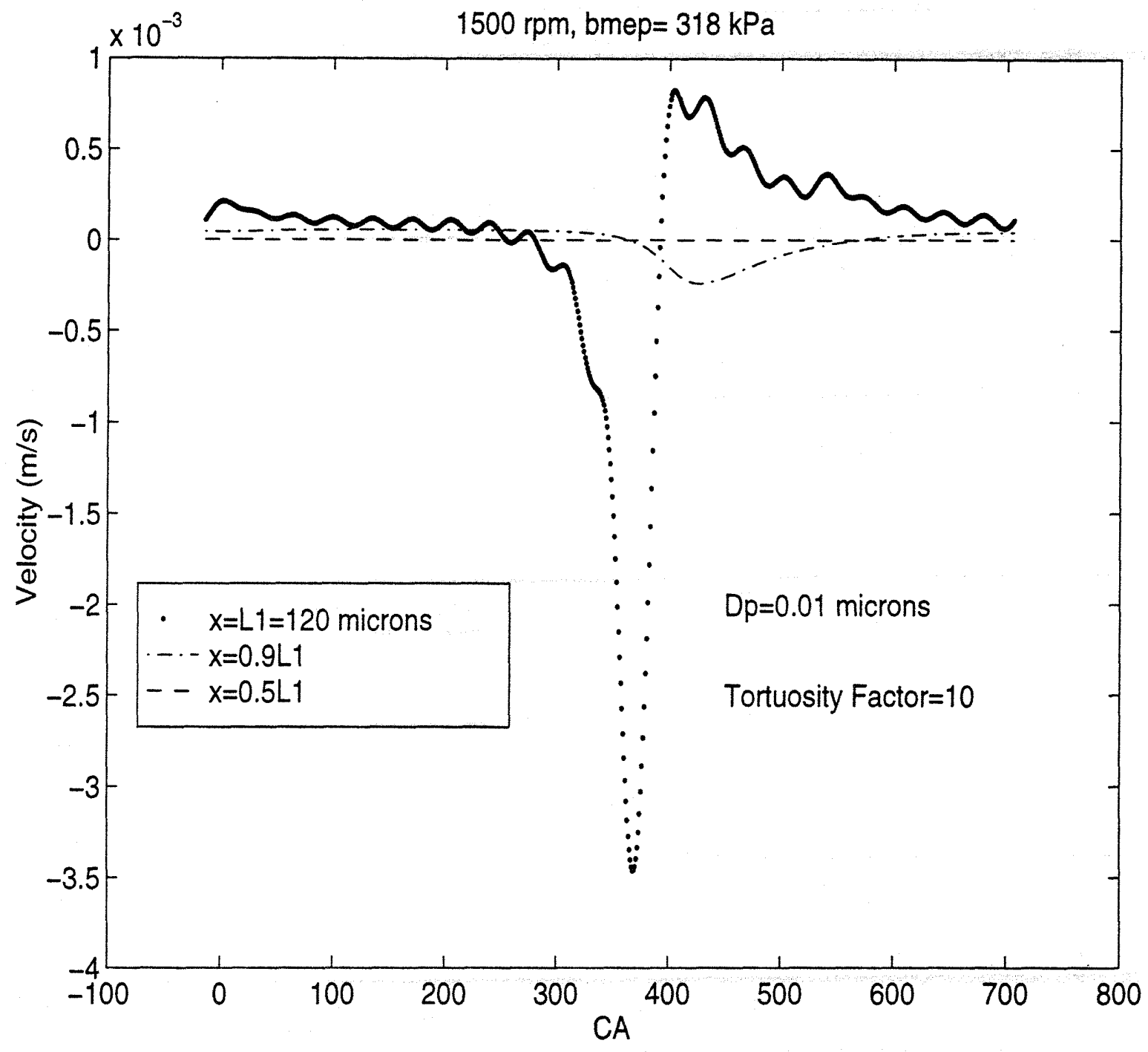

Figure 4.18 Velocity at different locations in the cylinder head deposit pores vs. CA at 1500 rpm, bmep= $318 \mathrm{kPa} . \mathrm{D}_{\mathrm{p}}=0.01 \mu \mathrm{m}, \tau=10$. 

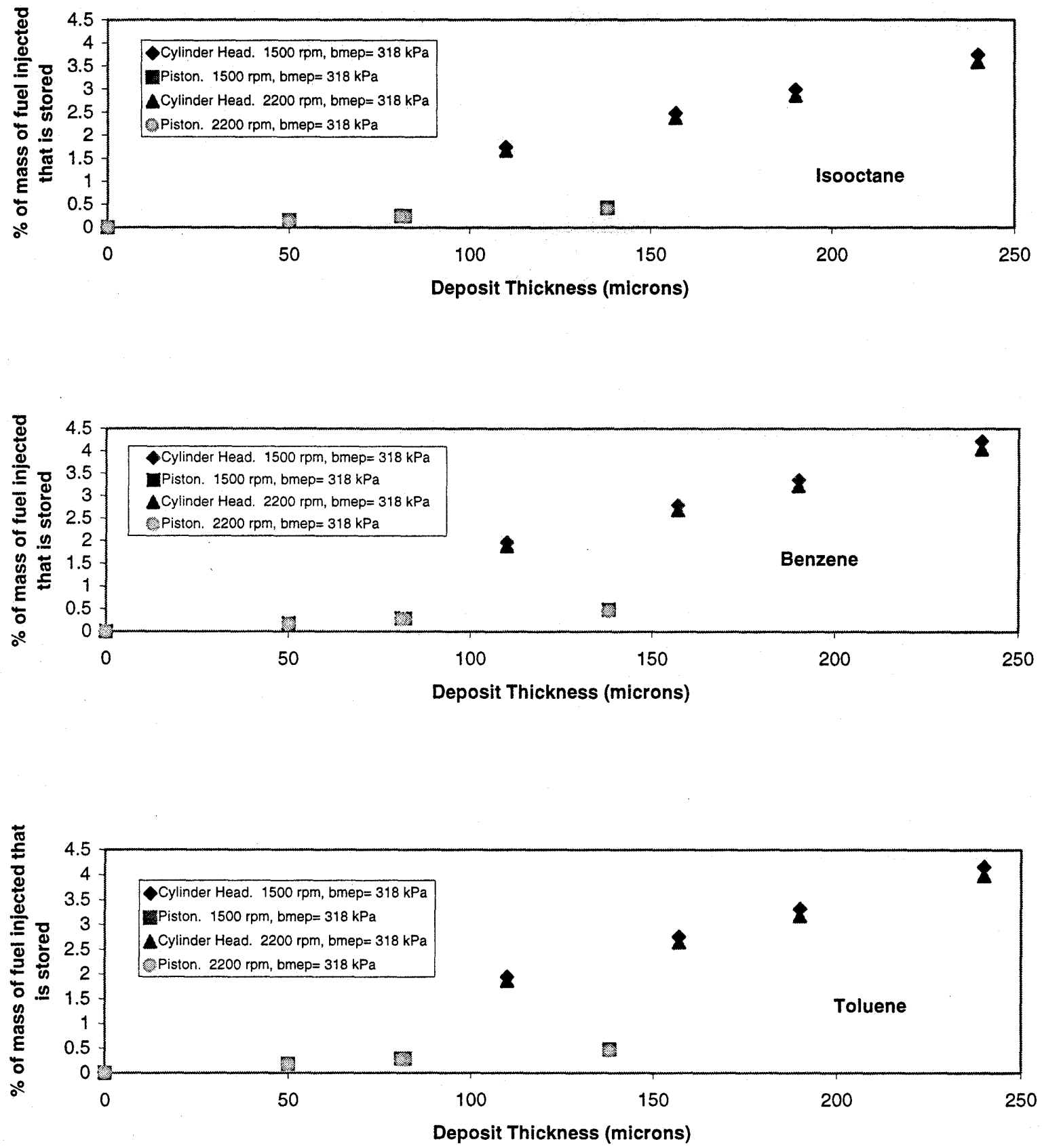

Figure 4.19 Deposit crevice model predictions for isooctane (top), benzene (middle) and toluene (bottom) as \% of mass of fuel injected that is stored in cylinder head and piston top deposit pores vs. deposit thickness at $1500 \mathrm{rpm}, \mathrm{bmep}=318 \mathrm{kPa}$ and $2200 \mathrm{rpm}, \mathrm{bmep}=318 \mathrm{kPa}$. 


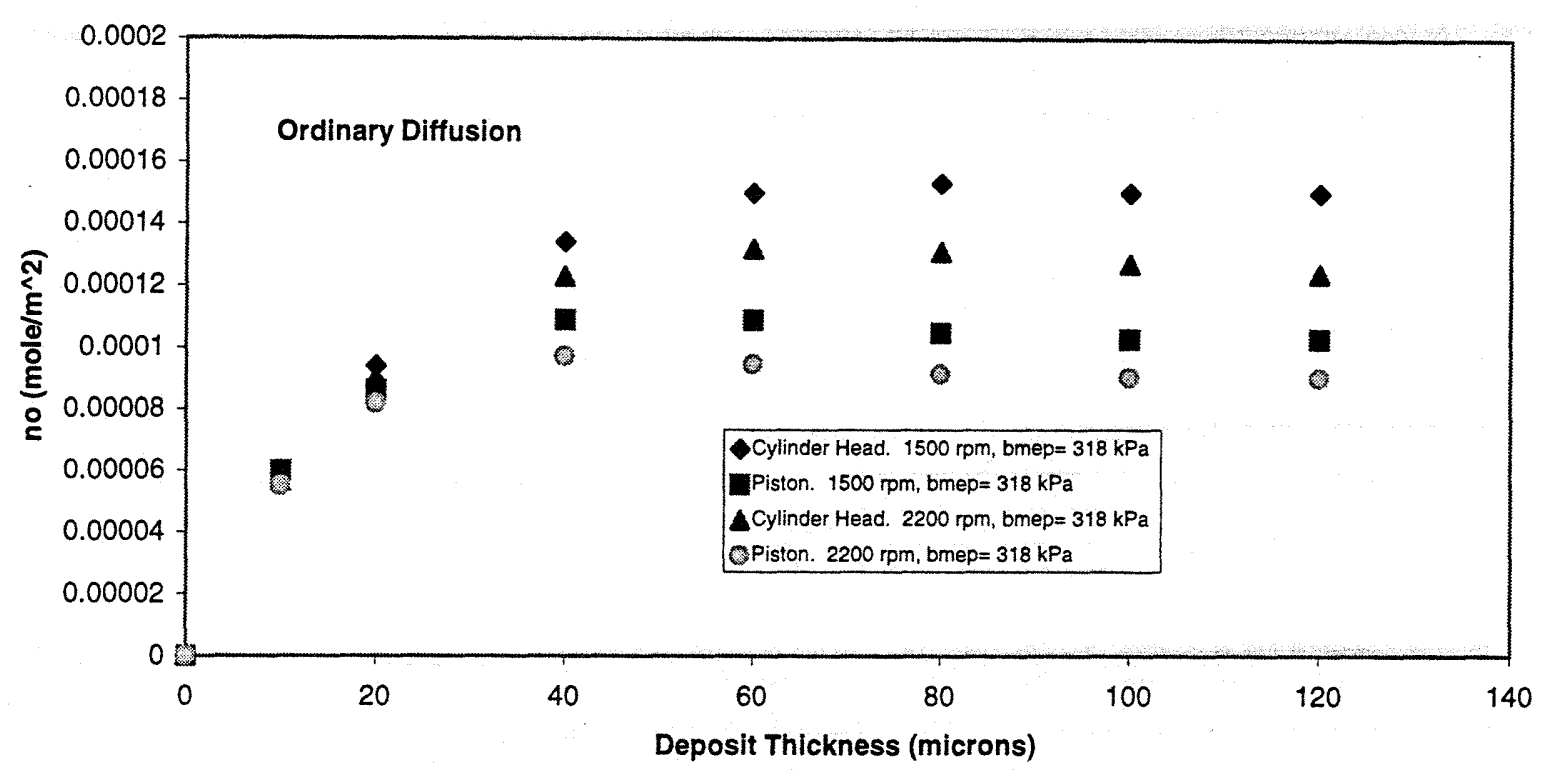

Figure 4.20 Ordinary diffusion model predictions for isooctane as number of moles per unit deposit area that diffuses into the cylinder head and piston top deposit pores vs. deposit thickness at $1500 \mathrm{rpm}$, bmep $=318 \mathrm{kPa}$ and $2200 \mathrm{rpm}, \mathrm{bmep}=318 \mathrm{kPa}$.

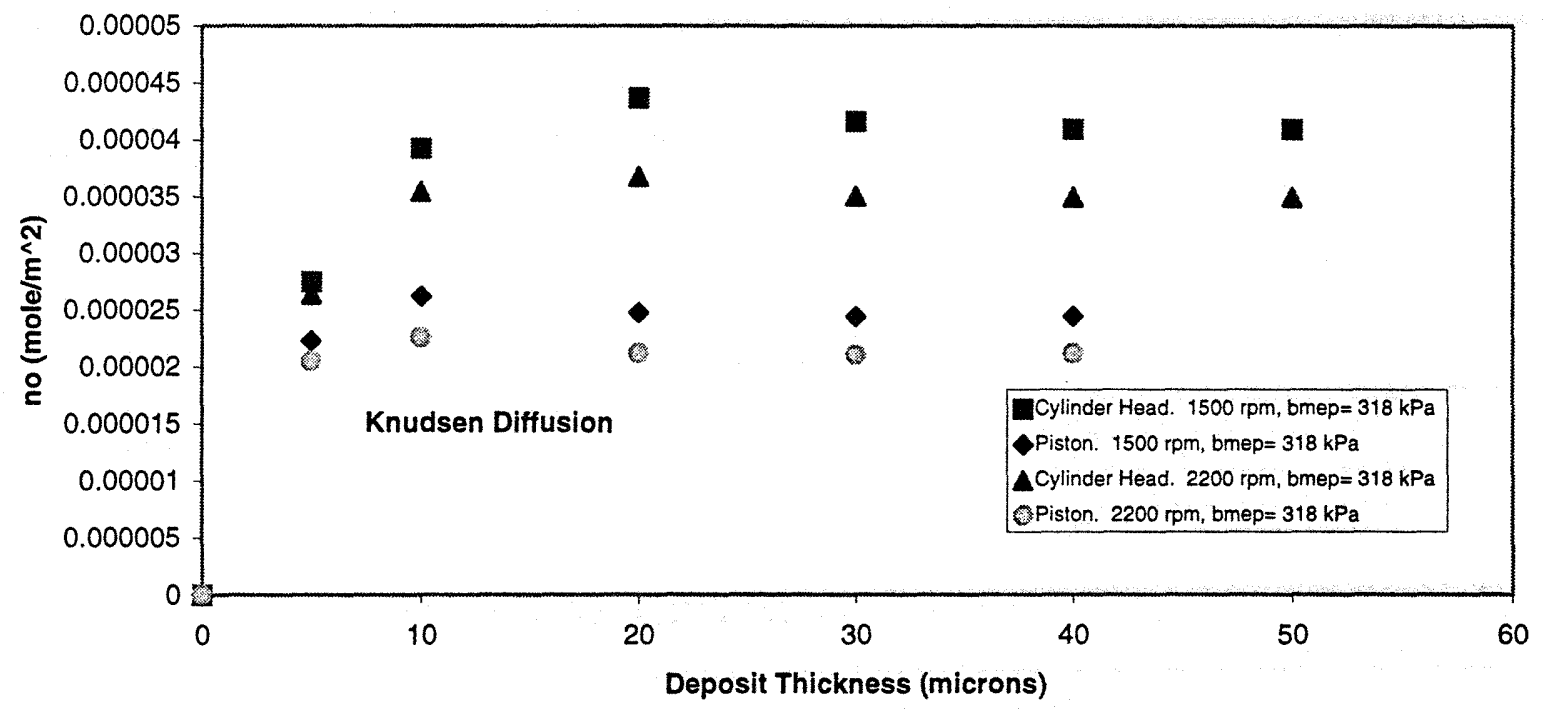

Figure 4.21 Knudsen diffusion model predictions for isooctane as number of moles per unit deposit area that diffuses into the cylinder head and piston top deposit pores vs. deposit thickness at $1500 \mathrm{rpm}, \mathrm{bmep}=318 \mathrm{kPa}$ and $2200 \mathrm{rpm}, \mathrm{bmep}=318 \mathrm{kPa}$. 


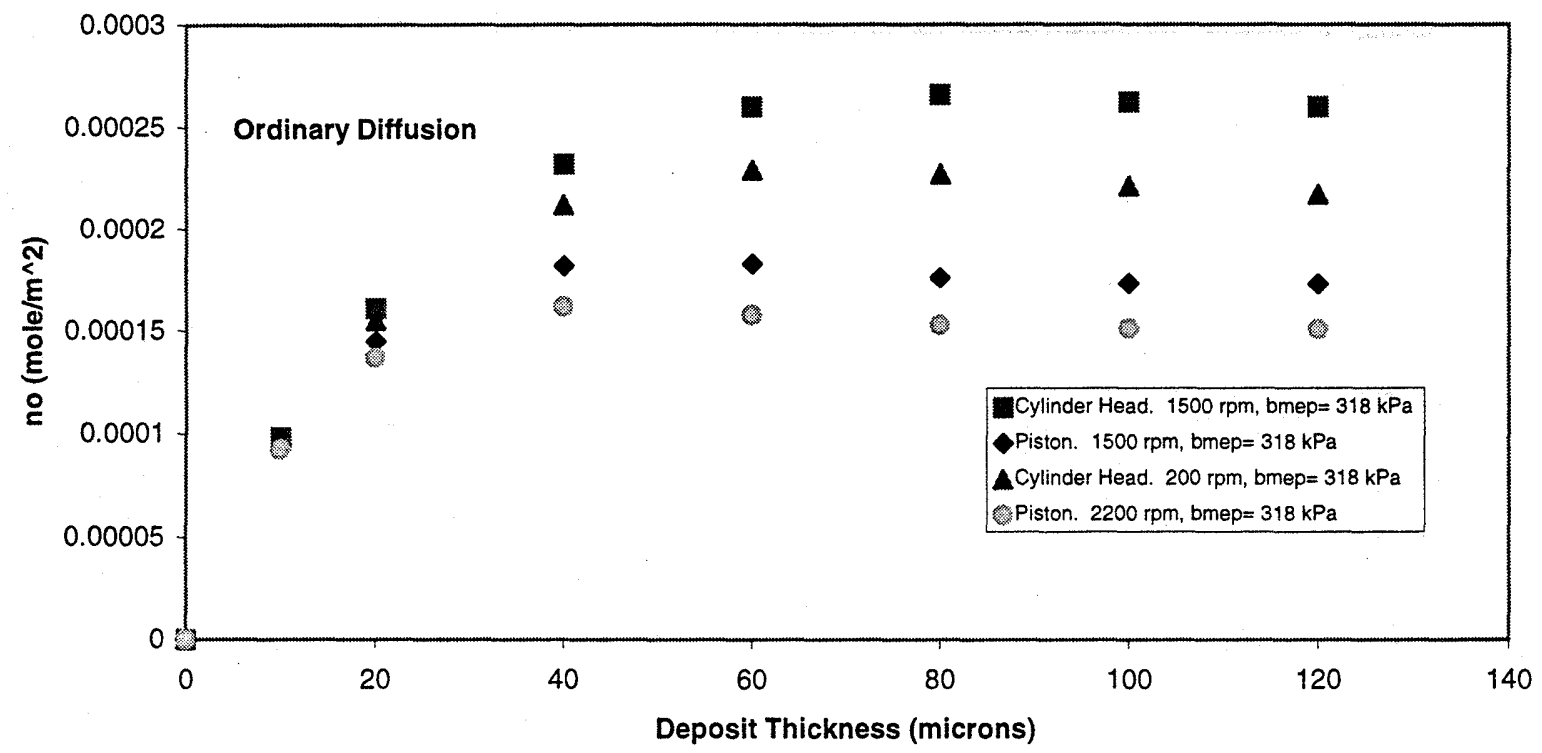

Figure 4.22 Ordinary diffusion model predictions for benzene as number of moles per unit deposit area that diffuses into the cylinder head and piston top deposit pores vs. deposit thickness at $1500 \mathrm{rpm}, \mathrm{bmep}=318 \mathrm{kPa}$ and $2200 \mathrm{rpm}, \mathrm{bmep}=318 \mathrm{kPa}$.

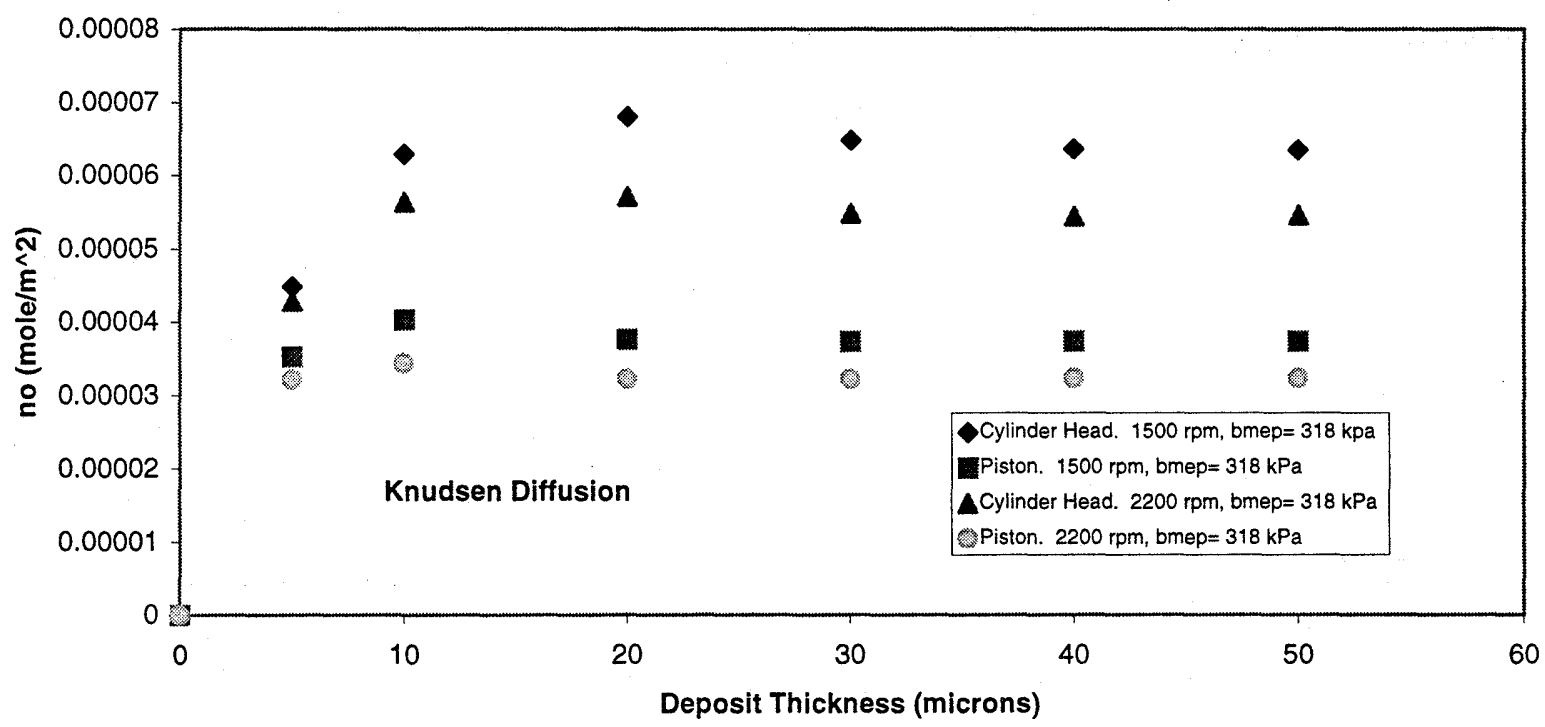

Figure 4.23 Knudsen diffusion model predictions for benzene as number of moles per unit deposit area that diffuses into the cylinder head and piston top deposit pores vs. deposit thickness at $1500 \mathrm{rpm}, \mathrm{bmep}=318 \mathrm{kPa}$ and $2200 \mathrm{rpm}, \mathrm{bmep}=318 \mathrm{kPa}$. 


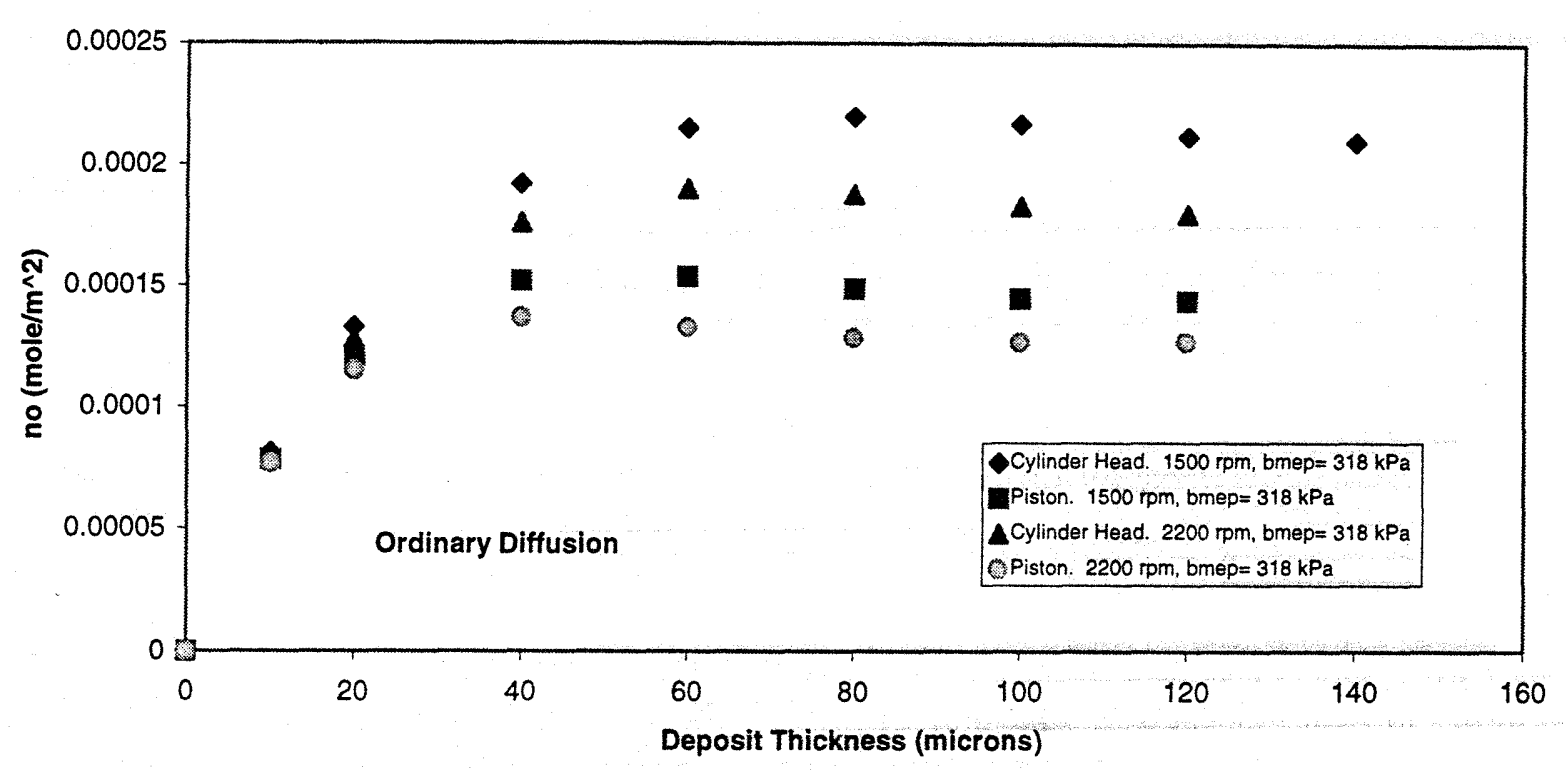

Figure 4.24 Ordinary diffusion model predictions for toluene as number of moles per unit deposit area that diffuses into the cylinder head and piston top deposit pores vs. deposit thickness at 1500 $\mathrm{rpm}, \mathrm{bmep}=318 \mathrm{kPa}$ and $2200 \mathrm{rpm}$, bmep $=318 \mathrm{kPa}$.

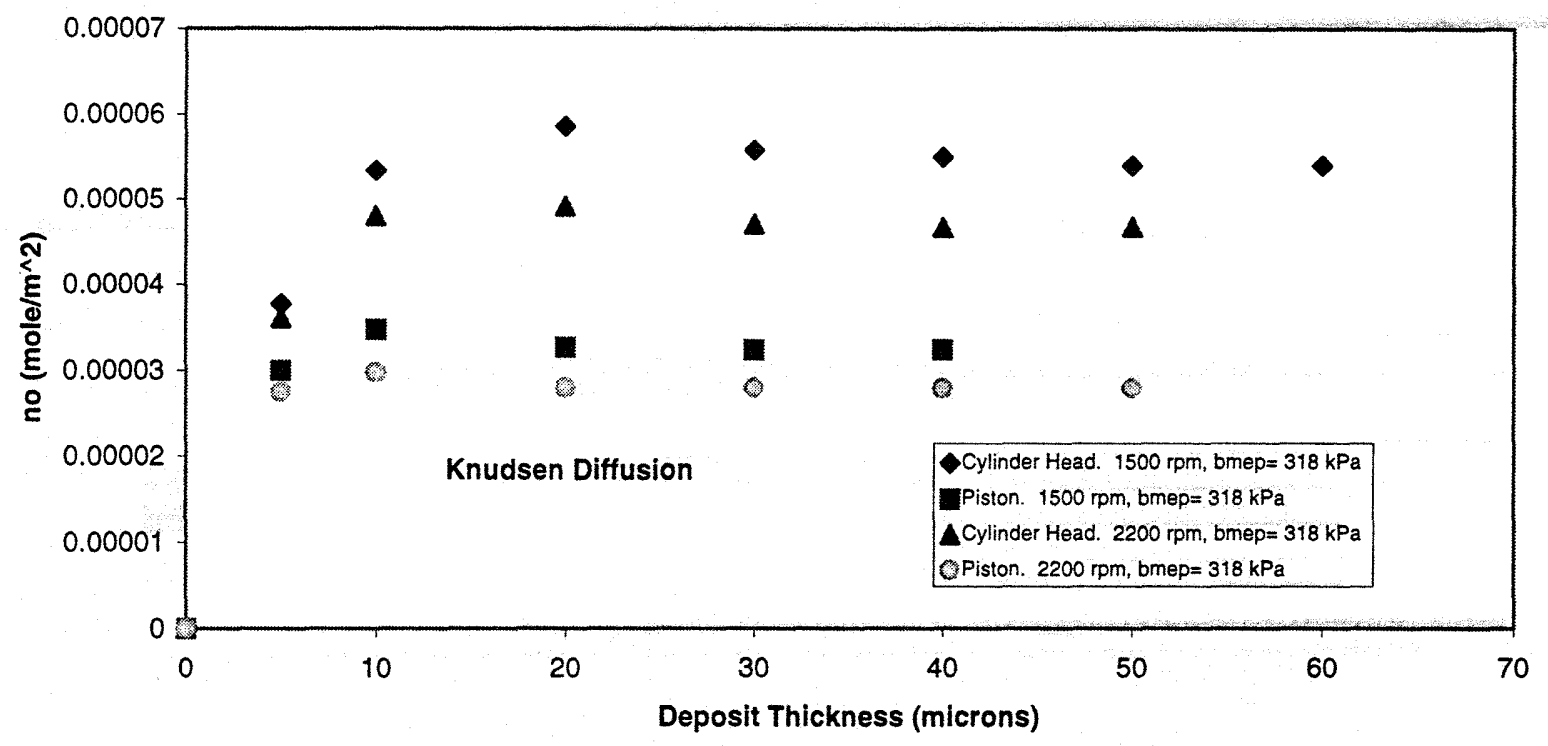

Figure 4.25 Knudsen diffusion model predictions for toluene as number of moles per unit deposit area that diffuses into the cylinder head and piston top deposit pores vs. deposit thickness at 1500 $\mathrm{rpm}, \mathrm{bmep}=318 \mathrm{kPa}$ and $2200 \mathrm{rpm}, \mathrm{bmep}=318 \mathrm{kPa}$. 


\section{CHAPTER 5: SUMMARY AND CONCLUSIONS}

\section{5-1 Summary}

An experimental facility was set up to study the effects of combustion chamber deposits on the $\mathrm{HC}$ emissions from a modern spark engine. An additized fuel designed to enhance the build-up of combustion chamber deposits was used to accumulate the combustion chamber deposits and for $\mathrm{HC}$ emission measurements. The additive package in the fuel kept the intake valves clean to isolate the effect of CCDs only on the HC emissions. The engine was subjected to a standardized two-operating condition cycle for deposit build-up. Before the start of deposit accumulation, the engine was disassembled, all the deposits were removed and reassembled. The clean-engine $\mathrm{HC}$ emissions were then established. The engine was operated for 10 hour daily and turned off overnight. The duration of the deposit accumulation tests varied from 110 hours to 25 hours. During deposit accumulation, the HC emission was continuously measured at the deposit build-up cycle operating conditions using an FID $\mathrm{HC}$ analyzer connected to a data acquisition system. In addition, the $\mathrm{HC}$ emission was measured at two more operating conditions every two hours. Four single-component fuels (isooctane, benzene, toluene, and xylene) were also twice used to measure the $\mathrm{HC}$ emission with the deposited and the clean engine. At the conclusion of the deposit accumulation test, the engine was disassembled, the cylinder head and piston top deposits removed. Then, the engine was reassembled and the $\mathrm{HC}$ emission measured to establish that it returned to the clean-engine levels. During the deposit build-up test, the deposit thickness at the center of the pistons was measured with an eddy-current probe inserted in the spark plug hole. In addition, deposit thickness profiles were also measured on the piston top and cylinder head after engine disassembly. The deposits from each piston and cylinder head were then separately collected and weighed.

After it was established experimentally that combustion chamber deposits caused a significant increase from the engine, a physically-based model was developed to determine why CCDs lead to an increase in HC emissions and quantify that increase. The model treated the deposits as a porous medium in which the fuel molecules get stored during the compression and combustion processes and get released during the expansion and exhaust processes. The model identified four separate mechanisms by which the fuel molecules get transported into the deposit pores: The deposit crevice mechanism, the Darcy flow mechanism, the ordinary diffusion mechanism with adsorption, and finally the Knudsen diffusion mechanism with adsorption. Mercury porosimetry measurements were used to obtain the deposit pore size distribution. This pore size distribution was then used to quantify the contribution of each mechanism to the deposit-related $\mathrm{HC}$ emission problem. In addition, surface area and adsorption isotherm measurements on CCDs were used in the ordinary and Knudsen diffusion models.

\section{5-2 Conclusions}

The contributions of this research project can be summarized in the following points: 
1. A procedure for building up consistent levels of combustion chamber deposits was developed and demonstrated. This was a useful development because unlike intake valve deposits, there are no standardized testing procedures for accumulating combustion chamber deposits.

2. The data base on the effect of the CCDs on HC emissions was enhanced by this work. Very little work (compared to work on the effect of crevices, oil layers and other $\mathrm{HC}$ emission sources) has been done on the role of CCDs as a possible HC emission source from sparkignition sources.

3. CCD's contribution to the total $\mathrm{HC}$ emission from the engine ranged from 10 to $20 \%$ for the deposit build-up fuel and 10 to $30 \%$ for the single-component fuels. This contribution establishes CCDs as a significant $\mathrm{HC}$ emission source from spark-ignition engines. Between 0.2 and $0.5 \%$ of the mass of injected fuel per cycle is emitted due to CCDs.

4. The $\mathrm{HC}$ emission showed a rapid increase in the first 15 hours of deposit accumulation and stabilization after about 25 hours, a short time in the overall life of an engine. The HC stabilization occurs at a deposit thickness of about $100 \mu \mathrm{m}$ on the cylinder head and $50 \mu \mathrm{m}$ on the piston top. The deposit thickness continued to increase long after the $\mathrm{HC}$ emissions had stabilized. This is an important finding in that it tells us that unless the additive packages that are being developed to reduce CCDs essentially eliminate them, they will offer only limited benefit in reducing the deposit-related $\mathrm{HC}$ emissions.

5. There were no significant differences in the effect of CCDs on the mass-based $\mathrm{HC}$ emission from the different single-component fuels. Although the total $\mathrm{HC}$ emission from all four fuels were different, which is expected, the additional mass of the fuel that is emitted due to CCDs was not significantly different among all four fuels.

6. Due to the large scatter in the $\mathrm{NO}_{\mathrm{x}}$ emission data, no conclusion could be reached on the effect of CCDs on the $\mathrm{NO}_{x}$ emissions.

7. The deposit surface area and pore size distribution were quantified using BET surface area and mercury porosimetry measurements as well as inspection using an optical microscope.

8. A physically-based model was developed to explain and quantify the contribution of the CCDs to the HC emissions. Using the Darcy flow model, the pore size spectrum was divided into regions where each mechanism dominates the transport of fuel into and out of the deposit pores. The deposit crevice mechanism (filling of deposit pores with fuel-air mixture at uniform pressure) occurred in pore sizes in the range of 100-0.4 $\mu \mathrm{m}$. Darcy flow in which viscous resistance to the flow of fuel-air mixture is significant, controlled the $0.4-0.1 \mu \mathrm{m}$ pore size range. Between 0.1 and $0.01 \mu \mathrm{m}$, ordinary diffusion of fuel molecules into the air and combustion gases trapped in the deposit pores and adsorption of these molecules in the micropores took over. Finally, Knudsen diffusion with adsorption occurred in pore sizes below $0.01 \mu \mathrm{m}$. 
9. The model predicted that the increase in $\mathrm{HC}$ emissions due to deposits was dominated by the fuel-air mixture flow (essentially a uniform pressure filling process) into the larger pores (the deposit crevice effect). This was due to a very large fraction of the deposit pore volume falling in the pore size range where the deposit crevice effect dominates. All the other effects turned out to be small compared to the deposit crevice effect

10. In the absence of surface adsorption, the crevice model predictions are proportional to the pore volume. Since deposit thickness continues to grow well beyond the point where the experiments indicate that $\mathrm{HC}$ emissions stabilize, this suggests that the pores in the lower layers of the deposits are not accessible to the fuel-air mixture, either due to pore closure or due to the adsorption of the fuel compounds entering the pores onto the pore walls.

11. The cylinder head deposit contribution to the deposit-related HC emission increase is much more important than the piston top deposit's. 


\section{REFERENCES}

1. M.O. Harpster Jr. Et al., "An Experimental Study of Fuel Composition and Combustion Chamber Deposit Effects on Emissions from a Spark Ignition Engine", SAE Paper 950740 (1995).

2. W.K. Cheng et al., "An Overview of Hydrocarbon Emissions Mechanisms in Spark Ignition Engines", SAE Paper 932708 (1993).

3. J.B. Heywood, Internal Combustion Engines Fundamentals, McGraw-Hill New York, 1988.

4. K.D., Min, "The Effects of Crevices on the Engine-out Hydrocarbon Emissions in Spark ignition Engines", Ph.D. Thesis, Department of Mechanical Engineering, Massachusetts Institute of Technology, 1994.

5. C.K. Westbrock et al., " A Numerical Study of Laminar Wall Quenching", Combustion and Flame, Vol. 40, pp. 81-99 (1981).

6. P. Bergner et al., "Flame Quenching and Exhaust Hydrocarbons in a Combustion Bomb as a Function of Pressure, Temperature and Equivalence Ratio for Methanol and other Alcohols", paper presented at the Third Alcohols Symposium, May 1979.

7. A.A. Adamczyk et al., "An Experimental Study of Hydrocarbon Emissions from Closed Vessel Explosions", Eighteenth Symposium (International) on Combustion, The Combustion Institute (1981).

8. B. Gatellier et al., "Hydrocarbon Emissions of SI Engines as influenced by Fuel Absorption-Desportion in Oil Films", SAE Paper 920095 (1992).

9. S. Ishizawa et al., "A Study of HC Emissions from a Spark Ignition Engine (The Effect of Fuel Absorbed into Cylinder Lubricating Oil Film)", JSME International Journal, Vol. 30, no. 260, 1987.

10. E.W. Kaiser et al., "Fuel Composition Effects on Hydrocarbon Emissions from a Spark-ignited Engine- Is Fuel Absorption in Oil Significant", SAE Paper 952542 (1995).

11. H.E. Leikanen et al., "The Effect of Leaded and Unleaded Gasolines on Exhaust Emissions as Influenced by Combustion Chamber Deposits", SAE Paper 710843 (1971).

12. T.H. Valtadoros et al., "Fuel Additive Effects on Deposit Build-up and Engine Operating Characteristics", Symposium on Fuel Composition/Deposit Tendencies, American Chemical Society Preprints, Vol. 36, no. 1, April 1991.

13. S.L. Bower et al., "The Effect of Fuel Composition and Engine Deposits on Emissions from a Spark Ignition Engine", SAE Paper 932707 (1993).

14. R.W. Wagner, "The Effects of Fuel Composition and Deposit Control Additives on Combustion Chamber Deposits", Proceedings of the CRC Workshop on Combustion Chamber Deposits, November 1993.

15. D.J. Reily et al., "Saturn DOHC and SOHC Four Cylinder Engines", SAE Paper 910676 (1991).

16. P.J. Choate et al., "Relationship between Combustion Chamber Deposits, Fuel Composition, and Combustion Chamber Deposit Structure", SAE Paper 932812 (1993). 
17. R.J. Price et al., "A Laboratory Simulation and Mechanism for the Fuel Dependence of SI Combustion Chamber Deposit Formation", SAE Paper 952445 (1995).

18. S.S. Cheng et al., "Effect of Engine Operating Parameters on Engine Combustion Chamber Deposits", SAE Paper 902108 (1990).

19. M.G. Norris et al., "Extent of Oxidation of Hydrocarbons Desorbing from the Lubricant Oil Layer in Spark-Ignition Engines", SAE Paper 960069 (1996).

20. R.L. Bond, Porous Carbon Solids, Academic Press New York, 1967.

21. J.W. Patrick, Porosity in Carbons: Characterization and Applications, Edward Arnold London, 1995.

22. R.C. Bansal et al., Active Carbon, Marcel Dekker New York, 1988.

23. B.S. Wood, "Gasification of Porous Combustion Chamber Deposits in a Spark Ignition Engine", SAE Paper 930773 (1993).

24. D.N. Assanis, "A Computer Simulation of the Turbocharged Turbocompounded Diesel Engine System For Studies of Low Heat Rejection Engine Performance", Ph.D. Thesis, Department of Ocean Engineering, Massachusetts Institute of Technology, 1985.

25. S.G. Poulos, "The Effect of Combustion Chamber Geometry on S.I. Engine Combustion Rates- a Modeling Study", S.M. Thesis, Mechanical Engineering Department, Massachusetts Institute of Technology, 1982.

26. T.K. Hayes et al., "The In-Situ Measurement of the Thermal Diffusivity of Combustion Chamber Deposits in Spark Ignition Engines", SAE Paper 920513 (1992).

27. F.P. Incropera et al., Fundamentals of Heat and Mass transfer, John Wiley \& Sons New York, 1985.

28. W.J. Annand, "Heat Transfer in the Cylinders of Reciprocating Internal Combustion Engines", Proc. Instn Mech. Engrs, vol. 177 no. 36, pp. 973-990, 1963.

29. I.C. Finalya et al., "Factors Influencing Combustion Chamber Wall Temperatures in a Liquid-cooled, Automotive, Spark-ignition Engine", Proc. Instn Mech. Engrs, vol. 199 no. D3, pp. 207-217, 1985.

30. R.A. Greenkorn, Flow Phenomena in Porous Media, Marcel Dekker New York, 1983.

31. C.N. Satterfield, Mass Transfer in Heterogeneous Catalysis, M.I.T. Press Cambridge, 1970.

32. M.M. Dubinin, "The Potential Theory of Adsorption of Gases and Vapors for Adsorbents with Energetically Nonuniform Surfaces", Chemical Reviews, Vol. 60, 1960.

33. T. Nakahara et al., "Adsorption of Hydrocarbons on Carbon Moelcular Sieve", Journal of Chemical and Engineering Data, Vol. 19., No. 4, 1974.

34. J.T. Wentworth, "More on Origins of Exhaust Hydrocarbons- Effects of Zero Oil Consumption, Deposit Location, and Surface Roughness", SAE Paper 720939 (1972).

35. W.K. Cheng et al., "An Overview of Hydrocarbon Emissions Mechanisms in SparkIgnition Engines", SAE Paper 932708 (1993). 


\section{APPENDIX A \\ Experimental Results}

$1500 \mathrm{rpm}, \mathrm{bmep}=262 \mathrm{kPa}$

\begin{tabular}{|l|l|l|l|l|l|}
\hline Fuel & $\begin{array}{l}{[\mathrm{HC}]_{\text {deposit }}} \\
(\mathrm{ppm} \mathrm{C1})\end{array}$ & $\begin{array}{l}{[\mathrm{HC}]_{\text {clean }}} \\
(\mathrm{ppm} \mathrm{C1})\end{array}$ & $\begin{array}{l}\Delta[\mathrm{HC}] \\
(\mathrm{ppm} \mathrm{C} 1)\end{array}$ & $\begin{array}{l}\Delta[\mathrm{HC}] /[\mathrm{HC}]_{\text {deposit }} \\
\%\end{array}$ & $\begin{array}{l}\% \text { of mass } \\
\text { of fuel } \\
\text { injected }\end{array}$ \\
\hline Isooctane & 2830 & 2223 & 607 & 21.4 & 0.48 \\
\hline Benzene & 2497 & 2033 & 464 & 18.6 & 0.3 \\
\hline Xylene & 3391 & 3398 & -7 & -0.2 & N/A \\
\hline
\end{tabular}

Table A1 Summary of effect of CCD on HC emission from single-component fuels. Data from 50-hour test

$1500 \mathrm{rpm}$, bmep $=318 \mathrm{kPa}$

\begin{tabular}{|l|l|l|l|l|l|}
\hline Fuel & $\begin{array}{l}{[\mathrm{HC}]_{\text {deposit }}} \\
(\mathrm{ppm} \mathrm{C1})\end{array}$ & $\begin{array}{l}{[\mathrm{HC}]_{\text {clean }}} \\
(\mathrm{ppm} \mathrm{Cl})\end{array}$ & $\begin{array}{l}\Delta[\mathrm{HC}] \\
(\mathrm{ppm} \mathrm{C} 1)\end{array}$ & $\begin{array}{l}\Delta[\mathrm{HC}] /[\mathrm{HC}]_{\text {deposit }} \\
\%\end{array}$ & $\begin{array}{l}\text { \% of mass } \\
\text { of fuel } \\
\text { injected }\end{array}$ \\
\hline Isooctane & 2710 & 2115 & 595 & 21.9 & 0.47 \\
\hline Benzene & 2738 & 1894 & 844 & 30.8 & 0.54 \\
\hline Xylene & 3350 & 3204 & 146 & 4.3 & 0.1 \\
\hline
\end{tabular}

Table A2 Summary of effect of CCD on HC emission from single-component fuels. Data from 50 -hour test 
$2200 \mathrm{rpm}, \mathrm{bmep}=318 \mathrm{kPa}$

\begin{tabular}{|l|l|l|l|l|l|}
\hline Fuel & $\begin{array}{l}{[\mathrm{HC}]_{\text {deposit }}} \\
(\mathrm{ppm} \mathrm{C1})\end{array}$ & $\begin{array}{l}{[\mathrm{HC}]_{\text {clean }}} \\
(\mathrm{ppm} \mathrm{C1})\end{array}$ & $\begin{array}{l}\Delta[\mathrm{HC}] \\
(\mathrm{ppm} \mathrm{C} 1)\end{array}$ & $\begin{array}{l}\Delta[\mathrm{HC}] /[\mathrm{HC}]_{\text {deposit }} \\
\%\end{array}$ & $\begin{array}{l}\% \text { of mass } \\
\text { of fuel } \\
\text { injected }\end{array}$ \\
\hline Isooctane & 2318 & 1952 & 366 & 15.8 & 0.29 \\
\hline Benzene & 2382 & 1786 & 596 & 25 & 0.38 \\
\hline Xylene & 2865 & 2959 & -94 & -3.3 & N/A \\
\hline
\end{tabular}

Table A3 Summary of effect of CCD on HC emission from single-component fuels. Data from 50-hour test 


\section{APPENIDX B \\ Experimental Results}

$1400 \mathrm{rpm}$, bmep= $106 \mathrm{kPa}$. EGR ON

\begin{tabular}{|l|l|l|l|l|l|}
\hline Fuel & $\begin{array}{l}{[\mathrm{HC}]_{\text {deposit }}} \\
(\mathrm{ppm} \mathrm{C} 1)\end{array}$ & $\begin{array}{l}{[\mathrm{HC}]_{\text {clean }}} \\
(\mathrm{ppm} \mathrm{Cl})\end{array}$ & $\begin{array}{l}\Delta[\mathrm{HC}] \\
(\mathrm{ppm} \mathrm{C} 1)\end{array}$ & $\begin{array}{l}\Delta[\mathrm{HC}] /[\mathrm{HC}]_{\text {deposit }} \\
\%\end{array}$ & $\begin{array}{l}\% \text { of mass } \\
\text { of fuel } \\
\text { injected }\end{array}$ \\
\hline Isooctane & 2654 & 2369 & 285 & 10.7 & 0.23 \\
\hline Benzene & 2365 & 1892 & 473 & 20 & 0.3 \\
\hline Toluene & 3268 & 2662 & 606 & 18.5 & 0.4 \\
\hline Xylene & 4072 & 3672 & 400 & 9.8 & 0.27 \\
\hline
\end{tabular}

Table B1 Summary of effect of CCD on HC emission from single-component fuels. Data from 35-hour test. EGR ON

$1500 \mathrm{rpm}$, bmep $=262 \mathrm{kPa}$. EGR ON

\begin{tabular}{|l|l|l|l|l|l|}
\hline Fuel & $\begin{array}{l}{[\mathrm{HC}]_{\text {deposit }}} \\
(\mathrm{ppm} \mathrm{C1})\end{array}$ & $\begin{array}{l}{[\mathrm{HC}]_{\text {clean }}} \\
(\mathrm{ppm} \mathrm{C} 1)\end{array}$ & $\begin{array}{l}\Delta[\mathrm{HC}] \\
(\mathrm{ppm} \mathrm{C} 1)\end{array}$ & $\begin{array}{l}\Delta[\mathrm{HC}] /[\mathrm{HC}]_{\text {deposit }} \\
\%\end{array}$ & $\begin{array}{l}\% \text { of mass } \\
\text { of fuel } \\
\text { injected }\end{array}$ \\
\hline Isooctane & 2753 & 2383 & 370 & 13.4 & 0.29 \\
\hline Benzene & 2423 & 2091 & 332 & 13.7 & 0.21 \\
\hline Toluene & 3314 & 2630 & 684 & 20.6 & 0.45 \\
\hline Xylene & 3932 & 3523 & 409 & 10.4 & 0.27 \\
\hline
\end{tabular}

Table B2 Summary of effect of CCD on HC emission from single-component fuels. Data from 35-hour test. EGR ON 
$1500 \mathrm{rpm}$, bmep $=318 \mathrm{kPa}$. EGR ON

\begin{tabular}{|l|l|l|l|l|l|}
\hline Fuel & $\begin{array}{l}{[\mathrm{HC}]_{\text {deposit }}} \\
(\mathrm{ppm} \mathrm{C1})\end{array}$ & $\begin{array}{l}{[\mathrm{HC}]_{\text {clean }}} \\
(\mathrm{ppm} \mathrm{C1})\end{array}$ & $\begin{array}{l}\Delta[\mathrm{HC}] \\
(\mathrm{ppm} \mathrm{C} 1)\end{array}$ & $\begin{array}{l}\Delta[\mathrm{HC}] /[\mathrm{HC}]_{\text {deposit }} \\
\%\end{array}$ & $\begin{array}{l}\text { \% of mass } \\
\text { of fuel } \\
\text { injected }\end{array}$ \\
\hline Isooctane & 2698 & 2296 & 402 & 14.9 & 0.32 \\
\hline Benzene & 2515 & 2021 & 494 & 19.6 & 0.32 \\
\hline Toluene & 3343 & 2622 & 721 & 21.6 & 0.47 \\
\hline Xylene & 3869 & 3384 & 485 & 12.5 & 0.32 \\
\hline
\end{tabular}

Table B3 Summary of effect of CCD on HC emission from single-component fuels. Data from 35-hour test. EGR ON

$2200 \mathrm{rpm}$, bmep= $318 \mathrm{kPa}$. EGR ON

\begin{tabular}{|l|l|l|l|l|l|}
\hline Fuel & $\begin{array}{l}{[\mathrm{HC}]_{\text {deposit }}} \\
(\mathrm{ppm} \mathrm{C1})\end{array}$ & $\begin{array}{l}{[\mathrm{HC}]_{\text {clean }}} \\
(\mathrm{ppm} \mathrm{C1})\end{array}$ & $\begin{array}{l}\Delta[\mathrm{HC}] \\
(\mathrm{ppm} \mathrm{C} 1)\end{array}$ & $\begin{array}{l}\Delta[\mathrm{HC}] /[\mathrm{HC}]_{\text {deposit }} \\
\%\end{array}$ & $\begin{array}{l}\% \text { of mass } \\
\text { of fuel } \\
\text { injected }\end{array}$ \\
\hline Isooctane & 3145 & 2667 & 478 & 15.2 & 0.38 \\
\hline Benzene & 2461 & 1877 & 584 & 23.7 & 0.37 \\
\hline Toluene & 3201 & 2677 & 524 & 16.4 & 0.34 \\
\hline Xylene & 3769 & 3385 & 384 & 10.2 & 0.26 \\
\hline
\end{tabular}

Table B4 Summary of effect of CCD on HC emission from single-component fuels. Data from 35-hour test. EGR ON 
$1400 \mathrm{rpm}$, bmep= $106 \mathrm{kPa}$. EGR OFF

\begin{tabular}{|l|l|l|l|l|l|}
\hline Fuel & $\begin{array}{l}{[\mathrm{HC}]_{\text {deposit }}} \\
(\mathrm{ppm} \mathrm{C1})\end{array}$ & $\begin{array}{l}{[\mathrm{HC}]_{\text {clean }}} \\
(\mathrm{ppm} \mathrm{C} 1)\end{array}$ & $\begin{array}{l}\Delta[\mathrm{HC}] \\
(\mathrm{ppm} \mathrm{C} 1)\end{array}$ & $\begin{array}{l}\Delta[\mathrm{HC}] /[\mathrm{HC}]_{\text {deposit }} \\
\%\end{array}$ & $\begin{array}{l}\% \text { of mass } \\
\text { of fuel } \\
\text { injected }\end{array}$ \\
\hline Isooctane & 2629 & 2398 & 231 & 8.8 & 0.18 \\
\hline Benzene & 2409 & 1874 & 535 & 22.2 & 0.34 \\
\hline Toluene & 3222 & 2690 & 532 & 16.5 & 0.35 \\
\hline Xylene & 3857 & 3619 & 238 & 6.2 & 0.16 \\
\hline
\end{tabular}

Table B5 Summary of effect of CCD on HC emission from single-component fuels. Data from 35-hour test. EGR OFF

$1500 \mathrm{rpm}$, bmep= $262 \mathrm{kPa}$. EGR OFF

\begin{tabular}{|l|l|l|l|l|l|}
\hline Fuel & $\begin{array}{l}{[\mathrm{HC}]_{\text {deposit }}} \\
(\mathrm{ppm} \mathrm{C1})\end{array}$ & $\begin{array}{l}{[\mathrm{HC}]_{\text {clean }}} \\
(\mathrm{ppm} \mathrm{C} 1)\end{array}$ & $\begin{array}{l}\Delta[\mathrm{HC}] \\
(\mathrm{ppm} \mathrm{C} 1)\end{array}$ & $\begin{array}{l}\Delta[\mathrm{HC}] /[\mathrm{HC}]_{\text {deposit }} \\
\%\end{array}$ & $\begin{array}{l}\% \text { of mass } \\
\text { of fuel } \\
\text { injected }\end{array}$ \\
\hline Isooctane & 2705 & 2165 & 540 & 20 & 0.43 \\
\hline Benzene & 2603 & 1898 & 705 & 27.1 & 0.45 \\
\hline Toluene & 3373 & 2594 & 779 & 23.1 & 0.51 \\
\hline Xylene & 3772 & 3201 & 571 & 15.1 & 0.38 \\
\hline
\end{tabular}

Table B6 Summary of effect of CCD on HC emission from single-component fuels. Data from 35-hour test. EGR OFF 
$1500 \mathrm{rpm}$, bmep= $318 \mathrm{kPa}$. EGR OFF

\begin{tabular}{|l|l|l|l|l|l|}
\hline Fuel & $\begin{array}{l}{[\mathrm{HC}]_{\text {deposit }}} \\
(\mathrm{ppm} \mathrm{C1})\end{array}$ & $\begin{array}{l}{[\mathrm{HC}]_{\text {clean }}} \\
(\mathrm{ppm} \mathrm{C1})\end{array}$ & $\begin{array}{l}\Delta[\mathrm{HC}] \\
(\mathrm{ppm} \mathrm{C} 1)\end{array}$ & $\begin{array}{l}\Delta[\mathrm{HC}] /[\mathrm{HC}]_{\text {deposit }} \\
\%\end{array}$ & $\begin{array}{l}\% \text { of mass } \\
\text { of fuel } \\
\text { injected }\end{array}$ \\
\hline Isooctane & 2606 & 1975 & 631 & 24.2 & 0.5 \\
\hline Benzene & 2535 & 1791 & 744 & 29.3 & 0.48 \\
\hline Toluene & 3246 & 2534 & 712 & 21.9 & 0.47 \\
\hline Xylene & 3830 & 3136 & 694 & 18.1 & 0.47 \\
\hline
\end{tabular}

Table B7 Summary of effect of CCD on HC emission from single-component fuels. Data from 35-hour test. EGR OFF

$2200 \mathrm{rpm}$, bmep= $318 \mathrm{kPa}$. EGR OFF

\begin{tabular}{|l|l|l|l|l|l|}
\hline Fuel & $\begin{array}{l}{[\mathrm{HC}]_{\text {deposit }}} \\
(\mathrm{ppm} \mathrm{C1})\end{array}$ & $\begin{array}{l}{[\mathrm{HC}]_{\text {clean }}} \\
(\mathrm{ppm} \mathrm{C1})\end{array}$ & $\begin{array}{l}\Delta[\mathrm{HC}] \\
(\mathrm{ppm} \mathrm{C} 1)\end{array}$ & $\begin{array}{l}\Delta[\mathrm{HC}] /[\mathrm{HC}]_{\text {deposit }} \\
\%\end{array}$ & $\begin{array}{l}\% \text { of mass } \\
\text { of fuel } \\
\text { injected }\end{array}$ \\
\hline Isooctane & 2387 & 1842 & 545 & 22.8 & 0.43 \\
\hline Benzene & 2302 & 1696 & 606 & 26.3 & 0.39 \\
\hline Toluene & 2901 & 2199 & 702 & 24.2 & 0.46 \\
\hline Xylene & 3046 & 2594 & 452 & 14.8 & 0.3 \\
\hline
\end{tabular}

Table B8 Summary of effect of CCD on HC emission from single-component fuels. Data from 35-hour test. EGR OFF 


\section{APPENDIX C \\ DARCY FLOW MODEL MATLAB PROGRAM}

clear all

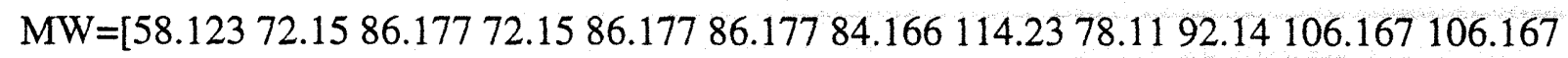

106.167 94];

$Y f=\left[\begin{array}{lllll}.033 & .0254 .0215 .0254 .0215 .0215 .0226 .0164 .0270 & .0226 .0194 .0194 .0194 .021]\end{array}\right.$

$\mathrm{Lc}=90 \mathrm{e}-3 ; \mathrm{Bc}=82 \mathrm{e}-3$;

$\mathrm{Ap}=(\mathrm{pi} / 4) * \mathrm{Bc}^{\wedge} 2$;

$\% \mathrm{Lc}$ and $\mathrm{Bc}$ are the stroke and bore of the engine;

Minj=[8.56 12.42 13.86 16.57 18.9 20.76 13.87 21.62 18.88]*1e-3;

$\% \mathrm{OC}=1==1400 \mathrm{rpm}, \mathrm{bmep}=106 \mathrm{kPa}$

$\% \mathrm{OC}=2==1500 \mathrm{rpm}, \mathrm{bmep}=262 \mathrm{kPa}$

$\%$ OC $=3==>1500 \mathrm{rpm}$, bmep $=318 \mathrm{kPa}$

$\% \mathrm{OC}=4==>1600 \mathrm{rpm}, \mathrm{bmep}=411 \mathrm{kPa}$

$\%$ OC $=5==>1800 \mathrm{rpm}, \mathrm{bmep}=511 \mathrm{kPa}$

$\%$ OC $=6=2000 \mathrm{rpm}, \mathrm{bmep}=625 \mathrm{kPa}$

$\%$ OC $=7==2200 \mathrm{rpm}, \mathrm{bmep}=318 \mathrm{kPa}$

$\%$ OC $=8==>1500 \mathrm{rpm}, \mathrm{bmep}=625 \mathrm{kPa}$

$\%$ OC $=9=\Rightarrow 1600 \mathrm{rpm}$, bmep $=511 \mathrm{kPa}$

$\% \mathrm{OC}$ stands for operating condition.

$\%$ fuel=1 n-butane;

$\%$ fuel=2 n-pentane;

$\%$ fuel $=3$ n-hexane;

$\%$ fuel=4 2-methyl-butane;

$\%$ fuel $=5$ 2-methyl-pentane;

\%fuel=6 3-methylpentane;

$\%$ fuel $=7$ methylcyclopentane;

$\%$ fuel $=8$ isooctane;

$\%$ fuel $=9$ benzene;

$\%$ fuel=10 toluene;

$\%$ fuel=11 O-xylene;

$\%$ fuel=12 m-xylene; 
$\%$ fuel=13 p-xylene;

$\%$ fuel=14 deposit build-up fuel;

Tcrit=[425.18 469.81 507.68 460.43 497.5 504.65 532.79543.96 562.16594.02 630.33617.046 $616.23500]$;

$\%$ Tcrit $(\mathrm{K})$ is the list of critical temperatures of all the fuels. The deposit fuel critical temperature

$\%$ was averaged over the whole fuel, more or less.

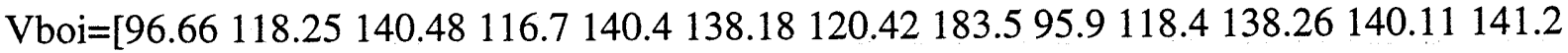
125.8];

$\%$ Vboi is the molar concentration of the saturated liquid $\left(\mathrm{cm}^{\wedge} 3 / \mathrm{mole}\right)$ of all the fuels at the normal boiling temperature.

$\% \% \% \% \% \% \% \% \% \% \% \%$

$\mathrm{OC}=3$

fuel=8;

Tmax $=10$;

$P \max =20$

$\% \% \% \% \% \% \% \% \% \% \% \%$

$\mathrm{Xf}=\mathrm{Yf}(\mathrm{fuel}) ; \% \mathrm{Xf}$ is the fuel molar fraction in the stoichiometric fuel-air mixture;

$\mathrm{Mf}=\mathrm{MW}$ (fuel); $\% \mathrm{Mf}$ is the molecular weight of the fuel

Tcr=Tcrit(fuel); \% Critical tmeperature of the fuel

$\mathrm{Vb}=\mathrm{Vboi}($ fuel);

$\operatorname{minj}=\operatorname{Minj}(\mathrm{OC}) ; \%$ the amount of fuel injected per cylinder per cycle at the specified operating condition;

if $\mathrm{OC}==1$

load d:Lhaissamlsimulp1.txt;

dum=p1;

$\mathrm{N}=1400$;

elseif $\mathrm{OC}==2$

load d:Lhaissamlsimulp2.txt;

dum=p2;

$\mathrm{N}=1500$;

elseif $\mathrm{OC}==3$

load d:Lhaissamlsimulp3.txt;

dum=p3;

$\mathrm{N}=1500$;

elseif $\mathrm{OC}==4$ 


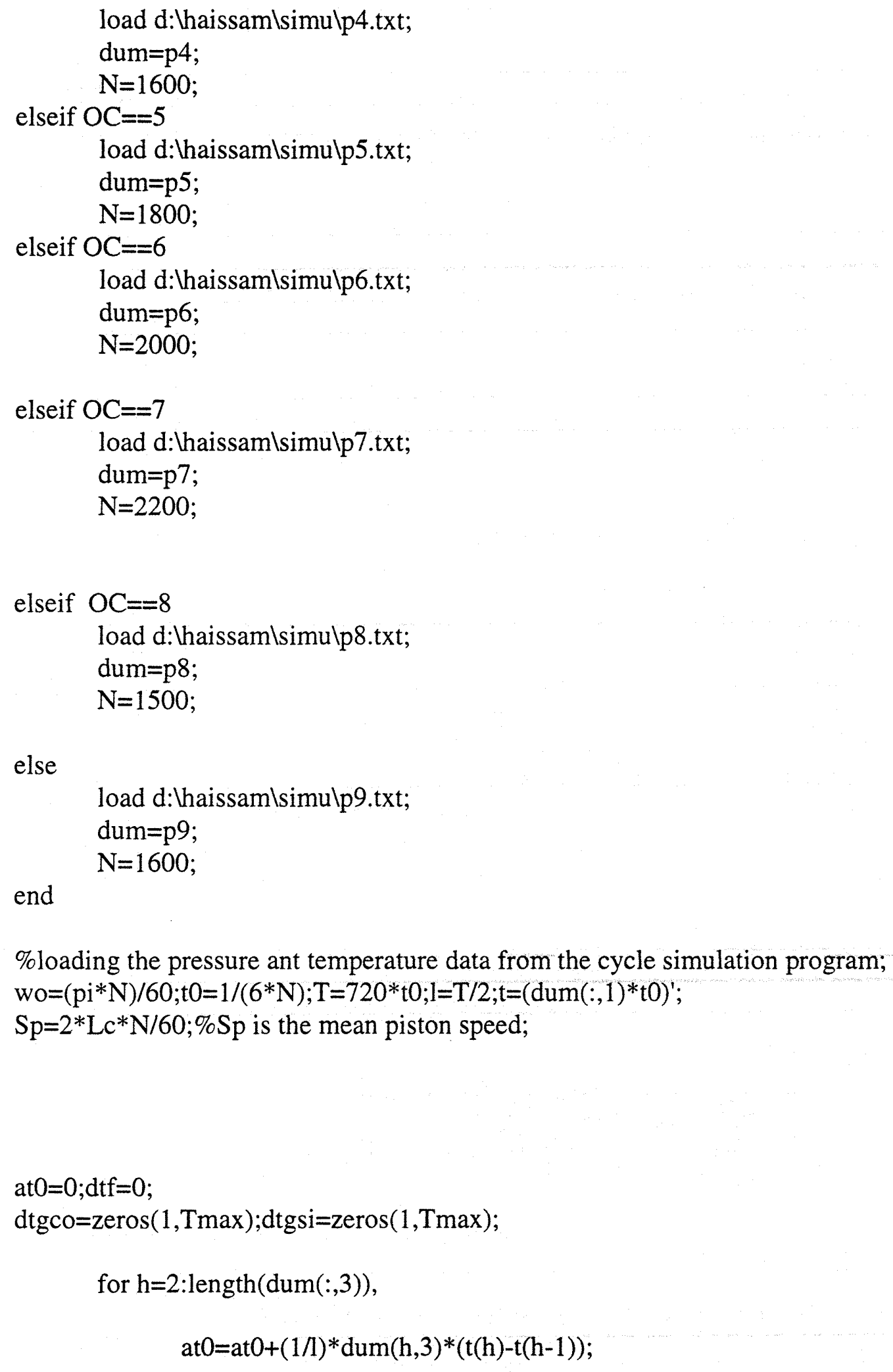

else

load d: \haissamlsimulp9.txt; dum=p9;

end

\%loading the pressure ant temperature data from the cycle simulation program; wo $=\left(\mathrm{pi}^{*} \mathrm{~N}\right) / 60 ; \mathrm{t0}=1 /(6 * \mathrm{~N}) ; \mathrm{T}=720 * \mathrm{t} 0 ; 1=\mathrm{T} / 2 ; \mathrm{t}=(\operatorname{dum}(:, 1) * \mathrm{t} 0)^{\prime}$; $\mathrm{Sp}=2 * \mathrm{Lc} * \mathrm{~N} / 60 ; \% \mathrm{Sp}$ is the mean piston speed;

at $0=0 ; \mathrm{dtf}=0$;

dtgco=zeros $(1$, Tmax $) ; \operatorname{dtgsi}=$ zeros $(1$, Tmax $)$;

for $h=2:$ length $(\operatorname{dum}(:, 3))$, at0 $=\mathrm{at} 0+(1 / 1) * \operatorname{dum}(\mathrm{h}, 3) *(\mathrm{t}(\mathrm{h})-\mathrm{t}(\mathrm{h}-1))$ 


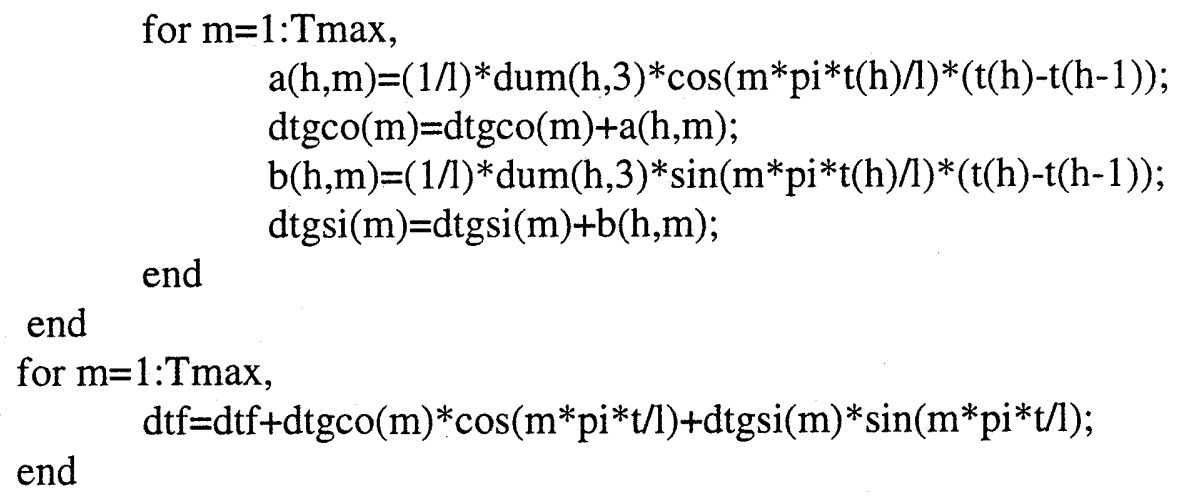


\% The above routine caluclates the Fourier series representation of the cylinder pressure;

$\% \mathrm{k} 1, \mathrm{a} 1,11$ are the thermal conductivity, diffusivity and thickness of deposits.

$\% \mathrm{k} 2, \mathrm{a} 2,12$ are the thermal conductivity, diffusivity and thickness of aluminum.

\%\%\%\%\%\%\%\%\%\%\%\%\%\%\%\%\%\%\%\%\%\%\%\%\%\%\%\%\%\%\%

$\mathrm{k} 1=0.5 ; \mathrm{a} 1=2 \mathrm{e}-7 ; 11=120 \mathrm{e}-6$;

$\mathrm{k} 2=180 ; \mathrm{a} 2=1 \mathrm{e}-4 ; 12=0.5 \mathrm{e}-2$;

$\% \% \% \% \% \% \% \% \% \% \% \% \% \% \% \% \% \% \% \% \% \% \% \% \% \% \% \% \% \% \%$

$\% \% \% \% \% \% \% \% \% \% \% \% \% \%$

$\mathrm{xt}=-0.5 * 11$;

$\mathrm{xp}=0.2 * 11$;

$\% \% \% \% \% \% \% \% \% \% \% \% \% \% \%$

$\% \mathrm{xp}=0$ corresponds to the deposit-aluminum interface

$\% \mathrm{xp}=11$ corresponds to the deposit-combustion chamber interface

\%the origin of the $\mathrm{x}$-axis in the temperature calculations, is taken at the interface between the \%the deposits and the aluminum. $\mathrm{X}=-11$ corresponds to the deposit-combustion chamber interface.

$\% \mathrm{x}=12$ corresponds to the aluminum-coolant interface.

$\% \% \% \% \% \% \% \% \% \% \% \% \% \%$

$\mathrm{hc}=2200 ; \mathrm{tc}=363$;

$\% \% \% \% \% \% \% \% \% \% \% \% \% \%$

$\%$ hc and tc are the heat transfer coefficient and temperature of the coolant.

$\%$ hc $=2200\left(\mathrm{~W} / \mathrm{m}^{\wedge} 2 . \mathrm{K}\right)$ for cylinder head and $\mathrm{hc}=900\left(\mathrm{~W} / \mathrm{m}^{\wedge} 2 . \mathrm{K}\right)$ for piston top;

\%calculation of the gas-side heat transfer coefficient, hg using Annand's correlation (Heywood $\mathrm{p}$. $678)$;

$\mathrm{ka}=0.038$

Roa $=0.589 ;$ nua $=29.74 \mathrm{e}-6$;

$\% \mathrm{ka}$, Roa, and nua are the thermal conductivity, density, and viscosity of air at $500 \mathrm{~K}$;

$\mathrm{hg}=(0.6 * \mathrm{ka} / \mathrm{Bc}) *\left(\mathrm{Roa}^{*} \mathrm{Sp} * \mathrm{Bc} / \mathrm{nua}\right)^{\wedge} 0.7$

$\operatorname{tgs}=\operatorname{at} 0 / 2$ 
$\%$ tgs is the steady-state component of the gas temperature;

$\mathrm{q}=($ tgs-tc $) /((1 / \mathrm{hg})+(11 / \mathrm{k} 1)+(12 / \mathrm{k} 2)+(1 / \mathrm{hc}))$;

$\mathrm{t} 1 \mathrm{~s}=\operatorname{tgs}-(\mathrm{q} / \mathrm{hg})$;

$\mathrm{t} 2 \mathrm{~s}=\mathrm{t} 1 \mathrm{~s}-\left(\mathrm{q}^{*} 11 / \mathrm{k} 1\right)$

$\mathrm{t} 3 \mathrm{~s}=\mathrm{t} 2 \mathrm{~s}-(\mathrm{q} * 12 / \mathrm{k} 2)$;

$\mathrm{t} 1 \mathrm{sx}=\mathrm{t} 1 \mathrm{~s}-\left(\mathrm{q}^{*}(11+\mathrm{xt}) / \mathrm{k} 1\right)$;

for $\mathrm{k}=1: \mathrm{Tmax}$

$\mathrm{wt}(\mathrm{k})=\mathrm{k}^{*} \mathrm{wo}$;

end

dte $1=0$;

dte $2=0$;

for $n=1: T \max$,

$\mathrm{d} 1(\mathrm{n})=\operatorname{sqrt}\left(\mathrm{i}^{*} \mathrm{wt}(\mathrm{n}) / \mathrm{a} 1\right)$

$\mathrm{d} 2(\mathrm{n})=\operatorname{sqrt}(\mathrm{i} * \mathrm{wt}(\mathrm{n}) / \mathrm{a} 2)$;

$\mathrm{g} 1(\mathrm{n})=\operatorname{sqrt}(\mathrm{wt}(\mathrm{n}) /(2 * \mathrm{a} 1))$;

$\mathrm{g} 2(\mathrm{n})=\operatorname{sqrt}(\mathrm{wt}(\mathrm{n}) /(2 * a 2))$;

$\mathrm{s} 1(\mathrm{n})=(\mathrm{k} 1 * \mathrm{~d} 1(\mathrm{n})-\mathrm{hg}) * \exp (-2 * 11 * \mathrm{~d} 1(\mathrm{n})) /(\mathrm{k} 1 * \mathrm{~d} 1(\mathrm{n})+\mathrm{hg})$;

$\mathrm{s} 2(\mathrm{n})=(\mathrm{hg} * \exp (-11 * \mathrm{~d} 1(\mathrm{n}))) /(\mathrm{k} 1 * \mathrm{~d} 1(\mathrm{n})+\mathrm{hg})$;

$\mathrm{s} 3(\mathrm{n})=(\mathrm{k} 2 * \mathrm{~d} 2(\mathrm{n})+\mathrm{hc}) * \exp (2 * 12 * \mathrm{~d} 2(\mathrm{n})) /(\mathrm{k} 2 * \mathrm{~d} 2(\mathrm{n})-\mathrm{hc})$;

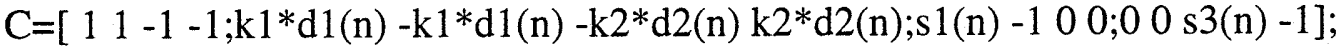

$\mathrm{D}=[0 ; 0 ;-\mathrm{s} 2(\mathrm{n}) ; 0]$;

$\mathrm{Y}(:, \mathrm{n})=\operatorname{inv}(\mathrm{C}) * \mathrm{D}$;

theta $1(n)=Y(1, n) * \exp \left(x t^{*} d 1(n)\right)+Y(2, n) * \exp \left(-x t^{*} d 1(n)\right)$;

theta2 $(n)=Y(3, n) * \exp (x t * d 1(n))+Y(4, n) * \exp \left(-x t^{*} d 1(n)\right)$;

$\operatorname{dt} 1 \mathrm{c}(\mathrm{n},:)=\operatorname{theta1}(\mathrm{n}) * \exp (\mathrm{i} * \mathrm{wt}(\mathrm{n}) * \mathrm{t})$;

$\% \operatorname{dt} 2 \mathrm{c}(\mathrm{n}, \mathrm{:})=\operatorname{theta} 2(\mathrm{n}) * \exp \left(\mathrm{i}^{*} \mathrm{wt}(\mathrm{n}) * \mathrm{t}\right)$;

$\operatorname{dT} 1(\mathrm{n},:)=\operatorname{dtg} \operatorname{co}(\mathrm{n}) * \operatorname{real}(\mathrm{dt} 1 \mathrm{c}(\mathrm{n},:))+\operatorname{dtg} \operatorname{si}(\mathrm{n}) * \operatorname{imag}(\mathrm{dt} 1 \mathrm{c}(\mathrm{n},:))$;

$\% \operatorname{dT2}(\mathrm{n},:)=\operatorname{dtg} c(\mathrm{n}) * \operatorname{real}(\operatorname{dt} 2 \mathrm{c}(\mathrm{n},:))+\operatorname{dtg} \operatorname{si}(\mathrm{n}) * \operatorname{imag}(\mathrm{dt} 2 \mathrm{c}(\mathrm{n},:))$;

dte $1=$ dte $1+\mathrm{dT} 1(\mathrm{n},:)$;

$\%$ dte2=dte2+dT2(n,:);

end

te $1=d t e 1+t 1 s x$

\% The above routine calculates the temperature te 1 at any deposit location as a function of time; tsum $=0$;

for $j=1$ :length(te 1 , tsum=tsum+te1(j);

end

Tav=tsum/length(te 1$)$

\% Tav is the average deposit temperature over the whole engine cycle at the specified location; end 
Mair=29e-3;

$\%$ Molecular weight of air in $\mathrm{Kg} / \mathrm{mole}$;

$\mathrm{Ru}=8.314$

$\%$ Universal gas constant in $\mathrm{J} /($ mole. $\mathrm{K}$ )

Rair=Ru/Mair;

Vis_air $=250.7 \mathrm{e}-7$;

$\%$ dynamic viscosity of air at $450 \mathrm{~K}$.

$\% \% \% \% \% \% \% \% \% \% \% \% \% \% \% \% \% \% \% \%$

$\mathrm{tm}=10$

$\mathrm{Vf}=0.46$;

$\mathrm{VCR}=0.92$;

$\mathrm{Cl}=1 / \mathrm{pav}$

$\mathrm{DP}=1 \mathrm{e}-6$

$\% \mathrm{DP}$ is the pore diameter in $\mathrm{m}$;

$\mathrm{Kperm}=(\mathrm{Vf} / \mathrm{tm}) *\left(\mathrm{DP}^{\wedge} 2 / 32\right)$;

\%\%\%\%\%\%\%\%\%\%\%\%\%\%\%\%\%\%\%\%\%

$\%$ Kperm is the permeability of the deposits

$\%$ tm = tortuosity factor;

$\% \mathrm{Vf}=$ Void fraction;

$\mathrm{Cop}=\mathrm{Kperm} /\left(\mathrm{Vf} * \mathrm{Cl} * \mathrm{Vis} \_\right.$air $)$;

for $n=1: P \max$,

$\mathrm{wc}(\mathrm{n})=\mathrm{n} * \mathrm{wo}$;

end

$\mathrm{dpo}=0 ; \mathrm{Vo}=0$

for $\mathrm{k}=1: \mathrm{Pmax}$,

$\operatorname{Dpp}(\mathrm{k})=\operatorname{sqrt}\left(\mathrm{i}^{*} \mathrm{wc}(\mathrm{k}) / \mathrm{Cop}\right)$;

$\operatorname{App}(k)=1 /(\exp (-D p p(k) * 11)+\exp (D p p(k) * 11))$;

thetap $(\mathrm{k})=\operatorname{App}(\mathrm{k}) *\left(\exp \left(\mathrm{xp}^{*} \mathrm{Dpp}(\mathrm{k})\right)+\exp (-\mathrm{xp} * \mathrm{Dpp}(\mathrm{k}))\right)$;

$\mathrm{dpp}(\mathrm{k}, \mathrm{:})=\operatorname{thetap}(\mathrm{k}) * \exp (\mathrm{i} * \mathrm{wc}(\mathrm{k}) * \mathrm{t})$;

$\mathrm{dPP}(\mathrm{k},:)=\mathrm{dpco}(\mathrm{k}) * \operatorname{real}(\mathrm{dpp}(\mathrm{k},:))+\mathrm{dpsi}(\mathrm{k}) * \operatorname{imag}(\mathrm{dpp}(\mathrm{k},:))$;

$\mathrm{dVp}(\mathrm{k},:)=-\left(\mathrm{Kperm} / \mathrm{Vis} \_\mathrm{air}\right) * \mathrm{Dpp}(\mathrm{k}) * A \mathrm{pp}(\mathrm{k}) *\left(\exp \left(\mathrm{xp}^{*} \mathrm{Dpp}(\mathrm{k})\right)-\exp (-\right.$

$\mathrm{xp} * \mathrm{Dpp}(\mathrm{k}))) * \exp \left(\mathrm{i}^{*} \mathrm{wc}(\mathrm{k}) * \mathrm{t}\right)$; 
$\mathrm{Vp}(\mathrm{k},:)=\mathrm{dpco}(\mathrm{k}) * \mathrm{real}(\mathrm{dVp}(\mathrm{k},:))+\mathrm{dpsi}(\mathrm{k}) * \operatorname{imag}(\mathrm{dVp}(\mathrm{k},:))$;

dpo $=$ dpo+dPP(k,:);

$\mathrm{Vo}=\mathrm{Vo}+\mathrm{Vp}(\mathrm{k},:)$;

end

$\mathrm{PP}=\mathrm{dpo}+\mathrm{ap} 0 / 2$;

$\%$ The above routine calculates the pressure and velocity at any deposit location as a function of time:

\%It is the implemenatation of the Darcy flow model discussed in the thesis;

$\mathrm{AF}=(\mathrm{Mair} * 1000 / \mathrm{Mf}) *(1-\mathrm{Xf}) / \mathrm{Xf}$

\% Mair is in $\mathrm{Kg} / \mathrm{mole}$ while $\mathrm{Mf}$ is in $\mathrm{g} /$ mole. We multiply Mair by 1000 ;

V_dep=11*Ap;

$\mathrm{mcr}=\mathrm{Xf} * \mathrm{P} \_$cyl $(384) * \mathrm{~V} \_d e p * \mathrm{Vf} * \mathrm{VCR} * \mathrm{Mf} /(\mathrm{Ru} * \mathrm{Tav})$;

fcr $=$ mcr* $100 /$ minj;

$\mathrm{CA}=-14+\operatorname{dum}(:, 1)$;

end 


\section{APPENDIX D \\ DIFFUSION MODELS MATLAB PROGRAM}

clear all

$\%$ See Appendix C for definitions of some of the variables

MW=[58.123 72.15 86.177 72.15 86.177 86.177 84.166 114.23 78.11 92.14 106.167 106.167

106.167 94];

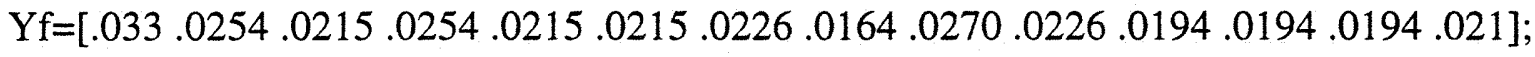

$\mathrm{Lc}=90 \mathrm{e}-3 ; \mathrm{Bc}=82 \mathrm{e}-3$;

$\mathrm{Ap}=(\mathrm{pi} / 4) * \mathrm{Bc}^{\wedge} 2$;

$\% \mathrm{Lc}$ and $\mathrm{Bc}$ are the stroke and bore of the engine;

Minj=[8.56 12.42 13.86 16.57 18.920 .7613 .8721 .6218 .88$]^{*} 1 \mathrm{e}-3$;

$\% \% \% \% \% \%$

$\mathrm{tm}=5$

$\mathrm{Vf}=0.46$

$\% \% \% \% \% \%$

$\%$ tm $=$ tortuosity factor;

$\% \mathrm{Vf}=$ Void fraction;

$\% \mathrm{OC}$ stands for operating condition.

$\%$ OC $=1 \Rightarrow 1400 \mathrm{rpm}, \mathrm{bmep}=106 \mathrm{kPa}$

$\% \mathrm{OC}=2=\Rightarrow 1500 \mathrm{rpm}$, bmep $=262 \mathrm{kPa}$

$\% \mathrm{OC}=3=\Rightarrow 1500 \mathrm{rpm}, \mathrm{bmep}=318 \mathrm{kPa}$

$\% O C=4=\Rightarrow 1600 \mathrm{rpm}$, bmep $=411 \mathrm{kPa}$

$\% \mathrm{OC}=5=\Rightarrow 1800 \mathrm{rpm}$, bmep $=511 \mathrm{kPa}$

$\% \mathrm{OC}=6==>2000 \mathrm{rpm}$, bmep $=625 \mathrm{kPa}$

$\% \mathrm{OC}=7==2200 \mathrm{rpm}, \mathrm{bmep}=318 \mathrm{kPa}$

$\% \mathrm{OC}=8 \Rightarrow 1500 \mathrm{rpm}, \mathrm{bmep}=625 \mathrm{kPa}$

$\% \mathrm{OC}=9=\Rightarrow 1600 \mathrm{rpm}$, bmep $=511 \mathrm{kPa}$

$\%$ fuel=1 n-butane;

$\%$ fuel=2 n-pentane;

$\%$ fuel $=3 \mathrm{n}$-hexane;

$\%$ fuel=4 2-methyl-butane; 
$\%$ fuel=5 2-methyl-pentane;

$\%$ fuel=6 3-methylpentane;

$\%$ fuel=7 methylcyclopentane;

$\%$ fuel $=8$ isooctane;

$\%$ fuel $=9$ benzene;

$\%$ fuel=10 toluene;

$\%$ fuel=11 O-xylene;

$\%$ fuel=12 m-xylene;

$\%$ fuel=13 p-xylene;

$\%$ fuel=14 deposit build-up fuel;

Tcrit=[425.18 469.81 507.68 460.43 497.5 504.65 532.79 543.96 562.16 594.02 630.33 617.046 $616.23500]$;

$\%$ Tcrit $(\mathrm{K})$ is the list of critical temperatures of all the fuels. The deposit fuel critical temperature

$\%$ was averaged over the whole fuel, more or less.

Vboi=[96.66 118.25 140.48116 .7140 .4138 .18120 .42183 .595 .9118 .4138 .26140 .11141 .2 $125.8]$

\% Vboi is the molar concentration of the saturated liquid $\left(\mathrm{cm}^{\wedge} 3 / \mathrm{mole}\right)$ of all the fuels at the normal boiling temperature.

$\% \% \% \% \% \% \% \% \% \% \% \% \% \%$

$\mathrm{OC}=3$;

fuel=8;

Tmax $=10 ; \% \operatorname{Tamx}$ is the number of harmonics in the Fourier series of the temperature; $\mathrm{Cmax}=40 ; \% \mathrm{Cmax}$ is the number of harmonics in the Fourier series of the fuel concentration ; $\% \% \% \% \% \% \% \% \% \% \% \%$

$\mathrm{Xf}=\mathrm{Yf}($ fuel);

$\mathrm{Mf}=\mathrm{MW}$ (fuel);

Tcr=Tcrit(fuel);

$\mathrm{Vb}=$ Vboi(fuel);

$\operatorname{minj}=\operatorname{Minj}(O C)$;

if $\mathrm{OC}==1$

load d:Lhaissamlsimulp1.txt; dum=p1;

$\mathrm{N}=1400$;

elseif $\mathrm{OC}==2$

load d:Lhaissamlsimulp2.txt; 


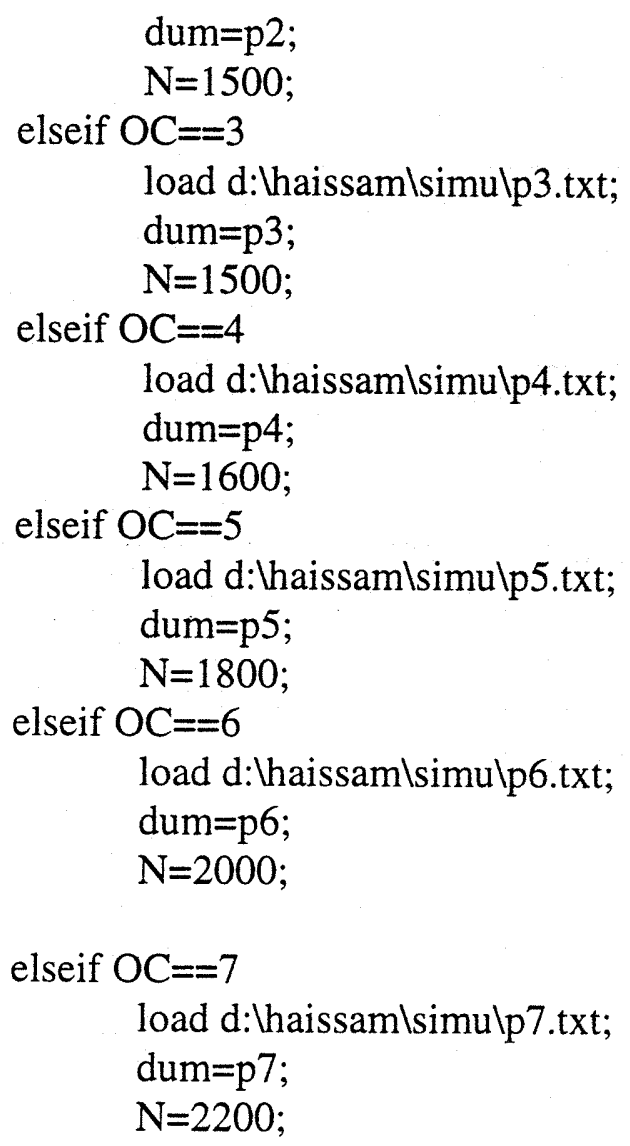

\section{elseif $\mathrm{OC}==8$}

load d:Thaissamlsimulp8.txt;

dum=p8;

$\mathrm{N}=1500$;

else

load d:Lhaissamlsimulp9.txt; dum=p9;$$
\mathrm{N}=1600 \text {; }
$$

end

wo $=\left(\mathrm{pi}^{*} \mathrm{~N}\right) / 60 ; \mathrm{t0}=1 /(6 * \mathrm{~N}) ; \mathrm{T}=720 * \mathrm{t0} ; \mathrm{l}=\mathrm{T} / 2 ; \mathrm{t}=(\mathrm{dum}(:, 1) * \mathrm{t} 0)^{\prime}$;

$\mathrm{Sp}=2 * \mathrm{Lc} * \mathrm{~N} / 60$

\section{$\% \% \% \% \% \% \% \% \% \% \% \% \% \% \% \%$}

$\mathrm{re}=30$;

Ds=1e-9;

$\% \% \% \% \% \% \% \% \% \% \% \% \% \%$

$\%$ re is the pore radius (Angstrom); 
$\% \mathrm{Ds}$ is the surface diffusion coefficient $\left(\mathrm{m}^{\wedge} 2 / \mathrm{s}\right)$

$\% \mathrm{Kh}$ is the adsorption equilibrium constant ( $\mathrm{m}^{\wedge} 3 \mathrm{gas} / \mathrm{m}^{\wedge} 2$ of surface);

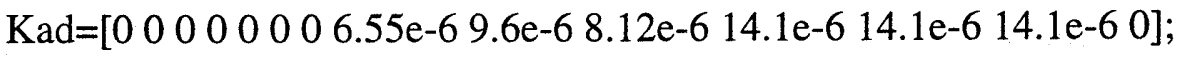

$\mathrm{Kh}=\mathrm{Kad}($ fuel);

$\% \mathrm{Kad}$ is the adsorption equilibrium constant for each fuel on deposits

\%zero was entered where no data is available on the fuel. It is also

$\%$ assumed that all the xylenes have the same Kad since the adsorption isotherm

$\%$ was measured on a mixture of all three xyelens.

at $0=0 ; \mathrm{dtf}=0$;

$\mathrm{dtgco}=\mathrm{zeros}(1, \mathrm{Tmax}) ; \mathrm{dtgsi}=\mathrm{zeros}(1, \mathrm{Tmax})$;

for $h=2:$ length $(\operatorname{dum}(:, 3))$,

$$
\text { at0 }=a t 0+(1 / 1) * \operatorname{dum}(\mathrm{h}, 3) *(\mathrm{t}(\mathrm{h})-\mathrm{t}(\mathrm{h}-1))
$$

for $\mathrm{m}=1: \mathrm{Tmax}$, $\mathrm{a}(\mathrm{h}, \mathrm{m})=(1 / \mathrm{l}) * \operatorname{dum}(\mathrm{h}, 3) * \cos (\mathrm{m} * \mathrm{pi} * \mathrm{t}(\mathrm{h}) / \mathrm{l}) *(\mathrm{t}(\mathrm{h})-\mathrm{t}(\mathrm{h}-1)) ;$ $\operatorname{dtgco}(\mathrm{m})=\operatorname{dtgco}(\mathrm{m})+\mathrm{a}(\mathrm{h}, \mathrm{m})$; $b(h, m)=(1 / 1) * d u m(h, 3) * \sin \left(m^{*} \mathrm{pi}^{*} \mathrm{t}(\mathrm{h}) / \mathrm{l}\right) *(\mathrm{t}(\mathrm{h})-\mathrm{t}(\mathrm{h}-1))$; $\operatorname{dtgsi}(\mathrm{m})=\mathrm{dtgsi}(\mathrm{m})+\mathrm{b}(\mathrm{h}, \mathrm{m})$;

end

end

for $\mathrm{m}=1: \mathrm{Tmax}$, $\mathrm{dtf}=\mathrm{dtf}+\mathrm{dtg} \operatorname{co}(\mathrm{m}) * \cos \left(\mathrm{m}^{*} \mathrm{pi} * \mathrm{t} / \mathrm{l}\right)+\mathrm{dtg} \operatorname{si}(\mathrm{m}) * \sin \left(\mathrm{m}^{*} \mathrm{pi}^{*} \mathrm{t} / \mathrm{l}\right) ;$

end

$\mathrm{tf}=\mathrm{at} 0 / 2+\mathrm{dtf}$

\% The above routine calculates the Fourier series representation of the gas temperature;

$\operatorname{Pmax}=20$; 


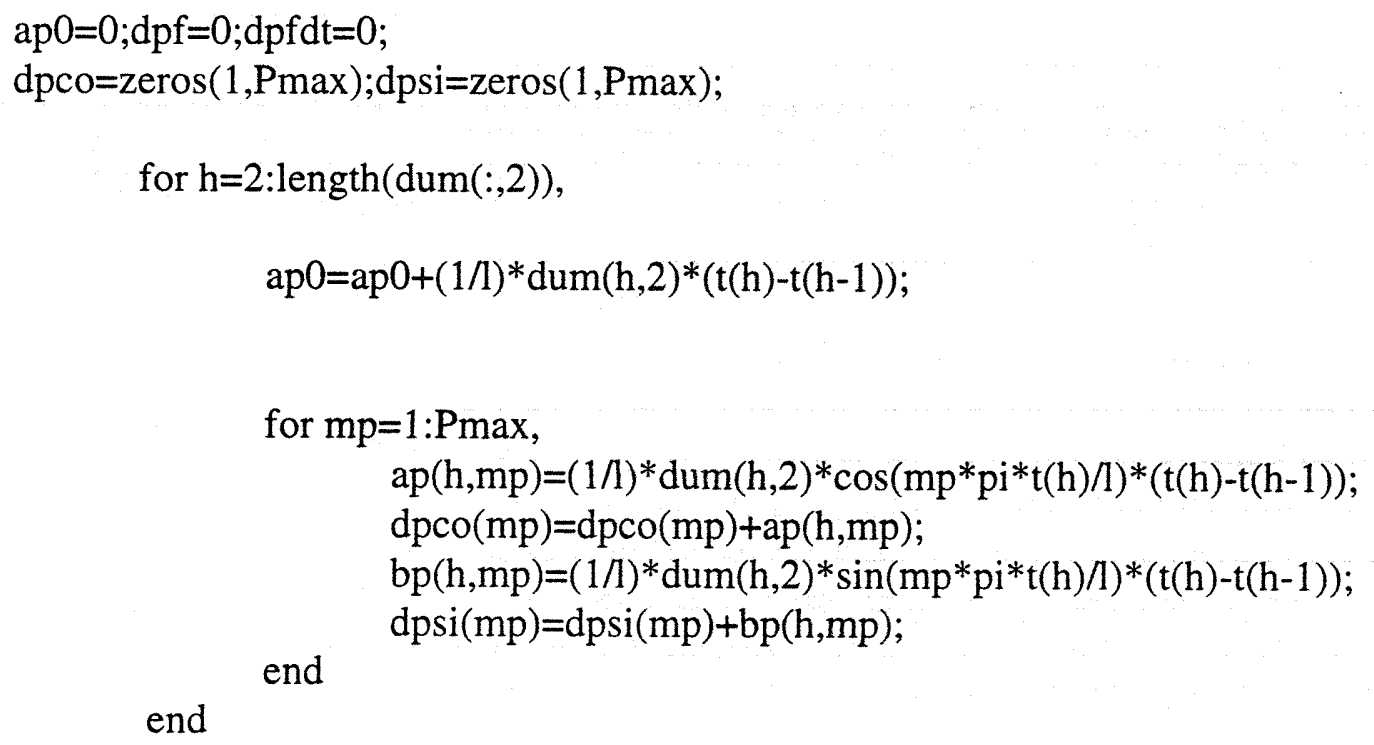

$\% \mathrm{k} 1, \mathrm{a} 1,11$ are the thermal conductivity, diffusivity and thickness of deposits.

$\% \mathrm{k} 2, \mathrm{a} 2,12$ are the thermal conductivity, diffusivity and thickness of aluminum.

$\% \% \% \% \% \% \% \% \% \% \% \% \% \% \% \% \% \% \% \% \% \% \% \% \% \% \% \% \% \%$

$\mathrm{k} 1=0.5 ; \mathrm{a} 1=2 \mathrm{e}-7 ; 11=120 \mathrm{e}-6$;

$\mathrm{k} 2=180 ;$ a2 $=1 \mathrm{e}-4 ; 12=0.5 \mathrm{e}-2$;

$\% \% \% \% \% \% \% \% \% \% \% \% \% \% \% \% \% \% \% \% \% \% \% \% \% \% \% \% \% \% \%$

$\% \% \% \% \% \% \% \% \% \% \% \% \%$

$\mathrm{xt}=-11 / 2$;

$\mathrm{xc}=0$;

$\% \% \% \% \% \% \% \% \% \% \% \% \% \%$

\%the origin of the $\mathrm{x}$-axis in the temperature calculations, is taken at the interface between the $\%$ the deposits and the aluminum. $\mathrm{X}=-11$ corresponds to the deposit-combustion chamber interface.

$\% \mathrm{x}=12$ corresponds to the aluminum-coolant interface.

\%for the concentration claculations, $x=0$ corresponds to the deposit-combustion gases interface, while $\mathrm{x}=11$ corresponds to the deposit-aluminum interface.

$\% \% \% \% \% \% \% \% \% \% \% \% \% \% \%$

$\mathrm{hc}=2200 ; \mathrm{tc}=363$;

$\% \% \% \% \% \% \% \% \% \% \% \% \% \%$ 
$\%$ hc and tc are the heat transfer coefficient and temperature of the coolant.

$\%$ calculation of the gas-side heat transfer coefficient, hg using Annand's correlation (Heywood p. 678);

$\mathrm{ka}=0.038$;

Roa $=0.589 ;$ nua $=29.74 \mathrm{e}-6$;

$\% \mathrm{ka}$, Roa, and nua are the thermal conductivity, density, and viscosity of air at $500 \mathrm{~K}$;

$\mathrm{hg}=(0.6 * \mathrm{ka} / \mathrm{Bc}) *(\mathrm{Roa} * \mathrm{Sp} * \mathrm{Bc} / \mathrm{nua})^{\wedge} 0.7$

$\operatorname{tgs}=a t 0 / 2$

\%tgs is the steady-state component of the gas temperature;

$\mathrm{q}=(\mathrm{tgs}-\mathrm{tc}) /((1 / \mathrm{hg})+(11 / \mathrm{k} 1)+(12 / \mathrm{k} 2)+(1 / \mathrm{hc}))$;

t1 $\mathrm{s}=\operatorname{tgs}-(\mathrm{q} / \mathrm{hg})$

$\mathrm{t} 2 \mathrm{~s}=\mathrm{t} 1 \mathrm{~s}-(\mathrm{q} * 11 / \mathrm{k} 1)$;

$\mathrm{t} 3 \mathrm{~s}=\mathrm{t} 2 \mathrm{~s}-(\mathrm{q} * 12 / \mathrm{k} 2)$;

$\mathrm{t} 1 \mathrm{sx}=\mathrm{t} 1 \mathrm{~s}-\left(\mathrm{q}^{*}(11+\mathrm{xt}) / \mathrm{k} 1\right)$;

for $\mathrm{k}=1:$ Tmax;

$\mathrm{wt}(\mathrm{k})=\mathrm{k}^{*} \mathrm{wo}$

end

dte $1=0$;

dte $2=0$;

for $n=1: T \max$,

$\mathrm{d} 1(\mathrm{n})=\operatorname{sqrt}\left(\mathrm{i}^{*} \mathrm{wt}(\mathrm{n}) / \mathrm{a} 1\right)$;

$\mathrm{d} 2(\mathrm{n})=\operatorname{sqrt}\left(\mathrm{i}^{*} \mathrm{wt}(\mathrm{n}) / \mathrm{a} 2\right)$

$\mathrm{g} 1(\mathrm{n})=\operatorname{sqrt}(\mathrm{wt}(\mathrm{n}) /(2 * \mathrm{a} 1))$

$\mathrm{g} 2(\mathrm{n})=\operatorname{sqrt}(w \mathrm{t}(\mathrm{n}) /(2 * \mathrm{a} 2))$

$\mathrm{s} 1(\mathrm{n})=(\mathrm{k} 1 * \mathrm{~d} 1(\mathrm{n})-\mathrm{hg}) * \exp (-2 * 11 * \mathrm{~d} 1(\mathrm{n})) /(\mathrm{k} 1 * \mathrm{~d} 1(\mathrm{n})+\mathrm{hg})$;

$\mathrm{s} 2(\mathrm{n})=(\mathrm{hg} * \exp (-11 * \mathrm{~d} 1(\mathrm{n}))) /(\mathrm{k} 1 * \mathrm{~d} 1(\mathrm{n})+\mathrm{hg})$;

$\mathrm{s} 3(\mathrm{n})=(\mathrm{k} 2 * \mathrm{~d} 2(\mathrm{n})+\mathrm{hc}) * \exp (2 * 12 * \mathrm{~d} 2(\mathrm{n})) /(\mathrm{k} 2 * \mathrm{~d} 2(\mathrm{n})-\mathrm{hc})$;

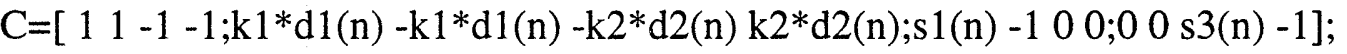

$\mathrm{D}=[0 ; 0 ;-\mathrm{s} 2(\mathrm{n}) ; 0]$;

$\mathrm{Y}(:, \mathrm{n})=\operatorname{inv}(\mathrm{C}) * \mathrm{D}$

theta $1(n)=Y(1, n) * \exp (x t * d 1(n))+Y(2, n) * \exp (-x t * d 1(n))$;

theta2(n) $=Y(3, n) * \exp (x t * d 1(n))+Y(4, n) * \exp \left(-x t^{*} d 1(n)\right)$

dt $1 \mathrm{c}(\mathrm{n}, \mathrm{:})=$ theta $1(\mathrm{n}) * \exp (\mathrm{i} * \mathrm{wt}(\mathrm{n}) * \mathrm{t})$;

$\% \mathrm{dt} 2 \mathrm{c}(\mathrm{n},:)=\operatorname{theta} 2(\mathrm{n}) * \exp \left(\mathrm{i}^{*} \mathrm{wt}(\mathrm{n}) * \mathrm{t}\right)$;

dT1(n,:)=dtgco(n)*real(dt1c(n,:))+dtgsi(n)*imag(dt1c(n,:));

$\% d T 2(n,:)=\operatorname{dtg} c o(n) * \operatorname{real}(\operatorname{dt} 2 c(n,:))+\operatorname{dtgsi}(n) * \operatorname{imag}(\operatorname{dt} 2 c(n,:))$; 


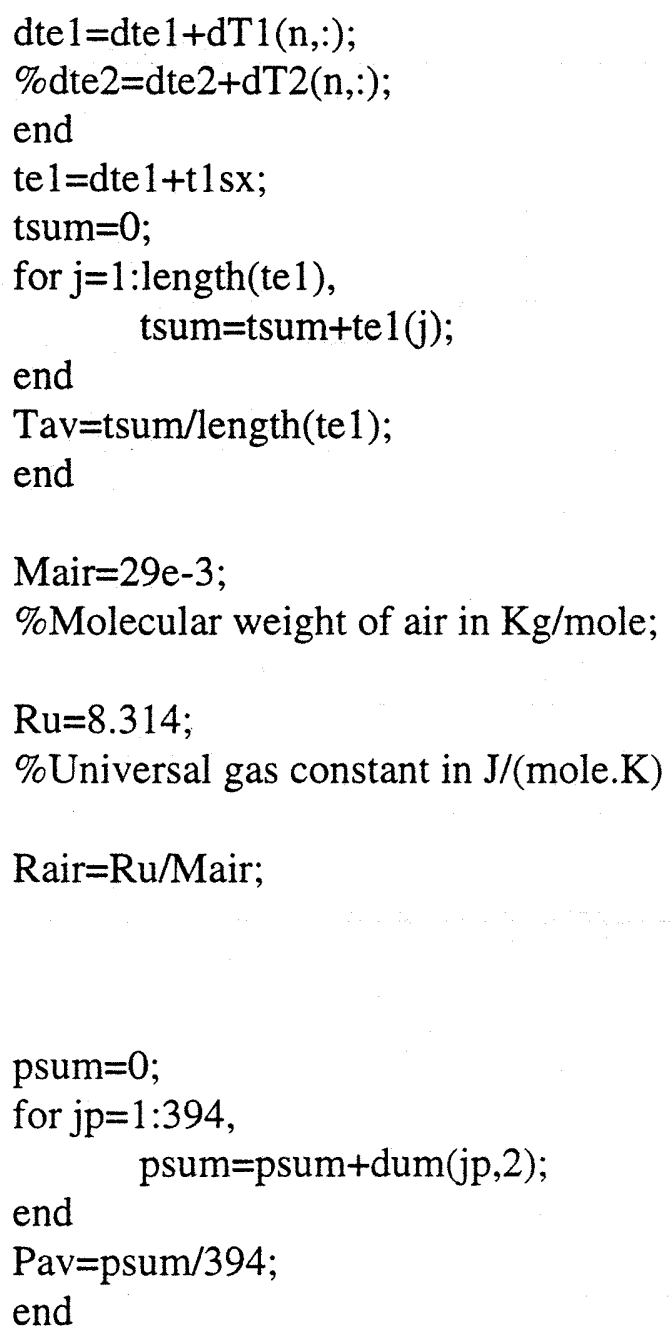

Dsum $=0$;

for $n n=1$ :length(te 1$)$,

KT_E12(nn) $=\operatorname{sqrt}\left(\mathrm{K} \_E a * t e 1(\mathrm{nn})\right) * \operatorname{sqrt}\left(\mathrm{K} \_E f * t e 1(\mathrm{nn})\right)$;

$\mathrm{Od}(\mathrm{nn})=1.3712 * \mathrm{KT} \_\mathrm{E} 12(\mathrm{nn})^{\wedge}(-0.3215)$;

$\%$ Od the collision integral as a function of temperature. The data on 
\%page 14 in Table 1.2 of Satterfield book.

$\operatorname{Daf}(\mathrm{nn})=1 \mathrm{e}-$

$4 *\left(0.001858 *(\operatorname{te} 1(\mathrm{nn}))^{\wedge} 1.5 * \operatorname{sqrt}((\mathrm{Mf}+\mathrm{Ma}) /(\mathrm{Mf} * \mathrm{Ma}))\right) /\left(\mathrm{Od}(\mathrm{nn}) * \operatorname{Si} 12^{\wedge} 2 * \operatorname{dum}(\mathrm{nn}, 2)\right)$;

Dsum=Dsum+Daf(nn);

end

Dc=Dsum/length(te 1);

D12=Dc;

$\% \mathrm{D} 12$ is the diffusion coefficient in the deposit, which is different from that in the combustion chamber, which is evaluated at higher temperatures;

nu=20e-6;

$\mathrm{Re}=\mathrm{Sp} * \mathrm{Bc} / \mathrm{nu}$;

$\%$ nu is the viscosity of air;

\% Calulating the mass transfer coefficient hm

$\%$ Dsumc $=0$;

$\%$ for kk=1:length(te1),

$\% \mathrm{KT} \_E 12 \mathrm{c}(\mathrm{kk})=\operatorname{sqrt}\left(\mathrm{K} \_E a * d u m(\mathrm{kk}, 3)\right) * \operatorname{sqrt}\left(\mathrm{K} \_E f * d u m(\mathrm{kk}, 3)\right)$;

$\% O d c(k k)=1.3712 * \mathrm{KT} \_\mathrm{E} 12 \mathrm{c}(\mathrm{kk})^{\wedge}(-0.3215)$;

$\%$ Odc the collision integral as a function of temperature. The data on

$\%$ page 14 in Table 1.2 of Satterfield book.

$\%$ Dafc $(\mathrm{kk})=1 \mathrm{e}-$

$4 *\left(0.001858 *(\operatorname{dum}(\mathrm{kk}, 3))^{\wedge} 1.5 * \operatorname{sqrt}((\mathrm{Mf}+\mathrm{Ma}) /(\mathrm{Mf} * \mathrm{Ma}))\right) /\left(\mathrm{Odc}(\mathrm{kk}) * \operatorname{Si} 12^{\wedge} 2^{*} \operatorname{dum}(\mathrm{kk}, 2)\right)$;

$\%$ Dsumc $=$ Dsumc + Dafc $(\mathrm{kk})$;

\%end

$\%$ Dcc=Dsumc/length(te 1$)$

$\mathrm{Sc}=\mathrm{nu} / \mathrm{D} 12$;

$\mathrm{Sh}=0.664 *(\mathrm{Re})^{\wedge} 0.5^{*}(\mathrm{Sc})^{\wedge} 0.333$;

$\mathrm{hm}=\mathrm{Sh} * \mathrm{D} 12 / \mathrm{Bc}$;

$\% \% \% \% \%$

Reg $=3$;

$\% \% \% \% \% \%$

$\%$ Reg is a variable that indicates which diffusions regime is taking place;

$\% \operatorname{Reg}=1==>$ bulk diffusion with no adsorption;

$\% \operatorname{Reg}=2==>$ Knudsen diffusion with no adsorption;

$\%$ Reg $=3==>$ Bulk diffusion with adsorption;

$\% \operatorname{Reg}=4==>$ Knudsen diffusion with adsorption;

$\mathrm{Dk}=(9700 \mathrm{e}-8 * \mathrm{re} * \operatorname{sqrt}(\mathrm{Tav} / \mathrm{Mf})) * 1 \mathrm{e}-4$

$\mathrm{Rd}=900$; 
$\mathrm{Sd}=500$

$\% \mathrm{Rd}$ is the deposit densitiy $\left(\mathrm{Kg} / \mathrm{m}^{\wedge} 3\right)$;

$\% \mathrm{Sd}$ is the deposit surface area $\left(\mathrm{m}^{\wedge} 2 / \mathrm{Kg}\right)$;

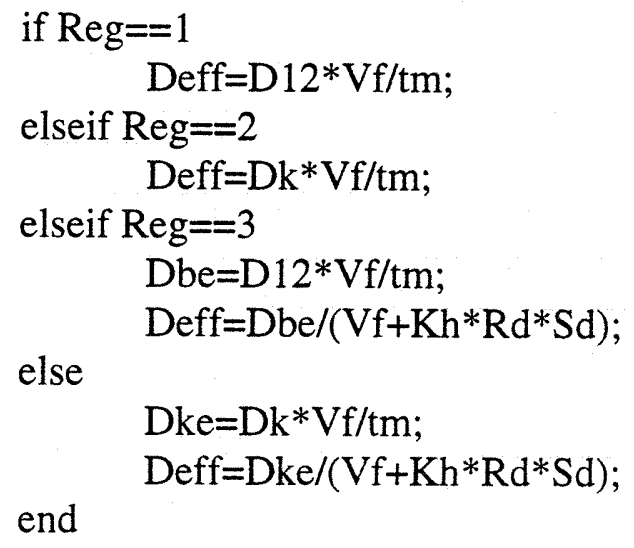

Df=Deff;

\%calculating the Fourier series expansion of the bulk fuel concentration;

$\operatorname{ac} 0=0$

dcgco=zeros $(1, \mathrm{Cmax})$; dcgsi=zeros $(1, \mathrm{Cmax})$;

$\mathrm{dcf}=0$;

\%calculation of the concentration of the fuel from the total concentration in the cylinder head $\%$ this concentration of fuel will be used to calculate its Fourier series.

$\% \mathrm{Xf}=$ mole fraction of the fuel in the fuel-air mixture;

$\% \mathrm{Ci}=$ bulk fuel concentration of the fuel as a function of $\mathrm{CA}$;

$\mathrm{Ci}=\mathrm{Xf} * \operatorname{dum}(:, 4)$;

for $h=2$ :length(Ci), $\mathrm{ac} 0=\mathrm{ac} 0+(1 / \mathrm{l}) * \mathrm{Ci}(\mathrm{h}) *(\mathrm{t}(\mathrm{h})-\mathrm{t}(\mathrm{h}-1))$;

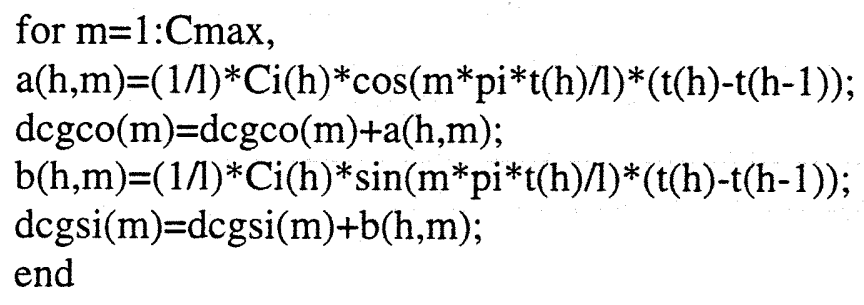


for $\mathrm{m}=1: \mathrm{Cmax}$, $\mathrm{dcf}=\mathrm{dcf}+\mathrm{dcgco}(\mathrm{m}) * \cos \left(\mathrm{m}^{*} \mathrm{pi}^{*} \mathrm{t} / \mathrm{l}\right)+\mathrm{dcgsi}(\mathrm{m}) * \sin (\mathrm{m} * \mathrm{pi} * \mathrm{t} / \mathrm{l}) ;$ end

$\mathrm{Cif}=\mathrm{ac} 0 / 2+\mathrm{dcf}$;

$\% \mathrm{hm}=$ mass transfer coefficient of the fuel

$\% \mathrm{D} 12=$ binary diffusion coefficient of the fuel in air;

for $\mathrm{k}=1: \mathrm{Cmax}$,

$\mathrm{wc}(\mathrm{k})=\mathrm{k} * \mathrm{wo}$

end

$\mathrm{dco}=0$

for $\mathrm{p}=1: \mathrm{Cmax}$,

$\mathrm{d}(\mathrm{p})=\operatorname{sqrt}\left(\mathrm{i}^{*} \mathrm{wc}(\mathrm{p}) / \mathrm{Df}\right)$

$\mathrm{B}(\mathrm{p})=\mathrm{hm} /((\mathrm{hm}+\mathrm{Df} * \mathrm{~d}(\mathrm{p}))+(\mathrm{hm}-\mathrm{Df} * \mathrm{~d}(\mathrm{p})) * \exp (-2 * \mathrm{~d}(\mathrm{p}) * 11))$;

$\mathrm{A}(\mathrm{p})=\mathrm{B}(\mathrm{p}) * \exp (-2 * \mathrm{~d}(\mathrm{p}) * 11)$

theta $(\mathrm{p})=\mathrm{A}(\mathrm{p}) * \exp (\mathrm{xc} * \mathrm{~d}(\mathrm{p}))+\mathrm{B}(\mathrm{p}) * \exp (-\mathrm{xc} * \mathrm{~d}(\mathrm{p}))$;

$\mathrm{dc}(\mathrm{p},:)=\operatorname{theta}(\mathrm{p}) * \exp \left(\mathrm{i}^{*} \mathrm{wc}(\mathrm{p}) * \mathrm{t}\right)$;

$\mathrm{dC}(\mathrm{p},:)=\operatorname{dcgco}(\mathrm{p}) * \operatorname{real}(\mathrm{dc}(\mathrm{p},:))+\mathrm{dcgsi}(\mathrm{p}) * \operatorname{imag}(\mathrm{dc}(\mathrm{p},:))$;

$\mathrm{dco}=\mathrm{dco}+\mathrm{dC}(\mathrm{p},:)$;

end

$\mathrm{C}=\mathrm{dco}+\mathrm{ac} 0 / 2$

$\mathrm{J} 0=\mathrm{hm}^{*}($ Cif-C $)$

ntot $=0$;

mtot $=0$;

for $\mathrm{k}=1$ :(length $(\mathrm{J} 0)-1)$,

ntot $=$ ntot + abs $(J 0(k)) *(t(k+1)-t(k))$;

mtot $=$ mtot + abs $(\operatorname{dmfdt}(\mathrm{k})) *(\mathrm{t}(\mathrm{k}+1)-\mathrm{t}(\mathrm{k}))$;

end

$\mathrm{CA}=-14+$ dum(:,1);

nav $=$ ntot $/ 2$;

$\mathrm{mst}=\mathrm{nav} * 2 * \mathrm{Ap} * \mathrm{Mf} * 1 \mathrm{e}+3$;

$\% \mathrm{mst}$ is in $\mathrm{mg}$;

$\mathrm{fst}=\mathrm{mst} * 100 /(\operatorname{minj} * 1 \mathrm{e}+3)$; 
mcrev $=\mathrm{mtot} / 2$;

fcrev $=$ mcrev $* 100 /(\operatorname{minj} * 1 \mathrm{e} 3)$; end 